\title{
ESTUDO DE PROPRIEDADES MECÂNICAS DE CONCRETOS COMPACTADOS COM INCORPORAÇÃO DE FRESADOS PARA BASES DE PAVIMENTOS
}

\author{
Tese apresentada à Escola \\ Politécnica da Universidade de São \\ Paulo como parte dos requisitos para \\ a obtenção do título de Doutor em \\ Engenharia
}

Orientador: Prof. Dr. José Tadeu Balbo 


\title{
TAÍS SACHET
}

Engenheira Civil, Universidade de Passo Fundo, 2004

Mestre em Engenharia, Universidade de Passo Fundo, 2007

\section{ESTUDO DE PROPRIEDADES MECÂNICAS DE CONCRETOS COMPACTADOS COM INCORPORAÇÃO DE FRESADOS PARA BASES DE PAVIMENTOS}

\begin{abstract}
Tese apresentada à Escola Politécnica da Universidade de São Paulo como parte dos requisitos para a obtenção do título de Doutor em Engenharia

Área de Concentração: Engenharia de Transportes - Infraestrutura de Transportes
\end{abstract}

Orientador: Prof. Dr. José Tadeu Balbo 
Este exemplar foi revisado e alterado em relação à versão original, sob responsabilidade única do autor e com a anuência de seu orientador.

São Paulo, 15 de agosto de 2012.

Assinatura do autor

Assinatura do orientador

FICHA CATALOGRÁFICA

Sachet, Taís

Estudo de propriedades mecânicas de concretos compactados com incorporação de fresados para bases de pavimentos I T. Sachet. - ed. rev. -- São Paulo, 2012.

$186 \mathrm{p}$.

Tese (Doutorado) - Escola Politécnica da Universidade de São Paulo. Departamento de Engenharia de Transportes.

1. Concreto compactado com rolo 2. Fresagem 3. Ensaios de fratura 4. Pavimentos flexíveis (Reciclagem) I. Universidade de São Paulo. Escola Politécnica. Departamento de Engenharia de Transportes II. t. 
Este trabalho não teria sido possível não fosse o apoio de tantas pessoas especiais e exemplos de vida e profissionalismo. Portanto, quero expressar aqui o meu mais profundo agradecimento a essas pessoas que fizeram a diferença em minha vida, possibilitando a conclusão e realização desta pesquisa.

A Deus pelas inúmeras bênçãos que tem me dado nesta vida e por ter me guiado pelos caminhos do bem.

Ao meu orientador Prof. Dr. José Tadeu Balbo pelo conhecimento transmitido, por acreditar e abraçar comigo a pesquisa e por ter sido um grande amigo quando da minha chegada em São Paulo.

A CAPES pelo auxilio financeiro, por meio de bolsa de estudos, para desenvolvimento da pesquisa.

Aos colaboradores do Departamento de Construção Civil, especialmente ao Prof. Dr. Antônio Figueiredo, que nos disponibilizaram o laboratório para realizarmos ensaios e moldar os corpos de prova.

Ao Prof. Dr. Carlos Eduardo Sansone, do Laboratório de Mecânica das Rochas da EPUSP, pela assistência proporcionada na realização dos ensaios de fratura.

Ao Eng. Dr. Edson Lima, do laboratório de Tecnologia da Pavimentação da EPUSP, pela amizade e ajuda dispensada em momentos importantes do trabalho.

Ao Eng. Valmir Bonfim que disponibilizou o fresado asfáltico, inclusive com transporte até a Escola Politécnica. 
A Holcim Brasil S/A, especialmente ao Eng. José Wanderlei Abreu, pela disponibilização dos agregados e cimento utilizados durante toda a pesquisa.

Meus colegas e amigos de laboratório Glenda Colim, Maria, Paulo Pinto, André Mugayar e José Eduardo Mallmann. Obrigada por sua amizade e companheirismo.

A minha amiga Francieli Tiecher, que se disponibilizou a me ajudar na realização dos ensaios de microscopia na Universidade Federal do Rio Grande do Sul - UFRGS.

À Universidade Estadual Paulista de Ilha Solteira, especialmente ao Profo. Claudio Luiz de Carvalho responsável pelo GDAM (Grupo Desenvolvimento e Aplicações de Materiais) que disponibilizou o laboratório para que as observações com lupa estereoscópica fossem realizadas e à Profa Drạ. Maria da Consolação Fonseca de Albuquerque.

Aos meus colegas de trabalho que me deram força a cada momento decisivo. A minha amiga e chefe Débora Targas que sempre entendeu minhas preocupações e incentivou meu trabalho. Ao Dr. Douglas Villibor e à Diretoria da LENC Engenharia, que incentiva seus colaboradores a se especializar e promovem a harmonia entre empresa e academia. Obrigada por me incentivarem.

Aos meus pais Aldemir e Gisselda, a minha querida avó Nereides, meu irmão Charles, exemplos de honestidade e força, obrigada por acreditarem em mim e me apoiarem. Saibam que nada no mundo paga a dedicação que tiveram com o meu filho neste tempo em que estive tão longe.

Obrigada meu filho querido e amado por ter entendido a ausência da sua mãe por tanto tempo. Você é a razão da minha vida.

Enfim, agradeço a todas aquelas pessoas que torceram por mim, que acreditaram em mim e que em suas orações lembraram meu nome. 


\section{SUMÁRIO}

LISTA DE FIGURAS ..................................................................................................

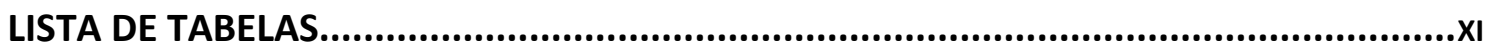

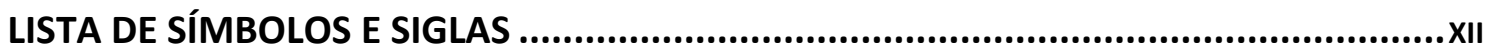

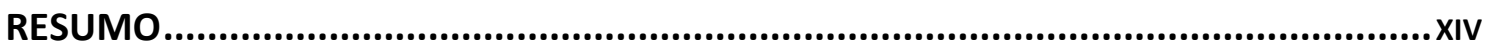

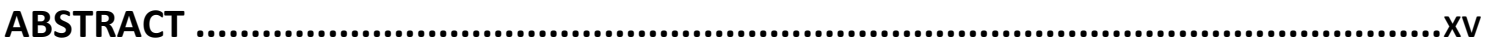

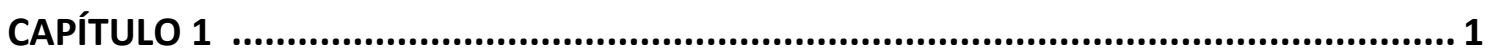

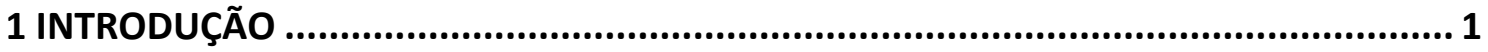

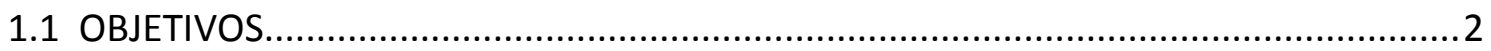

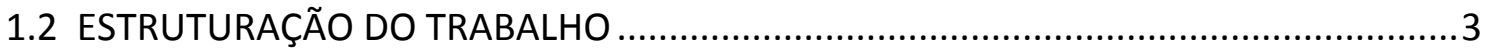

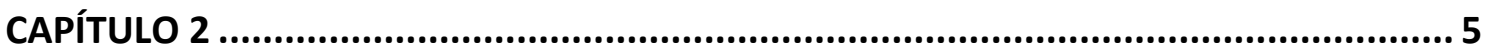

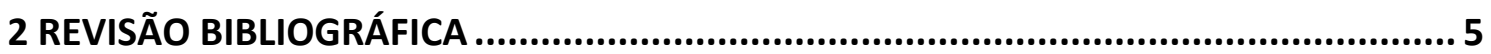

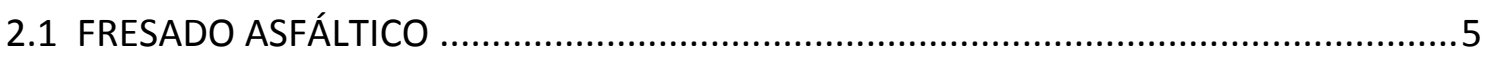

2.1.1 Processos de Produção do Material Fresado .......................................................10

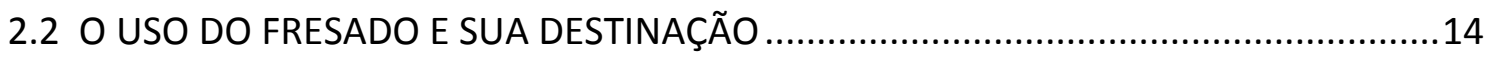

2.2.1 Reciclagem com Agregados Fresados em Concreto..........................................20

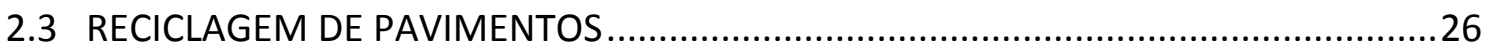

2.4 CONCRETO COMPACTADO COM ROLO: Conceituação e Características .................29

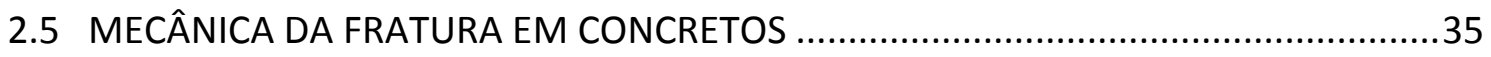

2.5.1 Estudos de Tenacidade em Concretos ............................................................. 41

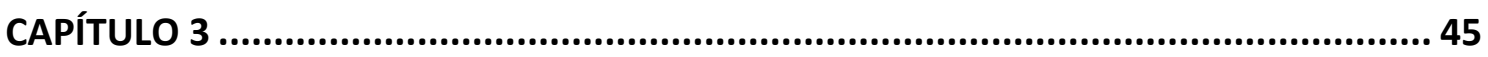

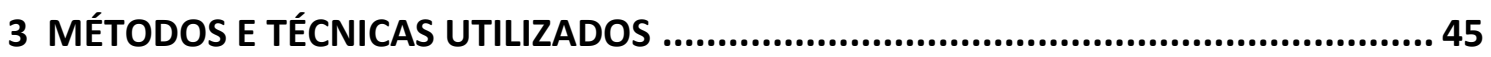

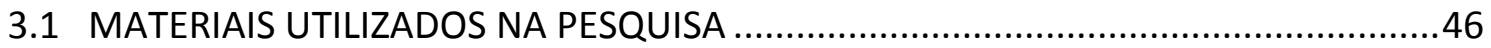

3.1.2 Definição da Composição Granulométrica das Misturas ......................................52

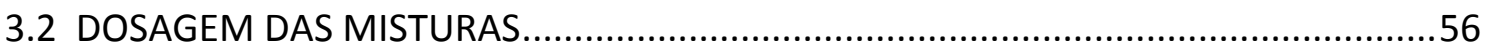




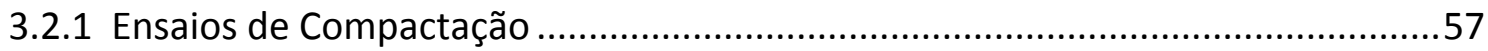

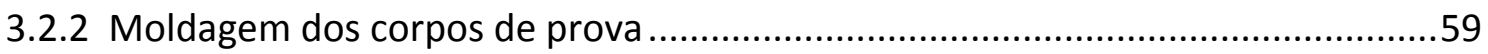

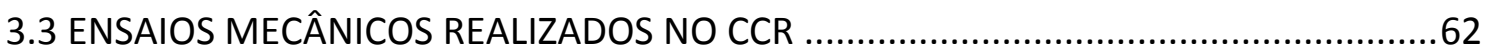

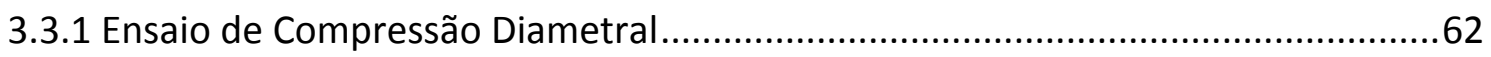

3.3.2 Ensaio de Tração na Flexão ............................................................................6 68

3.3.3 Ensaio por Pulso de Onda Ultrassônica - Módulo de Elasticidade ........................73

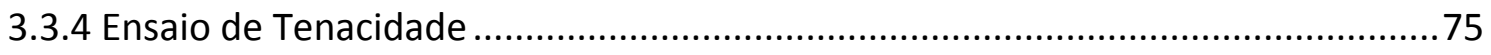

3.3.5 Observações com Microscópio Eletrônico de Varredura.......................................79

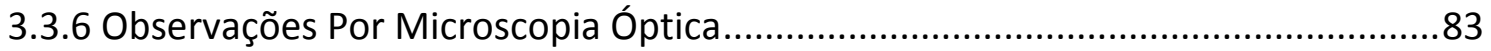

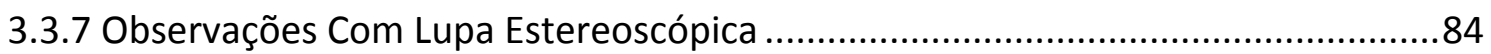

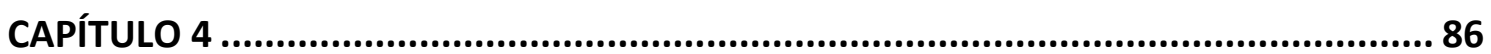

4 APRESENTAÇÃO E ANÁLISE DOS RESULTADOS ................................................. 86

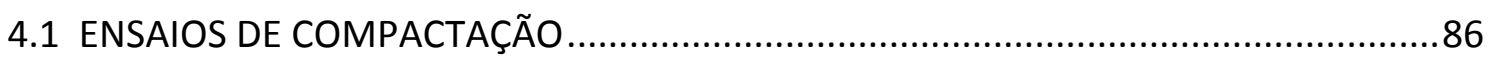

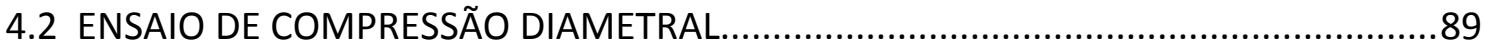

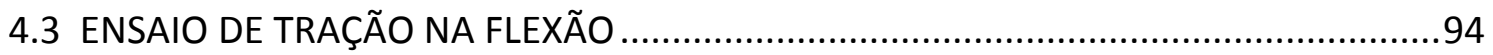

4.4 ENSAIO POR PULSO DE ONDA ULTRASSÔNICA .........................................................99

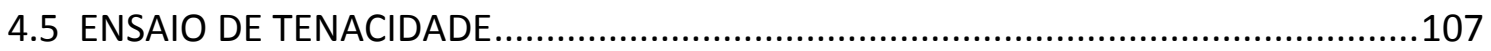

4.6 MICROSCOPIA ELETRÔNICA DE VARREDURA ..................................................113

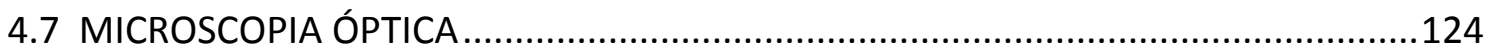

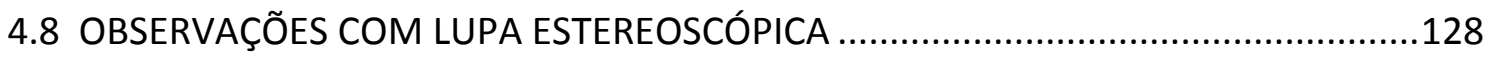

4.9 COMPARAÇÃO DE ESTRUTURAS DE PAVIMENTOS COM BASES DE CCR

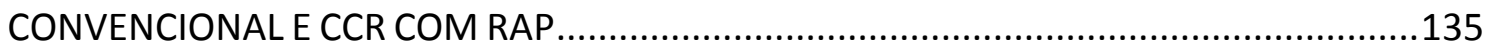

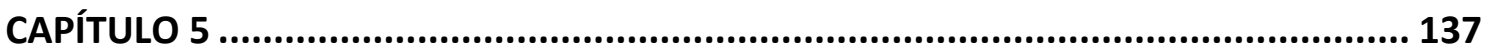

5 CONCLUSÕES E RECOMENDAÇÕES PARA NOVOS ESTUDOS ................................. 137

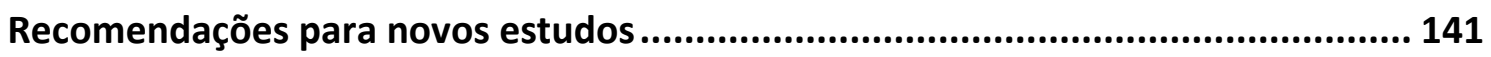

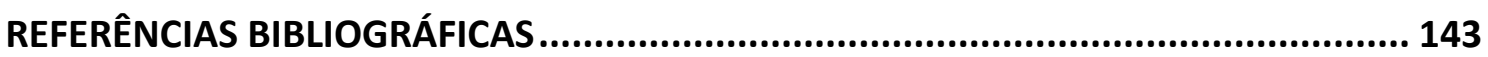

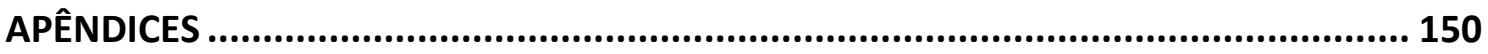




\section{LISTA DE FIGURAS}

Figura 1 - Técnicas de remoção do pavimento existente (a) fresagem (b) escarificação e (c) trituração 11

Figura 2 - Tipos de tambor com freses da máquina fresadora....................................... 11

Figura 3 - Grumos de fresado asfáltico $(5,0 \mathrm{~cm}, 4,5 \mathrm{~cm}$ e $3,5 \mathrm{~cm})$............................... 13

Figura 4 - Superfície resultante do processo de fresagem ......................................... 13

Figura 5 - Distribuição granulométrica do RAP e de agregados virgens ....................... 19

Figura 6 - Propagação de trinca no concreto simples e no concreto com RAP............. 21

Figura 7 - Superfície de fratura do concreto contendo RAP........................................ 24

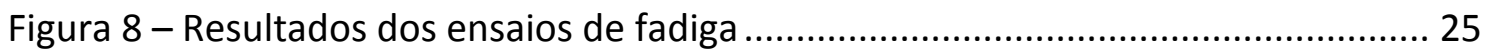

Figura 9 - Padrão das trincas nas amostras de concreto ............................................. 26

Figura 10 - Modos de propagação da trinca ................................................................. 37

Figura 11 - a) Material sem fissura, b) material com microfissuras e c) material fissurado 38

Figura 12 - a)Curva $\sigma-w$. A capacidade de transferência de tensão da zona microfissurada em função da deformação; b) a reta aproximada da curva na Figura a. 39

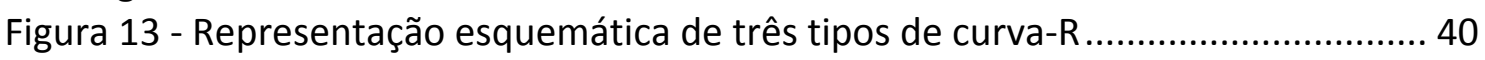

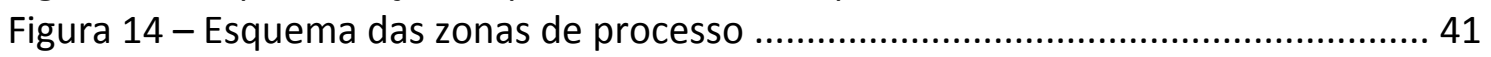

Figura 15 - Arranjo do ensaio de fratura ................................................................. 41

Figura 16 - Diagramas de tenacidade da BGTC em várias umidades de compactação. 43

Figura 17 - Etapas para execução do trabalho .............................................................. 45

Figura 18 - Curvas granulométricas dos materiais granulares ..................................... 47

Figura 19 - Sequência dos ensaios de caracterização dos materiais granulares

(granulometria por peneiramento e Chapman, Massa específica e unitária) ....... 48

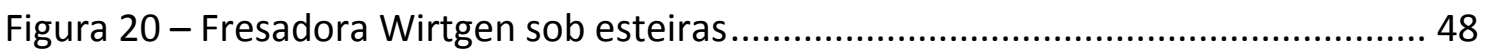

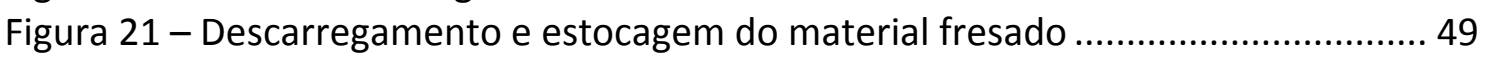

Figura 22 - Quarteamento do material fresado ........................................................... 49

Figura 23 - Amostras de fresado in situ (duas fotos superiores) e com extração do betume (foto à esquerda inferior) e forno Mufla utilizado para extração do betume

Figura 24 - Curvas granulométricas do fresado sem extração e com extração de

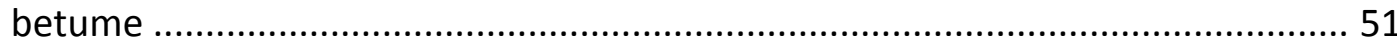

Figura 25 - Faixa granulométrica de Pittman e Ragan (1998) ..................................... 52

Figura 26 - Faixa granulométrica adotada para o CCR com areia industrial .................. 53

Figura 27 - Faixa granulométrica adotada para o CCR com areia natural ...................... 53

Figura 28 - Confecção do concreto em betoneira horizontal......................................... 54

Figura 29 - Moldagem dos CCR em corpos de prova: cilíndricos e prismáticos ............. 55

Figura 30 - Moldes: cilíndrico e prismático................................................................ 55

Figura 31 - Estoque de fresado peneirado nas frações fina, média e grossa ............... 56

Figura 32 - Granulometrias do fresado asfáltico utilizadas nas misturas.................... 57

Figura 33 - Procedimentos durante a compactação................................................... 58

Figura 34 - Acréscimo da resistência por consumo de cimento, aos 28 dias para corpos de prova cilíndricos e prismáticos ......................................................................... 59 
Figura 35 - Moldagem dos corpos de prova cilíndricos e prismáticos .........................60 60

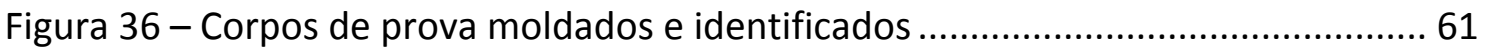

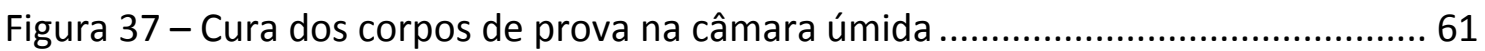

Figura 38 - Pesagem e aferição de medidas dos corpos de prova após cura na câmara úmida

Figura 39 - Arranjo do ensaio de compressão diametral (Laboratório de Mecânica de Pavimentos da EPUSP).

Figura 40 - Posição do strain gage no ensaio de compressão diametral (Laboratório de

Mecânica de Pavimentos da EPUSP)

Figura 41 - Arranjo do ensaio de compressão diametral (Laboratório de Mecânica de Pavimentos da EPUSP).

Figura 42 - Equipamento de aquisição de Sinais ....

Figura 43 - Exemplo de aquisição de dados do ensaio de compressão diametral por meio do programa computacional AQDADOS

Figura 44 - Prensa Solotest hidráulico-elétrica (Laboratório de Mecânica de Pavimentos da EPUSP)

Figura 45 - Exemplo de determinação da curva tensão $x$ deformação e estimativa do módulo de elasticidade secante em tração do material

Figura 46 - Preparação dos corpos de prova prismáticos para ensaio de tração na flexão

Figura 47 - Arranjo do ensaio de tração na flexão com LVDT e strain gage (Laboratório de Mecânica de Pavimentos da EPUSP) ...

Figura 48 - Exemplo de aquisição de dados do ensaio de compressão diametral por meio do programa computacional AQDADOS

Figura 49 - Exemplo de determinação da curva módulo de elasticidade em tração na

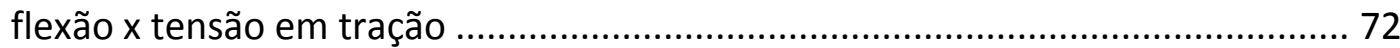

Figura 50 - Exemplo de determinação da curva tensão de tração x flecha .................. 73

Figura 51 - Ensaio de por pulso de onda ultrassônica ............................................... 74

Figura 52 - Esquema do ensaio com geometria de flexão a três pontos ....................... 75

Figura 53 - Representação do cálculo da energia total de fratura, $\gamma$ wof, através da medida da área sob a curva carga-deslocamento.................................................. 78

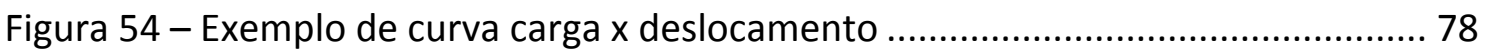

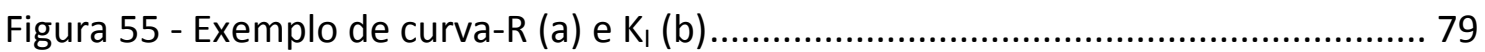

Figura 56 - Microscópio eletrônico de varredura JOEL-JSM 6060 (Centro de Microscopia Óptica da UFRGS) e Imagem típica obtida no microscópio eletrônico de varredura JOEL-JSM 6060

Figura 57 - Microscópio eletrônico de varredura Backscattered JSM 5800 - (Centro de Microscopia Óptica da UFRGS) e Imagem obtida no microscópio eletrônico de varredura Backscattered JSM 5800.

Figura 58 - Observações no microscópio óptico Olympus BX51M .............................. 84

Figura 59 - Imagem obtida por meio microscópio óptico Olympus BX51M ................. 84

Figura 60 - Lupa estereoscópica do tipo Carl Zeiss Jena.............................................. 85

Figura 61 - Curvas de compactação do CCR padrão e do CCR com areia natural ......... 86

Figura 62 - Curvas de compactação do CCR com fresado ............................................ 87

Figura 63 - Exsudação da água na superfície do CCR com RAP .................................... 88

Figura 64 - Ganho de resistência para tempo de cura de 7 dias dos CCR de dosagem com areia industrial, com 90, 110 e $130 \mathrm{~kg} / \mathrm{m}^{3}$ de cimento (cilíndricos)............... 89 
Figura 65 - Ganho de resistência com tempo de cura de 35 dias para os CCR de dosagem com areia industrial, com 90,110 e $130 \mathrm{~kg} / \mathrm{m}^{3}$ de cimento (cilíndricos) 89

Figura 66 - Tensão de ruptura das misturas de CRR (cilíndricos)

Figura 67 - Ensaio de compressão diametral do CCR1 (foto à esquerda - ruptura abrupta) e CCR com fresado (foto central e a direita - ruptura sem separação abrupta)

Figura 68 - Módulo de elasticidade para os diferentes tipos de CCR por meio da curva

tensão x deformação (strain gage) .................................................................... 93

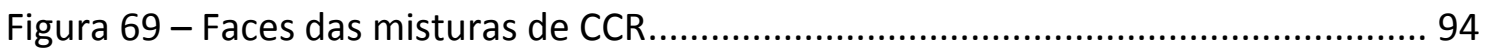

Figura 70 - Ganho de resistência para tempo de cura de 7 dias dos CCR com de dosagem com areia industrial, 90, 110 e $130 \mathrm{~kg} / \mathrm{m}^{3}$ de cimento (prismáticos).... 95

Figura 71 - Ganho de resistência para tempo de cura de 35 dias dos CCR com de dosagem com areia industrial, 90,110 e $130 \mathrm{~kg} / \mathrm{m}^{3}$ de cimento (prismáticos) .... 95

Figura 72 - Tensão de ruptura das misturas de CRR (prismáticos)............................... 97

Figura 73 - Módulos de elasticidade dos corpos-de-prova prismáticos: (1) curva tensão x deformação (strain gage) e; (2) Por Analogia de Möhr (flecha) ........................ 98

Figura 74 - Dados para obtenção dos módulos de elasticidade dinâmicos dos corpos de prova cilíndricos (C) e prismáticos (P) ................................................................ 99

Figura 75 - Módulos de elasticidade dinâmicos dos corpos de prova cilíndricos e prismáticos 101

Figura 76 - Comparação dos módulos de elasticidade pela curva tensão $\mathrm{x}$ deformação (strain gage), pela analogia de Möhr (flecha) e por pulso ultrassônico, dos corposde-prova prismáticos. 101

Figura 77 - Comparação dos módulos de elasticidade pela curva tensão x deformação

(SG) e por pulso ultrassônico dos corpos-de-prova cilíndricos.... 102

Figura 78 - Relação entre módulo de elasticidade e tensão de ruptura ...................... 103

Figura 79 - Relação entre módulo de elasticidade dinâmico e tensão de ruptura ..... 103

Figura 80 - Relação entre módulo de elasticidade dinâmico e velocidade de onda ... 104

Figura 81 - Tensão de ruptura dos corpos de prova cilíndricos e prismáticos ............. 105

Figura 82 - Umidades ótimas e massas específicas dos prismas e cilindros ................ 105

Figura 83 - Compilação dos resultados dos ensaios dinâmicos nos cilindros .............. 106

Figura 84 - Compilação dos resultados dos ensaios dinâmicos nos prismas ............... 107

Figura 85 - Sobreposição da curva força $x$ deslocamento do CCR1 com CCR-FT ........ 108

Figura 86 - (a) Sobreposição das curvas-R e (b) sobreposição das curvas $K_{R}$ do CCR1 e

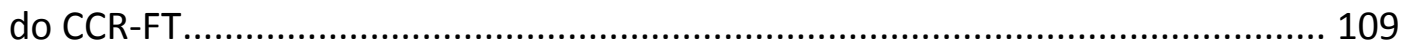

Figura 87 - Curvas-R obtidas com diferentes concretos (Lemaistre, 1988) ................ 111

Figura 88 - Curvas- $K_{R}$, para cinco diferentes concretos (Reinhardt \& Xu, 1999)......... 111

Figura 89 - Curvas- $K_{R}$ obtidas em concreto de alta resistência com ensaio de flexão a

três pontos (Ferreira 2007)

Figura - 90 Curvas- $K_{R}$ obtidas do concreto de alta resistência, Curva 1: concreto com adição de 40 kg/m3 de fibras de aço e Curva-2: com adição de 80 kg/m3 de fibras de aço, curva 2 (Ferreira, 2007).

Figura 91 - Observações com MEV na mistura CCR1 …............................................ 114

Figura 92 - Observações com MEV na mistura CCR2 …........................................... 115

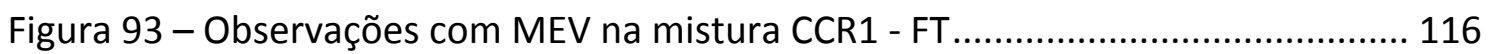

Figura 94 - Observações com MEV na mistura CCR1-AF ........................................... 116

Figura 95 - Observações com MEV na mistura CCR1-PF .......................................... 117 
Figura 96 - Observações com MEV na mistura CCR1-BF ......................................... 118

Figura 97 - Observações com MEV BSE na mistura CCR1.......................................... 120

Figura 98 - Observações com MEV BSE na mistura CCR2 ......................................... 121

Figura 99 - Observações com MEV BSE na mistura CCR1-AF .................................. 121

Figura 100 - Observações com MEV BSE na mistura CCR1 - FT ............................... 122

Figura 101- Observações com MEV BSE na mistura CCR1-PF .................................... 123

Figura 102 - Observações com MEV BSE na mistura CCR1-BF .................................... 124

Figura 103 - Observações com microscópio óptico na mistura CCR1 ......................... 125

Figura 104 - Observações com microscópio óptico na mistura CCR2 ......................... 126

Figura 105 - Observações com microscópio óptico na mistura CCR1-FT ...................... 126

Figura 106 - Observações com microscópio óptico na mistura CCR1-AF..................... 127

Figura 107 - Observações com microscópio óptico na mistura CCR1-PF ..................... 127

Figura 108 - Observações com microscópio óptico na mistura CCR1-BF .................... 128

Figura 109 - Observações com lupa da mistura CCR1 .............................................. 129

Figura 110 - Observações com lupa da mistura CCR2 .............................................. 129

Figura 111 - Observações com lupa da mistura CCR1-FT ......................................... 130

Figura 112 - Observações com lupa da mistura CCR1-PF ........................................ 130

Figura 113 - Observações com lupa da mistura CCR1-AF........................................ 131

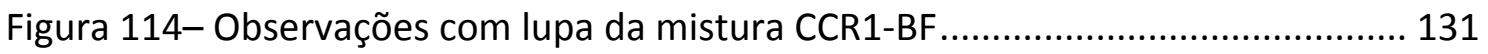

Figura 115 - Imagem da mistura CCR1 ........................................................... 132

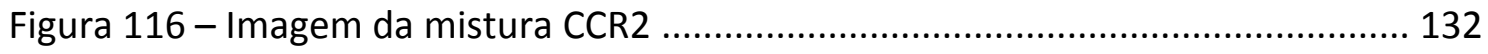

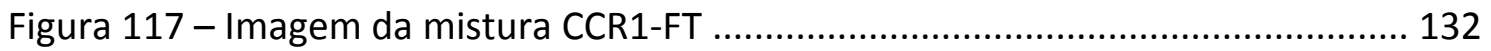

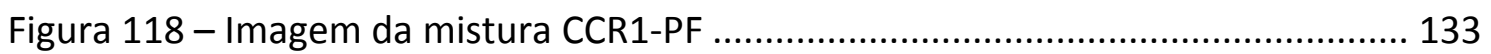

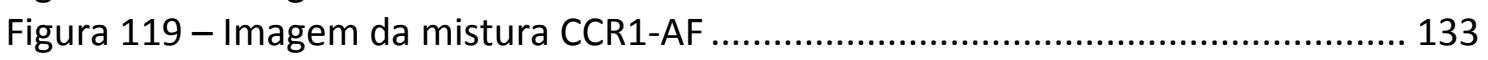

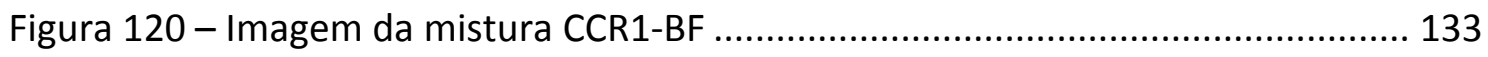

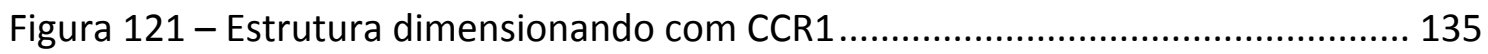

Figura 122 - Estrutura dimensionando com CCR1-PF............................................ 135

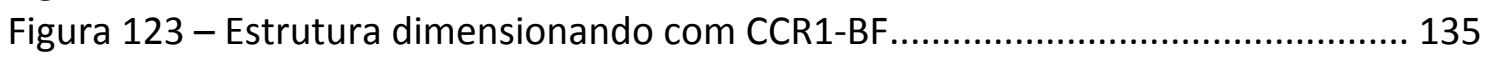

Figura 124 - Estrutura dimensionando com CCR1-FT ............................................... 136

Figura 125 - Estrutura dimensionando com CCR1-AF .............................................. 136 


\section{LISTA DE TABELAS}

Tabela 1 - Montantes e valores das misturas asfálticas obtidas de pavimentos em São Paulo, (Balbo e Bodi, 2004)

Tabela 2 - Resultados de umidade ótima e peso específico aparente seco máximo das

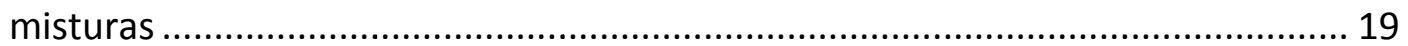

Tabela 3 - Composição de agregados, a/c = 0,5 e 0,4 (Delwar et al., 1997).................. 21

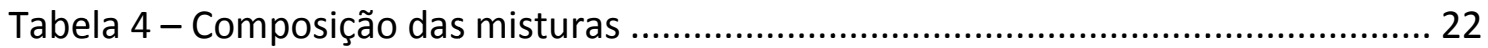

Tabela 5 - Valores de tenacidade no início da propagação da trinca, $K_{\text {Icip }}$, resistência à abertura da trinca, $R_{\text {médio, }}$ e energia de fratura por área de propagação, $2 \gamma_{\text {wof, }}$ para CCR com $100 \mathrm{~kg} / \mathrm{m}^{3}$ de cimento (Albuquerque et al., 2010) .............................. 42

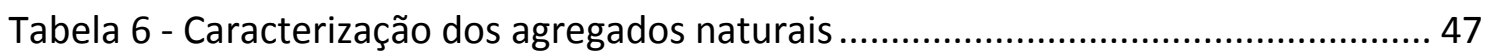

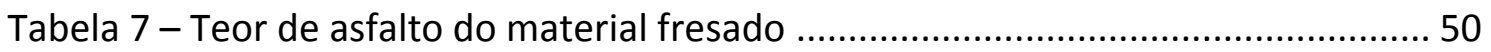

Tabela 8 - Caracterização dos agregados fresados................................................... 51

Tabela 9 - Composição das misturas com areia industrial (AI) e com areia natural (AN)

Figura 30 - Estoque de fresado peneirado nas frações fina, média e grossa............... 56

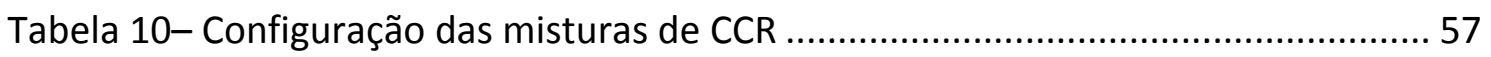

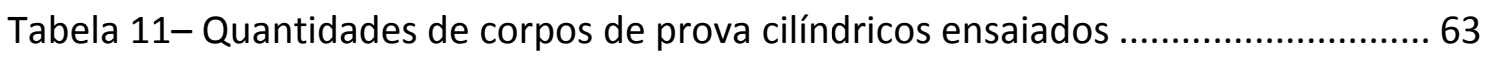

Tabela 12-Quantidade de corpos de prova prismáticos ensaiados.............................69

Tabela 13 - Função adimensional dependente da geometria do ensaio de três pontos

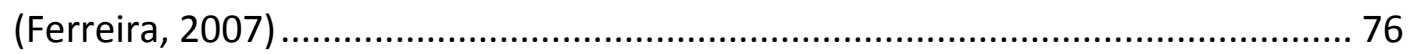

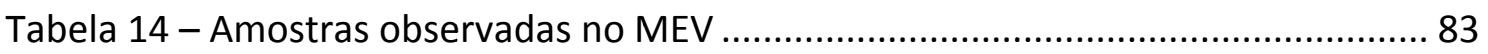

Tabela 15 - Umidade ótima para os CCR estudados................................................... 88

Tabela 16 - Valores de resistência à tração indireta dos CCR com areia industrial (CCR1)

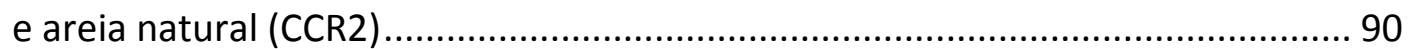

Tabela 17 - Valores de resistência à tração indireta dos CCR com RAP ..........................90

Tabela 18 - Valores de Módulo de elasticidade dos CCR estudados.............................. 91

Tabela 19 - Valores de resistência à tração na flexão dos CCR com areia industrial

(CCR1) e areia natural (CCR2) ........................................................................... 95

Tabela 20 - Valores de resistência à tração na flexão dos CCR com RAP ....................... 96

Tabela 21 - Valores de Módulo de elasticidade com medida da flecha e pela curva tensão-deformação dos CCR estudados............................................................. 97

Tabela 22 - Valores de Módulo de elasticidade por meio de pulso ultrassônico dos CCR

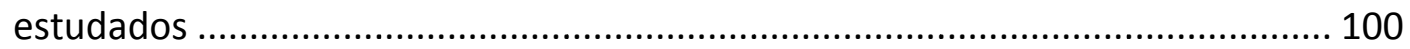

Tabela 23 - Valores de tenacidade para o início de propagação da trinca $\left(K_{\mathrm{ICIP}}\right)$, de resistência média à abertura de trinca $(\overline{\mathbf{R}})$ e de energia de fratura por área de propagação ( $2 Y_{\text {wof }}$ ) para o CCR1 e CCR1-FT......................................................... 110

Tabela 24 - Parâmetros utilizados no dimensionamento e espessuras obtidas para as estruturas de pavimentos 


\section{LISTA DE SÍMBOLOS E SIGLAS}

$a / c$

$\mathrm{ABCP}$

ABNT

$\mathrm{ACl}$

$\mathrm{AF}$

AG

Al

AN

ARRA

ASTM

BGTC

CAP

CBR

CCP

CCR

CCR-Al

CCR-AN

CCR1

CCR2

CCR1-AF

CCR1-BF

CCR1-FT

CCR1-PF

COMTOD

CMOD relação água - cimento

Associação Brasileira de Cimento Portland

Associação Brasileira de Normas Técnicas

American Concrete Institute

agregado fino

agregado graúdo

areia industrial

areia natural

Asphalt Recycling and Reclaiming Association

American Society for Testing and Materials

brita graduada tratada com cimento

concreto asfáltico de petróleo

\section{California Bearing Ratio}

concreto de cimento Portland

concreto compactado com rolo

concreto compactado com rolo com areia industrial

concreto compactado com rolo com areia natural

concreto compactado com rolo com areia industrial (referência)

concreto compactado com rolo com areia natural (de rio)

concreto compactado com rolo com areia industrial (referência) com substituição de $100 \%$ do pó-de-pedra por fresado

concreto compactado com rolo com areia industrial (referência) com substituição de $100 \%$ da brita 1 por fresado

concreto compactado com rolo com areia industrial (referência) com substituição de $50 \%$ da faixa total por fresado

concreto compactado com rolo com areia industrial (referência) com substituição de $100 \%$ do pedrisco por fresado

crack opening displacement

crack mouth opening displacement 
CONAMA Conselho Nacional do Meio Ambiente

$\mathrm{CP} \quad$ corpo de prova

CPCA Canadian Portland Cement Association

CV coeficiente de variação

DER/SP Departamento de Estradas de Rodagem do Estado de São Paulo

DERSA Desenvolvimento Rodoviário S.A.

E

módulo de elasticidade

$E_{d}$

módulo de elasticidade dinâmico

FHWA Federal Highway Administration

FDR

full depth reclamation

$f_{c t, s p}$

resistência à tração por compressão diametral

$f_{c t, f}$

resistência à tração na flexão

$\mathrm{G}_{\mathrm{c}}$

Valor crítico da taxa de liberação de energia potencial

GDOT

Departamento de Transportes da Geórgia

HAP hidrocarbonetos aromáticos policíclicos

ISC

Índice de Suporte Califórnia

$\mathrm{K}_{\mathrm{C}}$

fator de intensidade de tensão

$\mathrm{K}_{\mathrm{I}}$

fator de intensidade da trinca

$\mathrm{K}_{\mathrm{IC}}$

valor de tenacidade no início da propagação da trinca

LVDT

linear variable differential transformer

$M_{R}$

módulo de resiliência

MFEL

mecânica da fratura elástica linear

MEV

microscopia eletrônica de varredura

PCA

Portland Cement Association

RAP

reclaimed asphalt pavement

$R_{\text {médio }}$

resistência à abertura da trinca

SG

strain gage

v

velocidade de propagação de ondas

$\sigma_{6}$

tensão medida nos ensaios de fadiga

$Y_{\text {máx }}$

peso específico aparente seco máximo

$2 \gamma$ wof

energia de fratura por área de propagação 


\section{RESUMO}

O fresado asfáltico ou Reclaimed Asphalt Pavement (RAP), como é conhecido em língua inglesa, é um material proveniente da fresagem de revestimentos asfálticos quando da restauração de pavimentos flexíveis. Esse material é produzido em grandes quantidades nas grandes cidades, o que justifica a busca de soluções para sua destinação final. Neste trabalho foram estudados os efeitos da incorporação de RAP em concreto compactado com rolo (CCR). Foram produzidas seis diferentes misturas de CCR. O CCR de referência (CCR-1) foi produzido com areia industrial e serviu de parâmetro para análise das demais misturas: CCR com areia natural (CCR-2), CCR com substituição de $100 \%$ da areia por RAP (CCR1-AF), CCR com substituição de $100 \%$ do pedrisco por RAP (CCR1-PF), CCR com substituição de $100 \%$ da brita 1 por RAP (CCR1BF) e CCR com substituição de $50 \%$ de agregado natural por $50 \%$ da fração total do RAP (CCR1-FT). Os ensaios de compressão diametral e tração na flexão mostraram que a incorporação de RAP, em qualquer fração, diminui bruscamente a resistência mecânica dos corpos de prova, em relação ao CCR de referência, sendo a queda mais acentuada no caso da resistência à compressão. O módulo de elasticidade obtido por meio da instrumentação dos corpos de prova com LVDT (linear variable differential transformer) e strain gages, assim como o módulo de elasticidade dinâmico, obtido por pulso ultrassônico, apresentaram quedas significativas, quando comparados ao CCR de referência. Os CCR com incorporação de RAP apresentaram queda nos valores de tenacidade e aumento na resistência de propagação da trinca. As observações com microscópio óptico, lupa estereoscópica e com microscópio eletrônico de varredura mostraram que a interface entre o agregado fresado e a pasta de cimento foi prejudicada pela presença do filme asfáltico nos agregados de RAP. Embora a incorporação do RAP na mistura de CCR diminua a resistência das misturas e afete todos os parâmetros mecânicos, ainda assim é um material que pode ser utilizado como base e sub-base de pavimentos, pois alcançou parâmetros mecânicos que viabilizam seu uso.

Palavras - chave: concreto compactado com rolo, fresagem, ensaios de fratura, pavimentos flexíveis [reciclagem]. 
Reclaimed Asphalt Pavement (RAP) is a material obtained from asphalt pavement drilled during the restoration of flexible pavements. This material is produced in large amounts in large cities, what justifies the search for alternatives for its final disposal. In this paper, we will see the effects of the addition of RAP on Roller-Compacted Concrete (RCC). Six different mixes of RCC were produced. The reference RCC (RCC-1) was produced with industrial sand and used to verify the effects of RAP incorporation on mixes: RCC with natural sand (RCC-2), RCC with the replacement of $100 \%$ of sand with RAP (RCC1-AF), RCC with the replacement of $100 \%$ of small rocks with RAP (RCC1PF), RCC with the replacement of $100 \%$ of gravel with RAP (RCC1-BF) and RCC with the replacement of $50 \%$ of natural aggregate with $50 \%$ of the total RAP (RCC1-FT). The diametral compression and bending traction tests show that the addition of RAP, at any rate, abruptly decreases the strength of specimens compared with the reference RCC, and the decrease was greater for cylindrical specimens. The elastic modulus obtained through the instrumentation of specimens with LVDT (Linear Variable Differential Transformer) and strain gage, as well as those obtained by ultrasonic wave pulse- showed significant decreases as compared with the reference RCC. The RCC specimens with added RAP showed a decrease in toughness values and an increase in the spreading resistance of the cracks. Observations through optical microscope, stereoscopic glass and scanning electron microscope show that the interface between the milled aggregate and the cement paste was damaged by the presence of asphalt film in RAP aggregates. Even though the addition of RAP in the RCC mixture decreases the strength of the mixtures and affects all the mechanical parameters, it can still be used as a base and sub-base material for paving, since mechanical parameters have been met and make possible its use.

Keywords: roller-compacted concrete, milling, fracture tests, flexible pavements [recycling] 


\section{INTRODUÇÃO}

O Brasil é um dos países que possuem maior quantidade de obras construídas com Concreto Compactado com Rolo (CCR) ou em construção, no mundo. Já são mais de 50 barragens para abastecimento de água e geração de energia e novas barragens a serem construídas com CCR estão em fase de construção (SIMPÓSIO INTERNACIONAL DE CONCRETO COMPACTADO COM ROLO, 2008).

Conforme Filho (2003), a necessidade de se construir barragens em prazos antes inimagináveis, a custos cada vez menores, proporcionou o desenvolvimento atual da metodologia de construção do concreto compactado com rolo.

Na área de pavimentação rodoviária, o CCR também tem desempenhado um papel importante desde a década de 80 , quando seu uso teve um avanço expressivo no Brasil, seguindo o que acontecia em outros países, como por exemplo, os Estados Unidos.

Seguindo uma visão aprimorada de conservação ambiental, muitos trabalhos têm sido realizados com o intuito de utilizar ou reutilizar materiais, em todas as áreas, como forma de minimizar os impactos ambientais. Na pavimentação rodoviária tem se dado muita atenção a esses conceitos de preservação ambiental, já que este tipo de obra é uma das que mais impactam o meio ambiente.

O material fresado utilizado neste estudo vem prover uma redução nos impactos ambientais e mesmo no custo das obras de pavimentação. A utilização de pavimento asfáltico reciclado aumentou sensivelmente desde a sua primeira utilização em 1915 e foi retomada em meados de 1970, quando o embargo do petróleo árabe causou a inflação dos custos de construção (FHWA, 1997). 
A reciclagem de pavimentos é uma opção viável por várias razões, sejam elas, técnicas, econômicas ou ambientais. O uso do RAP (Reclaimed Asphalt Pavement) tem tido êxito em relação aos materiais virgens devido ao aumento no custo do asfalto, resultado da escassez de materiais de qualidade e à pressão exercida sobre a necessidade de preservação do meio ambiente.

\subsection{OBJETIVOS}

O objetivo geral da pesquisa é verificar a influência da substituição de agregados naturais por agregados fresados, provenientes da fresagem de pavimentos asfálticos, e seu possível uso em concretos compactados com rolo.

Considerando o exposto acima, os objetivos específicos que permeiam este estudo são:

1. Caracterizar o material fresado com o intuito de verificar seu enquadramento em uma faixa granulométrica possível de ser utilizada para confecção de concreto compactado com rolo;

2. Determinar a influência da substituição de $50 \%$ da faixa total de fresado pelos agregados naturais, bem como, da substituição de $100 \%$ das diferentes granulometrias (fina, média e grossa) do fresado nas misturas de CCR, para verificar se uma fração isolada resultaria em melhores resultados que a fração de $50 \%$ da faixa total;

3. Realizar ensaios estáticos de compressão diametral e tração na flexão, para verificação de resistência dos concretos produzidos, bem como, a determinação do Módulo de Deformação Secante dos CCR, por meio do uso de strain gages e LVDT (Linear Variable Differential Transformer).

4. Realizar ensaios para medida da velocidade do pulso ultrassônico para determinação dos módulos de elasticidade dinâmicos a fim de comparar com os módulos obtidos nos ensaios estáticos;

5. Realizar ensaios de mecânica de fratura nos CCR contendo $50 \%$ da faixa total de fresado e nos CCR com agregados convencionais, em corpos de 
prova prismáticos para verificar a tenacidade, energia e resistência à fratura das misturas e, por consequência, determinar a curva-R;

6. Realizar observações por meio de microscopia eletrônica de varredura para verificação do comportamento das ligações entre pasta de cimento e agregados fresados, bem como, possíveis alterações micro estruturais, devido à deformação do material fresado;

7. Verificar a presença de grumos (aglomeração de agregados e material asfáltico) e a presença de porosidade nos CCR confeccionados, por meio de lupa estereoscópica e microscópio óptico.

\subsection{ESTRUTURAÇÃO DO TRABALHO}

Esta tese está estruturada em cinco capítulos que sequenciam a introdução. Os assuntos de cada capítulo são sintetizados a seguir.

No Capítulo 2 estão apresentadas conceituações a respeito dos assuntos abordados na tese, os quais tratam sobre os fresados asfálticos, desde sua produção até sua utilização. Trata-se aqui também das características do concreto compactado com rolo e da reciclagem de pavimentos.

No capítulo 3 são descritas as metodologias adotadas para o desenvolvimento da pesquisa. São abordados os ensaios realizados em laboratório e como os resultados serão obtidos por meio dos mesmos. A metodologia contempla a caracterização dos materiais utilizados, preparação das misturas e ensaios mecânicos (compressão diametral, tração na flexão, ultrassom, tenacidade e observação microscópica).

No Capítulo 4 desenvolve-se a análise e apresentação dos resultados dos ensaios descritos no Capítulo 3. As análises procuram associar resultados de resistência dos concretos produzidos com os resultados de tenacidade e módulo de elasticidade. 
As considerações finais estão apresentadas no Capítulo 5, com as principais conclusões obtidas ao longo do desenvolvimento da pesquisa, incluindo sugestões para trabalhos futuros. 


\section{REVISÃO BIBLIOGRÁFICA}

\subsection{FRESADO ASFÁLTICO}

A produção de materiais fresados asfálticos (conhecidos em língua inglesa por Reclaimed Asphalt Pavement - RAP), provenientes de aberturas de valas e restauração de vias públicas, principalmente nas grandes cidades, é significativamente alta, levando órgãos públicos a terem preocupação quanto à destinação final deste material.

Fresado é um termo geralmente usado para descrever o material que é produzido através do processo de fresagem (retirada do revestimento asfáltico de pavimento). Na maioria das vezes a fresagem atinge somente a camada do revestimento, mas podendo ser executada, em alguns casos, até atingir parte das camadas subjacentes.

Huang, Shu \& Li (2005) definem o RAP como sendo material de pavimento composto por asfalto e agregado que é removido ou reprocessado.

Para Taha et al. (1999) o RAP é um revestimento betuminoso que é extraído por fresagem, e é usado como parte de um todo para pavimentos novos através da mistura com agregados virgens, cimento, cal e outros materiais.

Quando o material é originado somente de misturas asfálticas, o material é conhecido como recycled (ou reclaimed) asphalt pavement - RAP. No Reino Unido o termo é conhecido como asphalt arisings e na América do Norte como grindings (Peploe, 2006). 
Segundo a Federal Highway Administration (FHWA, 2009):

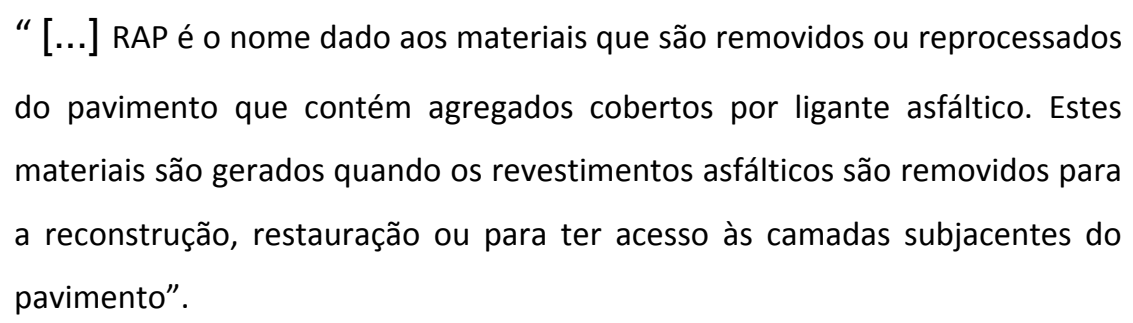

Considerando que a disposição de resíduos da construção civil em locais inadequados contribui para a degradação da qualidade ambiental, o CONAMA estabeleceu diretrizes que levam à minimização dos impactos ambientais. Segundo a resolução CONAMA № 307 de 5 de julho de 2002, resíduos da construção civil são os provenientes de construções, reformas, reparos, demolições de obras da construção civil, os resultantes da preparação e da escavação de terrenos, tais como: tijolos, blocos cerâmicos, concreto em geral, solos, rochas, metais, resinas, colas, tintas madeiras e compensados, forros, argamassa, gesso, telhas, pavimento asfáltico, vidros, plásticos, tubulações, fiação elétrica etc., comumente chamados de entulhos de obras, caliça ou metralha. A resolução ainda define que os resíduos, Classe A (citados acima), deverão ser reutilizados ou reciclados na forma de agregados ou encaminhados a áreas de aterro de resíduos da construção civil, sendo dispostos de modo a permitir a sua utilização ou reciclagem futura.

A utilização de pavimento asfáltico reciclado aumentou sensivelmente desde a sua primeira utilização em 1915 e foi retomada em meados de 1970, quando o embargo do petróleo árabe causou a inflação dos custos de construção (FWHA, 1997).

Taha et al. (1999) enfatizam que muitos estudos com RAP estão sendo realizados em vários locais do mundo como, por exemplo, em Ontário no Canadá, onde uma avaliação mostrou que a utilização de RAP como substituto para agregados de base e sub-base do pavimento teve um desempenho satisfatório e apresentou uma pequena melhora em relação aos materiais tradicionais. Da mesma forma, a Universidade de Illinois em Urbana-Champaign estudou o potencial do uso do RAP como material de base para pavimentos e também constatou que os resultados de laboratório e de campo indicaram que o RAP pode ser usado como material de base de 
pavimentos flexíveis. Fato também observado por outros autores (Taha et al., 2002; Garg e Tompson, 1996; Sayed et al., 1993; Peploe, 2006; entre outros).

O RAP a ser utilizado em misturas recicladas pode vir de diferentes camadas de misturas asfálticas a quente ou a frio, com diferentes composições ou de estoques formados por materiais de fontes distintas. Portanto, amostras representativas devem ser obtidas a partir dos pavimentos existentes para verificação de propriedades como granulometria e teor de asfalto. Quando se tratar de material fresado proveniente de estoques, indica-se retirar dez amostras de locais diferentes para evitar problemas com a segregação do material devido à estocagem (FWHA, 1997).

O Departamento de Transportes da Flórida (Florida Department Transportation, 2001) constatou que as propriedades do RAP não se modificam com o aumento no tempo de estocagem, sendo que a tensão de ruptura, o módulo secante e coesão se mantêm constantes ao longo do tempo.

Na Tabela 1 estão apresentados os dados referentes às quantidades de RAP produzidos no Município de São Paulo, fruto de recuperação de pavimentos urbanos que apresentavam revestimentos degradados e não são empregados nem mesmo para a reciclagem das próprias misturas asfálticas (BALBO e BODI, 2004).

Tabela 1 - Montantes e valores das misturas asfálticas obtidas de pavimentos em São Paulo, (Balbo e Bodi, 2004)

\begin{tabular}{|c|c|c|c|c|c|c|}
\hline $\begin{array}{c}\text { Serviço } \\
\text { anual }\end{array}$ & $\begin{array}{c}\text { Tipo de } \\
\text { material } \\
\text { extraído }\end{array}$ & $\begin{array}{c}\text { Quantidade } \\
\text { estimada } \\
\text { para } 2003(\mathrm{t})\end{array}$ & $\begin{array}{c}\text { Quantidade } \\
\text { de CAP } \\
\text { antigo } \\
\text { estimado } \\
(\mathrm{t})\end{array}$ & $\begin{array}{c}\text { Quantidade } \\
\text { de } \\
\text { agregados } \\
\text { recicláveis } \\
\text { estimado } \\
(\mathrm{t})\end{array}$ & $\begin{array}{c}\text { Custo } \\
\text { estimado do } \\
\text { CAP novo (R\$) }\end{array}$ & $\begin{array}{c}\text { Custo dos } \\
\text { agregados } \\
\text { novos } \\
(\mathrm{R} \$)\end{array}$ \\
\hline $\begin{array}{c}\text { Abertura de } \\
\text { valas }\end{array}$ & $\begin{array}{c}\text { Misturas } \\
\text { asfálticas } \\
\text { em blocos }\end{array}$ & 396.288 & 23.777 & 372.511 & $\mathbf{2 1 . 7 5 5 . 9 5 5 , 0 0}$ & $8.754 .008,50$ \\
\hline $\begin{array}{c}\text { Restauração } \\
\text { de vias } \\
\text { públicas }\end{array}$ & $\begin{array}{c}\text { Misturas } \\
\text { asfálticas } \\
\text { fresadas }\end{array}$ & 151.200 & 9.072 & 142.128 & $8.300 .880,00$ & $3.553 .200,00$ \\
\hline
\end{tabular}

Em alguns países, números como estes apresentados acima, justificam a existência de legislação sobre o reaproveitamento e a reciclagem deste tipo de material. Segundo Ruiz $(2002)^{1}$, citado por Balbo e Bodi (2004), a partir de 1974,

\footnotetext{
1 Ruiz-Rubio, A. (2002) Reciclado de mezclas bituminosas em planta en caliente: proceso, ventajas y limitaciones,empleo y perspectivas. Carreteras, Assossiación Española de la Carretera, n. 119, pp. 11-27, Madrid.
} 
estados como Texas e Nevada investiram muito na reciclagem a quente, técnica que rapidamente se disseminou nos EUA, sendo trabalho corriqueiro no cotidiano de serviços de manutenção e restauração no país.

De acordo com Taha et al. (1999), nos Estados Unidos mais de 50 milhões de toneladas de material asfáltico são fresados anualmente sendo que sua aplicação é predominante em reciclagem de misturas asfálticas.

Peploe (2006) destaca que aproximadamente 41 milhões de toneladas são geradas por ano no Canadá, das quais mais de $80 \%$ é reutilizado em pavimentos.

Al-Qadi et al. (2007) apresentam algumas características do RAP em relação às propriedades do asfalto presente no RAP e definem como dois os estágios do ligante asfáltico: curto prazo e longo prazo. Durante a construção (curto prazo), o ligante asfáltico é exposto a altas temperaturas, em torno de 135 a $163^{\circ} \mathrm{C}$, resultando em um aumento significativo na viscosidade (após resfriamento) e mudanças associadas às propriedades físico-químicas e reológicas, bem como do módulo de cisalhamento e da adesão. Durante a vida de serviço (longo prazo), o ligante asfáltico envelhece gradativamente e enrijece através de vários mecanismos. Conforme Roberts et al. $(1996)^{2}$; Tyrion (2000) ${ }^{3}$; Karlsson \& Isacsson (2006) $)^{4}$ citados por Al-Qadi et al. (2007), seis mecanismos principais estão associados ao enrijecimento e envelhecimento do ligante asfáltico:

- $\quad$ Oxidação através da reação difusiva entre o asfalto e o ar;

- Volatilização através da evaporação dos componentes mais leves, especialmente durante a construção;

- Polimerização através da reação química dos componentes moleculares;

- Tixotropia devido à formação de uma estrutura (ligante asfáltico começa a mudar suas cadeias) dentro do ligante asfáltico após um longo período de tempo;

- Separação através da remoção de constituintes oleosos, resinas e asfaltenos por agregados absorventes.

\footnotetext{
2 Roberts, F. L., P. S. Kandhal, E. R. Brown, D. Lee, and T. W. Kennedy, Hot Mix Asphalt Materials, Mixture Design, and Construction, 2nd Edition, Napa Education Foundation, Lanham, MD, 1996.

3 Tyrion, F. C., “Asphalt Oxidation,” Asphaltenes and Asphalts, Development in Petroleum Science, Vol. 40B, Elsevier, NY, 2000.

${ }^{4}$ Karlsson, R., and U. Isaacsson, "Material-Related Aspects of Asphalt Recycling - State of the Art," Journal of Materials in Civil Engineering, American Society of Civil Engineers, Vol. 18, No. 1, 2006, pp. 81-92.
} 
Apesar de existir resistência quanto ao uso do RAP, devido a uma possível contaminação deste tipo de material por uma variedade de materiais estranhos, Delwar, Fahmy \& Taha (1997) relatam que muito pouco tem se estudado a respeito desse assunto; entretanto, Young $(1980)^{5}$, apud Delwar, Fahmy \& Taha (1997) concluíram que a contaminação não produziria problemas nos concretos reciclados originários de pavimentos, muros de contenção, pontes, entre outros, a não ser que a contaminação ocorresse por cloretos ou sulfatos. Sadecki (1996) pesquisou sobre a lixiviação dos materiais fresados e concluiu que a concentração de hidrocarbonetos aromáticos policíclicos (HAP) está próxima ou abaixo dos limites aceitáveis.

A reciclagem de pavimentos é uma opção viável por várias razões, sejam elas, técnicas, econômicas ou ambientais. O uso do RAP tem tido êxito em relação aos materiais virgens devido ao aumento no custo do asfalto, à escassez de materiais de qualidade e à pressão exercida sobre necessidade de preservação do meio ambiente. Além disso, Al-Qadi et al. (2007) enfatizam que o uso do RAP tem diminuído a quantidade de resíduos, o que ajudou a resolver problemas com a destinação ou disposição final de materiais provenientes da construção de estradas, especialmente em grandes cidades.

Os benefícios ao meio ambiente e consideráveis economias com a aquisição de materiais são algumas vantagens do uso de resíduos, considerando que algumas agências viárias adotam o uso de até 50\% de RAP nas misturas em materiais estabilizados com betume ou quimicamente. Guthrie, Cooley \& Eggett (2007) estudaram o uso do RAP em bases granulares e adotaram consumos de RAP de 0\%, $25 \%, 50 \%, 75 \%$ e $100 \%$ e observaram que nas bases com porcentagens de 25 e $50 \%$ de RAP a umidade aumentava em relação à base convencional. As misturas com incorporação de RAP até $25 \%$ apresentaram aumento de resistência, ao contrário do que aconteceu com as demais frações, as quais tiverem sua rigidez diminuída. Muitos Estados americanos tenham estabelecido limites máximos para a porcentagem de RAP a ser adicionada à mistura variando em torno de 10 a 50\% (Al-Qadi et al., 2007).

Uma das técnicas utilizadas no Brasil tem sido a recuperação in situ de bases granulares degradadas. Esta técnica incorpora o material fresado do revestimento

\footnotetext{
${ }^{5}$ Young, J.F., "Contamination Problems in the Recycling of Concrete", Adhesion Problems in the Recycling of Concrete, Department of Civil Engineering, University of Illinois, Urbana, 1980, pp. 91-97.
} 
asfáltico ao material de base, constituindo uma nova base de pavimento. Estas operações aparecem como uma alternativa atrativa em termos ecológicos e econômicos. Sachet (2007) estudou a possibilidade de restauração de bases granulares envolvendo a reciclagem in situ através da incorporação de fresado asfáltico, obtendo resultados satisfatórios em termos de $C B R$, por meio de ensaios com cone de penetração dinâmica. Além disso, observou que a proposta de restauração através da reciclagem mostra-se uma alternativa bastante atraente no que se refere à agilidade no processo e vida útil do pavimento.

Embora estudos realizados (Kolias, 1996; Huang et al., 2005; Huang et al., 2006; Hossiney et al., 2008; entre outros) tenham constatado que a incorporação do RAP como agregado para concreto ocasione a diminuição da resistência das misturas em relação ao concreto convencional, muito pode ser feito com este material em obras de pavimentos rodoviários. Seu uso tem sido consolidado em misturas asfálticas a quente, em bases granulares e mais recentemente em concretos para pavimentação.

Em um estudo realizado por Araújo \& Farias (2004) referente à incorporação do fresado ao cascalho laterítico de base, no Distrito Federal, mostrou que existe uma percentagem ótima de fresado que ajuda na estabilidade da mistura, conferindo maior rigidez e resistência. Segundo os autores, os valores de resistência à compressão simples tiveram um ganho $50 \%$ para a mistura cascalho-fresado em relação ao cascalho puro e o módulo resiliente teve um ganho de rigidez em torno de $46 \%$. Os resultados mostraram que a incorporação do fresado para recuperação de bases granulares degradas é ecologicamente e tecnicamente viável.

\subsubsection{Processos de Produção do Material Fresado}

As técnicas mais utilizadas para a remoção do pavimento existente são a fresagem, escarificação e trituração do material (Figura 1). Cada técnica é empregada para um tipo de projeto, ou seja, a escolha pelo tipo de técnica depende dos defeitos observados no pavimento e dos parâmetros exigidos no projeto. A manutenção do greide da pista, especialmente em locais onde a altura é muito importante (sarjetas, túneis, etc) e a geometria precisa ser mantida, a escolha da técnica de remoção desempenha um papel muito importante. 


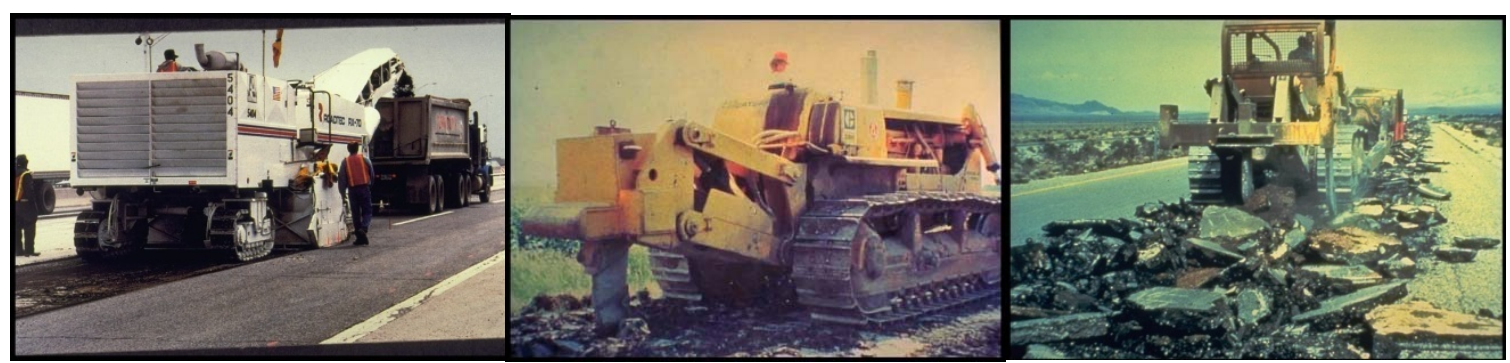

Figura 1 - Técnicas de remoção do pavimento existente (a) fresagem (b) escarificação e (c) trituração Fonte: FHWA, 1997, p. 5-4

O Departamento de Estradas de Rodagem do Estado de São Paulo - DER/SP (2006) define a fresagem a frio como uma técnica que consiste no corte ou desbaste de uma ou mais camadas do pavimento asfáltico por meio de processo mecânico a frio. É realizada através de cortes por movimento rotativo contínuo, seguido de elevação do material fresado para a caçamba do caminhão basculante.

A fresagem, conforme Bonfim (2007), é uma técnica de desbaste ou corte de metais, ou outras peças, por intermédio de um cortador giratório de ângulos diversos ou de várias freses em movimento giratório contínuo, como pode ser visto na Figura 2. A fresagem também pode ser caracterizada, na área rodoviária, como um processo em que se utiliza uma máquina fresadora para desagregar parte do pavimento existente.
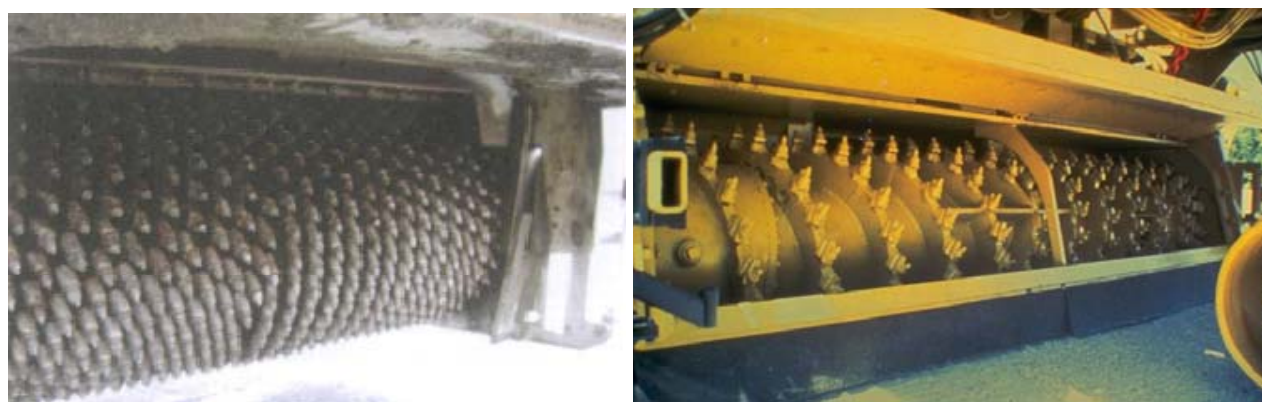

Figura 2 - Tipos de tambor com freses da máquina fresadora Fonte: Bonfim, p.40, 2007 e FHWA, 1997 p. 3-5

A fresagem a frio é definida pela FHWA (1997) como um método de remoção do pavimento, controlado automaticamente para alcançar uma profundidade desejada na camada, através de um equipamento especial, além de ser utilizada para restauração de superfícies de pavimento para um determinado greide ou inclinação, 
eliminação de sulcos e outras imperfeições. A Asphalt Recycling and Reclaimed Association - ARRA (1992) define cinco classes para a fresagem a frio:

a. Classe I: consiste da fresagem da superfície existente para remoção das irregularidades;

b. Classe II: refere-se à fresagem da superfície para uniformizar a espessura conforme previsto em projeto;

c. Classe III: é a fresagem do revestimento para obter uma espessura uniforme e a inclinação transversal prevista em projeto;

d. Classe IV: consiste da fresagem da espessura total do revestimento até a base ou subleito; e

e. Classe V: em que consiste da fresagem de espessura variável.

Bonfim (2007) destaca a importância da fresagem nos projetos de restauração, principalmente pela praticidade e rapidez, possibilitando pequenas intervenções. Algumas vantagens da fresagem:

- A manutenção do greide da pista;

- A execução de remendos sem desnível nas emendas, em recapeamento apenas de uma faixa exclusiva de tráfego ou em remendos no pavimento;

- A correção e/ou alteração da inclinação das pistas com relação aos dispositivos de drenagem superficial;

- A manutenção do nivelamento dos tampões de ferro, entre outras interferências, principalmente em pavimentos urbanos.

Quanto à espessura de corte, o autor classifica a fresagem como superficial e profunda. Sendo que a primeira atinge geralmente, somente as camadas superiores e em alguns casos pode chegar à camada de ligação. A profundidade de corte é em torno de cinco centímetros. Já na segunda o corte atinge espessuras consideráveis, podendo alcançar até a camada de sub-base do pavimento.

No que se refere ao material resultante da fresagem, pode-se dizer que apresentará grumos de mistura asfáltica que dependerão do tipo de mistura, da profundidade de fresagem e da velocidade de deslocamento da fresadora. Em geral os maiores grumos no material fresado têm tamanhos menores que $10 \mathrm{~cm}$. A Figura 3 apresenta grumos retirados do material fresado utilizado no presente estudo. 


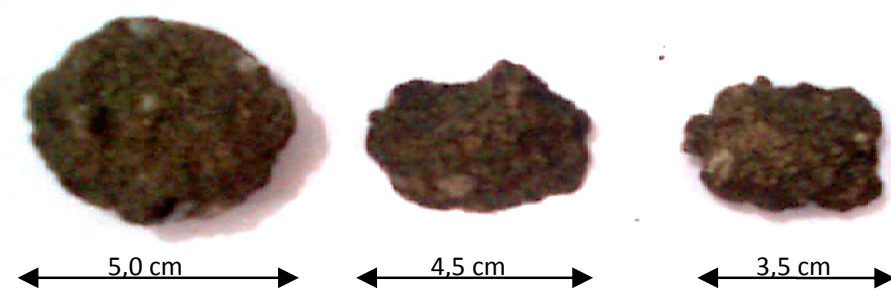

Figura 3 - Grumos de fresado asfáltico $(5,0 \mathrm{~cm}, 4,5 \mathrm{~cm}$ e 3,5 cm)

A ARRA recomenda que a superfície resultante da fresagem a frio seja uniforme, sem depressões descontínuas longitudinais, entre outras deformações. A Figura 4 mostra uma superfície típica resultante de uma fresagem a frio.

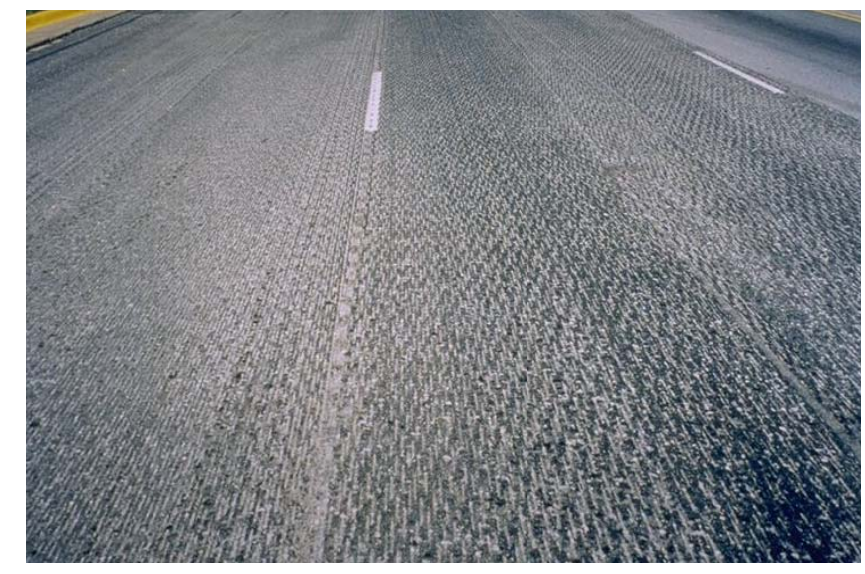

Figura 4 - Superfície resultante do processo de fresagem

Fonte: FHWA, 1997, p. 5-3

A fresagem possibilita várias aplicações, as quais têm suas especificidades para cada obra. Dentre seus usos pode ser utilizada para corrigir defeitos como exsudação, deformações plásticas, atenuação dos defeitos provenientes da reflexão de trincas, além de ser eficiente quando se necessita manter o greide da pista ou corrigir a inclinação do pavimento. 


\subsection{O USO DO FRESADO E SUA DESTINAÇÃO}

Nos Estados Unidos, devido à grande demanda por construções e restauração de rodovias, tem se dado crédito ao método da recuperação em toda espessura (em língua inglesa conhecido por Full Depth Reclamation - FDR). A FDR em conjunto com a estabilização com cimento vem sendo amplamente utilizada para a reconstrução de pavimentos flexíveis fatigados. O Guia da FHWA (1997) define a FDR como um método de reciclagem onde toda a seção do pavimento asfáltico e uma quantidade prédeterminada de material das camadas subjacentes podem ser tratadas para produzir uma nova base estabilizada. O sistema incorpora as camadas do pavimento com o revestimento asfáltico, com ou sem a adição de novos materiais, produzindo uma nova camada de base estabilizada para pavimentos que se encontram em estado de deterioração. Este método tem como vantagem a possibilidade de se corrigir defeitos estruturais no pavimento.

Contrariando a maioria das pesquisas já realizadas, Bejarano (2001) em sua avaliação do RAP em bases de pavimento para restaurar a California state highway 395, observou através de ensaios com Cone de Penetração Dinâmica que a resistência da base reciclada com RAP é maior do que a da base que existia no pavimento. Verificou também que os ensaios de deflexão após a reciclagem da base diminuíram em torno de $8 \%$. O módulo obtido através de retro-análise indicou aumento quando da incorporação do RAP, o que é de grande valia em se tratando de pavimentos flexíveis, já que bases com altos módulos reduzem as deflexões que provocam o trincamento por fadiga do concreto asfáltico e reduz a tensão que causa deformação permanente nas camadas subjacentes. A compactação em campo desempenha um papel muito importante no desempenho do material reciclado, sendo que com maiores níveis de compactação, maiores módulos e maior resistência ao cisalhamento são obtidos.

Um projeto desenvolvido para restaurar a Avenida Lincoln, Urbana/Illinois, em 1993, comprovou a potencialidade do RAP em bases e comparou seu desempenho com a de uma base executada com agregados virgens. Segundo Garg \& Thompson (1996), as bases com RAP e agregados virgens tiveram desempenho satisfatório sendo 
que passou dois anos sem apresentar problemas estruturais e os defeitos apresentados pelo pavimento não passaram de pequenas deformações permanentes.

Segundo Guthrie, Brown \& Eggett (2007) a FDR estabilizada com cimento é mais apropriada quando o recapeamento não é o viável para a restauração da rodovia, devido à presença de extensos defeitos na base ou sub-leito ou ainda quando uma porcentagem significativa da superfície necessita de remendo profundo. Este processo está tendo apelo porque reduz a procura por material de alta qualidade, o que preserva recursos naturais.

Guthrie, Browny \& Eggett (2007) desenvolveram um estudo que envolveu a estabilização com cimento dos materiais de bases feitas com RAP. Especificamente, a proposta do estudo era determinar o consumo ótimo de cimento necessário para estabilizar os materiais reciclados em função da variação do consumo de RAP. O consumo ótimo de cimento deve ser determinado dada a variabilidade da quantidade de RAP inerente ao projeto, já que a espessura da camada asfáltica varia ao longo da rodovia, sendo inevitável a variação da quantidade de RAP em diferentes locais do pavimento.

Os autores verificaram que os principais efeitos da quantidade de RAP se apresentam na resistência à compressão, pois aumentando a quantidade de RAP os valores de resistência diminuem e aumentando o consumo de cimento os valores de resistência aumentam. Fato que foi constatado também por Guthrie, Cooley \& Eggett (2007), os quais observaram que a queda nos valores de umidade ótima e massa específica aparente seca máxima das misturas estão associadas ao aumento das quantidades de RAP. As reduções acontecem porque o RAP consiste de agregados que são envoltos por asfalto, o que leva à redução dos valores de peso específico.

Outro fator importante abordado é que grandes quantidades de cimento podem afetar negativamente a estabilização, pois podem gerar fissuras de retração e sob tráfego pesado podem apresentar fissuras estruturais por se tornar um material muito rígido.

Taha (2003) também constatou queda nos valores de massa específica aparente seca máxima quando da incorporação do fresado à mistura, bem como, observou o aumento destes valores quando maiores quantidades de cimento e agregados virgens são inseridos na mistura. 
Em ensaios realizados por Taha (2003), as observações indicaram que os valores de CBR são afetados de forma a aumentá-los quando agregados virgens eram introduzidos à mistura. Assim como, a umidade ótima para misturas com RAP tende a ser muito menor que a do material convencional. Essa umidade só é aumentada quando cimento ou agregados virgens fizerem parte da mistura.

Sayed et al. (1993) caracterizaram o RAP como um material bem graduado e compararam seu peso específico aparente seco máximo à dos materiais granulares convencionais. Embora, a umidade ótima verificada no estudo seja muito menor para o RAP em relação aos materiais granulares convencionais. Estas propriedades foram obtidas em um estudo que verificava a possibilidade do uso de RAP como material de base para acostamentos.

Taha et al (2002) também classificaram o RAP como um material bem graduado; quanto aos Limites de Atterberg, verificaram que o RAP é material não plástico. O estudo desenvolvido pelos autores envolveu o uso de RAP estabilizado com cimento para uso em bases e sub-bases de pavimentos. Nos ensaios de resistência os pesquisadores observaram que quanto maiores as quantidades de agregados virgem e cimento nas misturas, maiores eram os valores de resistências encontrados. As possíveis razões para este aumento teria sido a melhora na transferência de carga entre os grãos proporcionada pelos grãos de agregado virgem e o escorregamento superficial desenvolvido pelo filme asfáltico do RAP. Além disso, os agregados virgens proporcionam uma melhora no intertravamento dos grãos, o que acarreta em aumento da resistência ao cisalhamento da mistura.

Kim, Labuz \& Dai (2007) realizaram um estudo com o objetivo de verificar o módulo de resiliência $\left(M_{R}\right)$ de bases granulares, sem adição de cimento, contendo RAP. $O M_{R}$ é comumente estudado em laboratório para determinar a rigidez do material de base. Na pesquisa os ensaios de $M_{R}$ foram realizados em amostras compactadas em laboratório com várias taxas de RAP e agregado britado para determinar o efeito do RAP e da umidade nos valores de $M_{R}$. As misturas consistiram de (\%RAP/\%agregado natural) $0 / 100,25 / 75,50 / 50$ e 75/25 e as umidades utilizadas foram $65 \%$ e $100 \%$ da umidade ótima. Observou-se que as curvas granulométricas contendo maior quantidade de RAP apresentam menor quantidade de finos. Quatro amostras foram preparadas em laboratório e uma in situ para os testes de $M_{R}$. Através do ensaio de 
Proctor foram definidas as umidades das amostras, sendo que a maior umidade foi observada nas amostras contendo $100 \%$ de material granular natural.

Constataram os autores, que a umidade ótima diminui com o aumento da quantidade de RAP. O aumento na quantidade de asfalto pode ter sido o responsável por essa diminuição. Os resultados de $M_{R}$ mostraram que para a umidade de $65 \%$ da umidade ótima as amostras com 50/50 (agregado natural/ RAP) apresentaram maior rigidez que as amostras contendo $100 \%$ de agregado natural. Entretanto, as misturas contendo RAP exibiram deformações permanentes maiores que as observadas nas amostras com $100 \%$ agregado natural.

Araújo e Farias (2004) também observaram em ensaios de módulo de resiliência que a incorporação do RAP produz misturas com maior rigidez e resistência, sobretudo quando adicionado $2 \%$ de cimento Portland para estabilização química da mistura. Através de ensaios de compressão simples, estes autores observaram que existe uma porcentagem ótima de fresado que ajuda na estabilidade da mistura (cascalho laterítico de base e fresado asfáltico) conferindo maior rigidez e resistência. A porcentagem ótima de RAP, encontrada pelos autores, foi de $25 \%$.

Os autores também constataram aumento na resistência à compressão simples conforme aumentava a quantidade de RAP na mistura. Fato que não foi constatado por Taha et al. (2002), na qual os resultados obtidos indicaram que para misturas contendo $100 \%$ agregados virgens apresentaram maior resistência à compressão e que as misturas com $100 \%$ e $90 \%$ de RAP levam a valores muito próximos de resistência à compressão quando ensaiados aos 28 dias de cura. Em relação ao Índice de Suporte Califórnia (ISC), a adição do fresado fez com que este valor diminuísse em relação aos valores de ISC de cascalho puro.

Contudo, Guthrie, Brown \& Eggett (2007) atentam para o fato de que fatores como a angularidade dos agregados e a granulometria da mistura reciclada podem influenciar as propriedades da base reciclada. $\mathrm{O}$ aumento na angularidade leva a maior friç̧ão intergranular e oferece maior resistência à deformação sob carregamento. Estes autores também testaram, assim como Araújo \& Farias (2004), a adição de 25\% de RAP, e constataram que nas suas misturas para base de pavimentos esta porcentagem acarreta uma queda de $29 \%$ na resistência quando comparada a uma 
mistura de materiais virgens bem como em uma redução de resistência de $13 \%$ a 15\% para cada $25 \%$ de adição de RAP na mistura.

Taha et. al. (1999) realizaram um estudo para avaliar a incorporação de RAP em materiais de base e sub-base granulares. As misturas elaboradas consistiam de porcentagens de RAP e porcentagens de materiais virgens nas seguintes proporções (\%RAP/\%material virgem): 100/0, 80/20,60/40, 40/60, 20/80 e 0/100. Os resultados obtidos indicaram que os melhores desempenhos nos testes físicos e valores de CBR foram obtidos para as misturas $80 / 20,60 / 40,40 / 60,20 / 80$ e 0/100. Os valores mais elevados de massa específica aparente seca e CBR foram obtidos para as misturas contendo maiores quantidades de material virgem.

Os autores destacam o sucesso do estudo para uso de RAP em base estabilizada com betume feito pelo Departamento de Transportes de Michigan, o qual indicou que a reciclagem a frio in situ de um pavimento asfáltico existente poderia ser estruturalmente equivalente a uma rodovia reconstruída com uma base nova.

Posteriormente, Taha et al. (2002) testaram misturas contendo maiores quantidades de RAP nas proporções de RAP/agregado virgem de 100/0, 90/10, 80/20, 70/30 e 0/100\%, bem como com adição de cimento em peso de 3,5 e 7\% . Verificou-se no estudo, assim como em outros, que a granulometria do RAP tem menor quantidade de finos do que o material virgem (Figura 5). Esse fato se deve aos grumos que são formados pelos agregados finos e o ligante asfáltico. Tanto que neste estudo os autores retiravam os grãos maiores que $19 \mathrm{~mm}$, considerando que são grumos formados pelos finos do material e o ligante asfáltico. Isso influencia na compactação da mistura, pois esses grãos tendem a ser quebrados durante o processo. 


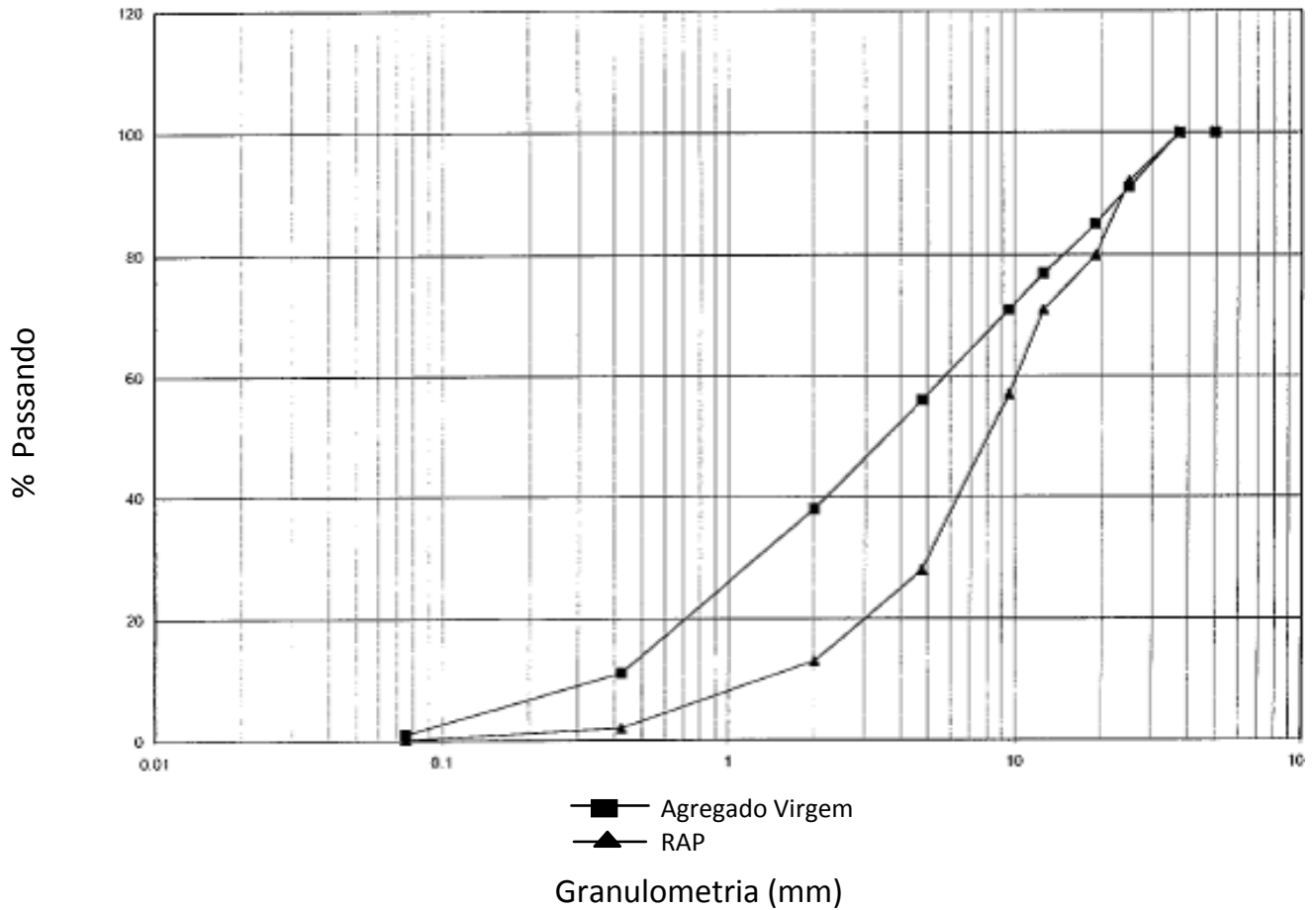

Figura 5 - Distribuição granulométrica do RAP e de agregados virgens

Fonte: Taha et al., 2002, p. 240

Outro fato importante observado nesta pesquisa é que para misturas com umidades baixas, as amostras se desintegravam quando retiradas dos moldes, fato que pode ser atribuído à falta de ligação entre os grãos devido ao filme asfáltico que envolve os agregados do RAP. Isso é comprovado quando quantidades de agregado virgem são incorporadas à mistura e melhoram a sua compactação e manuseio. Pelo fato de o RAP ser um material impermeável, a água tende a exsudar para superfície do corpo de prova quando a última camada está sendo compactada. A adição de cimento ao RAP teve um efeito pronunciado no módulo de resiliência das misturas. Na Tabela 2 são apresentados valores de umidade ótima e peso específico aparente seco máximo para todas as misturas.

Tabela 2 - Resultados de umidade ótima e peso específico aparente seco máximo das misturas

\begin{tabular}{|c|c|c|c|c|c|c|c|c|c|c|}
\hline \multirow{3}{*}{$\begin{array}{c}\% \text { de } \\
\text { cimento }\end{array}$} & \multicolumn{2}{|c|}{$100 \%$ RAP } & \multicolumn{2}{|c|}{$90 \%$ RAP } & \multicolumn{2}{|c|}{$80 \%$ RAP } & \multicolumn{2}{|c|}{$70 \%$ RAP } & \multicolumn{2}{|c|}{$100 \%$ agregados virgens } \\
\hline & \multirow{2}{*}{$\begin{array}{l}\text { Umidade } \\
\text { ótima (\%) }\end{array}$} & \multirow{2}{*}{$\begin{array}{c}\delta_{\max } \\
\left(\mathrm{g} / \mathrm{cm}^{3}\right)\end{array}$} & \multirow{2}{*}{$\begin{array}{l}\text { Umidade } \\
\text { ótima (\%) }\end{array}$} & \multirow{2}{*}{$\frac{\delta_{\text {máx }}}{\left(\mathrm{g} / \mathrm{cm}^{3}\right)}$} & \multirow{2}{*}{$\begin{array}{l}\text { Umidade } \\
\text { ótima (\%) }\end{array}$} & \multirow{2}{*}{$\frac{\delta_{\text {max }}}{\left(\mathrm{g} / \mathrm{cm}^{3}\right)}$} & \multirow{2}{*}{$\begin{array}{l}\text { Umidade } \\
\text { ótima (\%) }\end{array}$} & \multirow{2}{*}{$\begin{array}{c}\delta_{\text {máx }} \\
\left(\mathrm{g} / \mathrm{cm}^{3}\right)\end{array}$} & \multirow{2}{*}{$\begin{array}{l}\text { Umidade } \\
\text { ótima (\%) }\end{array}$} & \multirow{2}{*}{$\begin{array}{c}\frac{\delta_{\text {máx }}}{\left(\mathrm{g} / \mathrm{cm}^{3}\right)} \\
\end{array}$} \\
\hline & & & & & & & & & & \\
\hline 0 & 7 & 1,885 & 7,2 & 1,937 & 8 & 1,952 & 8,2 & 2,174 & 5,7 & 2,25 \\
\hline 3 & 7,8 & 1,921 & 8 & 1,988 & 8,2 & 2,06 & 8,6 & 2,187 & 6 & 2,313 \\
\hline 5 & 8,2 & 1,993 & 8,8 & 2,056 & 8,4 & 2,104 & 8,8 & 2,238 & 6,4 & 2,381 \\
\hline 7 & 8,5 & 2,014 & 9 & 2,096 & 9 & 2,116 & 9,1 & 2,246 & 7,4 & 2,387 \\
\hline
\end{tabular}




\subsubsection{Reciclagem com Agregados Fresados em Concreto}

Alguns estudos especiais vem sendo realizados com o intuito de utilizar o RAP e minimizar os impactos ambientais ocasionados por este tipo de resíduo, já que até o presente momento pouco tem se estudado e investido na preocupação com o destino deste material após sua retirada da pista.

A ideia de reciclar pavimentos surgiu em 1915 e foi pouco difundida até meados dos anos 70. No Brasil, teve início na década de 80, contemplando somente o concreto betuminoso usinado a quente reciclado, (DNER, 2005).

Delwar et al. (1997) conduziram um estudo com o objetivo de introduzir o RAP no concreto plástico e verificar o comportamento da mistura quanto às suas características mecânicas. As pesquisas foram realizadas em laboratório com corpos de prova cilíndricos de $15 \mathrm{~cm} \times 30 \mathrm{~cm}$ (diâmetro x altura), os quais foram moldados utilizando 10 composições de agregados que podem ser vistas na Tabela 3. Uma mistura padrão foi produzida com agregados naturais (areia e brita) e outras utilizando RAP fino (AF) e graúdo (AG). Agregado fino abaixo da peneira $4,8 \mathrm{~mm}$ e o material graúdo retido na peneira $4,8 \mathrm{~mm}$ e passante na peneira $19,0 \mathrm{~mm}$. Para cada mistura quatro amostras de concreto foram produzidas utilizando duas relações água/cimento $(0,4$ e 0,5$)$.

Os autores observaram que quanto maior é a proporção de RAP na mistura, menor é a tensão de ruptura. O aumento na quantidade de RAP no concreto faz com que a rigidez do concreto diminua; resultados que também foram observados por Mathias, Sedran e Larrad (2004). Os resultados de curva tensão-deformação indicam que o concreto contendo maiores quantidades de RAP falha a níveis de deformação maiores indicando que o agregado fresado pode causar alguma ductilidade no concreto. A amostra padrão sempre teve valores de resistência à compressão maior que as amostras contendo qualquer quantidade de RAP. Estas amostras tiveram fraturas do tipo abruptas e cônicas com separação do cilindro caracterizada pelo rompimento da argamassa. As amostras com adição de RAP tiverem as fraturas abruptas diminuídas. Os cilindros não separaram e continuaram sustentando carga após a fratura inicial. 
Tabela 3 - Composição de agregados, a/c = 0,5 e 0,4 (Delwar et al., 1997)

\begin{tabular}{|c|c|}
\hline Mistura & $\begin{array}{c}\text { Composição dos agregados } \\
\text { (\% de RAP) }\end{array}$ \\
\hline 1 & $\begin{array}{c}\mathrm{AG}-100 \\
\mathrm{AF}-100\end{array}$ \\
\hline 2 & $\begin{array}{c}A G-75+25 \% \text { de Brita } \\
\text { AF }-100\end{array}$ \\
\hline 3 & $\begin{array}{c}A G-50+50 \% \text { de Brita } \\
\text { AF }-100\end{array}$ \\
\hline 4 & $\begin{array}{c}\text { AG }-25+75 \% \text { de Brita } \\
\text { AF }-100\end{array}$ \\
\hline 5 & $\begin{array}{c}\text { AG }-100 \% \text { de Brita } \\
\text { AF }-100\end{array}$ \\
\hline 6 & $\begin{array}{c}\mathrm{AG}-100 \\
\mathrm{AF}-75+25 \% \text { de Areia }\end{array}$ \\
\hline 7 & $\begin{array}{c}A G-100 \\
A F-50+50 \% \text { de Areia }\end{array}$ \\
\hline 8 & $\begin{array}{c}A G-100 \\
A F-25+75 \% \text { de Areia }\end{array}$ \\
\hline 9 & $\begin{array}{c}\mathrm{AG}-100 \\
\mathrm{AF}-100 \% \text { de Areia }\end{array}$ \\
\hline 10 & $\begin{array}{l}\text { AG }-100 \% \text { de Brita } \\
\text { AF }-100 \% \text { de Areia }\end{array}$ \\
\hline
\end{tabular}

Delwar et al.(1997) e Huang et al.(2005) também verificaram que a fratura nas amostras contendo RAP não é abrupta, bem como, que o concreto com RAP experimentou uma melhora na tenacidade, ductilidade e comportamento elástico.

Huang et al. (2005) enfatizam que no concreto produzido com RAP, o asfalto forma um filme fino na interface da argamassa de cimento com o agregado, a qual pode impedir a propagação das trincas nos agregados, conforme pode ser visto na Figura 6.

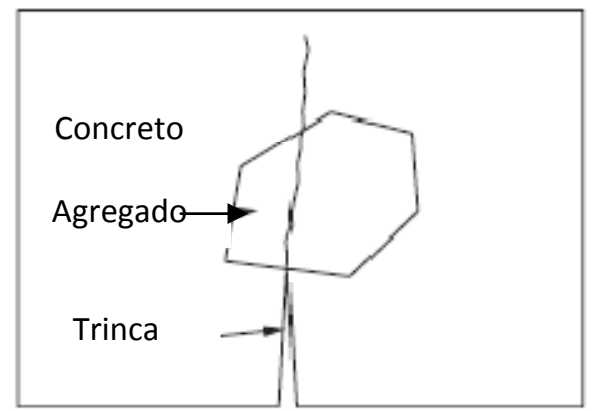

(a) Concreto sem RAP

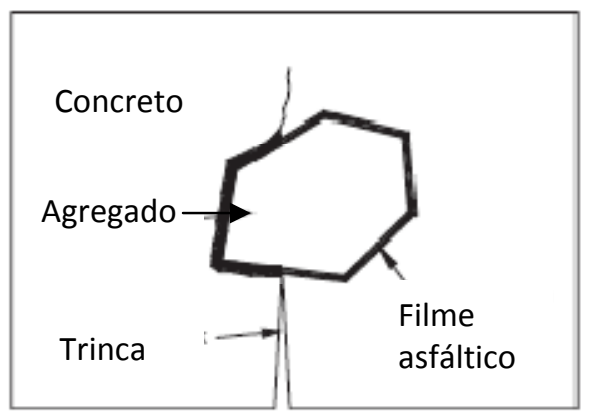

(b) Concreto com RAP

Figura 6 - Propagação de trinca no concreto simples e no concreto com RAP Fonte: Huang et al., 2005, p.2009 
Portanto, a trinca se desenvolve ao redor do agregado ao invés de passar pelo mesmo, durante a qual mais energia pode ser dissipada. O objetivo do estudo foi explorar o potencial do uso de RAP no concreto de cimento Portland (CCP) para aumentar a tenacidade e reduzir as chances de ruptura frágil. Foram utilizados dois tipos de RAP (fino e graúdo) para substituir os agregados da mistura padrão. Nesse estudo, o RAP foi preparado em laboratório tendo um filme de asfalto em torno do agregado da ordem de $8 \mu \mathrm{m}$. Os tempos de cura empregados foram de 3, 7, 14 e 28 dias para realização de testes para verificação das propriedades mecânicas das misturas. A preparação de quatro misturas (Tabela 4) foi realizada para investigar os diferentes efeitos da cobertura asfáltica nos agregados finos e graúdos.

Tabela 4 - Composição das misturas

\begin{tabular}{|c|c|c|}
\hline Número da Mistura & Agregado Graúdo & Agregado Miúdo \\
\hline 1 & Agregado natural & Agregado natural \\
\hline 2 & RAP & Agregado natural \\
\hline 3 & Agregado natural & RAP \\
\hline 4 & RAP & RAP \\
\hline
\end{tabular}

Os resultados mostraram que o abatimento do concreto produzido somente com RAP graúdo ou fino foi mais baixo que o concreto padrão. Esse fato pode estar relacionado à elevada viscosidade do ligante asfáltico. Surpreendentemente, o abatimento do concreto confeccionado com ambos os RAP (fino e graúdo) foi mais alto que o da mistura padrão. Quanto às propriedades do concreto endurecido, houve uma diminuição na resistência à compressão e à tração para as amostras com RAP. A presença do ligante asfáltico pode ter induzido uma concentração de tensões e causado microfissuras dentro da matriz de concreto. Porém, a taxa de redução da resistência à tração para misturas com RAP foi significativamente menor que aquela para a resistência à compressão.

Huang et al. (2006), desenvolveram um estudo focado na avaliação das propriedades mecânicas, em laboratório, do Concreto de Cimento Portland (CCP) feito com RAP. Utilizando os mesmos agregados de RAP (fino e graúdo) para substituir os agregados virgens, como no estudo anterior, mas acrescentando sílica ativa e aditivo 
superplastificante, para minimizar a baixa resistência resultante da incorporação do RAP. Para investigar os efeitos dos diferentes fatores no desempenho do concreto de cimento Portland (CCP), um conjunto de 17 misturas foi preparado para o estudo. Aos 28 dias de cura a resistência à compressão do concreto controle (feito com agregados virgens) foi 41,3 MPa. Esse valor diminuiu para 10,5 MPa quando todo o agregado graúdo foi substituído pelo RAP, resultando em uma redução de aproximadamente 75\%. O efeito do agregado miúdo foi semelhante ao do agregado graúdo. A resistência à compressão diminui para 19,1 MPa quando todo o agregado fino foi substituído por RAP (a redução foi superior a 50\%). O concreto contendo ambos os RAP (fino e graúdo) exibiu um maior decréscimo na resistência à compressão do que os concretos produzidos com apenas um dos dois RAP. A introdução da sílica não teve um efeito significativo na resistência do concreto. O concreto contendo sílica e superplastificante também não exibiu um desempenho significativo como se esperava.

Kolias (1996) observou os mesmos efeitos na base produzida com RAP em laboratório, ou seja, o módulo de resiliência e a resistência à compressão tendem a diminuir com a incorporação do RAP. Kolias também observou em seu estudo que os valores de módulos de elasticidades estáticos têm maior redução que o módulo de elasticidade dinâmico (obtido através de pulso ultrassônico).

Hossiney et al. (2008) também trabalharam com a possibilidade de uso de RAP em concreto para aplicação em pavimento de concreto. O concreto foi produzido em laboratório e suas propriedades foram avaliadas. Análises com elementos finitos foram realizadas para determinar como concretos contendo diferentes quantidades de RAP se comportariam se fossem empregados em um pavimento de concreto típico do Estado da Flórida. Os resultados deste estudo mostraram que:

- As resistências à compressão, à tração e à flexão, bem como o módulo de elasticidade diminuíram com o aumento da porcentagem de RAP;

- A retração por secagem parece diminuir com o aumento da quantidade de RAP;

- A tensão máxima no pavimento diminuiu com o aumento na quantidade de RAP, devido à queda no módulo de elasticidade;

- Os vazios de ar aumentam com o aumento da quantidade de RAP;

- O coeficiente de expansão térmica aparentemente não foi afetado com a introdução do RAP. 
A Figura 7 mostra a superfície de fratura da amostra de concreto contendo RAP. Podese observar que a pasta de cimento está bem aderida às partículas de RAP.

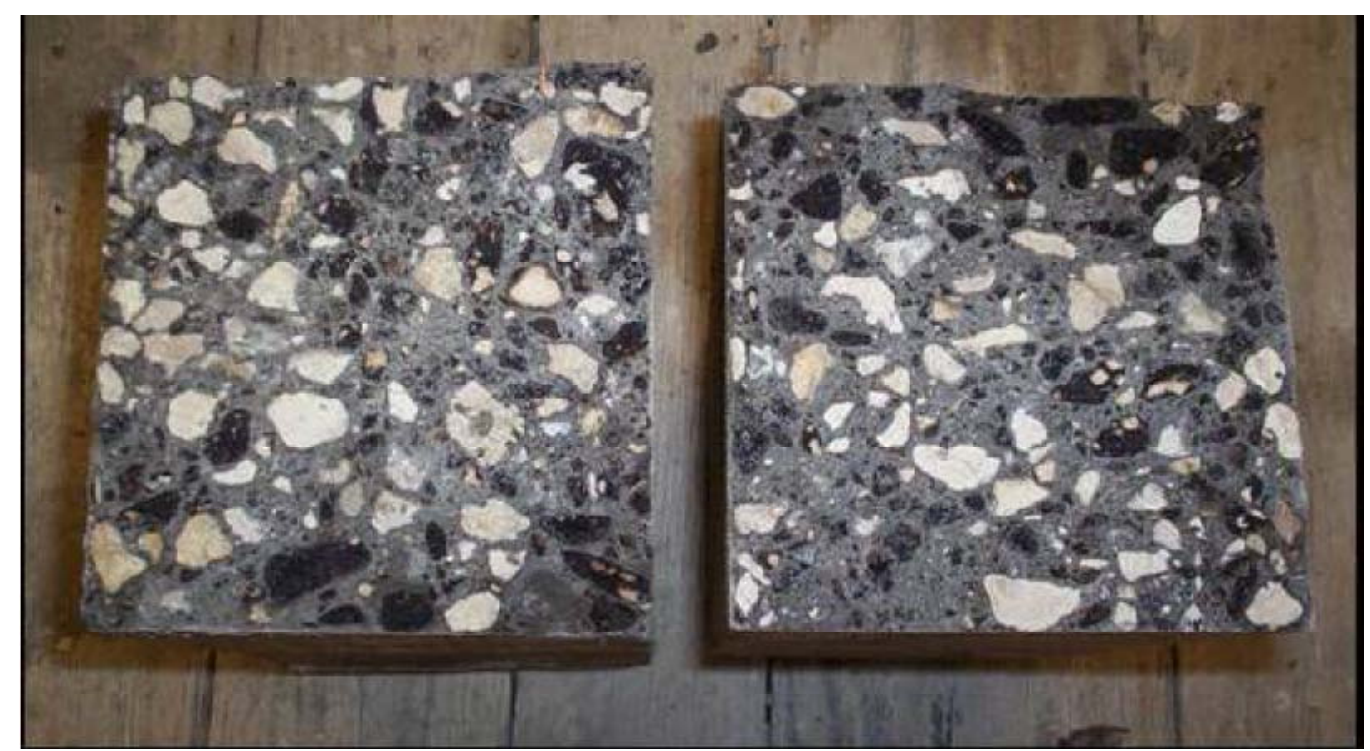

Figura 7 - Superfície de fratura do concreto contendo RAP Fonte: Hossiney et al. (2008) p.8

Os concretos feitos com RAP seguem os mesmos padrões de execução que um CCR ou CCP comum, ou seja, podem ser compactados em laboratório através de golpes, pela queda de um peso ou através de vibração. Quanto à estabilização desse tipo de material, como visto anteriormente, pode ser feita através da inserção de quantidades de cimento à mistura, bem como de materiais pozolânicos dentre outras possibilidades.

Dentre as poucas pesquisas realizadas em campo com RAP, destaca-se o trabalho realizado por Taha et al. (2002), que tornou possíveis algumas conclusões quanto ao uso do RAP em pista:

- Todas as misturas com RAP e agregado virgem sem cimento (exceto $100 \%$ agregado virgem) são impraticáveis no campo com pequenas espessuras. Isto também foi confirmado por Taha et al. (1999) e Mathias, Sedran \& Larrard (2004);

- O uso de $100 \%$ RAP, estabilizado com 3,5 ou 7,0\% de cimento, pode prover uma economia em comparação ao uso de $100 \%$ agregado virgem com cimento; 
- A capacidade de um agregado de RAP funcionar como um componente estrutural é maior quando é estabilizado com cimento do que quando é somente misturado com agregados virgens.

Na França, Mathias, Sedran \& Larrard (2004) buscaram inovar o uso do RAP com o intuito de prover maior utilidade deste material que é produzido em grande quantidade, em torno de 2 milhões de toneladas por ano na França, e consideraram o seu uso em concreto vibrado e em concreto compactado com rolo. Assim como em outros estudos já citados, observou-se a diminuição na resistência à tração e no módulo de elasticidade da mistura quando o RAP é incorporado. Quanto ao comportamento à fadiga, observaram que a introdução do RAP no concreto leva a uma diminuição no $\sigma_{6}$, (tensão medida nos ensaios de fadiga) devido à queda nos valores de resistência à tração na flexão. Por outro lado, o concreto com RAP apresentou menor dispersão no fator SN (dado pela análise estatística de todas as amostras testadas). Na Figura 8 estão apresentados os valores de fadiga, onde BF 0300 e BF 0220 são as misturas controle sem RAP e com consumos de cimento de 330 e $220 \mathrm{~kg} / \mathrm{m}^{3}$; as demais indicam a porcentagem de RAP e o consumo de cimento.

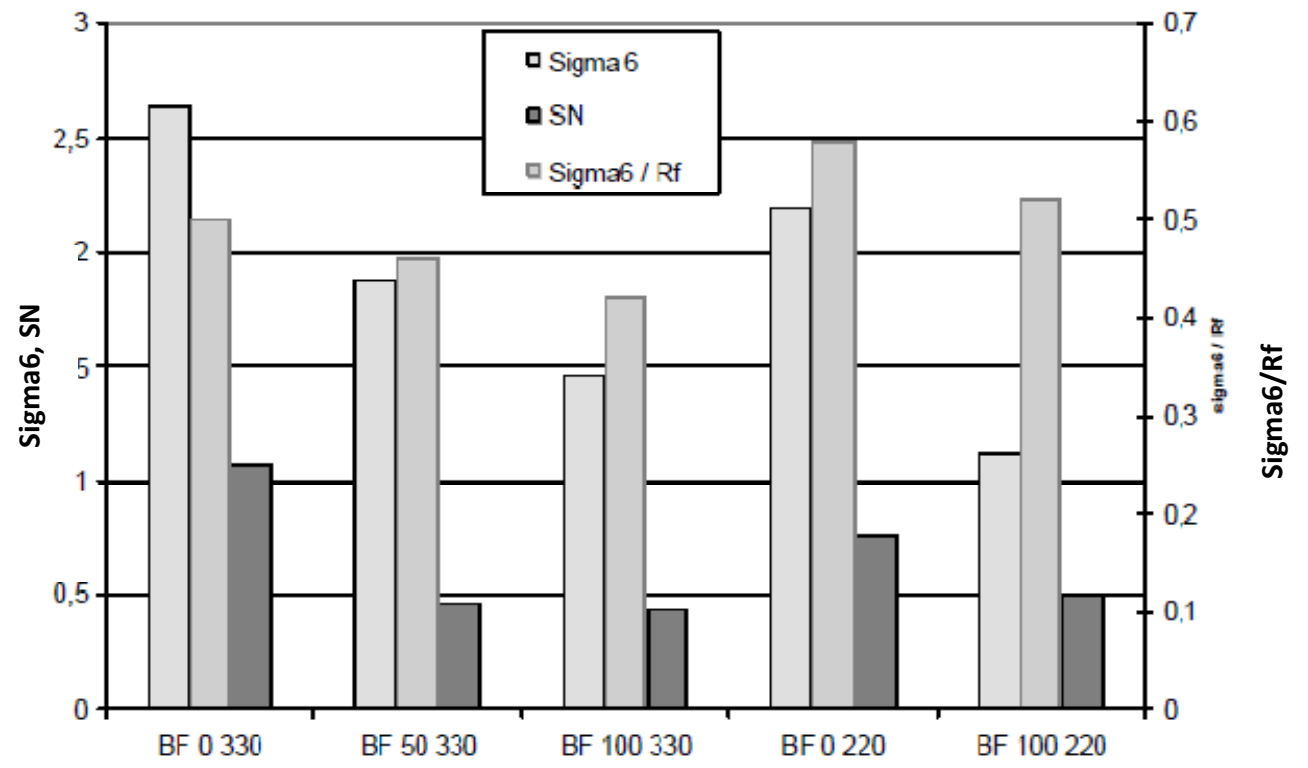

Figura 8 - Resultados dos ensaios de fadiga

Fonte: Mathias, Sedran \& Larrard (2004), p. 8 
Observando o comportamento à fadiga do concreto controle (sem RAP) e do concreto com 0 e $50 \%$ de RAP, os autores concluíram que respondem de forma similar no teste comparativo. No primeiro ensaio, foram utilizados $330 \mathrm{~kg}$ de cimento por $\mathrm{m}^{3}$, três trincas apareceram nos dois concretos e praticamente ao mesmo tempo, quando ensaiados a uma temperatura de $30^{\circ} \mathrm{C}$. No segundo ensaio, com $25 \%$ menos de cimento, uma única trinca se desenvolveu em cada uma das vigas e também praticamente com o mesmo tempo de ensaio (Figura 9). Esses resultados poderiam ser explicados pela temperatura de lançamento do concreto.

Primeiro ensaio

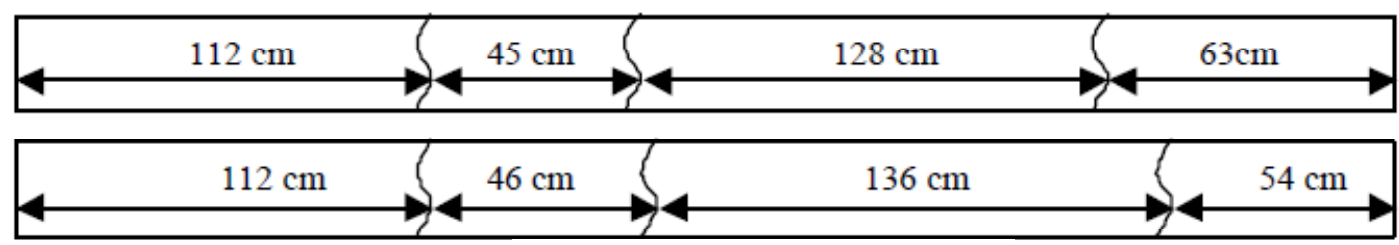

Segundo ensaio
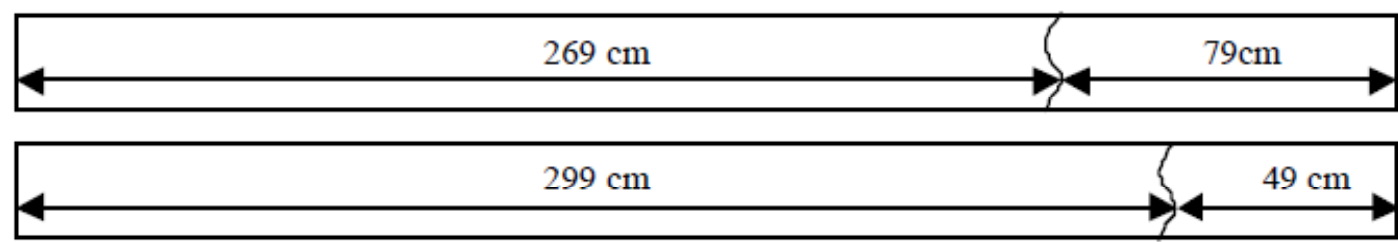

Figura 9 - Padrão das trincas nas amostras de concreto Fonte: Mathias, Sedran \& Larrard (2004), p. 8

Assim como outros autores, Mathias, Sedran \& Larrard (2004) concluíram que é possível a incorporação do RAP em concreto para pavimentos. Mesmo aumentando a espessura das camadas quando utilizado o RAP, ainda assim se torna uma opção técnica e economicamente viável.

\subsection{RECICLAGEM DE PAVIMENTOS}

A reciclagem de pavimentos asfálticos para restauração e reconstrução de pavimentos apresenta várias vantagens como ressalta FHWA (1997): reduções consideráveis com material, dinheiro e energia se destacam neste tipo de técnica. Entretanto, podem ser citados os demais benefícios alcançados pela reciclagem:

a. Redução nos custos de construção;

b. Conservação de agregados e ligantes; 
c. Preservação da geometria do pavimento;

d. Preservação do meio-ambiente;

e. Conservação de energia; e

f. Rápida liberação ao tráfego.

A escolha pela alternativa de restauração depende dos defeitos presentes no pavimento, bem como da avaliação do material existente no pavimento e dos parâmetros de projeto. Outros fatores importantes, na escolha da melhor alternativa de restauração, têm relação com a manutenção da geometria, das camadas do pavimento e de passagens subterrâneas.

Tuchumantel em 1988 mencionava a técnica de reciclagem como uma inovação no campo de recuperação de estruturas flexíveis quando comparada com as técnicas convencionais adotadas em nosso país. Segundo o autor, o químico F. S. FOSTER teve um grande papel na descoberta da reciclagem de pavimentos betuminosos quando estudou a caracterização química dos asfaltos nas suas duas frações: asfaltenos e maltenos. Estudando o efeito do envelhecimento dos asfaltos conhecido como uma ação termo-oxi-degradativa no ligante, caracterizada pela perda de suas propriedades iniciais físico-químicas aglutinantes e pelo seu endurecimento, tornando-se quebradiço. Esse envelhecimento é causado pelo desequilíbrio de seus componentes, principalmente das frações maltênicas mais reativas, as quais são responsáveis pela boa dispersão dos asfaltenos no sistema. Logo, aumentando a fração de maltenos devidamente equilibrada, haverá novamente equilíbrio desses componentes e consequentemente o pavimento envelhecido e oxidado voltará a ter as propriedades físico-químicas semelhantes à de um asfalto novo.

A Asphalt Recycling and Reclaiming (ARRA) define cinco diferentes categorias para os métodos de reciclagem:

- A quente (Hot recycling);

- A quente in situ (Hot in-place recycling);

- A frio (Cold recycling);

- A frio in situ (Cold in-place recycling); e

- Recuperação da espessura total (Full depth reclamation). 
A reciclagem a quente é um processo no qual o pavimento asfáltico recuperado (RAP) é combinado com novos materiais, eventualmente com agentes recicladores para produzir uma mistura asfáltica a quente (hot mix asphalt - HMA). Para as misturas recicladas a quente, geralmente são utilizados de 10 a 30\% de RAP. O desempenho alcançado por essas misturas é igual ou superior quando comparado a um HMA convencional.

O estado de Illinois tem utilizado material reciclado de RAP desde 1980 em misturas asfálticas a quente (HMA), mas ainda existem questões quanto ao uso correto do RAP em projetos de HMA. Portanto, um estudo realizado pelo Departamento de Transportes daquele estado buscou o entendimento da interação entre asfaltos velhos e virgens no RAP. Esse entendimento procurou estabelecer o nível apropriado de RAP na mistura e como isso interfere no desempenho e na durabilidade das misturas quando comparado ao HMA produzido com agregados virgens.

Em 1996, estimou-se que em torno de 33\% de todo o pavimento asfáltico nos Estados Unidos foi reciclado com HMA (Sullivan, 1996). Após 30 anos da primeira experiência em Nevada e no Texas, o uso do RAP parece não ser somente uma alternativa benéfica para o futuro, mas também a necessidade de assegurar a concorrência na construção de pavimentos flexíveis.

A reciclagem a quente in situ consiste no aquecimento, amolecimento e consequente fresagem de uma dada espessura do pavimento. Essa técnica pode ser realizada com operação de passagem simples ou passagem múltipla do trem de reciclagem. A profundidade do tratamento varia de 20 a $50 \mathrm{~mm}$.

A reciclagem a frio in situ envolve a reutilização do material do pavimento existente sem aquecimento. Os custos com transporte são reduzidos já que não existe transporte de material, exceto de agentes recicladores (emulsão asfáltica ou ligante) quando necessário. Cinza volante ou cal também podem ser adicionadas. Esses aditivos surtem bons efeitos em misturas com baixa estabilidade. A profundidade de tratamento varia de 75 a $100 \mathrm{~mm}$. Esse método possibilita tratar defeitos estruturais, alargar o pavimento e minimizar problemas ambientais.

A recuperação da espessura total (FDR) tem sido definida como um método em que toda a espessura do pavimento asfáltico e uma quantidade pré-determinada do material de base são tratadas para produzir uma nova base estabilizada 
granulometricamente. É basicamente o processo de reciclagem a frio em que diferentes aditivos, como emulsão asfáltica, aditivos químicos (cloreto de cálcio, cimento Portland, materiais pozolânicos e cal) são adicionados para obter uma base melhorada. Esse processo de reciclagem é geralmente realizado de 100 a $300 \mathrm{~mm}$ de profundidade. Esse método tem como vantagem o tratamento de muitos defeitos do pavimento, minimização dos custos de transporte e significativas melhoras estruturais.

Kearney e Huffman (1999) relatam que nos Estados Unidos a FDR vem se tornando um dos métodos mais populares para restauração de pavimentos. Na FDR uma nova base é produzida pela pulverização do pavimento asfáltico existente misturado como material granular das camadas subjacentes do pavimento. 0 recapeamento asfáltico tem sido substituído por tratamentos como a reciclagem a frio e a quente e pelo processo de recuperação de toda a espessura. Os autores enfatizam o fato de que na reciclagem a frio e a quente, somente os materiais das camadas asfálticas são utilizados para produzir uma nova camada asfáltica. A FDR se difere dos outros dois processos porque são processadas à camada asfáltica mais uma espessura pré-determinada dos materiais granulares das camadas subjacentes para produzir uma base estabilizada granulometricamente.

\subsection{CONCRETO COMPACTADO COM ROLO: Conceituação e Características}

O concreto compactado com rolo (CCR) é um concreto que pode ser compactado devido à sua consistência seca. Tem seu uso consolidado em barragens, sub-bases, bases e camadas de revestimento para pavimentos rodoviários variando o consumo de cimento com o tipo de aplicação. Assim como no concreto convencional, no CCR, os agregados normalmente utilizados são: areia natural, areia artificial e agregados graúdos.

Genericamente, o concreto seco pode ser definido como o concreto que tem consistência inicial significativamente alta em relação a um concreto convencional. Marchand et. al (1996), enfatizam que a mistura de concreto seco é bastante rígida sendo compactado por meio de rolos compactadores (como é o caso de CCR) ou 
permitindo desmolde imediato. A alta consistência exigida é normalmente alcançada pela redução da quantidade de água ou pela baixa fração de pasta da mistura.

O CCR foi desenvolvido com o intuito de ser um concreto econômico e que proporcionasse maior rapidez na construção de barragens conforme o American Concrete Institute - $\mathrm{ACl}$ (1988). Nas últimas duas décadas observou-se um aumento significativo do número de barragens construídas em concreto compactado com rolo, no Brasil, devido às vantagens que a técnica permite inclusive pela redução no custo global da obra.

O American Concrete Institute $(\mathrm{ACl}, 1987)$ define o CCR como um concreto seco de ampla utilização na construção de barragens, pisos industriais e estruturas de pavimentos. É um material seco que tem sido consolidado por vibração externa.

A Portland Cement Association (PCA, 1987) e ACI (1988), conceituam o CCR como um concreto não plástico que é misturado, espalhado e compactado com os mesmos equipamentos utilizados na pavimentação asfáltica.

Pittman e Ragan (1998) definem o CCR como um concreto com "zero-slump" que geralmente é misturado em usina, colocado na pista e compactado com rolos. Devido à sua consistência seca possibilita que camadas de concreto possam ser lançadas imediatamente após o adensamento da camada anterior (KUPERMAN, 2005).

Conforme o DNIT (2005), o CCR é um concreto seco, de consistência rija e trabalhabilidade tal que permite ser compactado por rolos compressores, vibratórios ou não. O consumo de cimento no CCR é muito menor do que o usual para concretos de pavimentação, que fica em torno de 85 a $220 \mathrm{~kg} / \mathrm{m}^{3}$ no primeiro contra $320 \mathrm{~kg} / \mathrm{m}^{3}$, no mínimo, no segundo.

Segundo Andriolo (1998), o termo "concreto compactado com rolo" descreve um concreto usado em um processo construtivo que combina técnicas rápidas e econômicas de concretagem, com as propriedades mecânicas do concreto tradicional, como durabilidade e resistência. Andriolo (1998) conceitua o CCR como sendo uma tecnologia caracterizada, principalmente, pelo uso de rolos compactadores. O autor enfatiza que a qualidade da mistura depende, principalmente, da qualidade dos materiais utilizados, do consumo de cimento e do grau de compactação.

A expressão inglesa Lean Concrete originou na década de 70 a terminologia "concreto magro". Por volta de 1980 o Brasil adotou esse tipo de concreto 
denominando-o concreto pobre rolado. Os japoneses exploraram as técnicas de construção deste tipo de concreto e passaram empregar o termo "concreto compactado com rolo", expressão que hoje em dia é a mais usual e correta.

Conforme descrito por Paulon et al. (2004), inicialmente o CCR foi encarado por duas diferentes filosofias: "primeiramente, foram utilizadas soluções baseadas no controle da umidade ótima da mistura através da compactação de materiais soltos, de forma a garantir a maior densidade possível. Neste caso, não havia garantia do total preenchimento dos vazios e, tampouco, preocupação com os parâmetros de resistência do material. De outro lado, surgiu o procedimento de estudo e desenvolvimento baseado na tecnologia de concreto utilizando seus princípios básicos."

De acordo com Trichês (1993), o emprego do CCR teve um grande impulso nos anos 70, favorecido pela crise do petróleo, que elevou os custos da pavimentação com o concreto asfáltico. Alguns países passaram a utilizá-lo na pavimentação de áreas industriais, militares, pátios de aeroportos e rodovias.

Carvalho (1988) enfatiza que na Inglaterra desde o ano de 1944 o CCR é utilizado de forma abundante, a ponto de ser tão conhecido que na época era empregado em mais da metade das obras de pavimentação rodoviária.

A primeira utilização de pavimento de CCR foi como camada inferior de pavimento composto, construído em 1893 nos Estados Unidos, na cidade de Bellefontaine, Ohio, conforme documentado pela American Concrete Paving Association (1975).

Alguns registros mostram que as primeiras experiências de utilização do CCR no Brasil datam de meados dos anos 70 com a construção da barragem de São Simão entre 1977 e 1978.

Conforme Carvalho (1991), no Brasil, o DERSA - Desenvolvimento Rodoviário S.A. - empregou o CCR com revestimento betuminoso na duplicação da SP-65 - trecho Jacareí-Campinas e da SP-75 - trecho Campinas-Sorocaba, num total de aproximadamente $160 \mathrm{~km}$.

Conforme Tayabji \& Halpenny (1987), desde o primeiro uso o CCR na construção de barragens nos Estados Unidos, durante os anos 70, seu uso vem sendo ampliado para outras aplicações, devido ao seu baixo custo, fácil concretagem e bom 
desempenho. A partir de então o CCR tem sido empregado em portos, estradas de acesso, aeroportos, bases e sub-bases de pavimentos, entre outros.

Pittman (1996) considera o CCR como uma nova técnica de construção, que vêm sendo utilizada em aplicações militares e civis nos Estados Unidos desde 1983. O custo do CCR resulta em torno de 20 a 30\% menor que o de um concreto convencional, além de ser espalhado com o mínimo trabalho e compactado com rolos. A ausência de armadura e barras de transferência contribuem para diminuição nos custos.

No Brasil, o CCR começou a ser empregado na construção rodoviária, a partir da década de 80. A Associação Brasileira de Cimento Portland ( $\mathrm{ABCP}$ ) alavancou o uso do CCR no Brasil, utilizando-o em camadas de revestimento nas ruas da Grande São Paulo. No entanto, as primeiras obras registradas datam de 1972, quando foram executadas pela Prefeitura Municipal de Porto Alegre/RS, camadas de base em CCR para pavimentos asfálticos de vias urbanas. Dentre elas destacam-se as Avenidas Sertório, Bento Gonçalves, Primeira e Segunda Perimetrais e Oswaldo Aranha, as quais totalizaram 1700 metros de extensão de pavimentos constituídos por uma base de 200 $\mathrm{mm}$ de CCR sob revestimento asfáltico de $100 \mathrm{~mm}$.

Dentre as primeiras aplicações de CCR como base de pavimento de peças prémoldadas no Brasil, Carvalho, Godinho \& Júnior (1988) destacam as quatro obras dos postos de pesagem em Santa Catarina e Minas Gerais, obras que foram realizadas entre os anos de 1984 e 1986.

O CCR desempenha um papel fundamental na estrutura de pavimentos rígidos. $\mathrm{O}$ seu emprego evita o bombeamento de finos, serve como um controlador da expansão de alguns tipos de solos encontrados nos subleitos, além de melhorar as condições estruturais do pavimento como um todo.

De acordo com Balbo (2007), os CCR não podem ser empregados como materiais estabilizados com cimento, mas como concretos, já que a mistura e os resultados obtidos após a cura são os normalmente encontrados nos concretos tradicionais e especialmente pelo envolvimento da argamassa ou pasta de cimento com os agregados.

A Canadian Portland Cement Association - CPCA (sem data) caracteriza o CCR como um concreto de zero-slump que é compactado com rolo e pode ser executado com equipamentos tradicionalmente utilizados na pavimentação asfáltica, além de ser 
mais econômico. A CPCA compara o CCR com o concreto convencional, destacando algumas de suas características:

- Leva menor quantidade de água;

- Tem baixa quantidade de pasta de cimento (argamassa);

- Geralmente requer maior quantidade de agregados finos (para produzir uma mistura que seja estável sob a ação do rolo vibratório);

- Usualmente tem um tamanho máximo de agregado de $19 \mathrm{~mm}$ (no sentido de minimizar a segregação e produzir uma superfície menos irregular).

Dentre as diversas vantagens apresentadas pelo CCR tem-se a rápida liberação ao tráfego, que pode ser realizada em poucos dias, principalmente, quando se trata de obras de restauração.

Pittman \& Ragan (1998) enfatizam que a técnica construtiva do CCR permite que uma grande quantidade de pavimento de concreto seja produzida, com uma mínima quantidade de trabalho, de equipamentos e não necessita armadura, além de apresentar um custo reduzido de 20 a $30 \%$ em relação a pavimentos de concreto convencionais.

Tayabji \& Halpenny (1987) ressaltaram que o CCR usado para pavimentos pode ser projetado pra alcançar, aos 28 dias, resistência à compressão similar aquela de um concreto comum. Outra característica dos pavimentos de CCR que contribui para a economia deste tipo de construção é a frequente ausência de trincas de contração normalmente utilizadas para controlar as trincas de retração que ocorrem naturalmente no concreto (PITTMAN, 1996).

Godinho \& Grossi (1991), destacam algumas características tecnológicas que consideram mais importantes para o CCR:

- Os agregados não precisam estar enquadrados em faixas granulométricas específicas;

- Consumos de cimento variando entre 85 e $280 \mathrm{~kg} / \mathrm{m}^{3}$;

- Pode ser produzido na obra, em betoneiras estacionárias;

- Resistência à compressão aos 28 dias entre 5,0 MPa e $35 \mathrm{MPa}$;

- Resistência à tração na flexão aos 28 dias entre 1,0 MPa e 4,0 MPa;

- Umidade ótima em torno de 6\%; 
- Módulo estático de deformação aos 28 dias entre $14.000 \mathrm{MPa}$ e $30.000 \mathrm{MPa}$.

Antigamente nos pavimentos de CCR não era realizada a serragem das juntas de retração, fato que contribuía para o desenvolvimento de trincas por retração e trincamento por fadiga do concreto. Esse procedimento não era realizado por vários motivos, entre eles os custos adicionais que eram gerados pela serragem das juntas e que, na época, eram considerados desnecessários (PITTMAN E RAGAN, 1998).

O CCR, assim como o concreto convencional, é afetado pela retração por secagem, fator que contribui para o trincamento do pavimento nos primeiros dias de cura após a concretagem. Este trincamento ocorre porque o concreto retrai devido ao seu resfriamento durante a cura, ao mesmo tempo em que é restringido pela fundação sobre a qual ele está disposto. Esta restrição é a responsável pela geração das tensões de tração na placa de concreto. Por isso, conforme Pittman e Ragan (1998), as juntas de retração são geralmente feitas nas primeiras 24 horas para induzir o local da trinca criando uma zona enfraquecida na placa.

De acordo com Neville $(1981)^{6}$, apud Pittman e Ragan (1998), a retração por secagem do concreto depende de duas variáveis principais: a umidade inicial do concreto e o volume de agregado da mistura. Portanto, um concreto tendo uma umidade relativamente alta ou alta relação água/cimento tem maior potencial de desenvolver uma grande retração por secagem do que um concreto com baixa umidade. No entanto, os autores enfatizam que a retração por secagem no CCR é relativamente baixa se comparado ao concreto convencional usado para pavimento, 0 que permite maior espaçamento entre as juntas transversais.

Experiências por todo mundo comprovam a eficiência do CCR como bases de pavimento. Em 2004, o Departamento de Transportes da Geórgia (GDOT) utilizou o CCR para reconstruir os acostamentos da estrada interestadual 285, em Atlanta. Foi o primeiro uso de pavimento em CCR em estradas interestaduais nos Estados Unidos embora, desde a metade dos anos 80 , mais de cem ruas urbanas e interseções foram construídas e tendo como revestimento uma fina camada de concreto asfáltico para melhorar a qualidade de rolamento, já que o CCR resulta em uma superfície muito rugosa.

\footnotetext{
${ }^{6}$ Neville, A.M., Properties of Concrete, $3^{\text {rd }}$ ed., Longman Scientific and Technical, Essex, England, 1981.
} 


\subsection{MECÂNICA DA FRATURA EM CONCRETOS}

A mecânica da fratura tem se tornado um método muito interessante quando se trata da determinação do comportamento do concreto submetido a cargas estáticas. Effting \& Bressan (2003), enfatizam que para a aplicação dos conceitos de mecânica da fratura ao concreto, é necessário que se conheçam os parâmetros que regem o comportamento à tração do material, como por exemplo, a tenacidade à fratura e a energia de fratura.

Para Barr et al. (1996), a mecânica da fratura tem relação com a iniciação e propagação das fissuras e possibilita a determinação das propriedades de fratura do material.

Conforme Fortes (2003), a tenacidade à fratura pode ser considerada uma propriedade do material e, portanto deve ser independente de tamanho, geometria e níveis de carregamento para um material com uma determinada microestrutura.

Para Albuquerque (1998) a mecânica da fratura fornece uma descrição quantitativa da transformação de um componente estrutural intacto em um fraturado pelo crescimento de uma trinca.

Broek (1986) ${ }^{7}$, citado por Balbo (2006), define a tenacidade como a quantidade de energia absorvida por qualquer material durante seu processo de desenvolvimento de fratura estrutural, sendo que estruturas com materiais de alta resistência normalmente apresentam baixa resistência ao fraturamento.

Griffith em 1920 desempenhou um papel muito importante na área da mecânica da fratura, contribuindo com sua origem e promovendo grandes avanços nesta área. De acordo com Albuquerque (2003) a relação entre a tensão de fratura e o tamanho da trinca é conhecida como balanço de energia de Griffith e é o ponto inicial para o desenvolvimento da mecânica da fratura.

Segundo Souza (2001), Griffth $(1921)^{8}$ utilizou o trabalho de Inglis $(1913)^{9}$ para formular um critério de energia, baseado nas Leis da Termodinâmica, o qual explica o crescimento instável de fissuras em materiais frágeis. Dessa forma, conforme Souza

\footnotetext{
${ }^{7}$ Broeck, B. (1986) Elementary Engineering Fracture Mechanics. Martinus Nijhoff Publishers, Dordrecht, The Netherlands.

${ }^{8}$ Griffith, A. A. The phenomenon of rupture and flow in solids, Phill. Trans. R. Soc. London, Series A, 221, 163 198, 1921.

${ }^{9}$ Inglis, C. E.. Stress in a Plate Due to the Presence of Cracks and Sharp Corners. Trans. Inst Nav. Archit., 55, 219 $230,1913$.
} 
(2001), os ensaios de Griffth (1921) foram o marco inicial do estudo da Mecânica da Fratura, relacionando de forma quantitativa o tamanho das fissuras e a resistência do material.

Griffith $(1920)^{10}$, citado por Albuquerque (1998), admite que um corpo atinja a ruptura quando a propagação da trinca presente neste corpo ocorrer de maneira instável ou incontrolada. Isso ocorre quando a taxa de transferência de energia de deformação liberada for maior que a taxa de absorção da energia de superfície necessária para desencadear o processo de fraturamento.

Irwin contribuiu muito para o desenvolvimento da Mecânica da Fratura no ano de 1948 quando estabeleceu as condições de aplicabilidade da Mecânica da Fratura Elástica Linear (MFEL) e critérios de dimensionamento a partir da teoria introduzida por Griffth, em 1921 (Souza, 2001). Irwin, em 1957, desenvolveu uma nova técnica para tratar a Mecânica da Fratura, baseada no fator de intensidade de tensões (K).

Segundo Whittaker et al. (1992) ${ }^{11}$, citado por Albuquerque (1998), Kc, fator de intensidade de tensão, é um parâmetro que indica a habilidade de materiais não elásticos resistir ao fraturamento por fadiga ou estático.

A “Integral J” apresentada por RICE (1968) é uma formulação que possibilita quantificar o fluxo de energia em contorno fechado na região da ponta da trinca para materiais não-elásticos que não poderiam ser representados pela Mecânica da Fratura Elástica Linear - MFEL.

De acordo com Catalano (1983), citado por Santos, Sousa e Bittencourt (2003), Kaplan (1961) foi o primeiro pesquisador a aplicar os princípios da mecânica da fratura elástico linear em materiais cimentícios (argamassa e concreto) chegando à conclusão de que o valor crítico da taxa de liberação de energia potencial $\left(G_{c}\right)$ pode ser utilizado como critério para propagação rápida da fissura e fratura do concreto.

Segundo Broek (1988), citado por Souza (2001), a Teoria da Elasticidade é usada para calcular o campo de tensões existente na região da ponta da fissura e o material é considerado elástico seguindo a Lei de Hooke.

\footnotetext{
${ }^{10}$ Griffith, A. A., The phenomena of rupture and flow in solids. Phil. Trans. Of the Royal of London, Series A, Vol. 221, pp. 163-197, 1920.

11 Whittaker B. N., SING R. N. \& SUN G.. Rock Fracture Mechanics - Principles, Design and Applications. Elsevier Science, Amsterdam 1992.
} 
Conforme Petersson (1980), no campo de mecânica da fratura Gc e Kc são dois parâmetros de máxima importância. O parâmetro "Gc" no trabalho de Petersson é chamado de energia de fratura que é definido como a quantidade de energia requerida para criar uma fissura em uma unidade de área. Embora, em outros trabalhos "Gc" seja chamado de taxa de liberação de energia para deformação crítica ou tenacidade. "Kc" é o fator de intensidade de tensão, ou seja, é a medida da magnitude de concentração de tensão que existe na frente da ponta da trinca quando a mesma começa a se propagar.

Petersson (1980) mostra que existe uma relação entre os dois parâmetros, Gc e Kc, expressa pela equação (1) sugerida por Irwin (1957):

$K_{c}=\sqrt{G_{c} \times E}$

Onde:

$E$ = módulo de elasticidade; isto possibilita que Kc seja determinado ou então, que Gc seja calculado e vice-versa. Para materiais como concreto a diferença entre tensão plana e deformação plana é muito pequena.

A expressão acima caracteriza o estado plano de tensão. O estado plano de deformação é expresso pela equação (2):

$G_{c}=K^{2} \frac{\left(1-v^{2}\right)}{E}$

As fissuras podem ocorrer de três maneiras em um sólido, as quais são dependentes do tipo de solicitação a que estão submetidos (Figura 10).
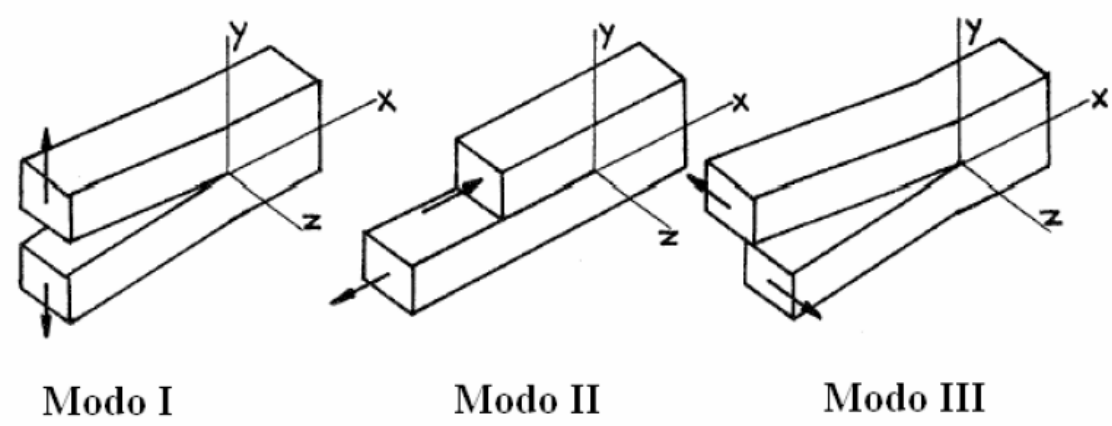
O Modo I se dá de forma que a propagação da fissura force a sua abertura (openning mode). As tensões são aplicadas ao plano da fissura. O Modo II (shear mode) se caracteriza pela propagação no plano provocada pelo escorregamento entre as faces na direção do comprimento da abertura, ou seja, as tensões cisalhantes são paralelas ao eixo da trinca. Quando a fissura ocorre na direção normal ao comprimento da fissura por escorregamento entre as faces, tem-se o Modo III (tearing mode). Neste modo ocorre o que se chama de rasgamento.

Segundo Souza (2001) dificilmente os Modos II e III ocorrem isoladamente, geralmente eles ocorrem juntamente com o Modo I.

Um campo de tensões é formado quando o material apresenta defeitos, fissuras, descontinuidades dentre outros. Essas tensões geram linhas de fluxo que podem ser igualmente espaçadas, quando o carregamento se dá de forma distribuída em toda a placa. No caso em que um corte é realizado na placa, o fluxo de tensões tende a gerar maior concentração de tensões neste local (Souza, 2001).

De acordo com Petersson (1980) quando uma amostra de concreto possui uma fissura pré-existente (Figura 11a) e é carregado, existirá uma concentração de tensão próxima à ponta da trinca. Quando a tensão de resistência é alcançada, uma zona de microfissuras começa a se desenvolver (Figura 11b). A zona microfissurada continua se desenvolvendo com o aumento da carga e finalmente algumas das microfissuras se unem e uma fissura real é aberta (Figura 11c).

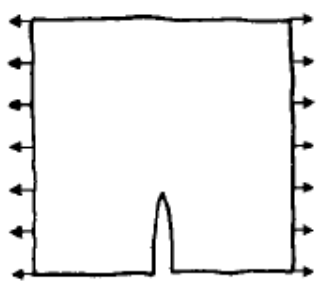

a)

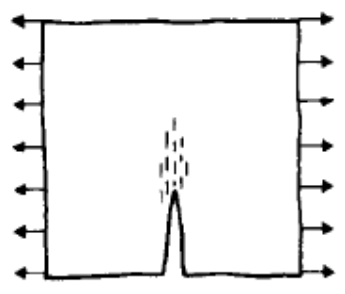

b)

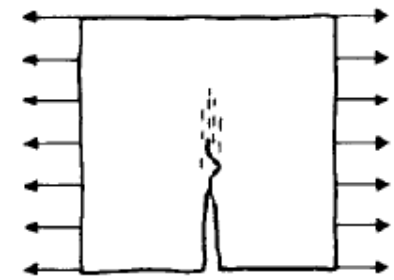

c)

Figura 11 - a) Material sem fissura, b) material com microfissuras e c) material fissurado Fonte: Petersson, p. 81, 1980

A determinação de $G c$ se dá pela área formada abaixo da curva tensão $x$ deformação como pode ser visto na Figura 12. 


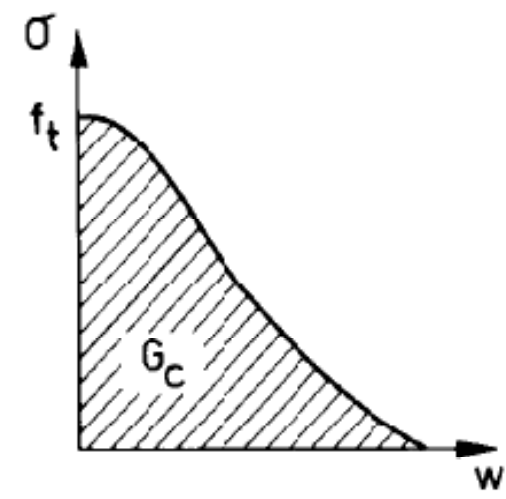

a)

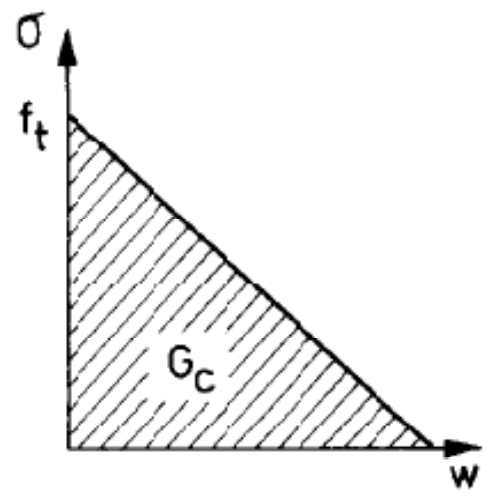

b)

Figura 12 - a)Curva $\sigma-w$. A capacidade de transferência de tensão da zona microfissurada em função da deformação; b) a reta aproximada da curva na Figura a.

Fonte: Petersson, p. 81, 1980

Como Gc é definido como a quantidade necessária de energia consumida para abertura da fissura em uma unidade de área, então Gc pode ser calculado pela expressão 3 (Petersson, 1980):

$G_{c}=\frac{\left[\int_{\delta}^{\delta_{\text {max }}} F(\delta) d \delta+\frac{m g \delta_{\text {máx }}}{2}\right]}{[(d-a) b]}$

Onde:

$$
\begin{aligned}
& m=\text { peso da viga } \\
& g=9,81 \mathrm{~m} / \mathrm{s}^{2} \\
& d=\text { espessura da viga } \\
& b=\text { largura da viga } \\
& a=\text { profundidade do entalhe } \\
& \delta_{\text {máx }}=\text { deflexão máxima }
\end{aligned}
$$

O último termo entre colchetes é uma correção da energia fornecida pelo peso da viga.

A propagação da trinca pode ser caracterizada pela determinação da curva- $R$ (Albuquerque, 2003). Segundo a autora, para a obtenção dessa curva é necessária a condição de propagação estável da trinca. 
A curva-R possibilita a visualização do comportamento da resistência à propagação da trinca, ou seja, a resistência à criação de uma superfície de fratura (Albuquerque, 2003). A curva-R é um gráfico que caracteriza o aspecto energético da fratura dos materiais. Pode ser definida como a curva de resistência à propagação da trinca, $R(a)$, em função do tamanho instantâneo da trinca (a) ou em função do incremento do comprimento da trinca $(\Delta a)$ ou ainda em função do comprimento relativo da trinca, $\alpha(=a / w)$, sendo $w$ a altura do corpo-de-prova por onde a trinca se propagará.

Na Figura 13, Sakai e Bradt (1988) ${ }^{12}$, citados por Albuquerque (2003), ilustram os três tipos de curva-R. Um dos tipos de curva-R é a plana, onde a resistência à propagação da trinca não aumenta com o incremento no tamanho da trinca. Os outros dois tipos de curva-R são denominados curva-R crescente, sendo um crescente com patamar e o outro sempre crescente. Um material com esse tipo de curva-R exibe um comportamento de aumento da resistência à propagação com o incremento no tamanho da trinca.

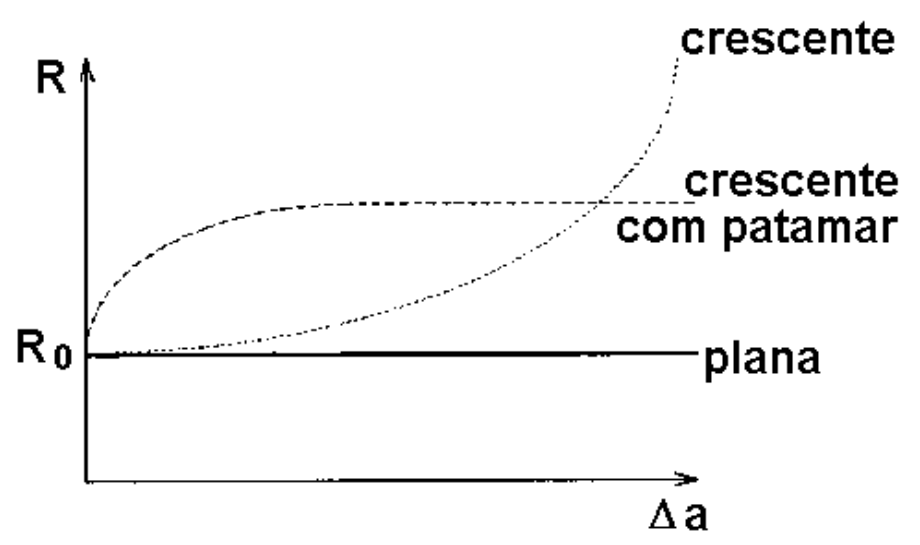

Figura 13 - Representação esquemática de três tipos de curva-R Fonte: Sakai e Bradt, 1998, adaptado por Albuquerque, 2003.

O comportamento de curva- $\mathrm{R}$ crescente ocorre devido aos mecanismos de tenacificação. Estes se dão ao longo de uma zona de processo na frente da trinca e/ou no rastro da trinca, conforme Figura 14 (Albuquerque, 2003).

\footnotetext{
12 Sakai, M., Bradt, R. C.. The crack Growth Resistence Curve of Non- Tranforming Ceramics. Journ. of Ceram. Soc.. Jap. Int, 96, 779, (1988).
} 


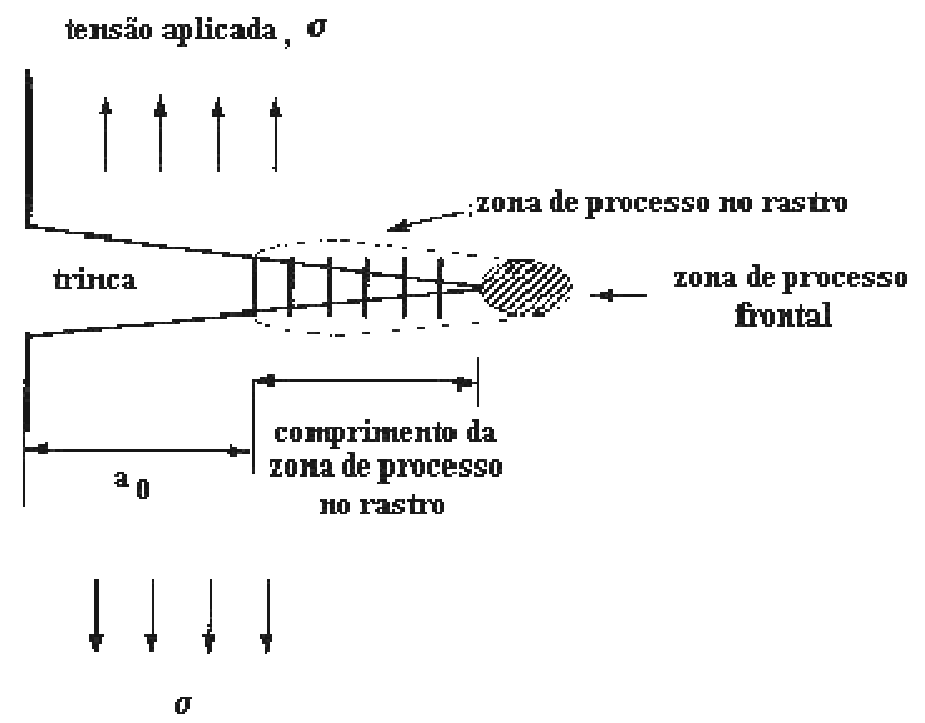

Figura 14 - Esquema das zonas de processo

Fonte: Albuquerque, 2003.

\subsubsection{Estudos de Tenacidade em Concretos}

Muitos autores têm estudado o comportamento à fratura de concretos (Petersson, 1980; Patterson, 1975, Albuquerque, 2003; Balbo 2006; Ferreira, 2007; entre outros).

No Brasil, Albuquerque et al. (2010) estudaram o comportamento à fratura de concretos compactados com rolo (CCR) convencionais e com incorporação de escória como agregado substituto da areia, em ensaios de tensão com um cutelo (Figura 15). 0 ensaio foi realizado sob carregamento contínuo e deslocamento controlado, usando uma taxa de deslocamento de $5 \mu \mathrm{m} / \mathrm{min}$.
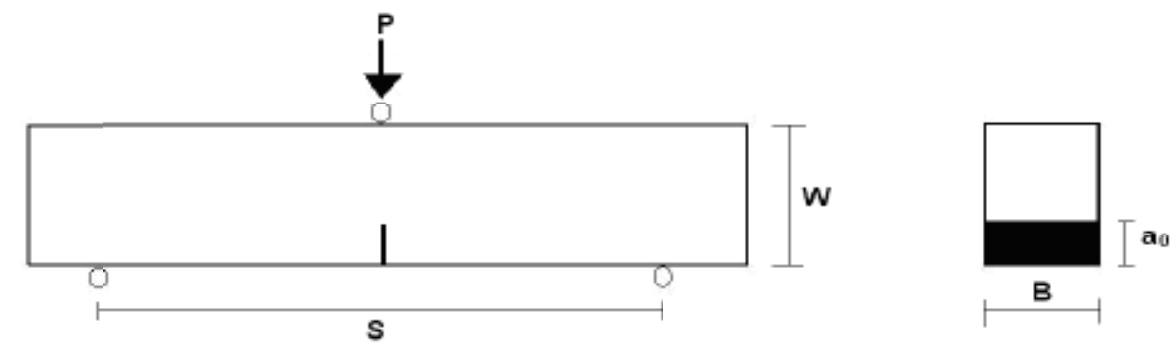

Fonte: Albuquerque, 2010

Figura 15 - Arranjo do ensaio de fratura 
Os autores observaram que o comportamento do CCR com escória é muito parecido com o CCR padrão feito com agregados naturais. Os materiais apresentaram comportamento crescente da curva- $R$, fato que indica aumento na resistência à propagação de trincas, bem como da sua abertura. Os resultados dos ensaios realizados em nove corpos de prova estão apresentados na Tabela 5, onde está apresentado o valor de tenacidade no início da propagação da trinca (K $\left.\mathrm{K}_{\mathrm{ICIP}}\right)$, a resistência à abertura da trinca ( $\left.R_{\text {médio }}\right)$ e a energia de propagação a trinca ( $\left.2_{\gamma_{\text {wof }}}\right)$.

Tabela 5 - Valores de tenacidade no início da propagação da trinca, $\mathrm{K}_{\mathrm{ICip}}$, resistência à abertura da trinca, $R_{\text {médio, }}$ e energia de fratura por área de propagação, $2_{\gamma \text { wof }}$, para CCR com $100 \mathrm{~kg} / \mathrm{m}^{3}$ de cimento

(Albuquerque et al., 2010)

\begin{tabular}{|c|c|c|c|c|}
\hline Mistura & Amostra & $\begin{array}{c}\mathrm{K}_{\text {ICip }} \\
\left(\mathrm{MPa} \cdot \mathrm{m}^{1 / 2}\right)\end{array}$ & $\begin{array}{c}\mathrm{R}_{\text {médio }} \\
\left(\mathrm{J} / \mathrm{m}^{2}\right)\end{array}$ & $\begin{array}{c}2_{\gamma_{\text {woo }}} \\
\left(\mathrm{J} / \mathrm{m}^{2}\right)\end{array}$ \\
\hline \multirow{4}{*}{ CCR Padrão } & CCR 1 & 1,94 & 574 & 426 \\
\cline { 2 - 5 } & CCR2 & 2,06 & 589 & 524 \\
\cline { 2 - 5 } & CCR3 & 1,98 & 809 & 569 \\
\cline { 2 - 5 } & CCR5 & 1,6 & 616 & 404 \\
\cline { 2 - 5 } & Média & 1,89 & 647 & 481 \\
\cline { 2 - 5 } & Desvio Padrão & 0,20 & 109 & 79 \\
\hline \multirow{4}{*}{ CCR com } & CCR 1 & 1,07 & 360 & 242 \\
\cline { 2 - 5 } & CCR2 & 1,42 & 567 & 415 \\
\cline { 2 - 5 } & CCR3 & 1,30 & 558 & 429 \\
\cline { 2 - 5 } & CCR4 & 1,71 & 839 & 697 \\
\cline { 2 - 5 } & CCR5 & 1,51 & 1030 & 707 \\
\cline { 2 - 5 } & Média & 1,40 & 671 & 200 \\
\cline { 2 - 5 } & Desvio Padrão & 0,24 & 263 & 200 \\
\hline
\end{tabular}

Levando em conta o valor de $\mathrm{K}_{\mathrm{Icip}}$, Albuquerque et al. (2010) concluíram que estes foram muito altos, porque mais energia é necessária para iniciar a propagação de trincas. Após o início da propagação, a energia necessária para continuar a propagação das trincas foi maior para o CCR com escória e, portanto, apresenta maior resistência à propagação catastrófica da trinca que o CCR padrão.

Balbo (2006) estudou o comportamento à fratura de britas graduadas tratadas com cimento (BGTC) em ensaios de fratura no Modo I, em tração, com corpos de prova cilíndricos. Durante o ensaio o autor observou três zonas distintas de fratura, conforme Figura 16. Na primeira zona há um crescimento disperso das fissuras, considerando-se um comportamento praticamente linear do material. Na segunda zona do ensaio, tem-se uma formação de processos inelásticos, quando se tem o 
processamento da fratura; o deslocamento de abertura da ponta do entalhe (CTOD crack tip opening displacement) ainda não é crítico, bem como o fator de intensidade de tensões $\left(K_{l}\right)$ ainda não atinge seu valor crítico. Ao atingir o pico da força, tem-se o valor de CTODc crítico e o fator de intensidade de tensões é estável e crítico. Na terceira fase, tem se um estágio de continuidade de crescimento da fissura (CMOD crack mouth opening displacement) com a diminuição da carga aplicada.

Balbo (2006) constatou em seu estudo que as amostras compactadas na menor umidade apresentam tenacidade à tração inferior àquelas compactadas na umidade ótima (5,5\%), embora apresentem diferenças pequenas. Portanto, o material teria sua fragilidade aumentada quando compactado no ramo seco, em sentido contrário ao aumento da resistência esperado. Por outro lado, valores de umidade acima da ótima tornariam o material pouco resistente, ou seja, seriam desfavoráveis para sua tenacidade, que resultaria menor em comparação à umidade ótima de compactação.

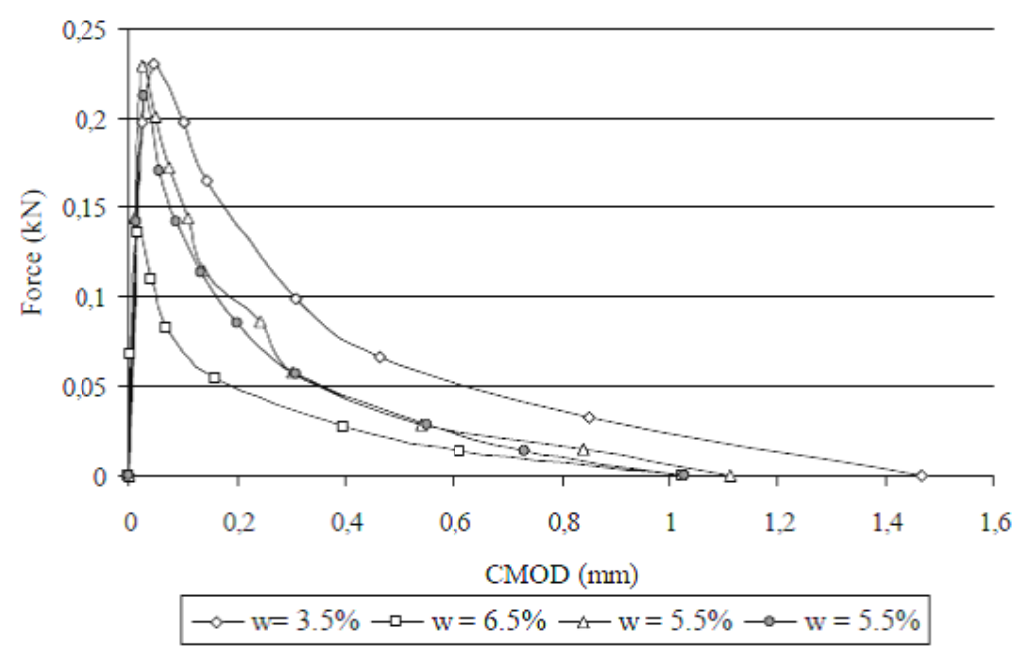

Figura 16 - Diagramas de tenacidade da BGTC em várias umidades de compactação Fonte: Balbo, p. 50, 2006.

Conforme Naus e Lott $(1969)^{13}$, citados por Santos, Souza e Bittencourt (2003), realizaram testes para a determinação dos efeitos de vários parâmetros de mistura no valor da tenacidade à fratura em pasta de cimento, argamassa e concreto. Os autores concluíram que há um aumento no valor da tenacidade à fratura em pasta de cimento e argamassa com o aumento da idade do corpo de prova e da quantidade de água da

\footnotetext{
${ }^{13}$ Naus, D. J. and Lott, J. L., Fracture toughness of Portland cement concrete, Journal of American Institute. Vol. 66, $\mathrm{n}^{\mathrm{o}} 01$, pp. 91-101, 1980.
} 
mistura. Com relação à argamassa, o valor da tenacidade à fratura cresce com o aumento da relação água/cimento. No caso do concreto, verificaram um aumento da tenacidade à fratura com o aumento do tamanho do agregado graúdo. Outro fator observado foi que os valores de tenacidade diminuem de forma direta quando a quantidade de ar contido aumenta, em todos os materiais estudados. Isso também acontece quando a relação areia/cimento aumenta no concreto. Ao contrário de Balbo (2006) que estudou comportamento à fratura da BGTC e Petersson (1980), Santos, Souza e Bittencourt (2003) observaram que a relação água/cimento não apresentou interferência nos valores de tenacidade à fratura do concreto. 


\section{MÉTODOS E TÉCNICAS UTILIZADOS}

Neste capítulo estão apresentadas a metodologia adotada e as técnicas utilizadas para execução dos trabalhos experimentais. Tais técnicas foram adotadas baseadas na literatura e nos objetivos do estudo. Na Figura 17 está apresentada a estruturação para elaboração dos ensaios realizados em laboratório.

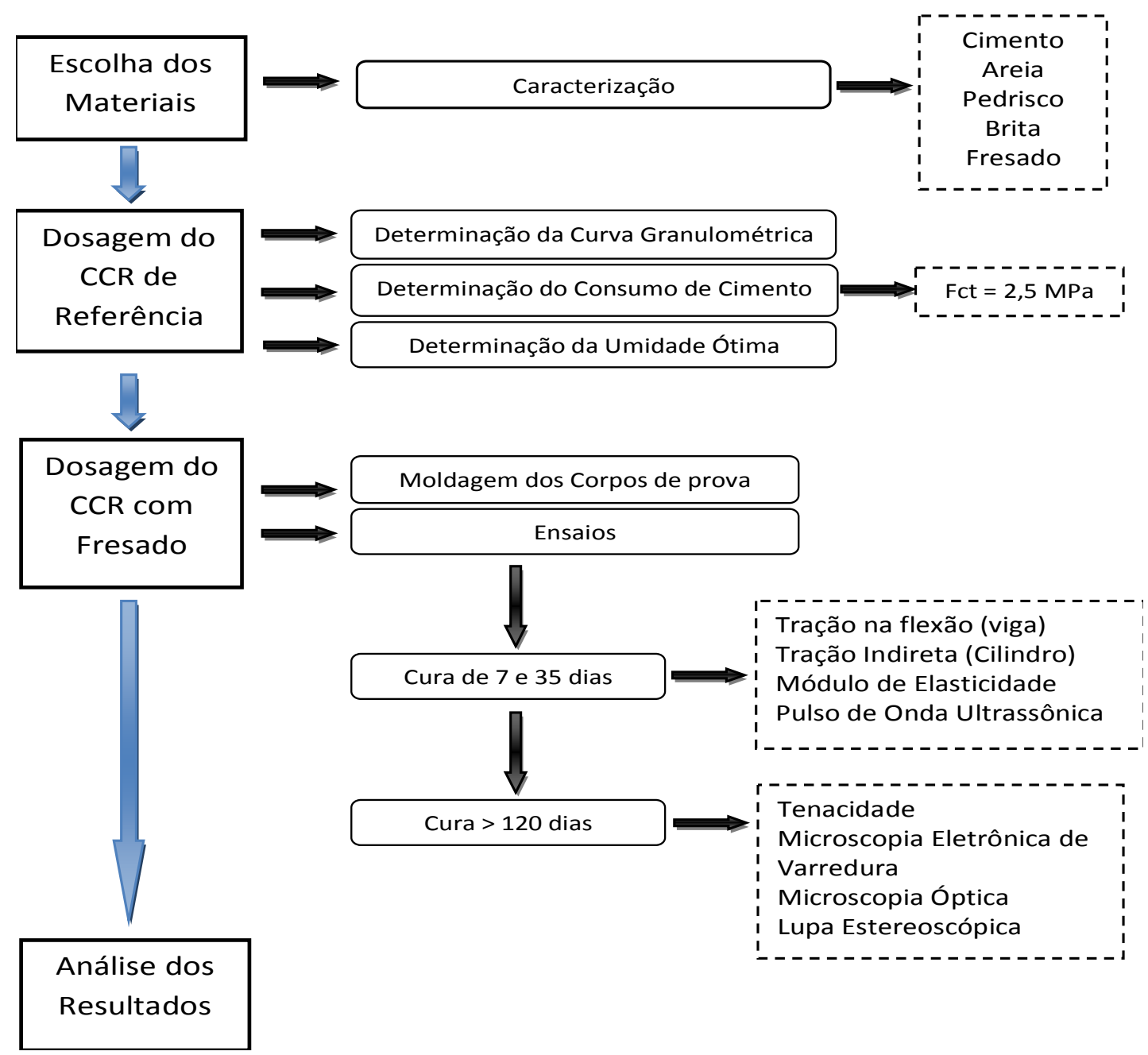

Figura 17 - Etapas para execução do trabalho 
Para a dosagem do concreto de referência foi estipulado inicialmente uma resistência à tração indireta $\left(f_{c t, s p}\right)$, obtida no ensaio de tração por compressão diametral, de 2,5 MPa (valor típico em bases cimentadas para pavimentos asfálticos), o que determinou a dosagem de todas as misturas. O diâmetro máximo estipulado para o agregado foi $19 \mathrm{~mm}$ e o consumo de cimento adotado para alcançar a resistência estipulada foi de $100 \mathrm{~kg} / \mathrm{m}^{3}$ de concreto.

O CCR, quando endurecido, apresenta características semelhantes àquelas de um concreto convencional. No entanto existe um importante diferencial na forma de dosagem de seus materiais, pois o CCR tem sua dosagem regida pela umidade ótima da mistura, que por sua vez é obtida quando se alcança a massa específica máxima da mistura. Para obtenção desses dois parâmetros realizou-se o ensaio de compactação segunda a NBR 7182 (ABNT, 1986a). Os resultados de umidade são influenciados pelos tipos de materiais que constituem a mistura, bem como pelo consumo de cimento.

\subsection{MATERIAIS UTILIZADOS NA PESQUISA}

Como no concreto comum, no CCR os materiais utilizados são água, areia, brita e cimento. Neste estudo, para a confecção das misturas de CCR foram utilizados materiais britados (brita 01, pedrisco e areia industrial), os quais foram cedidos pela Pedreira Cantareira (São Paulo), areia de rio disponibilizada pela Serveng (São Paulo) e cimento tipo CPIII-40-RS, cedido pela empresa Holcim (Barroso, Minas Gerais). A água de amassamento é proveniente da empresa abastecedora da cidade de São Paulo (SABESP), a qual se presume apta para ser utilizada sem acarretar problemas para as misturas. Optou-se por utilizar o cimento CPIII-40RS por estar disponível em grande quantidade e ser o tipo mais utilizado nesta região, além de sua característica de menor calor de hidratação em relação a outros cimentos como, por exemplo, o cimento CP II.

Na Tabela 6 são apresentados os dados de caracterização dos materiais britados naturais, os quais foram disponibilizados pela Pedreira Cantareira e verificados em laboratório. A curva granulométrica dos materiais britados (virgens) está apresentada na 
Figura 18. Os ensaios de granulometria de todos os materiais granulares convencionais e do fresado foram realizados conforme a NBR 7217 (ABNT, 1987b).

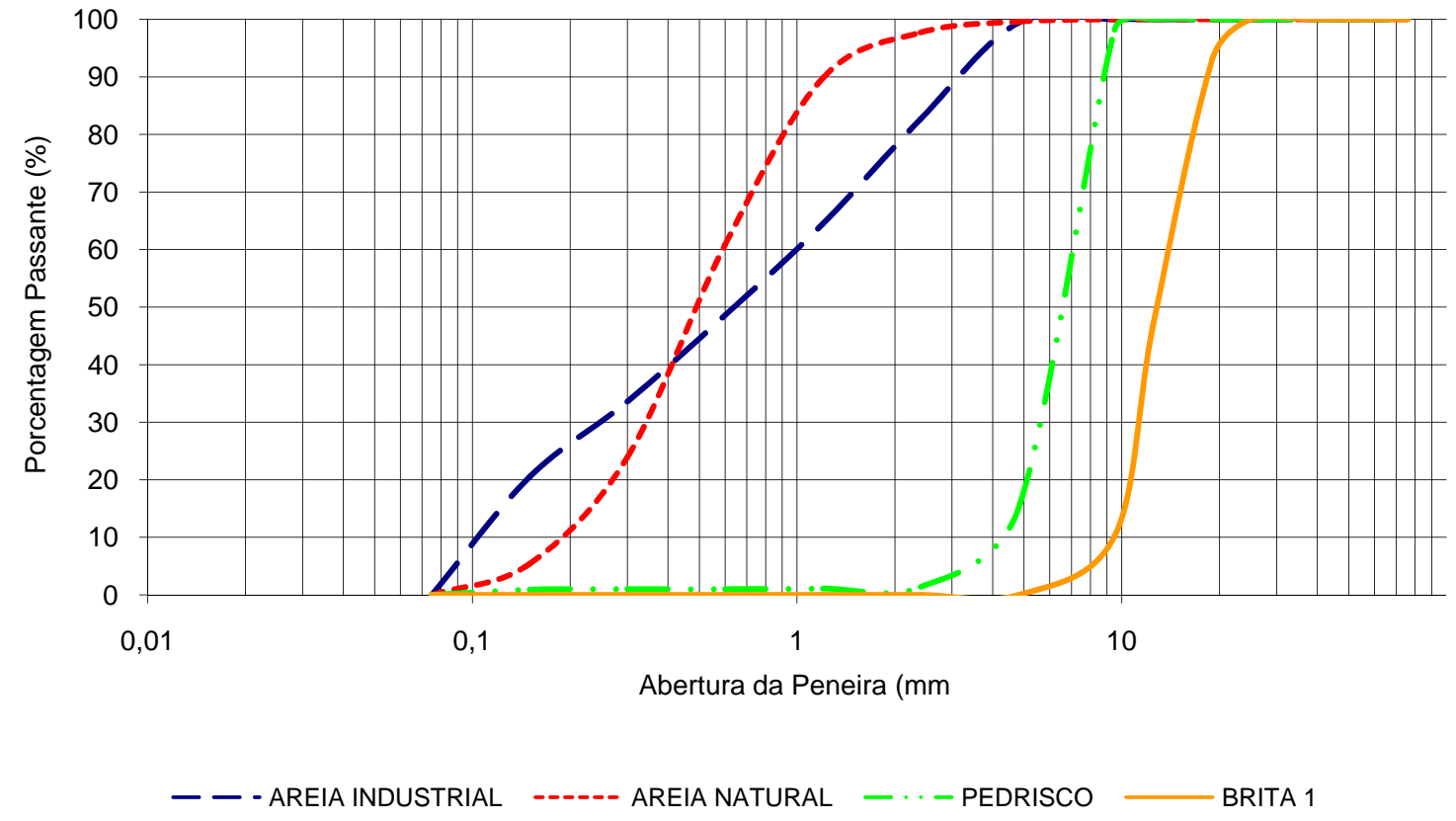

Figura 18 - Curvas granulométricas dos materiais granulares

Tabela 6 - Caracterização dos agregados naturais

\begin{tabular}{|l|c|c|c|c|c|}
\hline \multicolumn{1}{|c|}{ Parâmetro } & $\begin{array}{c}\text { Areia } \\
\text { natural }\end{array}$ & $\begin{array}{c}\text { Areia } \\
\text { industrial }\end{array}$ & Pedrisco & Brita 1 & Especificação \\
\hline $\begin{array}{l}\text { Dimensão Máxima } \\
\text { Característica (mm) }\end{array}$ & 4,80 & 2,4 & 9,5 & 19 & NBR 7211/83 \\
\hline Módulo de Finura & 4,018 & 3,507 & 6,814 & 7,967 & NBR 7217/87 \\
\hline $\begin{array}{l}\text { Massa Específica } \\
\left(\mathrm{kg} / \mathrm{dm}^{3}\right)\end{array}$ & 2,632 & 2,620 & 2,708 & 2,682 & $\begin{array}{c}\text { NBR } 9776 / 87 \\
\text { NBR NM: } 2003\end{array}$ \\
\hline $\begin{array}{l}\text { Massa Unitária Seca } \\
\left(\mathrm{g} / \mathrm{cm}^{3}\right)\end{array}$ & 1,590 & 1,630 & 1,390 & 1,430 & NBR 9778/2005 \\
\hline
\end{tabular}

Na Figura 19 está mostrada a sequência de ensaios de caracterização realizados no laboratório do Departamento de Engenharia de Construção Civil da Escola Politécnica da USP. 


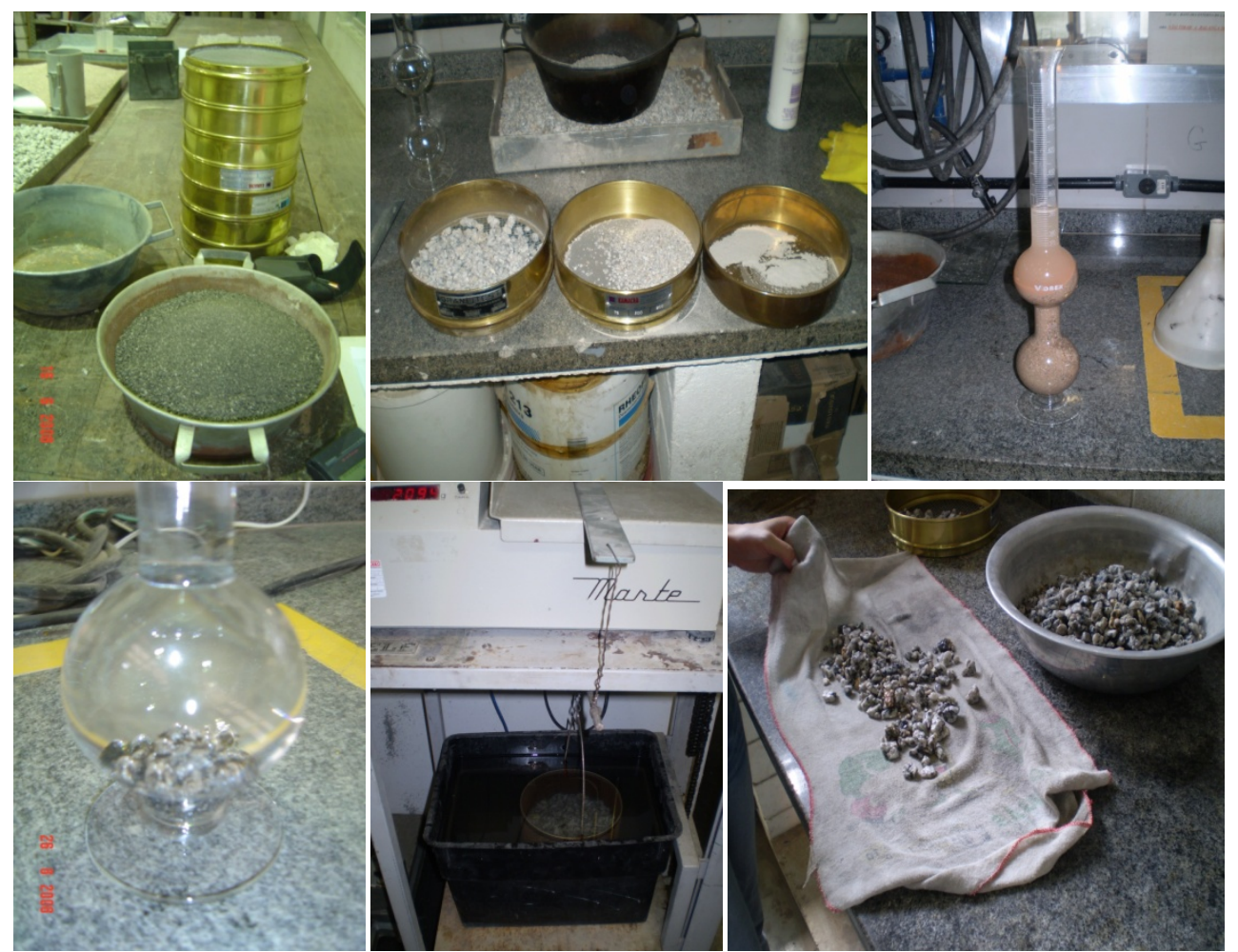

Figura 19 - Sequência dos ensaios de caracterização dos materiais granulares (granulometria por peneiramento e Chapman, Massa específica e unitária)

O fresado foi coletado pela empresa ECOVIAS, na Via Anchieta, quilômetro 39, sentido Litoral - São Paulo. A fresagem foi realizada no revestimento asfáltico com uma espessura de $60 \mathrm{~mm}$ por meio de uma máquina fresadora da marca Wirtgen apoiada sob esteiras (Figura 20).

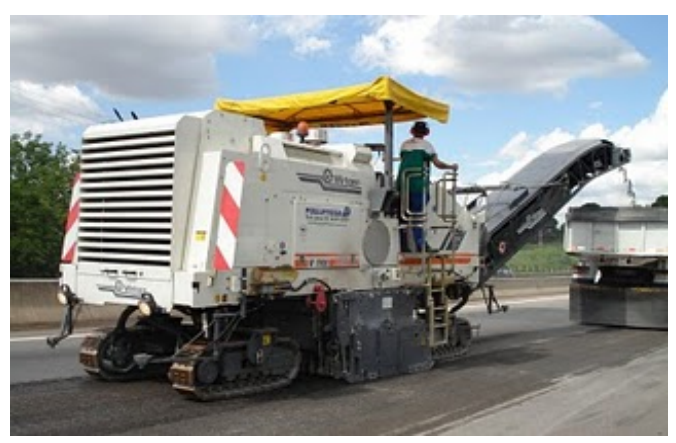

Figura 20 - Fresadora Wirtgen sob esteiras

O material foi conduzido até a Escola Politécnica da Universidade de São Paulo (EPUSP) logo após sua retirada da pista, descarregado sobre uma lona e mantido coberto durante todo o tempo em que esteve estocado para uso na pesquisa. A Figura 21 mostra o 
material fresado sendo descarregado e estocado no pátio do laboratório do Departamento de Engenharia de Construção Civil da Escola Politécnica da EUSP.

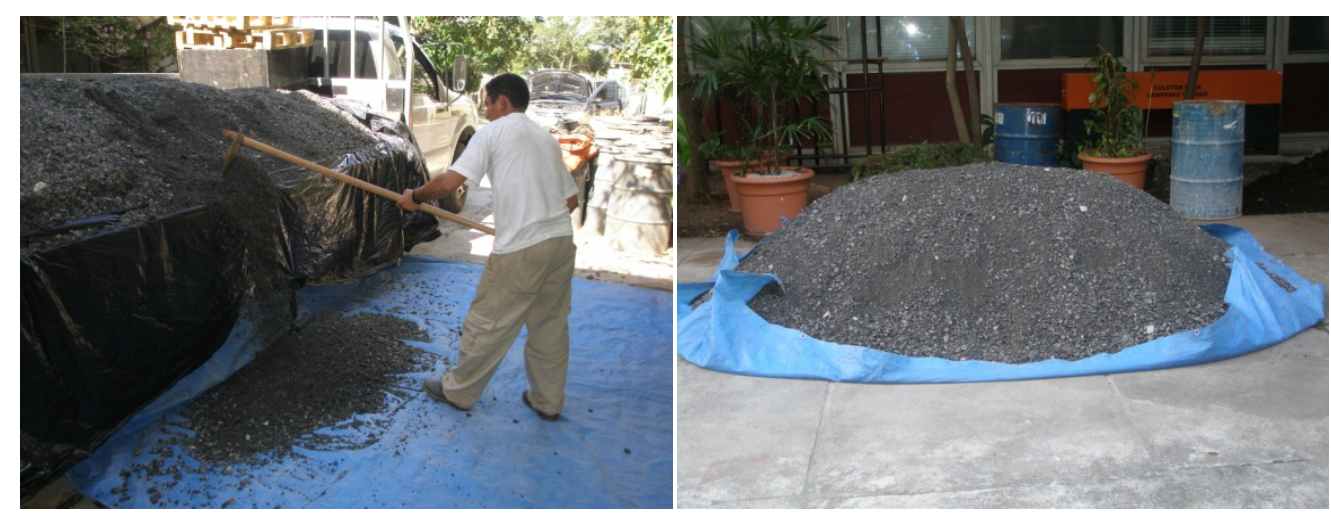

Figura 21 - Descarregamento e estocagem do material fresado

Inicialmente, foi realizado o quarteamento do material fresado (Figura 22) seguindo as diretrizes contidas na ABNT NBR-5427/1989, com a finalidade de retirar amostras representativas do material para serem utilizadas durante o estudo.

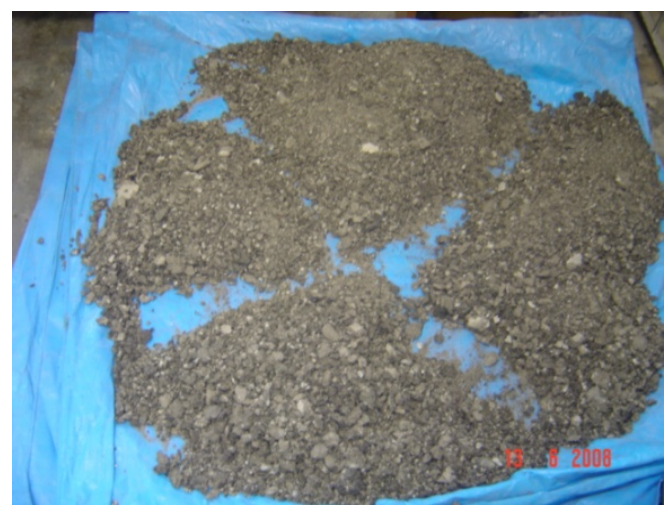

Figura 22 - Quarteamento do material fresado

O fresado foi caracterizado no seu estado natural e com a extração de betume. A extração foi feita através de um forno mufla a $500^{\circ} \mathrm{C}$ por 5 horas, no Laboratório de Tecnologia de Pavimentação da EPUSP. O forno mufla atinge altas temperaturas fazendo com que o material asfáltico se desprenda do agregado e elimine seus componentes através da sua queima. Quatro amostras foram ensaiadas para a verificação do teor de betume 
(Tabela 7). O valor médio encontrado para o teor de betume do fresado (5,03\%) é aquele regularmente utilizado na confecção das misturas; na Figura 23 está apresentado o equipamento utilizado para extração de betume e as quatro amostras ensaiadas.

Tabela 7 - Teor de asfalto do material fresado

\begin{tabular}{|l|c|c|c|c|}
\hline \multicolumn{1}{|c|}{ Amostra } & 01 & 02 & 03 & 04 \\
\hline Tara + Fresado & 435,03 & 438,55 & 472,16 & 467,22 \\
\hline Tara & 131,72 & 139,32 & 132,8 & 133,42 \\
\hline Tara + Agregado & 419,75 & 423,59 & 455,18 & 450,26 \\
\hline Teor de betume (\%) & 5,04 & 5,00 & 5,00 & 5,08 \\
\hline Teor de betume médio (\%) & & \multicolumn{5}{|c|}{5,03} \\
\hline
\end{tabular}

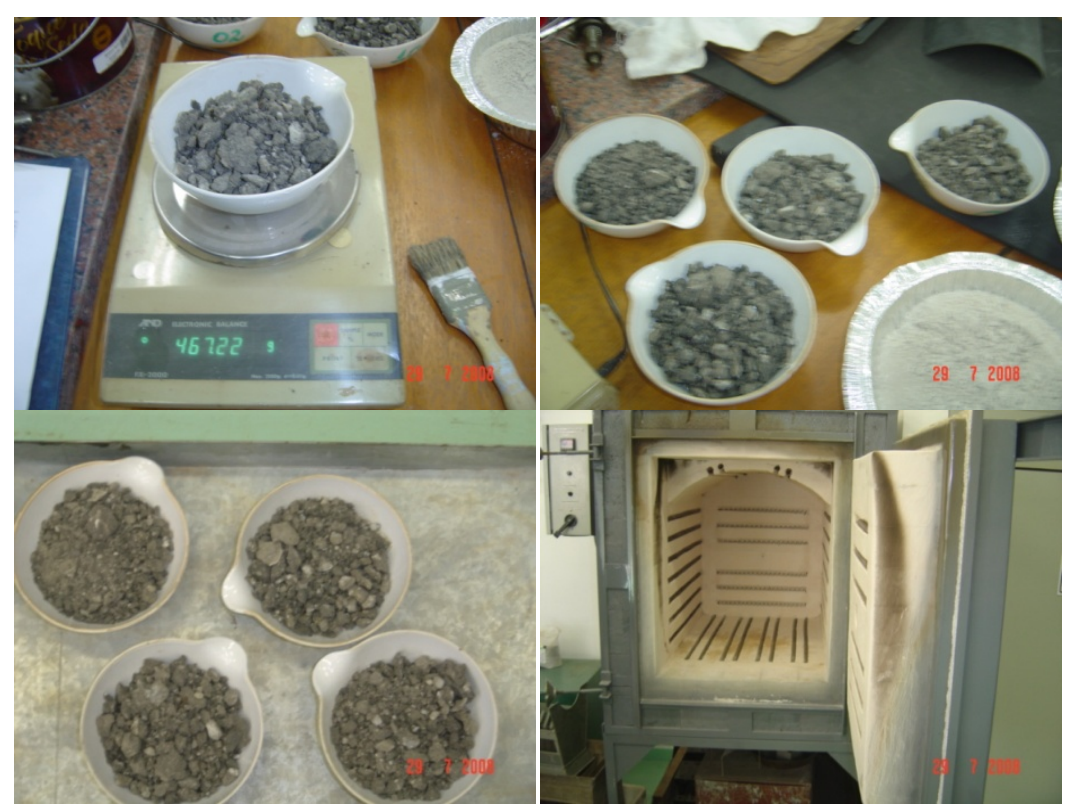

Figura 23 - Amostras de fresado in situ (duas fotos superiores) e com extração do betume (foto à esquerda inferior) e forno Mufla utilizado para extração do betume

As curvas granulométricas do material fresado sem extração e com extração do betume estão apresentadas na Figura 24. A caracterização física do fresado está apresentada na Tabela 8. Uma análise das curvas granulométricas de duas amostras de fresado revelou 
que as mesmas são bastante homogêneas. Após a extração um novo peneiramento foi realizado no fresado em duas amostras e se observou nas curvas que a quantidade de finos tende a aumentar com a extração do betume, já que o cimento asfáltico de petróleo existente nos fresados faz com que haja uma grande variação no tamanho dos grãos, devido aos grumos que se formam com a fração fina do agregado, gerando assim uma curva diferenciada do agregado natural. Observa-se que enquanto a quantidade de finos passando na peneira 1 é de $60 \%$ para o fresado com extração de betume, a quantidade que passa na mesma peneira para o material sem extração de betume, fica em torno de $10 \%$.

Os grumos formados pela aglomeração de material asfáltico e agregados compõem um agregado que pode ser dito "composto", o qual tende a ser deformável por sua natureza, devido ao modo como é extraído no campo. A fresagem gera fissuras no agregado fresado, tornando-o um agregado com falhas, que deverá ser traduzida em quedas de resistência das misturas, bem como influenciar outros parâmetros mecânicos.

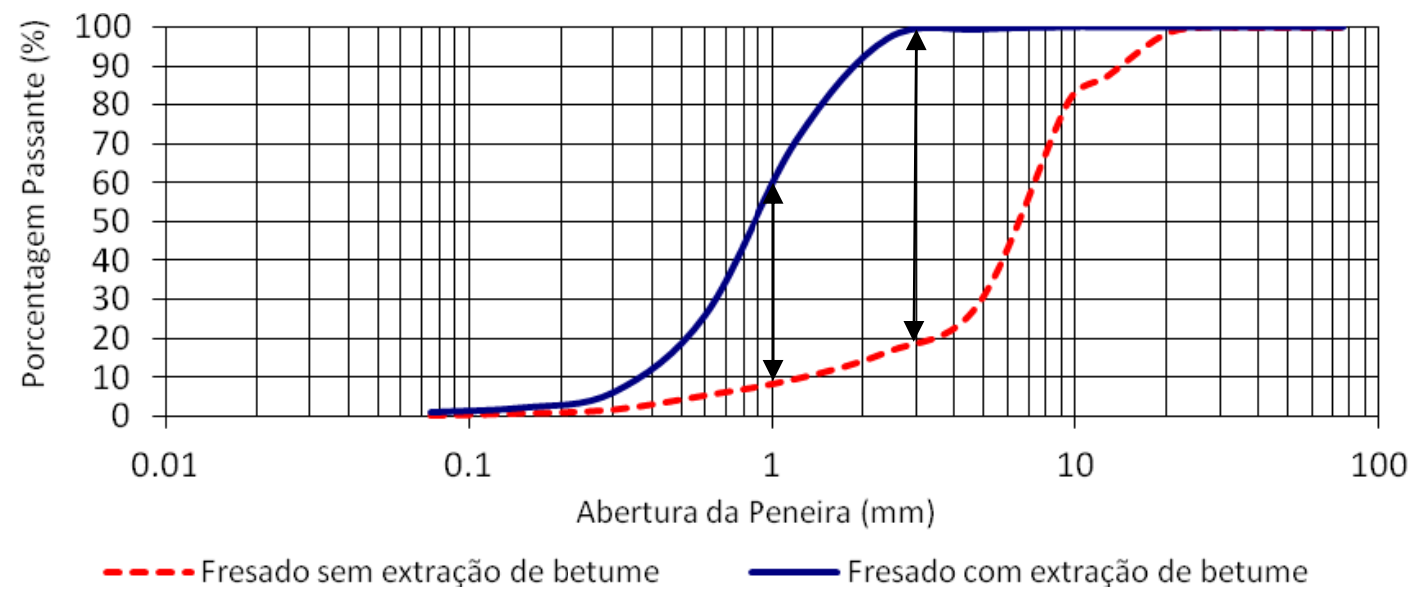

Figura 24 - Curvas granulométricas do fresado sem extração e com extração de betume

Tabela 8 - Caracterização dos agregados fresados

\begin{tabular}{|l|c|c|}
\hline \multicolumn{1}{|c|}{ Parâmetro } & Fresado Graúdo* & Fresado Miúdo* \\
\hline Dimensão Máxima Característica $(\mathrm{mm})$ & 19,0 & 2,40 \\
\hline Densidade aparente dos grãos $\left(\mathrm{g} / \mathrm{cm}^{3}\right)$ & 2,288 & 2,157 \\
\hline Absorção (\%) & 1,32 & - \\
\hline Módulo de finura & 0,78 & 4,43 \\
\hline
\end{tabular}

*sem extração de betume 
Bonfim (2007) observou que as curvas granulométricas obtidas para o material fresado são deslocadas em relação à curva do material original. As curvas obtidas com a extração de betume, ou seja, sem grumos, são deslocadas para cima, tornando a distribuição mais fechada. Ocorre o inverso para as curvas obtidas sem a extração de betume, apesar da quebra de parte dos agregados durante a fresagem. O material empregado na preparação de misturas de CCR, naturalmente, é aquele gerado pela fresagem sem extração de betume.

\subsubsection{Definição da Composição Granulométrica das Misturas}

No caso do CCR não existe um "confinamento" granulométrico ou a obrigatoriedade de se trabalhar com uma faixa específica, obedecendo a limites específicos de granulometria, como é o caso das misturas asfálticas, por exemplo. O CCR permite uma maior flexibilidade na definição de sua composição granulométrica, possibilitando a adoção de variadas faixas granulométricas, exigindo apenas que os limites superiores e inferiores de uma determinada faixa sejam respeitados.

Para este estudo utilizou-se a faixa granulométrica proposta por Pittman e Ragan (1998). Os limites superior e inferior da mesma orientavam a determinação das misturas de CCR (Figura 25).

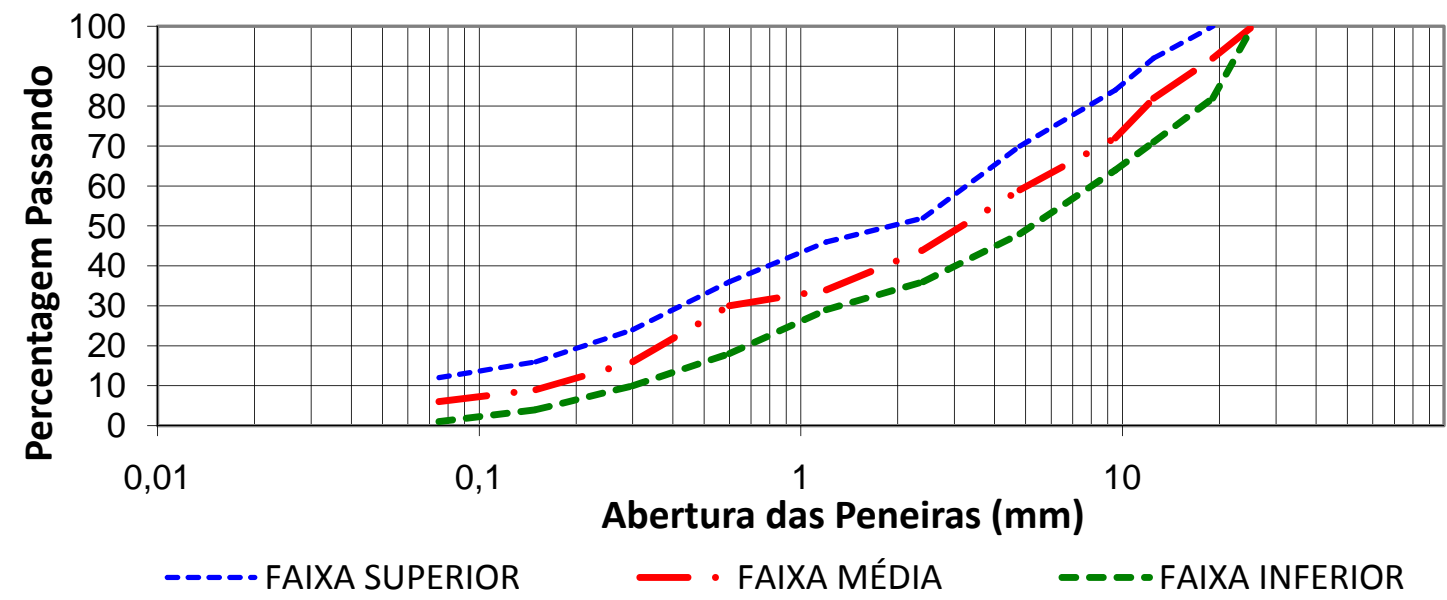

Figura 25 - Faixa granulométrica de Pittman e Ragan (1998)

As tentativas de enquadramento dentro dos limites foram realizadas até se encontrar a mistura considerada ideal. As misturas foram confeccionadas com areia 
industrial (Figura 26) e com areia natural de rio (Figura 27). Os dois tipos de areia foram utilizados para verificar a influência de ambos os materiais na mistura. Sendo que foi considerada amostra padrão aquela produzida com areia industrial que servirá como comparação às amostras confeccionadas com fresado asfáltico. Na Tabela 9 estão mostradas as porcentagens de material utilizadas paras as duas misturas.

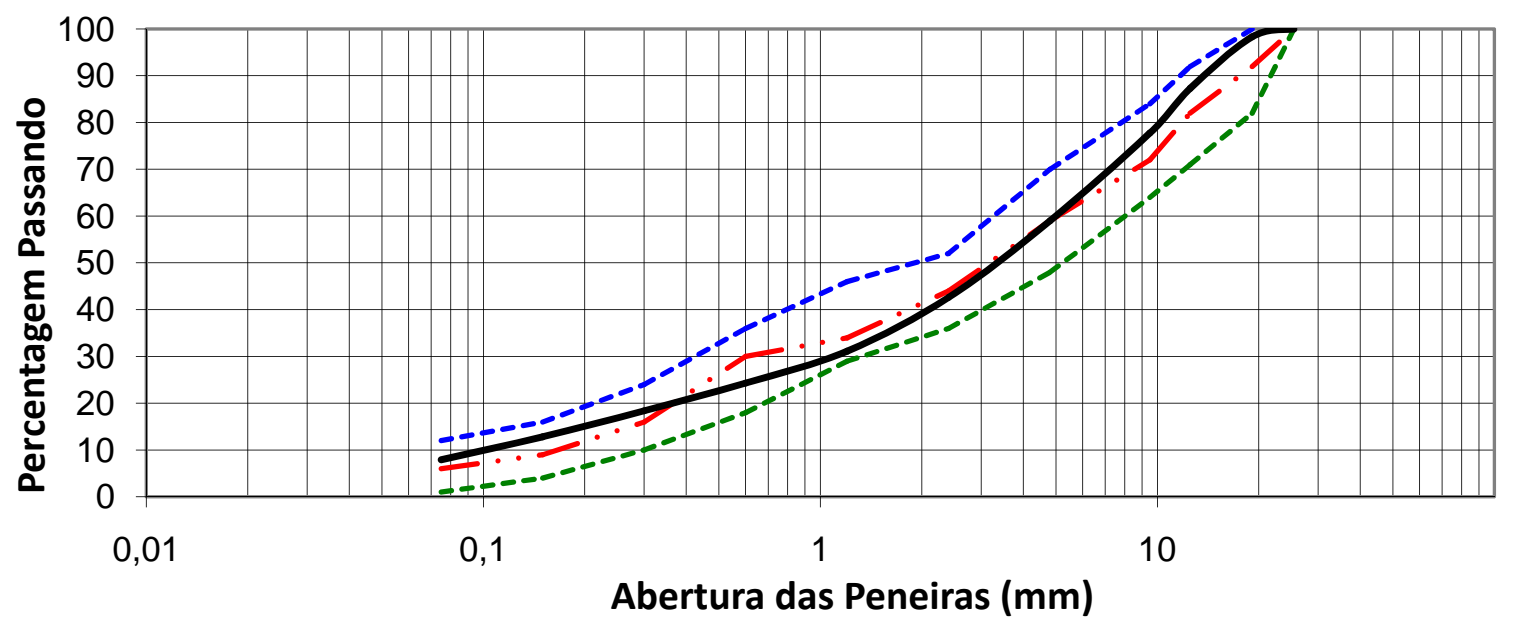

FAIXA SUPERIOR - - FAIXA MÉDIA FAIXA INFERIOR FAIXA CCR REFERENCIA

Figura 26 - Faixa granulométrica adotada para o CCR com areia industrial

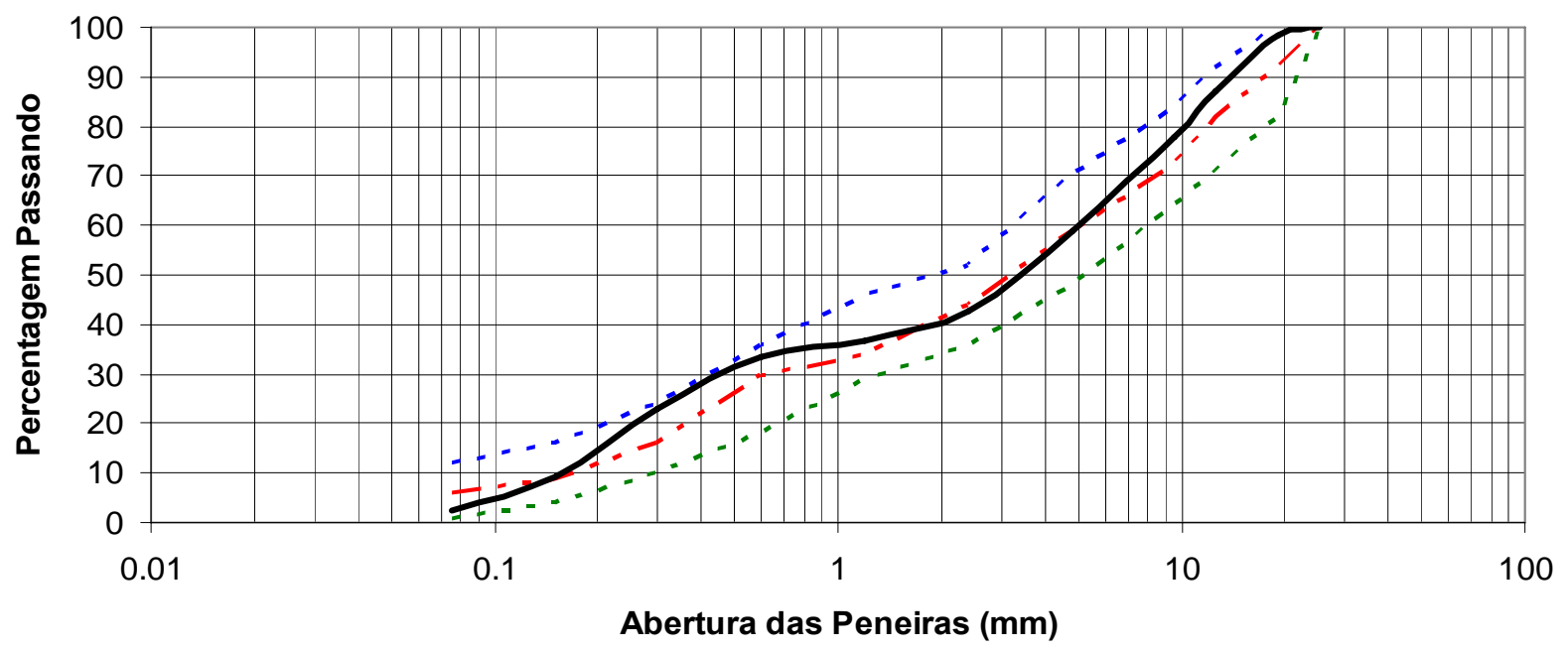

- - - Faixa Superior - - - Faixa Média - - - Faixa Inferior — Faixa do CCR - AN

Figura 27 - Faixa granulométrica adotada para o CCR com areia natural 
Tabela 9 - Composição das misturas com areia industrial (AI) e com areia natural (AN)

\begin{tabular}{|c|c|c|c|c|}
\hline Mistura & $\begin{array}{c}\text { Areia } \\
(\%)\end{array}$ & $\begin{array}{c}\text { Pedrisco } \\
(\%)\end{array}$ & $\begin{array}{c}\text { Brita 1 } \\
(\%)\end{array}$ & $\begin{array}{c}\text { Relação } \\
\text { a/c }\end{array}$ \\
\hline CCR-AI & 37 & 39 & 24 & 1,137 \\
\hline CCR-AN & 34 & 42 & 24 & 1,196 \\
\hline
\end{tabular}

Definidas as porcentagens de cada material para as misturas com areia natural e areia industrial, passou-se à execução dos ensaios de compactação para determinação da umidade ótima das misturas e posterior moldagem do CCR.

A concepção inicial de dosagem consistiu em obter uma mistura que atingisse uma resistência à tração indireta de $2,5 \mathrm{MPa}$ (um valor para base de pavimentos de melhor qualidade que BGTC). Foram definidos três consumos de cimento de 90, 110 e $130 \mathrm{~kg} / \mathrm{m}^{3}$ com o intuito de determinar qual consumo alcançaria a resistência prédeterminada.

Para cada consumo de cimento $\left(90,110\right.$ e $\left.130 \mathrm{~kg} / \mathrm{m}^{3}\right)$ foi realizado o ensaio de compactação com cinco pontos, sendo que, para cada ponto, foi utilizada uma umidade, que ficou na faixa de $5,5 \%$ a $9,5 \%$.

Os materiais foram misturados em betoneira horizontal (Figura 28) no laboratório do Departamento de Engenharia de Construção Civil da EPUSP. Para a mistura seguiu-se uma sequência de adição dos materiais, na qual o material mais grosso era misturado com uma parte da água por alguns segundos, em seguida os outros agregados eram adicionados à mistura juntamente com o cimento e o restante da água obedecendo a uma quantidade mínima de 30 litros. A mistura era mantida na betoneira em média 3 minutos ou até a sua perfeita homogeneização, constatada visualmente.
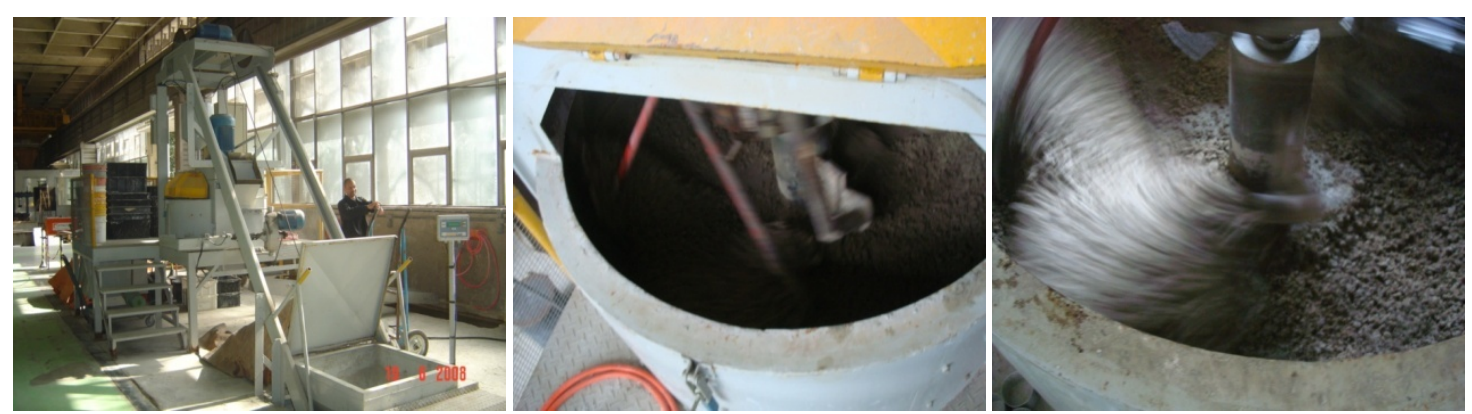

Figura 28 - Confecção do concreto em betoneira horizontal 
Os corpos de prova eram moldados em moldes cilíndricos e prismáticos para serem testados aos 7 e aos 35 dias de cura (Figura 29). O período de cura de 35 dias foi determinado após terem ocorridos problemas com a prensa, que seria utilizada para ensaios de compressão diametral e tração na flexão, adiando assim em uma semana a realização dos ensaios e forçando adotar o tempo de cura de 35 dias para todas as amostras.
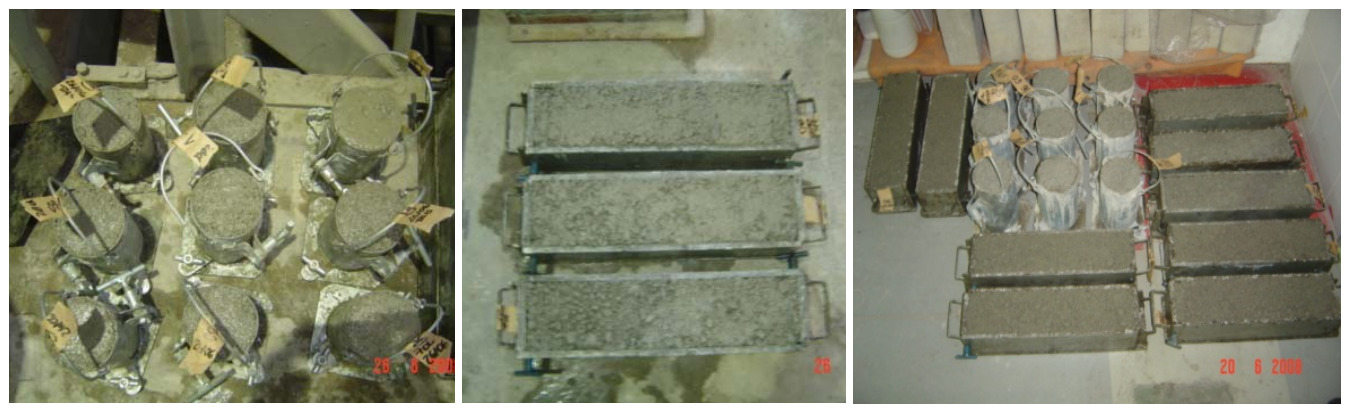

Figura 29 - Moldagem dos CCR em corpos de prova: cilíndricos e prismáticos

Os moldes cilíndricos tinham diâmetro de $100 \mathrm{~mm}$ e altura de $200 \mathrm{~mm}$, conforme especificado na NBR 5738 (ABNT, 1994a) e; os moldes prismáticos (100 mm x $100 \mathrm{~mm} \times 400 \mathrm{~mm}$ ) seguindo a mesma especificação (Figura 30).
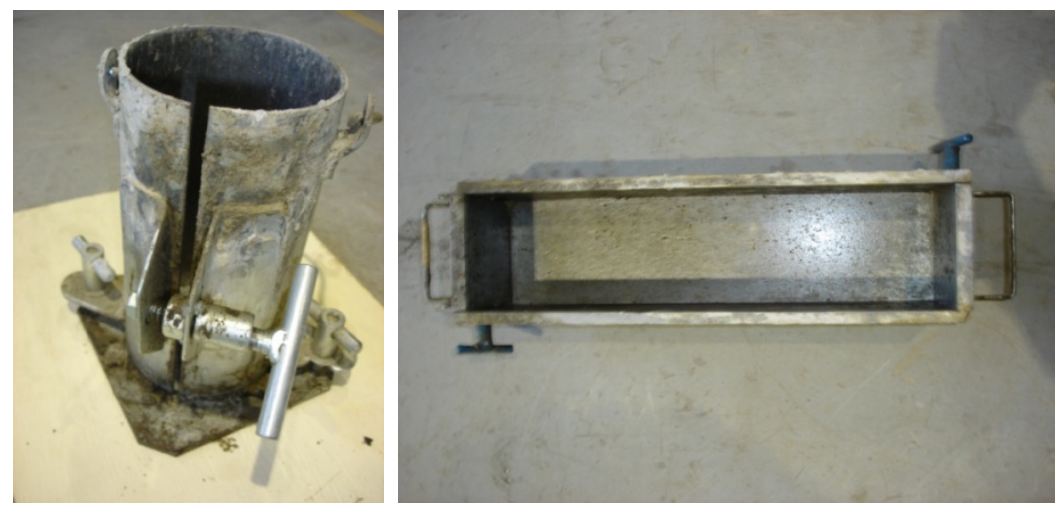

Figura 30 - Moldes: cilíndrico e prismático

Na sua forma original a especificação recomenda o uso de moldes prismáticos com medidas de $150 \times 150 \times 500 \mathrm{~mm}^{3}$. Porém, um estudo realizado por Cervo (2004) 
aperfeiçoou este ensaio com o uso de moldes de dimensões reduzidas, quando análises de testes estatísticos comprovaram não ser afetados em comparação a resultados obtidos com moldes de maiores dimensões. Ainda, reduzindo o consumo de materiais e reduzindo o desgaste físico do operador pelo número de golpes aplicados.

\subsection{DOSAGEM DAS MISTURAS}

A preparação das misturas inclui ensaios de compactação, moldagem dos corpos de prova e realização de ensaios mecânicos.

As misturas preparadas para serem ensaiadas tiveram como objetivo a substituição dos agregados naturais pelos agregados fresados, sendo que essas substituições resultaram em quatro misturas com fresado, conforme mostrado na Tabela 10. O RAP foi peneirado para se obter três faixas granulométricas: graúdo ou Brita 1 (diâmetro entre 9,5 e 19,0 mm), médio ou pedrisco (diâmetro entre 2,4 e 9,5 mm) e fino ou areia (diâmetro < 2,4 mm), conforme mostrado na Figura 32. Uma grande quantidade de fresado foi peneirada para se ter um estoque que permitisse a realização dos ensaios com o material já separado e seco (Figura 31).
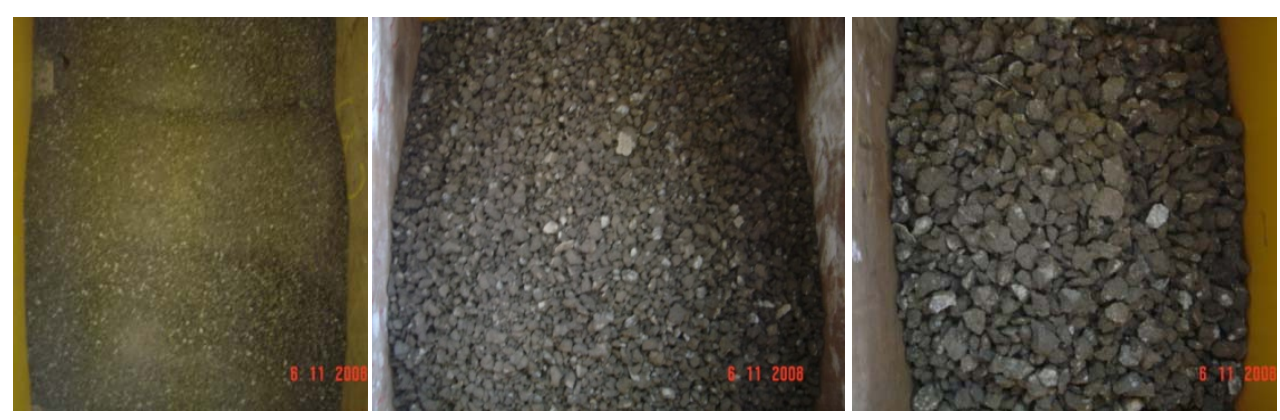

Figura 31 - Estoque de fresado peneirado nas frações fina, média e grossa

As quantidades de agregado foram definidas de forma que se enquadrassem nos limites da curva determinada para a dosagem. Portanto, não só a o teor de umidade, mas também as quantidades de agregados presentes em cada mistura podem influenciar o comportamento mecânico de cada uma. 
Tabela 10- Configuração das misturas de CCR

\begin{tabular}{|c|l|c|c|}
\hline Mistura & \multicolumn{1}{|c|}{ Composição } & $\begin{array}{c}\text { Agregado } \\
\text { Natural (\%) }\end{array}$ & $\begin{array}{c}\text { Agregado } \\
\text { Fresado (\%) }\end{array}$ \\
\hline $\begin{array}{c}\text { CCR1 } \\
\text { (referência) }\end{array}$ & $\begin{array}{l}\text { CCR referência com areia industrial (pó-de- } \\
\text { pedra) }\end{array}$ & 100 & - \\
\hline CCR2 & CCR com areia de natural (de rio) & 100 & - \\
\hline CCR1-AF & $\begin{array}{l}\text { CCR referência com substituição de 100\% do } \\
\text { areia industrial por fresado }\end{array}$ & 63 & $\begin{array}{c}37 \\
(<2,4 \mathrm{~mm})\end{array}$ \\
\hline CCR1-PF & $\begin{array}{l}\text { CCR referência com substituição de 100\% do } \\
\text { pedrisco por fresado }\end{array}$ & 61 & $\begin{array}{c}39 \\
(2,4 \text { a 9,2mm) }\end{array}$ \\
\hline CCR1-BF & $\begin{array}{l}\text { CCR referência com substituição de 100\% da } \\
\text { brita 1 por fresado }\end{array}$ & 76 & $\begin{array}{c}24 \\
(9,2 \text { a 19 mm) }\end{array}$ \\
\hline CCR1-FT & $\begin{array}{l}\text { CCR referência com substituição de 50\% da } \\
\text { faixa total por fresado }\end{array}$ & 50 & $\begin{array}{c}50 \\
\text { (Faixa Total) }\end{array}$ \\
\hline
\end{tabular}

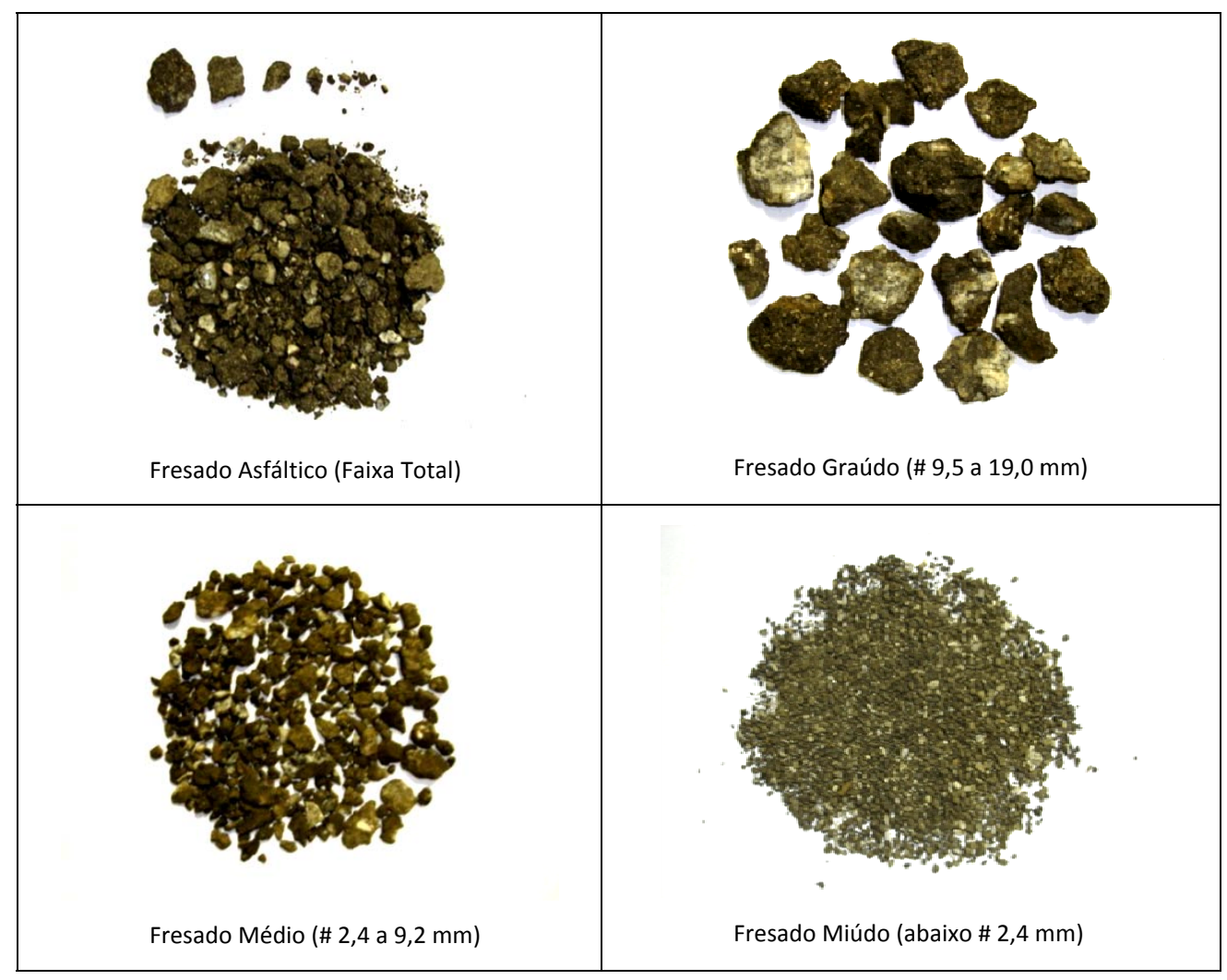

Figura 32 - Granulometrias do fresado asfáltico utilizadas nas misturas

\subsubsection{Ensaios de Compactação}

Os ensaios de compactação das misturas de CCR foram realizados seguindo-se a NBR 7182, sem reuso de material, com moldes cilíndricos. As misturas foram compactadas 
em cinco camadas com 24 golpes cada uma, na Energia Normal, utilizando-se um soquete de $2,5 \mathrm{~kg}$ e altura de queda de $300 \mathrm{~mm}$.

Antes da mistura cada fração dos agregados era pesada, separadamente. Após a pesagem, os agregados eram misturados manualmente em uma forma metálica, com auxílio de espátulas. Primeiramente era colocada a fração graúda, a qual era umedecida com parte da água a ser utilizada. Em seguida era acrescentada a fração média e mais uma parte da água. Por fim, a fração areia e o cimento eram incluídos e misturados até a completa homogeneidade da mistura. A quantidade de água adicionada variou de 5,5 a 9,0\%. Durante a compactação algumas medidas de controle foram realizadas, tais como, homogeneidade da mistura, identificação das amostras, controle de altura das camadas, arrasamento da superfície e retirada de amostras para posterior verificação da umidade (Figura 33).

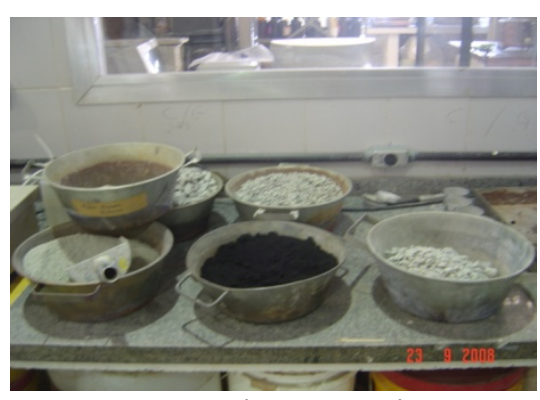

Pesagem dos agregados

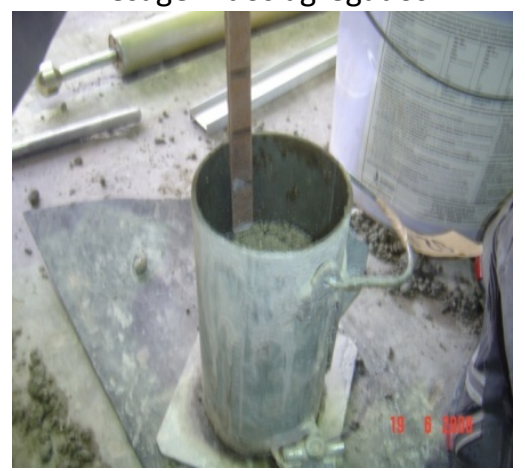

Compactação das camadas verificação da altura
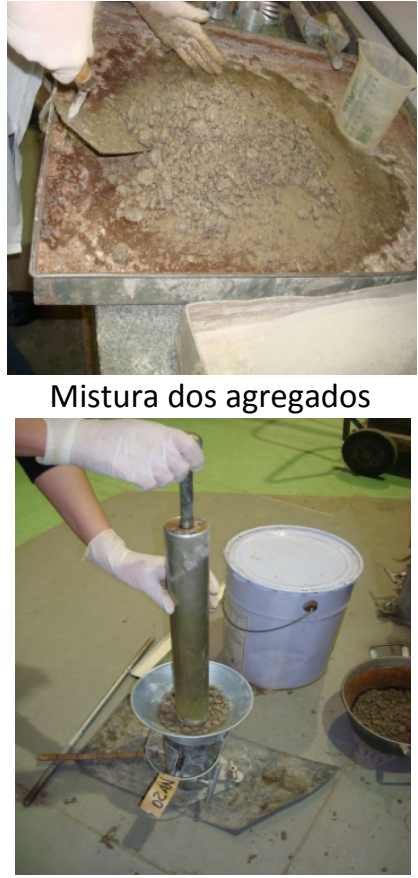

Compactação da última camada

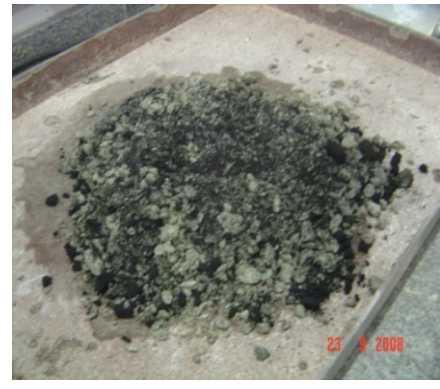

Agregados homogeneizados

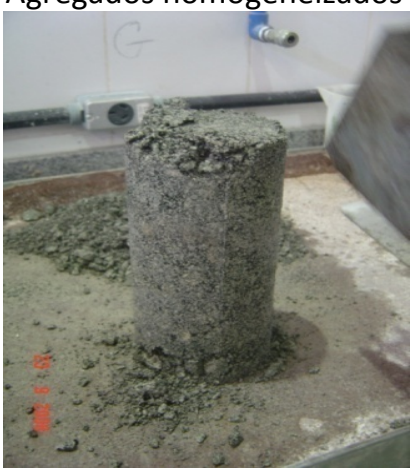

Corpo de prova desmoldado após compactação

Figura 33 - Procedimentos durante a compactação

As amostras para verificação da umidade eram colocadas em estufa, onde permaneciam por 24 horas para evaporação total da umidade ou constância de peso. Este mesmo procedimento de retirada de amostras foi realizado durante a moldagem 
dos corpos de prova, onde três amostras eram retiradas da betoneira para verificação da umidade real da mistura que estava sendo produzida.

Para que a resistência preestabelecida $\left(\mathrm{f}_{\mathrm{ct}, \mathrm{sp}}=2,5 \mathrm{MPa}\right)$ fosse alcançada (Figura 34), com o CCR contendo areia industrial (CCR1), no ensaios de compressão diametral (tração indireta) foi necessário um consumo de cimento de $100 \mathrm{~kg} / \mathrm{m}^{3}$. Pode-se observar no gráfico abaixo que o consumo de $90 \mathrm{~kg} / \mathrm{m}^{3}$ de cimento alcançou aos 28 dias a resistência predeterminada, mas como esse consumo caracteriza uma brita graduada simples, optou-se por adotar o consumo de $100 \mathrm{~kg} / \mathrm{m}^{3}$ de cimento. Consumo este que foi utilizado para confeccionar as demais misturas.

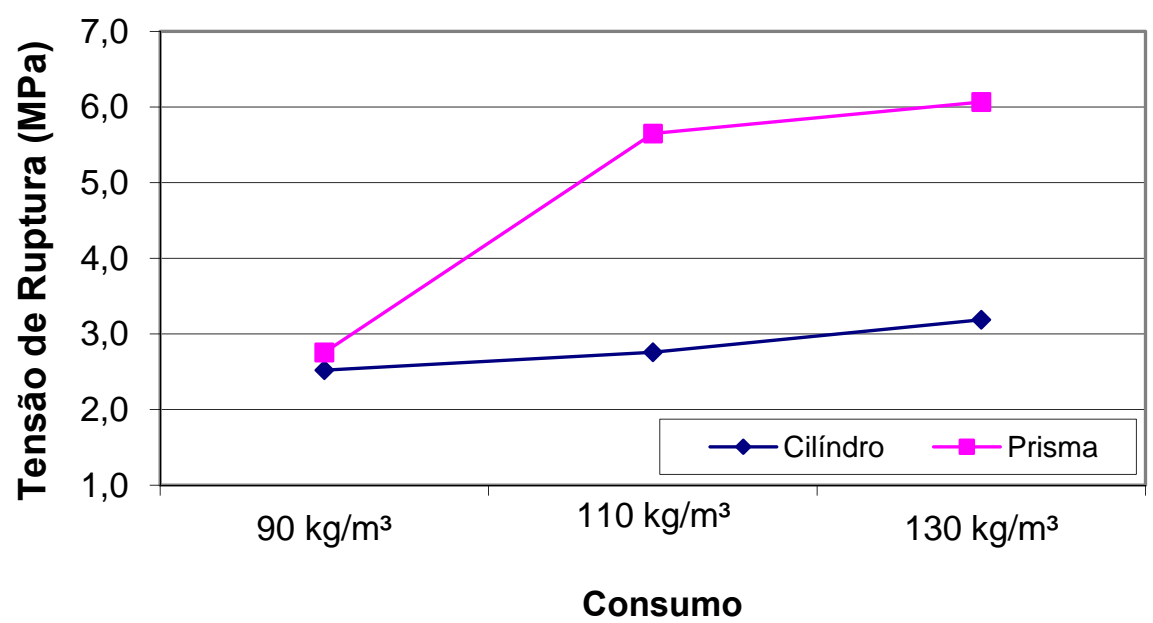

Figura 34 - Acréscimo da resistência por consumo de cimento, aos 28 dias para corpos de prova cilíndricos e prismáticos

\subsubsection{Moldagem dos corpos de prova}

Realizados os ensaios de compactação e determinada a umidade ótima para a qual o peso específico máximo era alcançado, procedeu-se a moldagem dos corpos de prova das misturas contendo fresado.

Foram realizadas moldagens em corpos de prova cilíndricos e prismáticos, como já mencionado anteriormente. Primeiramente, foram moldadas as misturas para o CCR padrão e em seguida os CCR com substituição de fresado miúdo, ou seja, com substituição da fração areia (diâmetro máximo de 2,4 mm). 
A substituição foi feita conforme proporção determinada na amostra padrão para cada tipo de agregado, acertando a umidade ótima conforme o ensaio de compactação realizado para cada mistura. Da mesma forma, procedeu-se à substituição dos demais agregados (médio, graúdo e fração total).

Os corpos de prova cilíndricos foram moldados em cinco camadas, compactadas cada uma com 24 golpes. Os corpos de prova prismáticos foram moldados em duas camadas compactadas com 156 golpes cada uma. A última camada, em ambas as moldagens, era compactada com o uso de um colarinho, o qual possibilitava que a quantidade necessária de material para a compactação da última camada fosse utilizada de forma que não se tivesse perda do material.

Adotou-se durante a compactação das camadas, um cuidado especial com a distribuição dos golpes nos corpos de prova prismáticos, buscando manter uma configuração padrão para que os mesmos atingissem toda a superfície do corpo de prova, assegurando que a compactação se desse de forma regular. Na Figura 35 estão apresentadas as etapas de moldagem dos corpos de prova.
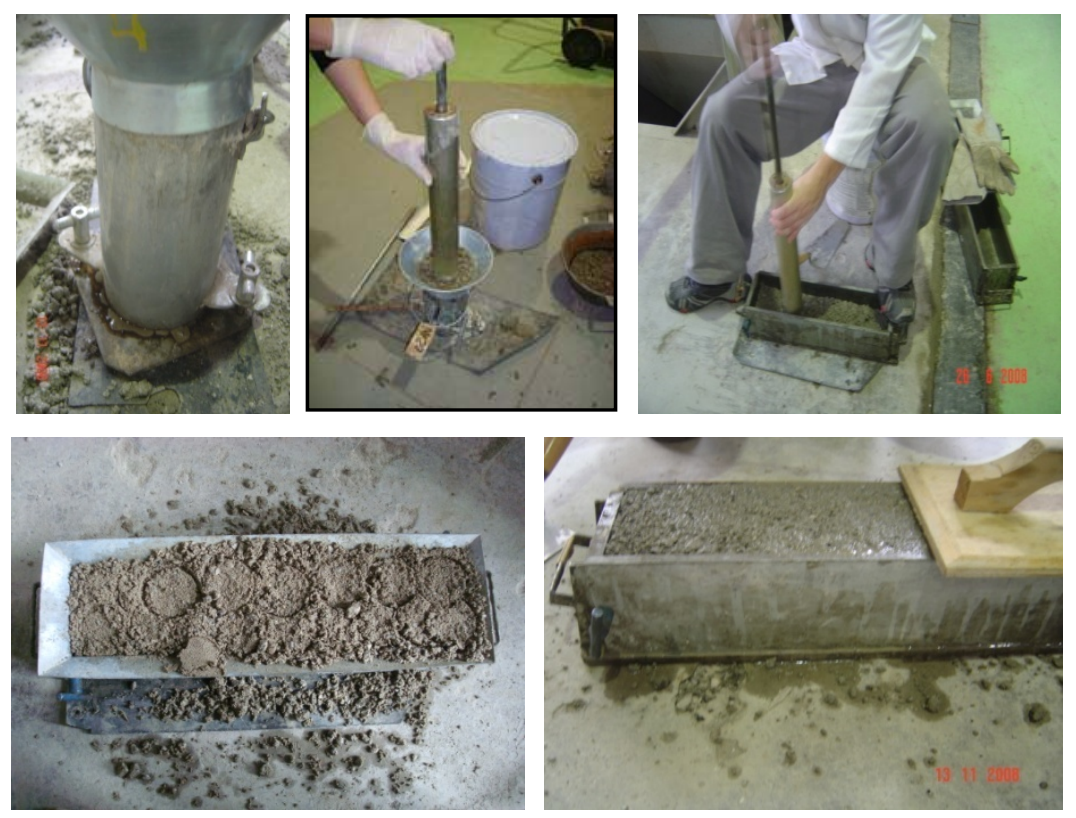

Figura 35 - Moldagem dos corpos de prova cilíndricos e prismáticos 
Os corpos de prova moldados foram conservados por 48 horas nas formas e cobertos por plásticos para que mantivessem a umidade até serem desmoldados e colocados na câmara úmida (Figuras 36 e 37). Os mesmo foram armazenados a uma temperatura de $23^{\circ} \mathrm{C} \pm 2^{\circ} \mathrm{C}$ e umidade relativa de aproximadamente $95 \%$, permanecendo nesse ambiente durante todo o tempo de cura estipulado (7 e 35 dias). O tempo de cura de 35 dias foi determinado após a impossibilidade de realização dos ensaios no prazo de 28 dias. Todos os moldes foram identificados com o nome da mistura, data de moldagem e numerados conforme a ordem de moldagem. Quando retirados da câmara úmida, os corpos de prova eram pesados e tinham suas medidas aferidas com paquímetro, como pode ser visto na Figura 38.

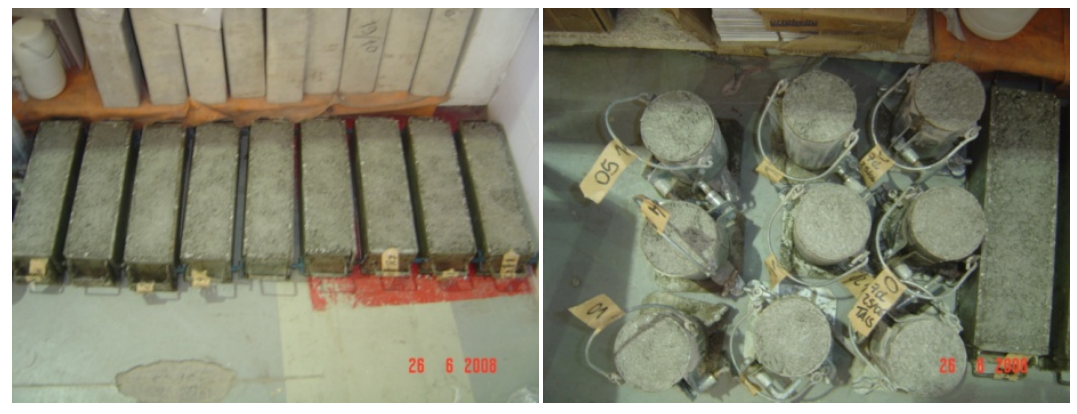

Figura 36 - Corpos de prova moldados e identificados

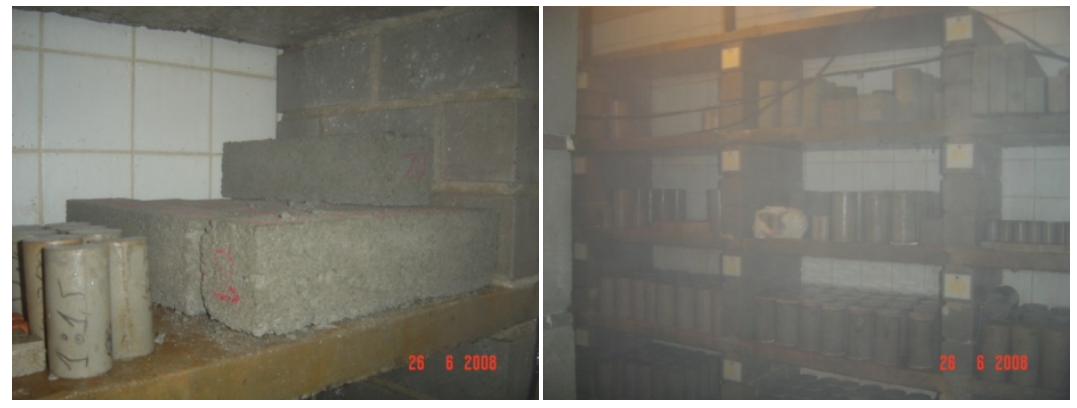

Figura 37 - Cura dos corpos de prova na câmara úmida

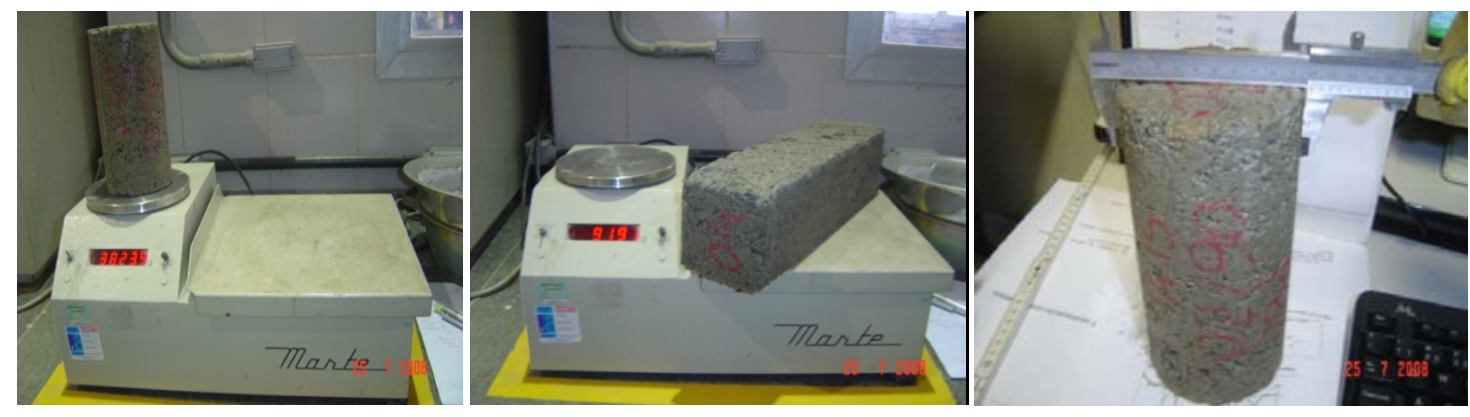

Figura 38 - Pesagem e aferição de medidas dos corpos de prova após cura na câmara úmida 


\subsection{ENSAIOS MECÂNICOS REALIZADOS NO CCR}

Após a cura em câmara úmida por 7 e 35 dias, os corpos de prova foram submetidos ao seguintes ensaios:

- Compressão diametral (Ensaio Brasileiro): para verificação da resistência à tração indireta;

- Tração na flexão: para determinação da flecha e do módulo de elasticidade;

- Pulso de onda ultrassônica: para verificação do módulo de elasticidade dinâmico;

- Tenacidade: para determinação da Curva-R;

- Análises microscópicas: por meio do microscópio eletrônico de varredura, por microscópio óptico e com lupa estereoscópica, para identificar o nível de porosidade das misturas, possíveis alterações microestruturais e, principalmente, o aspecto da interface entre agregado fresado e pasta de cimento.

\subsubsection{Ensaio de Compressão Diametral}

O ensaio de compressão diametral seguiu a NBR 7222/94 e foi realizado em corpos de prova cilíndricos (100 mm x $200 \mathrm{~mm}$ ), em três amostras aos sete dias de cura, e em seis amostras, aos trinta e cinco dias de cura, para as amostras com 90, 110 e 130 $\mathrm{kg} / \mathrm{m}^{3}$ de cimento e em seis amostras aos trinta e cinco dias no caso do CCR padrão e com fresado (Tabela 11).

Os corpos de prova cilíndricos, antes de serem ensaiados à compressão diametral, foram pesados, medidos, marcados com giz para se ter a exata posição da amostra na prensa (Figura 39). Em seguida, foram submetidos ao ensaio de determinação da velocidade de pulso ultrassônico. O ensaio está apresentado no item 3.3.3. 
Tabela 11- Quantidades de corpos de prova cilíndricos ensaiados

\begin{tabular}{|c|c|c|}
\hline Amostra & № de amostras & Dias de cura \\
\hline $90 \mathrm{~kg} / \mathrm{m}^{3}$ & 3 & $7^{*}$ \\
\hline $90 \mathrm{~kg} / \mathrm{m}^{3}$ & 6 & 35 \\
\hline $110 \mathrm{~kg} / \mathrm{m}^{3}$ & 3 & 7 \\
\hline $110 \mathrm{~kg} / \mathrm{m}^{3}$ & 3 & 35 \\
\hline $130 \mathrm{~kg} / \mathrm{m}^{3}$ & 6 & 7 \\
\hline $130 \mathrm{~kg} / \mathrm{m}^{3}$ & 3 & 35 \\
\hline $\mathrm{CCR} 1$ & 6 & 7 \\
\hline CCR1 & 3 & 35 \\
\hline CCR2 & 6 & 7 \\
\hline CCR2 & 6 & 35 \\
\hline CCR1-AF & 6 & 35 \\
\hline CCR1-PF & 6 & 35 \\
\hline CCR1-BF & 69 & 35 \\
\hline CCR1-FT & & \\
\hline TOTAL DE AMOSTRAS & 69 & 35 \\
\hline
\end{tabular}
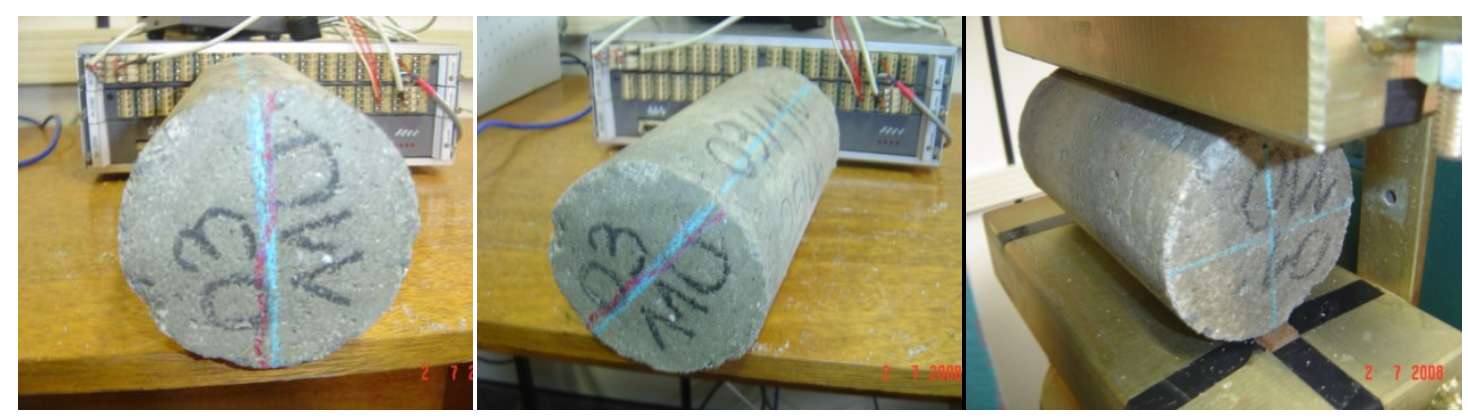

Figura 39 - Arranjo do ensaio de compressão diametral (Laboratório de Mecânica de Pavimentos da EPUSP)

A marcação realizada nos corpos de prova também foi necessária no momento de colar os strain gages para medida de deformação durante os ensaios. Cada corpo

\footnotetext{
* A cura com tempo de 7 dias foi realizada somente com o intuito de verificar o bom andamento dos ensaios. A cura com 35 dias foi utilizada para a determinação das medidas dos parâmetros mecânicos, tendo-se em conta a programação de uso de prensa em laboratório.
} 
de prova recebeu um strain gage que foi colado na face inferior (face da primeira camada compactada). A face foi previamente lixada e limpa para ficar o mais lisa possível para que a aderência do strain gage ao corpo de prova não fosse prejudicada. A localização dos strain gages nos corpos de prova e a posição dos mesmos na prensa durante os ensaios pode ser visto na Figura 40.

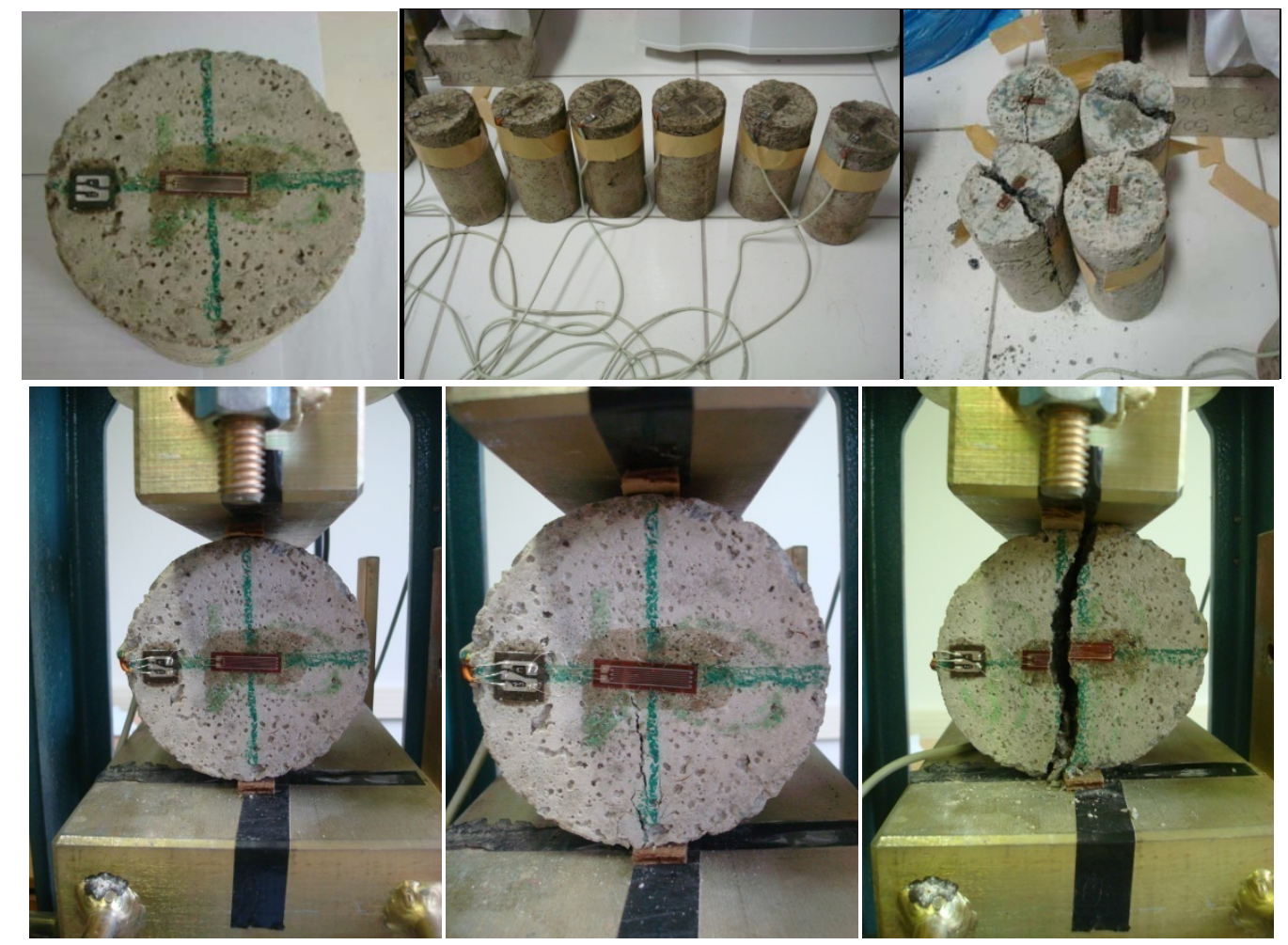

Figura 40 - Posição do strain gage no ensaio de compressão diametral (Laboratório de Mecânica de Pavimentos da EPUSP)

A determinação da resistência à tração pelo ensaio de compressão diametral é importante na medida em que permite a comparação entre as duas possibilidades de medida de resistência à tração (cilindro e viga), mas principalmente pela facilidade do arranjo do ensaio brasileiro, inclusive para determinação do módulo de elasticidade em tração do material, por meio da fixação de strain gages nos corpos de prova, que possibilitavam medir as deformações específicas na zona central tracionada do corpo de prova. O arranjo do ensaio está apresentado na Figura 41. 

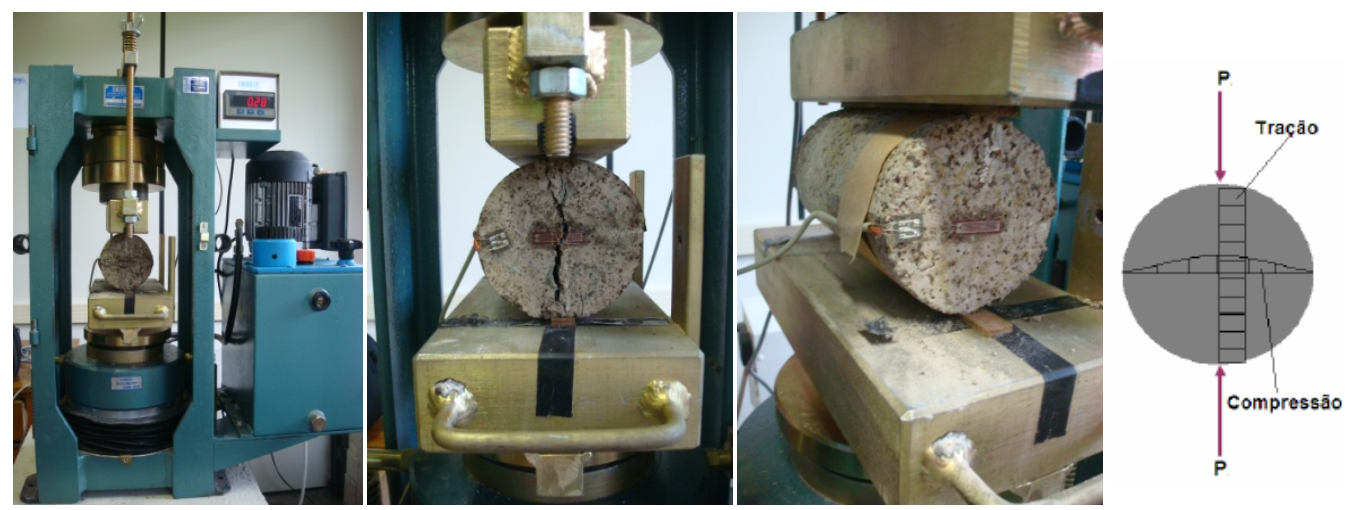

Figura 41 - Arranjo do ensaio de compressão diametral (Laboratório de Mecânica de Pavimentos da EPUSP)

O programa computacional utilizado para aquisição de dados durante os ensaios foi o AQDADOS, o qual era alimentado por um sistema de aquisição de dados conectado aos strain gages (Figura 42). A forma de apresentação de dados que o sistema fornece está mostrada na Figura 43.
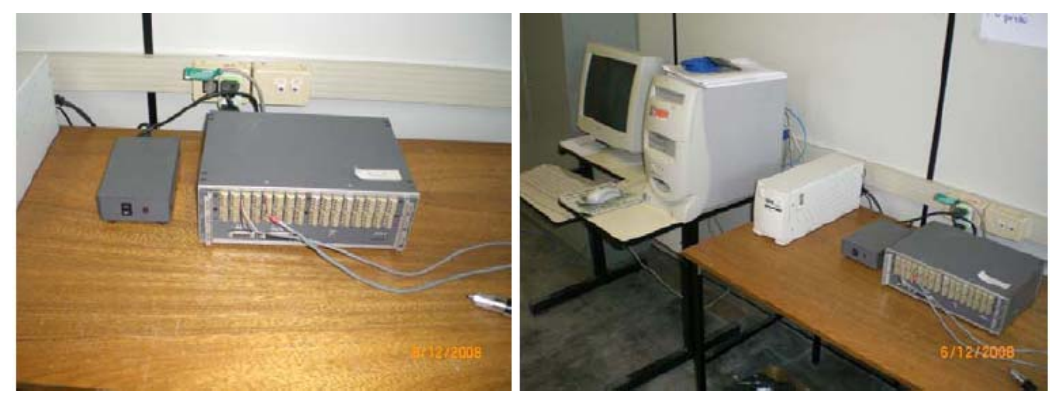

Figura 42 - Equipamento de aquisição de Sinais

A prensa utilizada para os ensaios foi do tipo SOLOTEST hidráulico-elétrica (Figura 44) com capacidade de 100 toneladas, na qual foi acoplada uma célula de carga de 10 toneladas, adequadamente calibrada. O modelo de prensa a utilizar foi determinado pensando no seu emprego no campo e no vasto uso desse tipo em laboratórios em todo o Brasil. A mesma permite a execução de ensaios do tipo compressão diametral, compressão simples, tração na flexão com um ou dois cutelos, bem como a adaptação de dispositivos como o suporte para LVDT - linear variable differential transformer - para medida de deslocamento, assim como dispõem de programas para captação dos dados durante a realização dos ensaios. 


\begin{tabular}{|c|c|c|r|}
\hline Data & Hora & carga $(t)$ & Straingage $(\mu \varepsilon)$ \\
\hline $17 / 12 / 08$ & $14: 42: 07$ & $2,60 \mathrm{E}-01$ & $5,89 \mathrm{E}+01$ \\
\hline $17 / 12 / 08$ & $14: 42: 09$ & $5,29 \mathrm{E}-01$ & $5,89 \mathrm{E}+01$ \\
\hline $17 / 12 / 08$ & $14: 42: 10$ & $7,09 \mathrm{E}-01$ & $7,05 \mathrm{E}+01$ \\
$17 / 12 / 08$ & $14: 42: 11$ & $1,34 \mathrm{E}+00$ & $7,25 \mathrm{E}+01$ \\
$17 / 12 / 08$ & $14: 42: 12$ & $1,97 \mathrm{E}+00$ & $7,44 \mathrm{E}+01$ \\
$17 / 12 / 08$ & $14: 42: 13$ & $3,04 \mathrm{E}+00$ & $8,02 \mathrm{E}+01$ \\
$17 / 12 / 08$ & $14: 42: 14$ & $4,57 \mathrm{E}+00$ & $8,60 \mathrm{E}+01$ \\
$17 / 12 / 08$ & $14: 42: 15$ & $6,54 \mathrm{E}+00$ & $9,38 \mathrm{E}+01$ \\
$17 / 12 / 08$ & $14: 42: 16$ & $9,23 \mathrm{E}+00$ & $1,05 \mathrm{E}+02$ \\
$17 / 12 / 08$ & $14: 42: 17$ & $1,22 \mathrm{E}+01$ & $1,19 \mathrm{E}+02$ \\
$17 / 12 / 08$ & $14: 42: 18$ & $1,59 \mathrm{E}+01$ & $1,36 \mathrm{E}+02$ \\
$17 / 12 / 08$ & $14: 42: 19$ & $1,96 \mathrm{E}+01$ & $1,58 \mathrm{E}+02$ \\
$17 / 12 / 08$ & $14: 42: 21$ & $2,35 \mathrm{E}+01$ & $1,75 \mathrm{E}+02$ \\
$17 / 12 / 08$ & $14: 42: 22$ & $2,73 \mathrm{E}+01$ & $2,00 \mathrm{E}+02$ \\
$17 / 12 / 08$ & $14: 42: 23$ & $3,12 \mathrm{E}+01$ & $2,35 \mathrm{E}+02$ \\
$17 / 12 / 08$ & $14: 42: 24$ & $3,53 \mathrm{E}+01$ & $2,82 \mathrm{E}+02$ \\
$17 / 12 / 08$ & $14: 42: 25$ & $3,96 \mathrm{E}+01$ & $3,67 \mathrm{E}+02$ \\
$17 / 12 / 08$ & $14: 42: 26$ & $4,26 \mathrm{E}+01$ & $1,07 \mathrm{E}+03$ \\
\hline $17 / 12 / 08$ & $14: 42: 27$ & $4,03 \mathrm{E}+01$ & $4,69 \mathrm{E}+03$ \\
\hline $17 / 12 / 08$ & $14: 42: 28$ & $3,28 \mathrm{E}+01$ & $4,69 \mathrm{E}+03$ \\
\hline $17 / 12 / 08$ & $14: 42: 29$ & $2,91 \mathrm{E}+01$ & $4,69 \mathrm{E}+03$ \\
\hline $17 / 12 / 08$ & $14: 42: 30$ & $2,66 \mathrm{E}+01$ & $4,69 \mathrm{E}+03$ \\
\hline $17 / 12 / 08$ & $14: 42: 32$ & $2,45 \mathrm{E}+01$ & $4,69 \mathrm{E}+03$ \\
\hline $17 / 12 / 08$ & $14: 42: 33$ & $2,20 \mathrm{E}+01$ & $4,69 \mathrm{E}+03$ \\
\hline $17 / 12 / 08$ & $14: 42: 34$ & $1,78 \mathrm{E}+01$ & $4,69 \mathrm{E}+03$ \\
\hline $17 / 12 / 08$ & $14: 42: 35$ & $6,81 \mathrm{E}+00$ & $4,69 \mathrm{E}+03$ \\
\hline $17 / 12 / 08$ & $14: 42: 36$ & $2,23 \mathrm{E}+00$ & $4,69 \mathrm{E}+03$ \\
\hline $17 / 12 / 08$ & $14: 42: 37$ & $6,19 \mathrm{E}-01$ & $4,69 \mathrm{E}+03$ \\
\hline $17 / 12 / 08$ & $14: 42: 38$ & $8,05 \mathrm{E}-02$ & $4,69 \mathrm{E}+03$ \\
\hline & & & \\
\hline
\end{tabular}

Figura 43 - Exemplo de aquisição de dados do ensaio de compressão diametral por meio do programa computacional AQDADOS

Para a determinação da resistência à tração $\left(f_{c t, s p}\right)$ por compressão diametral foi empregada a equação (4):

$$
f_{c t, s p}=\frac{2 \times P}{\pi \times d \times h}
$$

Onde:
$P$ : carga aplicada no momento da ruptura;
d: diâmetro do corpo de prova cilíndrico;
$h$ : altura do corpo de prova cilíndrico. 


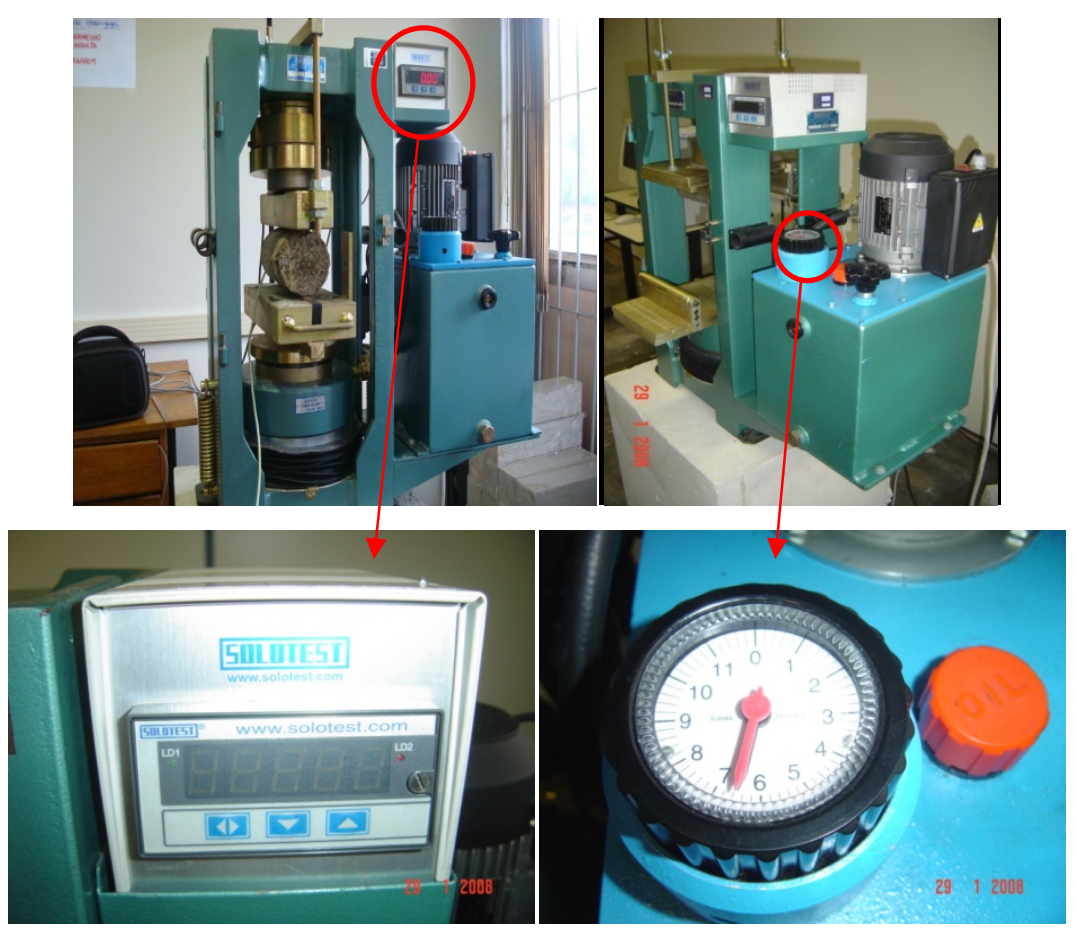

Figura 44 - Prensa Solotest hidráulico-elétrica (Laboratório de Mecânica de Pavimentos da EPUSP)

Para cada material a prensa era calibrada previamente, ou seja, através de um relógio analógico a velocidade de aplicação de carga era estipulada seguindo a preconização das normas técnicas para o tipo de ensaio, onde para ensaio de compressão diametral a velocidade estipulada é de $0,45 \mathrm{MPa} / \mathrm{s}(3,53 \mathrm{kN} / \mathrm{s})$ e para ensaio de tração na flexão a velocidade é de $0,02 \mathrm{MPa} / \mathrm{s}(0,056 \mathrm{kN} / \mathrm{s})$.

Por meio da instrumentação eletrônica do ensaio, a leitura de valores de carga e deformação foi possível, o que permitiu a construção das curvas tensão $x$ deformação (Figura 45) para a estimativa dos valores de módulo de elasticidade à tração do material. Para as estimativas adotou-se a reta que correlaciona os níveis de tensão aplicada de $5 \%$ a $70 \%$ da tensão de ruptura de cada amostra. 


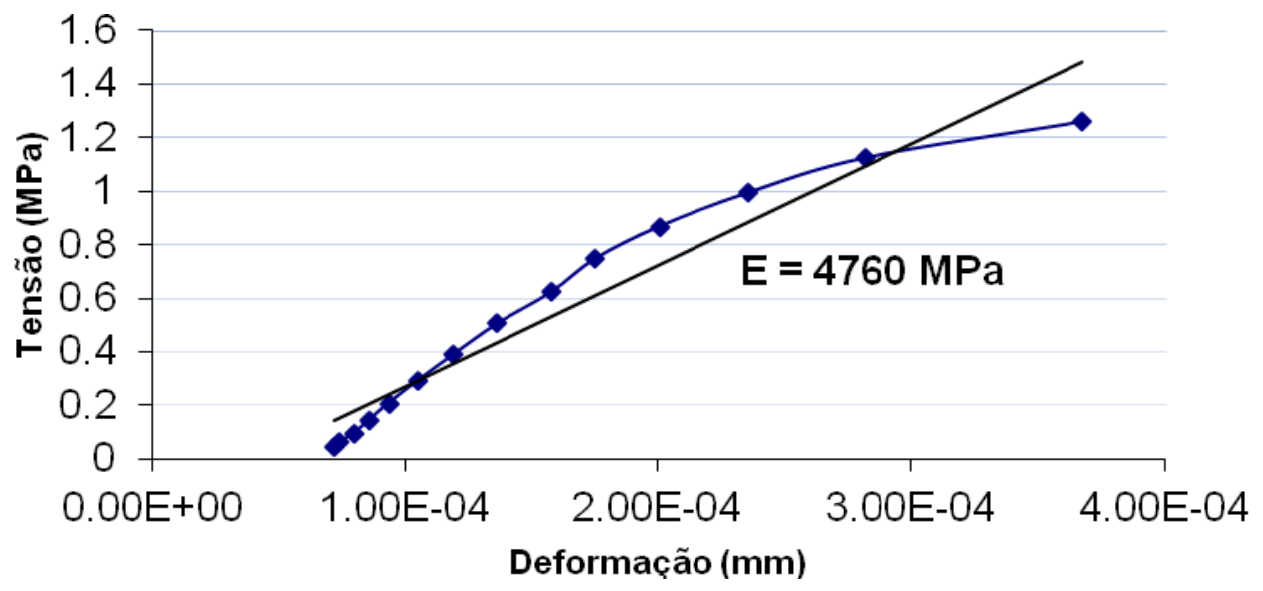

Figura 45 - Exemplo de determinação da curva tensão x deformação e estimativa do módulo de elasticidade secante em tração do material

\subsubsection{Ensaio de Tração na Flexão}

Os ensaios de tração na flexão foram realizados em corpos de prova prismáticos, conforme preconizado pela norma da ASTM - C78-08 (2008), sendo realizados em três amostras aos sete dias e seis amostras aos trinta e cinco dias de cura, para as misturas com 90, 110 e $130 \mathrm{~kg} / \mathrm{m}^{3}$ e para os CCR1 e CCR2. Os CCR confeccionados com fresado foram ensaiados aos 35 dias de cura (Tabela 12).

A preparação dos corpos de prova para os ensaios de tração na flexão consistiu na sua pesagem, logo após sua retirada da câmara úmida, aferição de suas medidas e marcação dos pontos que identificavam a posição das amostras na prensa e os pontos de aplicação de carga. Assim como no caso dos corpos de prova cilíndricos, os prismas também foram submetidos ao ensaio de determinação de velocidade de pulso de onda ultrassônica.

Os corpos de prova foram instrumentados com strain gages e o ensaio controlado com LVDT, para determinação do módulo de elasticidade por ambos os métodos. Para cada corpo de prova foi colado um strain gage na sua face de apoio (em dois cutelos). A superfície para colagem do strain gage foi lixada e limpa para se obter a melhor aderência possível com a amostra ensaiada (Figura 46). 
Tabela 12-Quantidade de corpos de prova prismáticos ensaiados

\begin{tabular}{|c|c|c|}
\hline Amostra & № de amostras & Dias de cura \\
\hline $90 \mathrm{~kg} / \mathrm{m}^{3}$ & 3 & 7 \\
\hline $90 \mathrm{~kg} / \mathrm{m}^{3}$ & 6 & 35 \\
\hline $110 \mathrm{~kg} / \mathrm{m}^{3}$ & 3 & 7 \\
\hline $110 \mathrm{~kg} / \mathrm{m}^{3}$ & 6 & 35 \\
\hline $130 \mathrm{~kg} / \mathrm{m}^{3}$ & 6 & 7 \\
\hline $130 \mathrm{~kg} / \mathrm{m}^{3}$ & 3 & 35 \\
\hline $\mathrm{CCR} 1$ & 6 & 7 \\
\hline CCR1 & 3 & 35 \\
\hline CCR2 & 6 & 35 \\
\hline CCR2 & 6 & 35 \\
\hline CCR1-AF & 6 & 35 \\
\hline CCR1-PF & 6 & 35 \\
\hline CCR1-BF & 69 & 35 \\
\hline CCR1-FT & & \\
\hline TOTAL DE AMOSTRAS & 6 & 35 \\
\hline
\end{tabular}
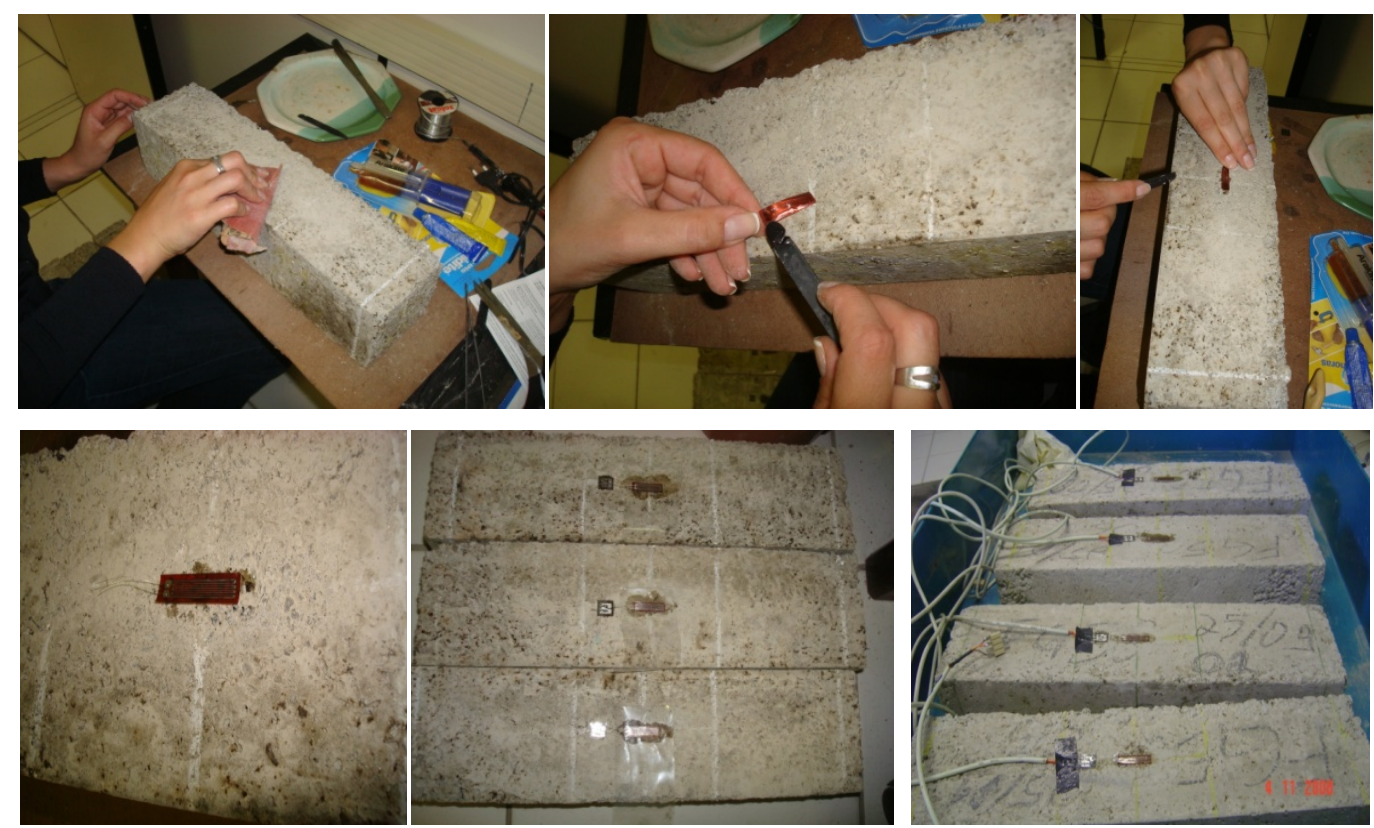

Figura 46 - Preparação dos corpos de prova prismáticos para ensaio de tração na flexão 
A aplicação de carga foi realizada com apenas um cutelo superior, posicionado exatamente no meio do vão da vigota e apoiado em apoios dispostos a $20 \mathrm{~mm}$ da borda do corpo de prova. O arranjo do ensaio está apresentado na Figura 47. A mesma prensa utilizada no ensaio de compressão diametral é usada neste ensaio.

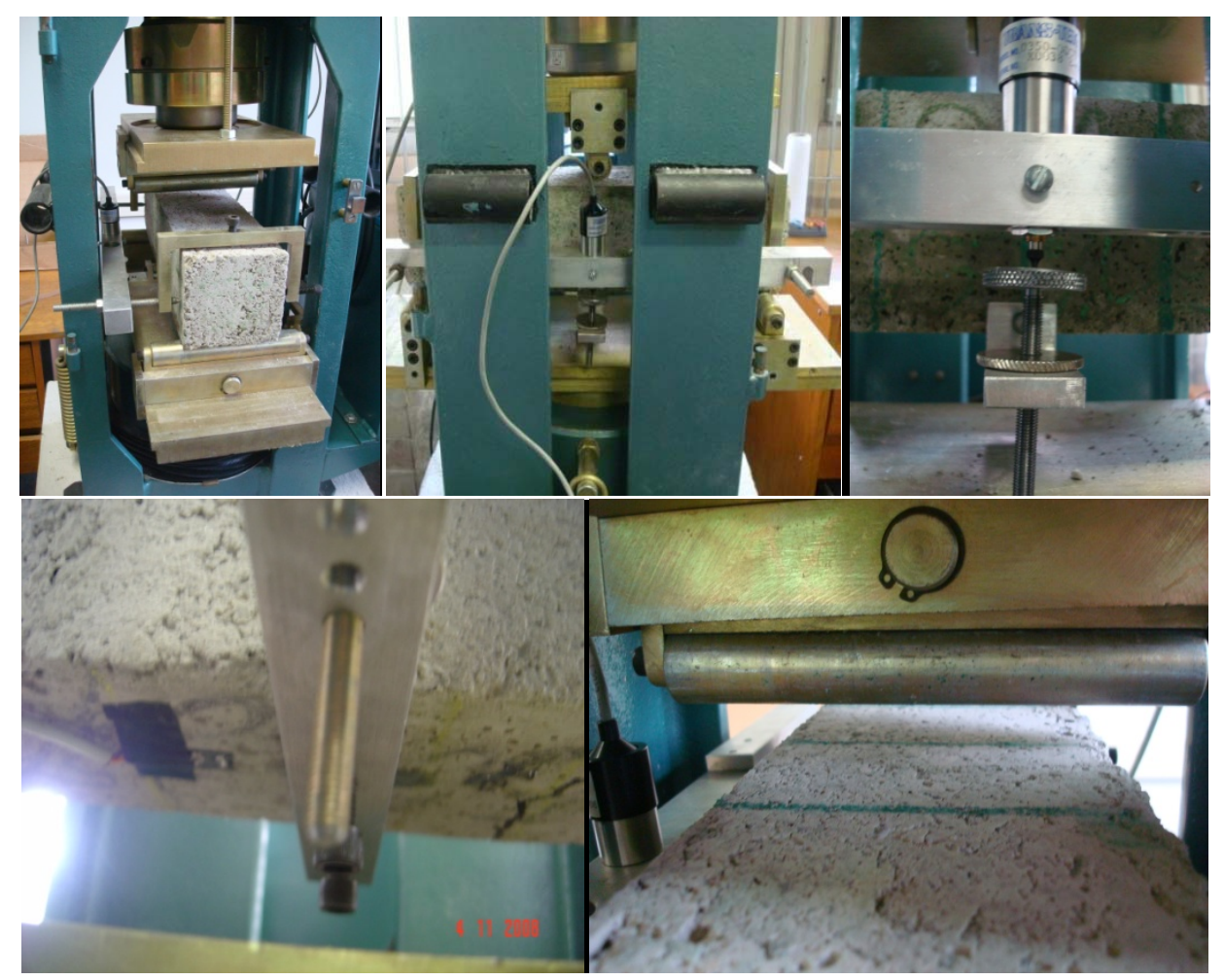

Figura 47 - Arranjo do ensaio de tração na flexão com LVDT e strain gage (Laboratório de Mecânica de Pavimentos da EPUSP)

Optou-se pela determinação de resistências baseadas em ensaios de um cutelo, pois a rótula do aplicador de carga da prensa utilizada não apresentava flexibilidade para que a descida dos dois cutelos se desse de forma simultânea e paralela, o que poderia impor aplicação de cargas desiguais nos dois cutelos.

Para medida de deslocamento vertical durante o ensaio da vigota, foi instalado um aparato para suporte do LVDT - linear variable differential transformer $\left(10^{-6} \mathrm{~mm}\right)$ que possibilitou a determinação da flecha durante o ensaio até a ruptura. Um exemplo de planilha obtida com o programa AQDADOS, está apresentada na Figura 48. 


\begin{tabular}{|c|c|c|c|c|}
\hline Data & Hora & LVDT & Carga (t) & Straingage $(\mu \varepsilon)$ \\
\hline $16 / 12 / 08$ & $15: 32: 27$ & -9,09E-03 & $-3,80 \mathrm{E}-03$ & $-2,14 \mathrm{E}+01$ \\
\hline $16 / 12 / 08$ & $15: 32: 28$ & $-1,20 E-02$ & $-3,80 E-03$ & $-2,14 E+01$ \\
\hline $16 / 12 / 08$ & $15: 32: 29$ & $-1,20 E-02$ & $-9,35 E-02$ & $-2,14 E+01$ \\
\hline 16/12/08 & $15: 32: 30$ & $-1,20 E-02$ & $-3,80 E-03$ & $-1,95 E+01$ \\
\hline $16 / 12 / 08$ & $15: 32: 31$ & $-1,48 E-02$ & $8,59 E-02$ & $-1,95 E+01$ \\
\hline $16 / 12 / 08$ & $15: 32: 32$ & $-1,48 E-02$ & $-3,80 \mathrm{E}-03$ & $-1,95 E+01$ \\
\hline $16 / 12 / 08$ & $15: 32: 33$ & $-1,48 E-02$ & $-3,80 E-03$ & $-1,95 E+01$ \\
\hline 16/12/08 & $15: 32: 34$ & $-1,48 \mathrm{E}-02$ & $-3,80 E-03$ & $-2,14 E+01$ \\
\hline $16 / 12 / 08$ & $15: 32: 36$ & $-1,48 E-02$ & $-3,80 E-03$ & $-1,95 E+01$ \\
\hline $16 / 12 / 08$ & $15: 32: 37$ & $-1,77 \mathrm{E}-02$ & 8,59E-02 & $-1,95 E+01$ \\
\hline $16 / 12 / 08$ & $15: 32: 38$ & $-1,48 E-02$ & 8,59E-02 & $-1,95 E+01$ \\
\hline $16 / 12 / 08$ & $15: 32: 39$ & -1,77E-02 & 8,59E-02 & $-1,95 E+01$ \\
\hline $16 / 12 / 08$ & $15: 32: 40$ & $-1,48 E-02$ & $8,59 E-02$ & $-1,95 E+01$ \\
\hline $16 / 12 / 08$ & $15: 32: 41$ & $-1,48 E-02$ & $-3,80 \mathrm{E}-03$ & $-1,95 E+01$ \\
\hline $16 / 12 / 08$ & $15: 32: 42$ & $-1,48 E-02$ & $-3,80 \mathrm{E}-03$ & $-1,95 E+01$ \\
\hline $16 / 12 / 08$ & $15: 32: 43$ & $-1,20 \mathrm{E}-02$ & 8,59E-02 & $-1,95 E+01$ \\
\hline $16 / 12 / 08$ & $15: 32: 44$ & $-1,48 E-02$ & 1,76E-01 & $-1,95 E+01$ \\
\hline $16 / 12 / 08$ & $15: 32: 45$ & $-1,48 E-02$ & $-3,80 \mathrm{E}-03$ & $-1,95 E+01$ \\
\hline $16 / 12 / 08$ & $15: 32: 46$ & $-1,20 \mathrm{E}-02$ & 1,76E-01 & $-1,56 E+01$ \\
\hline $16 / 12 / 08$ & $15: 32: 47$ & $-1,20$ E-02 & 1,76E-01 & $-1,18 E+01$ \\
\hline $16 / 12 / 08$ & $15: 32: 49$ & $-9,09 E-03$ & 5,35E-01 & $-5,94 E+00$ \\
\hline $16 / 12 / 08$ & $15: 32: 50$ & $-6,23 E-03$ & 8,04E-01 & $1,81 \mathrm{E}+00$ \\
\hline $16 / 12 / 08$ & $15: 32: 51$ & $-3,37 E-03$ & $1,25 E+00$ & $9,56 \mathrm{E}+00$ \\
\hline $16 / 12 / 08$ & $15: 32: 52$ & 2,35E-03 & $1,70 E+00$ & $2,31 E+01$ \\
\hline $16 / 12 / 08$ & $15: 32: 53$ & 8,08E-03 & $2,06 E+00$ & $3,47 E+01$ \\
\hline $16 / 12 / 08$ & $15: 32: 54$ & 1,09E-02 & $2,42 E+00$ & $4,83 E+01$ \\
\hline 16/12/08 & $15: 32: 55$ & 1,95E-02 & $2,96 E+00$ & 6,96E+01 \\
\hline $16 / 12 / 08$ & $15: 32: 56$ & 2,53E-02 & $3,41 E+00$ & $9,09 E+01$ \\
\hline $16 / 12 / 08$ & $15: 32: 57$ & 3,38E-02 & $3,86 E+00$ & $1,24 \mathrm{E}+02$ \\
\hline $16 / 12 / 08$ & $15: 32: 59$ & 4,53E-02 & $4,39 E+00$ & $1,92 \mathrm{E}+02$ \\
\hline 16/12/08 & 15:33:00 & 5,96E-02 & $4,75 E+00$ & $3,16 E+02$ \\
\hline 16/12/08 & 15:33:01 & 1,43E-01 & $3,41 E+00$ & $1,32 \mathrm{E}+03$ \\
\hline $16 / 12 / 08$ & $15: 33: 02$ & 3,09E-01 & $1,61 E+00$ & $7,90 E+02$ \\
\hline $16 / 12 / 08$ & 15:33:03 & 4,09E-01 & $1,16 E+00$ & $6,16 E+02$ \\
\hline $16 / 12 / 08$ & 15:33:04 & 5,00E-01 & 8,94E-01 & $5,33 E+02$ \\
\hline $16 / 12 / 08$ & 15:33:05 & 5,89E-01 & 8,04E-01 & $4,92 E+02$ \\
\hline $16 / 12 / 08$ & $15: 33: 06$ & 6,69E-01 & 7,14E-01 & $4,80 E+02$ \\
\hline $16 / 12 / 08$ & 15:33:07 & 7,52E-01 & 5,35E-01 & $4,73 E+02$ \\
\hline $16 / 12 / 08$ & 15:33:09 & 8,50E-01 & 5,35E-01 & $4,32 E+02$ \\
\hline $16 / 12 / 08$ & $15: 33: 10$ & 9,33E-01 & 4,45E-01 & $4,32 \mathrm{E}+02$ \\
\hline
\end{tabular}

Figura 48 - Exemplo de aquisição de dados do ensaio de compressão diametral por meio do programa computacional AQDADOS

Duas formas foram utilizadas para obtenção do módulo de elasticidade: (a) Por analogia de Möhr foi possível a determinação do módulo de elasticidade em flexão do material, já que se conhecia a força aplicada e o deslocamento sofrido no centro do vão (flecha); nas Figuras 49 e 50 são apresentados exemplos de determinação dos valores de deformação em função da carga nos ensaios de tração na flexão; (b) Pela deformação medida por meio do strain gage $(\mu \varepsilon)$ que era colado na parte inferior do corpo de prova (oposta à aplicação de carga).

A equação 5 foi aplicada para a determinação da resistência à tração na flexão $\left(f_{c t, f}\right)$ para o ensaio realizado com um cutelo.

$$
f_{c t, f}=\frac{3 \times P \times l}{2 \times b \times h^{2}}
$$


onde:
$P$ : carga de ruptura;
I: comprimento do vão entre os dois apoios;
$b$ : largura da base do corpo-de-prova;
$h$ : altura do corpo de prova.

A medida do módulo de elasticidade, por meio da analogia de Möhr, foi obtida através da equação 6 , com uso dos valores de flecha máxima para o centro da vigota.

$$
E=\frac{P \times l^{2}}{4 \times f \times b \times h}
$$

onde:

I: comprimento do vão entre os dois apoios;

$b$ : largura da base do corpo-de-prova;

$h$ : altura do corpo de prova.

$f$ : deslocamento vertical central da vigota.

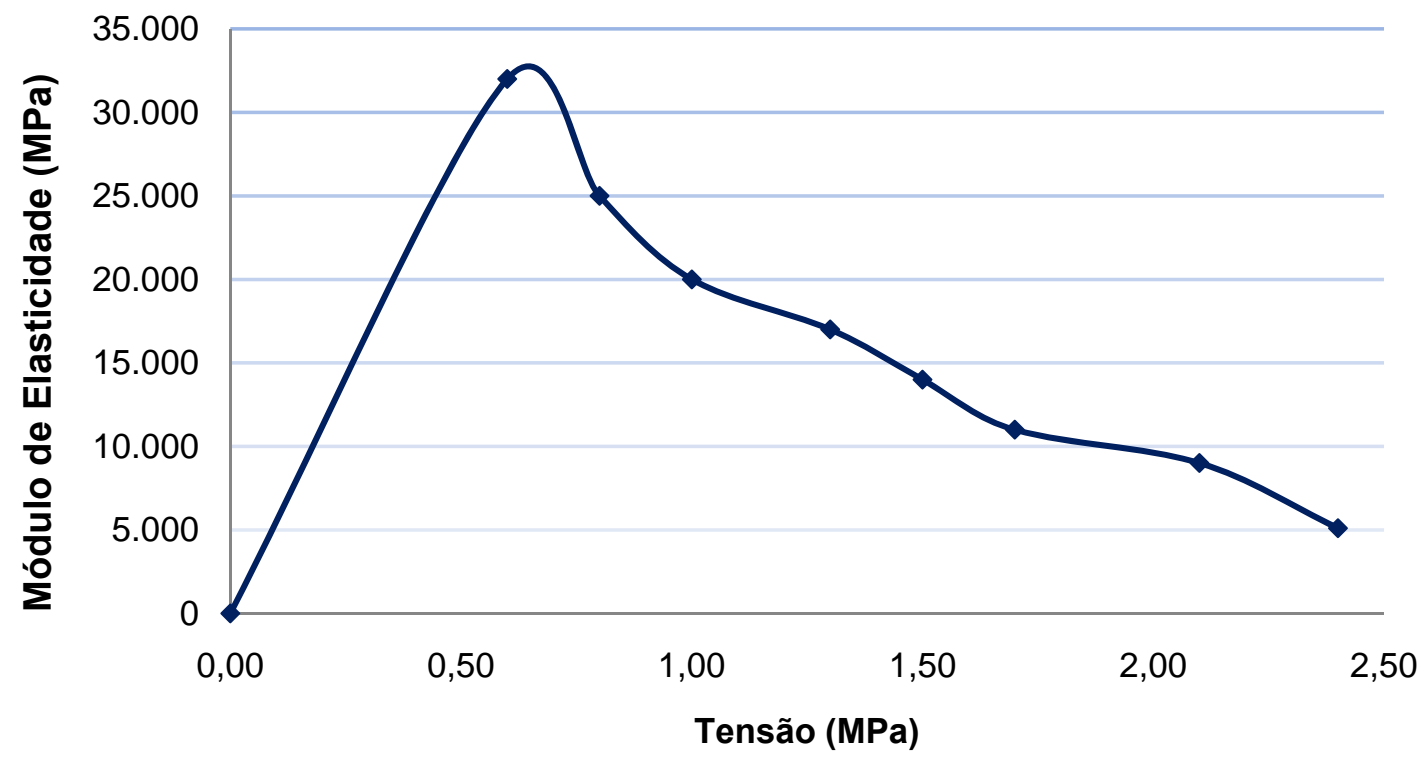

Figura 49 - Exemplo de determinação da curva módulo de elasticidade em tração na flexão x tensão em tração 


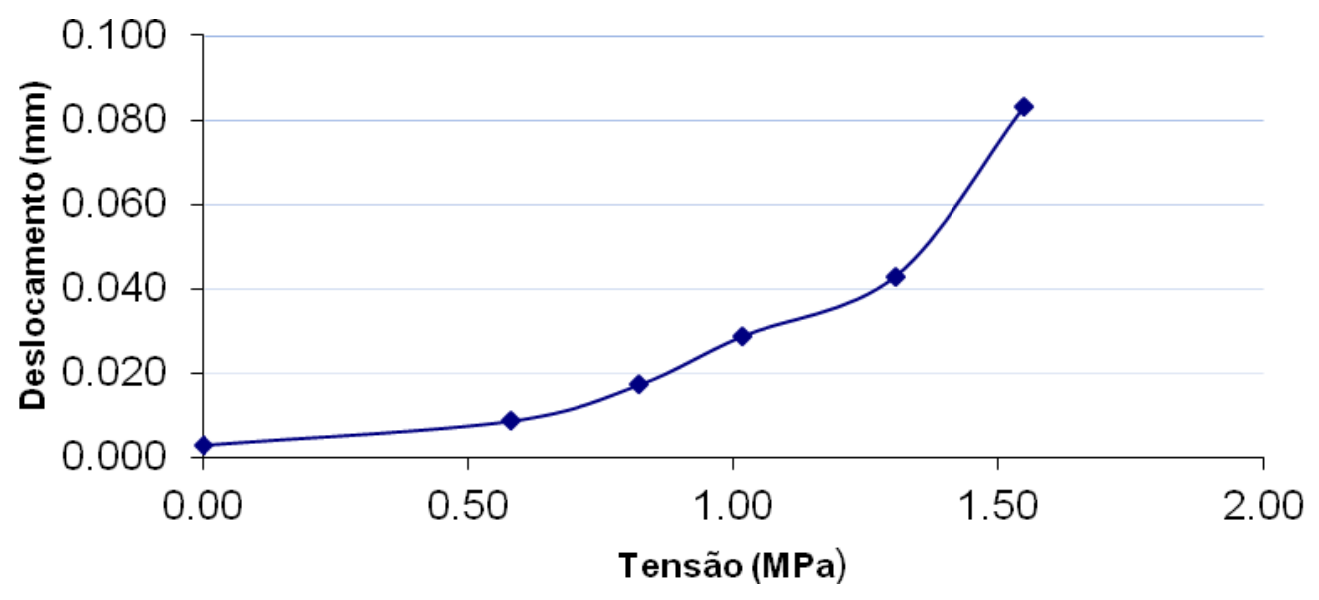

Figura 50 - Exemplo de determinação da curva tensão de tração x flecha

\subsubsection{Ensaio por Pulso de Onda Ultrassônica - Módulo de Elasticidade}

Antes de serem ensaiados à compressão diametral e à tração na flexão, os corpos de prova foram submetidos ao ensaio de determinação de velocidade de pulso ultrassônico, com o equipamento PUNDIT (Figura 51). Aproveitou-se o ensaio para verificar o módulo de elasticidade, segundo as condições previstas pelo projeto de norma ABNT/CP-18:400.04-008 e também para a determinação da massa específica, segundo a relação massa/volume.

Conforme NBR 8802/94 - Determinação da velocidade de propagação de onda ultrassônica, o ensaio não-destrutivo auxilia na verificação da homogeneidade do concreto, detecção de eventuais falhas internas de concretagem, bem como da profundidade de fissuras e outras imperfeições.

O ensaio consiste na aplicação de uma onda longitudinal com frequência de vibração acima de $5 \mathrm{kHz}$. A onda percorre o interior do material de forma que o deslocamento das partículas é realizado na mesma direção da propagação do distúrbio. O sistema é composto por um circuito gerador-receptor com precisão de leitura de pelo menos $0,1 \mu \mathrm{s}$, um aparelho transdutor-emissor que transforma a onda de choque em pulso elétrico, além de um circuito medidor de tempo. 

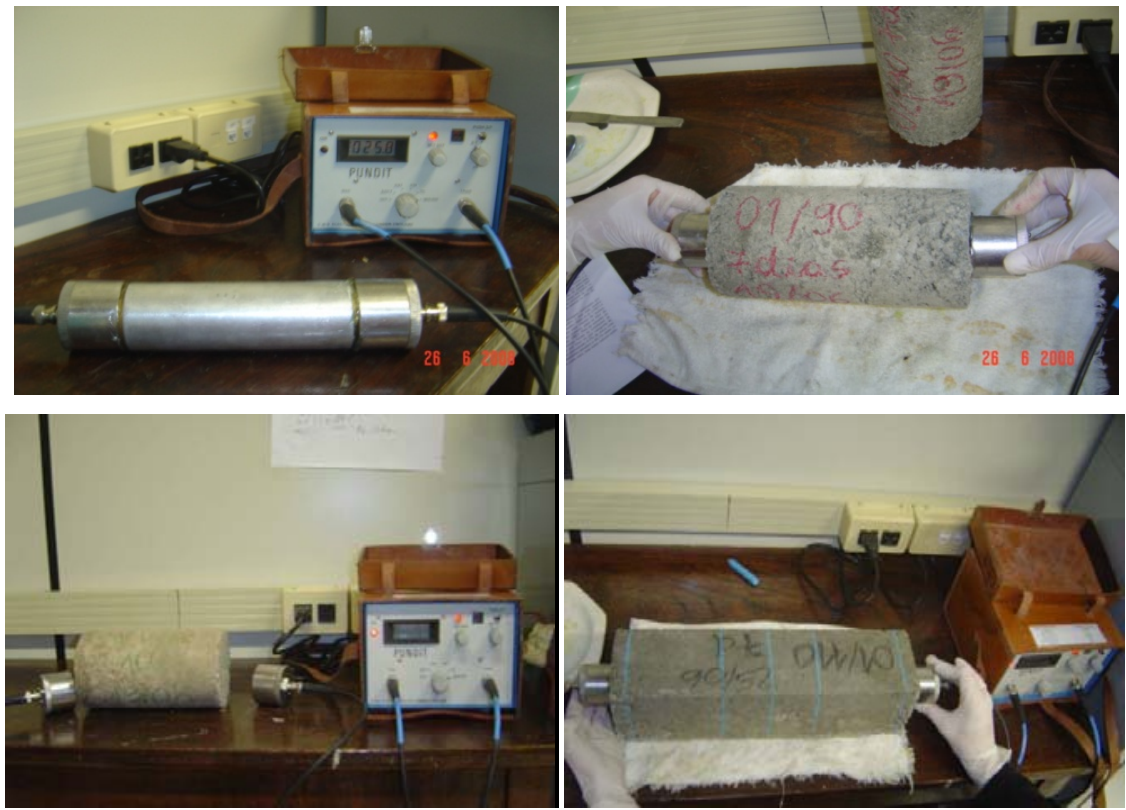

Figura 51 - Ensaio de por pulso de onda ultrassônica

Para calcular a velocidade de propagação de ondas utilizou-se a equação 7 (NBR 8802/1994) abaixo:

$V=\frac{L}{t}$

onde:

$V$ : velocidade de propagação $(\mathrm{m} / \mathrm{s})$;

L: distância entre os pontos de acoplamento dos centros das faces dos

transdutores $(\mathrm{m})$;

$t$ : tempo decorrido desde a emissão da onda até a sua recepção (s).

Segundo o projeto normativo CB-18:400.04-008 (ABNT, 2008), O módulo de elasticidade dinâmico $\left(E_{d}\right)$ deve ser calculado por meio da equação 8.

$$
E_{d}=y \times v^{2} \times \frac{(1+v) \times(1-2 v)}{(1-v)}
$$

Onde:

E: módulo de elasticidade dinâmico $\left(\mathrm{MN} / \mathrm{m}^{2}\right)$;

v. coeficiente de Poisson;

$Y$ : massa específica do concreto $\left(\mathrm{kg} / \mathrm{m}^{3}\right)$. 


\subsubsection{Ensaio de Tenacidade}

Para ensaio de tenacidade à fratura, utilizou-se no presente trabalho o ensaio padronizado para materiais metálicos, ASTM E-399, que utiliza corpos de prova prismáticos sob tração na flexão. As medidas dos corpos de prova foram as mesmas utilizadas para o ensaio de tração na flexão, sendo que para a obtenção da curva-R os corpos de prova receberam um entalhe central vertical de $25 \mathrm{~mm}$, na face inferior do corpo de prova. O valor do entalhe foi obtido experimentalmente, de modo que esta abertura foi o menor valor para o qual se obteve propagação estável da trinca.

Para estudar o comportamento à fratura do CCR de referência e do CCR (com incorporação de fresado) foi realizado ensaio de flexão a três pontos, conforme mostrado na Figura 52, com carregamento contínuo e controle de deslocamento. A velocidade utilizada durante o ensaio foi de $5 \mu \mathrm{m} /$ minuto (velocidade que permitiu a determinação da curva carga $x$ deslocamento com crescimento lento da fissura pósruptura).

O ensaio de tenacidade para determinação da curva- $R$ foi realizado em quatro corpos de prova do CCR de referência e em mais quatro do CCR contendo $50 \%$ de fresado faixa total, pois esta substituição é a mais simples e econômica, já que não necessita de peneiramento, podendo ser utilizado na forma como é retirado do campo. Os corpos de prova foram ensaiados com mais de 120 dias de cura, considerando que, com esta idade, o concreto apresentaria menor possibilidade de ganho de resistência, já que praticamente todas as reações já teriam ocorrido.

Para este ensaio foi utilizada uma prensa MTS Universal servo-controlada do Laboratório de Mecânica de Rochas - Departamento de Minas da EPUSP.
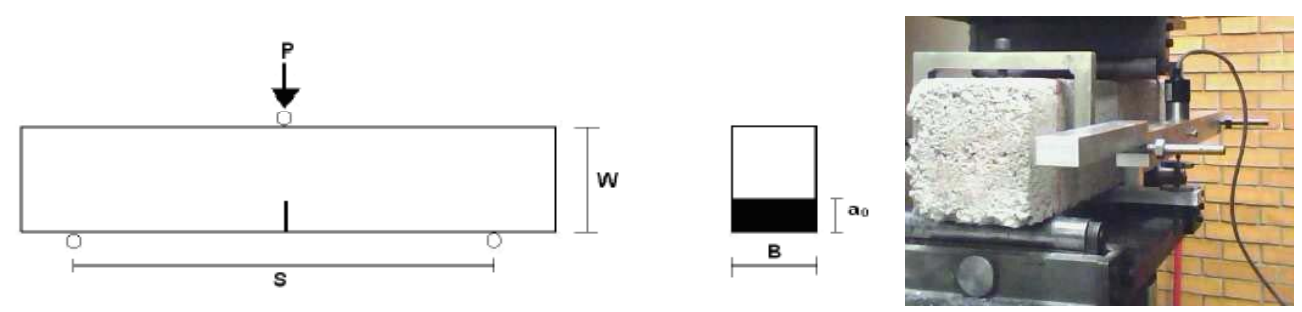

Figura 52 - Esquema do ensaio com geometria de flexão a três pontos 
No ensaio foi determinado o fator de intensidade da trinca $\left(K_{l}\right)$ que é obtido em função da carga, dimensões da amostra e comprimento da trinca, conforme equação 9.

$$
K_{I}=\frac{1.5 \cdot P \cdot S \cdot(\pi \cdot a)^{1 / 2}}{B \cdot W^{2}} f(\alpha)
$$

onde $P$ é a carga aplicada em Newton, $B, W$ e $S$ (largura, altura e distância entre dois apoios) em $\mathrm{mm}$, $a$ é o comprimento instantâneo de trinca em metros, $\alpha=a / W$ é o comprimento normalizado da trinca para altura $W$ e $f(\alpha)$ é uma equação do quinto grau que representa o ajuste de $K_{\perp}$ em função do comprimento da trinca. Dessa forma, $\mathrm{K}_{\mathrm{l}}$ é obtido em $\mathrm{MPa}(\mathrm{m})^{1 / 2}$.

Para determinação do comprimento instantâneo da trinca $\left(a_{i}\right)$ foi usada a relação entre o deslocamento na linha de carga aplicada, conforme equação (10).

$\delta=\frac{1.5 \cdot P \cdot S^{2}}{B \cdot W^{2} \cdot E} V(\alpha)$

Onde $E$ é o módulo de elasticidade em $\mathrm{MPa}$ e $V(\alpha)$ é uma função adimensional dependente da geometria do ensaio, válida para $\mathrm{B}=\mathrm{W}$. Para uma viga prismática com $S / W=3$, sujeito à configuração de flexão a três pontos as funções adimensionais $f(\alpha)$ e $V(\alpha)$ podem ser calculadas no intervalo de $0.05 \leq \alpha \leq 0.75$ usando a equação 11.

$f(\alpha)$ ou $V(\alpha)=a \alpha^{5}+b \alpha^{4}+c \alpha^{3}+d \alpha^{2}+e \alpha+f$

Onde $\alpha$ é igual a $a / W$ e os coeficientes são fornecidos por Ferreira (2007), e estão apresentados na Tabela 13.

Tabela 13 - Função adimensional dependente da geometria do ensaio de três pontos (Ferreira, 2007)

\begin{tabular}{|c|c|c|c|c|c|c|}
\hline Parâmetros & $a$ & $b$ & $c$ & $d$ & $e$ & $f$ \\
\hline$f(\alpha)$ & 60.398928 & -86.787007 & 47.418483 & -8.234774 & 0.092058 & 0.998367 \\
\hline$V(\alpha)$ & 352.294990 & -542.694230 & 321.336060 & -80.619223 & 9.756626 & 0.292978 \\
\hline
\end{tabular}


Para o caso de materiais que apresentam curva-R crescente e sob a condição de propagação quase-estática de uma trinca, "R" (resistência à propagação da trinca), pode ser calculado por meio de sua relação com o fator de intensidade de tensão instantâneo na ponta da trinca. Portanto, $\mathrm{R}$ pode ser encontrado usando-se a mecânica da fratura elástica linear (MFEL), de acordo com Irwin (1957), conforme equação 12.

$$
R=\frac{K_{I}^{2}}{E}
$$

A determinação da energia total de fratura $\left(\gamma_{\text {wof }}\right)$ pode ser um critério para avaliar se os valores de R obtidos são confiáveis. Este processo é realizado por meio da comparação do valor médio de $R, \bar{R}$, e da energia total de fratura, $\gamma_{\text {wof }}$ (Kleinlein \& Hubner, 1977; Bornhauser et al., 1999). Para aplicar esse critério calculou-se o valor de $R$ médio $(\bar{R})$ empregando-se a relação apresentada na equação (13):

$$
\bar{R}=\left(\frac{1}{a_{f}-a_{0}}\right) \cdot \int_{a_{0}}^{a_{f}} R(a) d \cdot a
$$

onde $a_{f}$ é o último comprimento de trinca com propagação estável no intervalo válido $(\alpha \leq 0.75)$ e $a_{0}$ é o comprimento do entalhe.

O valor de $2 \gamma_{\text {wof }}$ foi calculado através da área de propagação estável da curva $P$ $x d$, no intervalo válido para $\alpha$, considerando que não houve deformação permanente.

Para a determinação da energia total de fratura foi necessário o cálculo do trabalho realizado pela máquina sobre o corpo de prova, conforme a equação $14 \mathrm{e}$ apresentado na Figura 53, entretanto considerando o intervalo válido para $\alpha$. Para isto calculou-se a integral da curva carga $x$ deslocamento utilizando-se o programa computacional Origin 6.0. Com a integral desta curva, tem-se a energia total. Para determinar a energia de fratura, no intervalo válido, subtraiu-se da energia total a energia elástica relativa a $\alpha<0,75$. O valor da área da propagação da trinca, $A$, da 
equação 14 foi calculado pela equação $11(\alpha=a / W)$, multiplicando a pela largura, $B$, do corpo de prova.

$\gamma_{\text {wof }}=\frac{A_{c} x P x d}{2 A}$

Onde:

$$
\begin{aligned}
& A C \text { = área sob a curva } \\
& A=\text { área de fratura }
\end{aligned}
$$

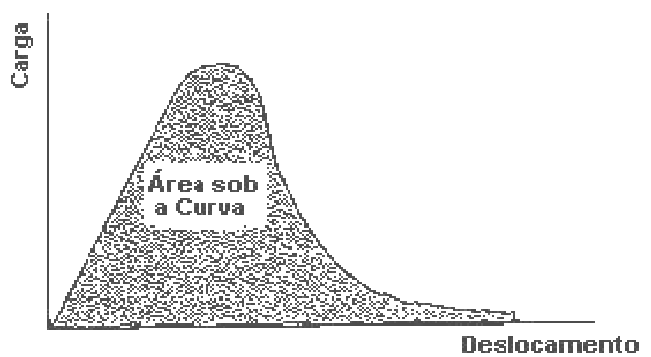

Figura 53 - Representação do cálculo da energia total de fratura, $\gamma$ wof, através da medida da área sob a curva carga-deslocamento

Na Figura 54 está apresentado um exemplo do gráfico gerado para as curvas carga x deslocamento e na Figura 55 (a) e (b) está apresentado um exemplo gráfico de curva-R obtida no presente estudo.

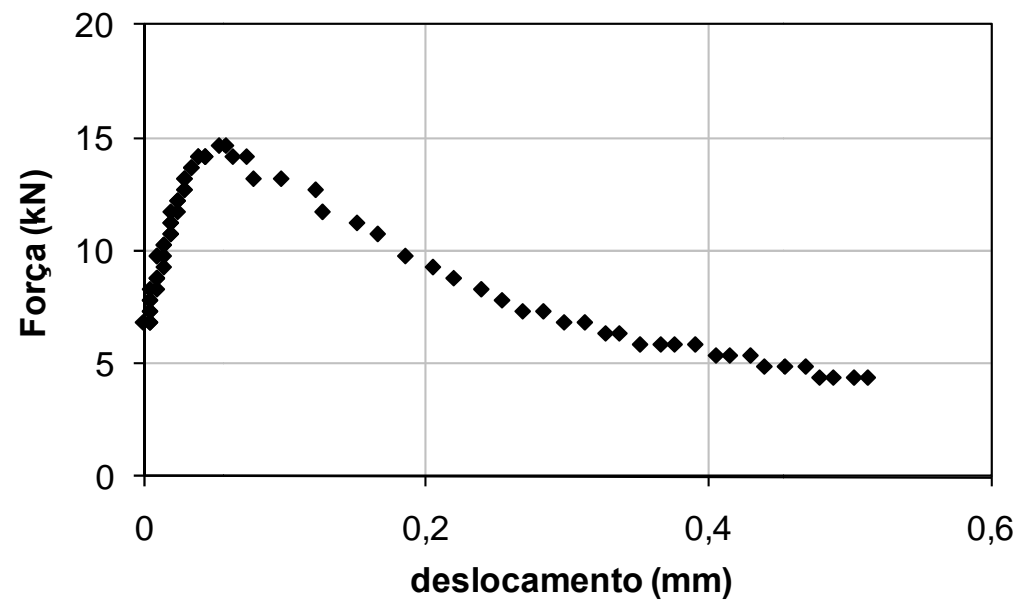

Figura 54 - Exemplo de curva carga $x$ deslocamento 


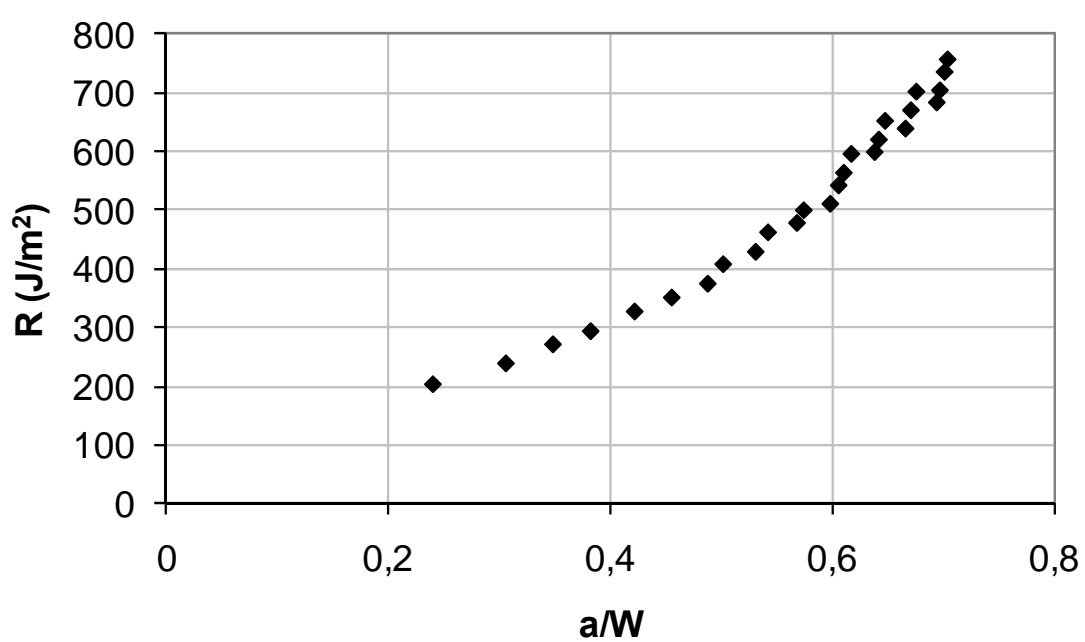

(a) Curva-R

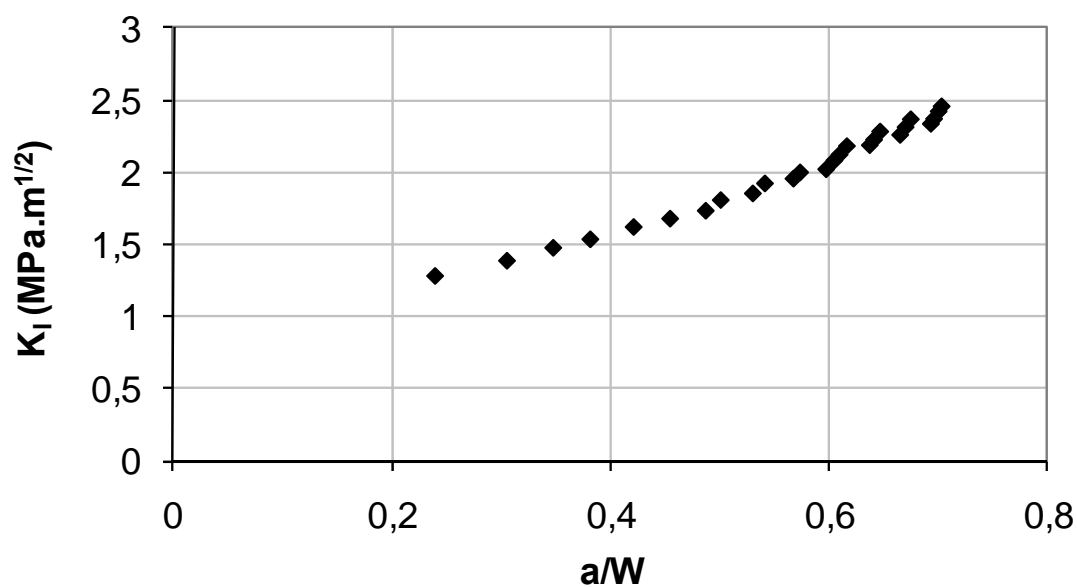

(b) $\mathrm{K}_{1}$

Figura 55 - Exemplo de curva-R (a) e $\mathrm{K}_{\mathrm{l}}(\mathrm{b})$

\subsubsection{Observações com Microscópio Eletrônico de Varredura}

De acordo com Dedavid et al. (2007) o microscópio eletrônico de varredura (MEV), além de ser um dos mais versáteis instrumentos disponíveis para a observação e análise de características microestruturais, ainda fornece rapidamente informações sobre a morfologia e identificação de elementos químicos de uma amostra sólida.

Segundo Mehta e Monteiro (1994), analisando a microestrutura do concreto com auxílio de microscópio é possível distinguir as diferenças entre a pasta de cimento em contato com o agregado graúdo (de 10 a $50 \mu \mathrm{m}$ ) do restante da pasta, podendo ser considerada mais uma fase do concreto. 
A nível macroscópico, Mehta e Monteiro (1994) consideram que o concreto é um material bifásico, consistindo de partículas de agregado dispersas em uma matriz de cimento. A matriz/pasta de cimento é constituída por vários compostos hidratados do cimento, sendo eles: o C-S-H, originado pela hidratação de dois tipos de silicatos de cálcio presentes no cimento, o silicato tricálcico $\left(C_{3} S\right)$ e o silicato dicálcico $\left(C_{2} S\right)$; o carbonato de cálcio $\mathrm{Ca}(\mathrm{OH})_{2}$, também chamado de Portlandita e; a etringita que cristaliza no início da pega em forma de agulhas.

O princípio de funcionamento do MEV consiste na utilização de um feixe de elétrons de pequeno diâmetro para explorar a superfície da amostra, por linhas sucessivas e transmitir o sinal do detector a uma tela catódica cuja varredura está perfeitamente sincronizada com aquela do feixe incidente. O sinal recolhido pelo detector é utilizado para modular o brilho do monitor, permitindo a observação. (Dedavid et al., 2007).

O MEV é geralmente utilizado para observações de amostras espessas, ou seja, não transparente a elétrons. A razão principal de sua utilização está associada à alta resolução que pode ser atingida, atualmente da ordem de $3,0 \mathrm{~nm}$ e à grande profundidade do foco, da ordem de 300 vezes maior do que o microscópio óptico (MO) resultando em imagens com aparência tridimensional quando analisados por elétrons secundários.

Os sinais utilizados para a obtenção da imagem são originários de elétrons secundários (secondary electron - SE). Os elétrons secundários no MEV resultam da interação do feixe eletrônico como material da amostra. São elétrons resultantes de baixa energia $(<50 \mathrm{eV}$ ) e formam imagens com alta resolução (3-5 mm), os quais representam em tons de cinza o mapeamento e a contagem de elétrons secundários (SE- secondary electrons) e retroespalhados (BSE-backscattered electrons) emitidos pelo material analisado.

A imagem de SE fornece detalhes da superfície do material em tons de cinza e são principalmente utilizados para visualização topográfica da amostra, permitindo analisar a textura e a rugosidade da superfície da amostra. A imagem de BSE é gerada pela emissão de elétrons retroespalhados e possibilita a observação de diferenças composicionais na região ionizada do material. O volume da região ionizada depende do número atômico (Z) médio da zona de interação do material com o feixe de 
elétrons. As imagens BSE são representadas em tons de cinza, onde os tons claros correspondem às porções constituídas por elementos com Z médio relativamente maior do que aquelas com tons mais escuros. Contudo, a resolução da imagem de BSE é menor que a de $\mathrm{SE}$, pois as regiões de BSE abrangem uma área maior que aquelas de liberação de elétrons secundários na superfície analisada (Duarte et al., 2003).

\section{MEV SE (Elétrons Secundários):}

As seis amostras de CCR foram cortadas com serra, de modo a resultarem em pastilhas com aproximadamente $5,0 \mathrm{~mm}$ de espessura. Em seguida, foram selecionadas regiões de interface agregado/pasta de cimento e cortadas amostras com aproximadamente $1,0 \mathrm{~cm}$ de lado, as quais foram secas em estufa, à temperatura de $50{ }^{\circ} \mathrm{C}$. Posteriormente, as amostras foram coladas sobre uma fita de carbono em um stub (porta amostra).

As amostras foram metalizadas com ouro e observadas em um microscópio eletrônico de varredura do tipo JEOL JSM - 6060 (Figura 56) para identificar alterações microestruturais no concreto. As alterações podem ser observadas nas diferentes microestruturas e nas zonas de transição dos agregados convencionais e dos agregados fresados com a pasta de cimento. Os ensaios foram realizados no Centro de Microscopia Óptica da Universidade Federal do Rio Grande do Sul. O microscópio opera entre 0,3 a $30 \mathrm{kV}$, com resolução de imagem de ponto de 3,5 nm, com uma faixa de magnificação de $18 \times$ a 300.000 X, estágio goniométrico motorizado de 5 eixos, eucêntrico em todas as posições, com inclinação de amostras de -10 o a + 90ㅇ e rotação de 360․ 


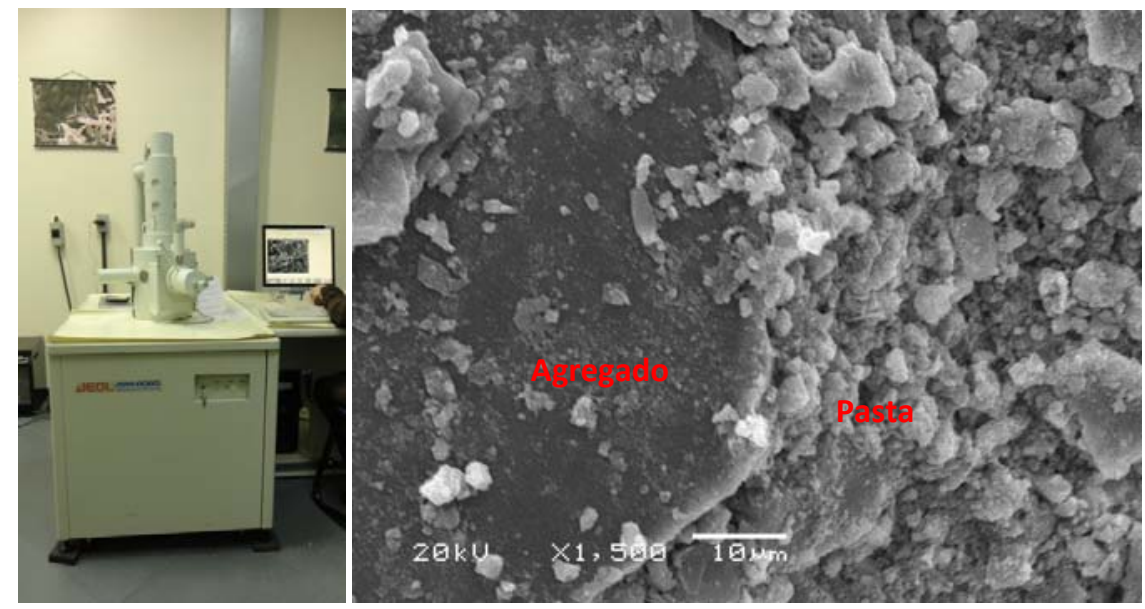

Figura 56 - Microscópio eletrônico de varredura JOEL-JSM 6060 (Centro de Microscopia Óptica da UFRGS) e Imagem típica obtida no microscópio eletrônico de varredura JOEL-JSM 6060

\section{MEV BSE (Elétrons Retroespalhados):}

As seis amostras dos corpos-de-prova de CCR foram metalizadas com carbono e avaliadas em um microscópio eletrônico de varredura (JEOL JSM - 5800), para identificar possíveis alterações microestruturais nas diversas misturas de CCR, bem como avaliar a zona de transição entre agregado e pasta de cimento, e a influência da presença do agregado fresado na mistura (Figura 57). Os ensaios foram realizados no Centro de Microscopia Óptica da Universidade Federal do Rio Grande do Sul. Este microscópio opera entre 0,3 a $30 \mathrm{kV}$, com resolução para imagem de ponto $3,5 \mathrm{~nm}$, faixa de magnificação: $18 \mathrm{X}$ a $300.000 \mathrm{X}$, com estágio goniométrico motorizado de 5 eixos, eucêntrico em todas as posições ( $X=125 \mathrm{~mm}, Y=100 \mathrm{~mm}, Z=43 \mathrm{~mm}$ ), inclinação de amostras de $-10^{\circ}$ a $+90^{\circ}$ e rotação de $360^{\circ}$, com uma pré-câmara de vácuo, sendo possível a análise de raios-x EDS - Sistema de Dispersão em Energia, com capacidade de deteç̧ão de elementos entre B e U. 


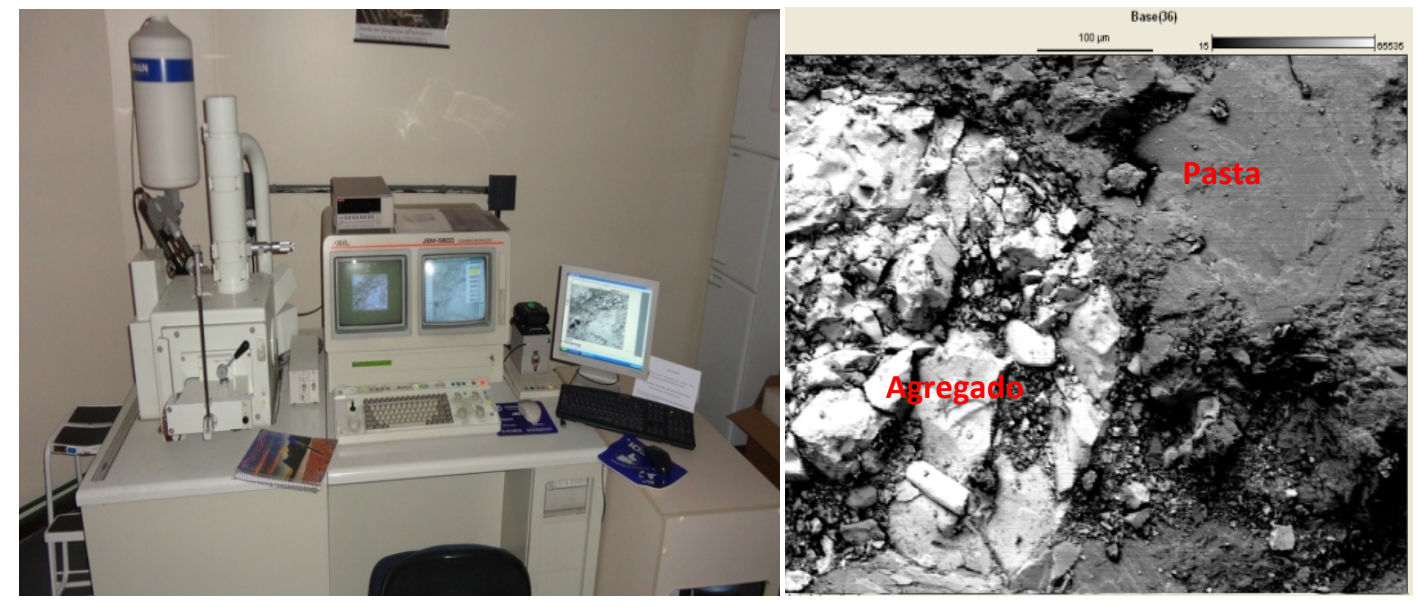

Figura 57 - Microscópio eletrônico de varredura Backscattered JSM 5800 - (Centro de Microscopia Óptica da UFRGS) e Imagem obtida no microscópio eletrônico de varredura Backscattered JSM 5800

Foram analisadas duas amostras, para cada um dos CCR confeccionados, totalizando 12 amostras (Tabela 14), as quais foram retiradas do centro dos corpos de prova rompidos, com mais de 120 dias cura.

Tabela 14 - Amostras observadas no MEV

\begin{tabular}{|c|c|}
\hline Amostra & № de Amostras \\
\hline CCR1 & 2 \\
\hline CCR2 & 2 \\
\hline CCR1-AF & 2 \\
\hline CCR1-PF & 2 \\
\hline CCR1-BF & 2 \\
\hline CCR1-FT & 2 \\
\hline $\begin{array}{c}\text { TOTAL DE } \\
\text { AMOSTRAS }\end{array}$ & 12 \\
\hline
\end{tabular}

\subsubsection{Observações Por Microscopia Óptica}

Foram realizadas observações com microscópico óptico em 6 amostras de CCR que foram retiradas de faces de corpos de prova rompidos, a fim de detectar a presença de poros nos diferentes CCR e possíveis alterações microscópicas nas misturas estudadas.

Principalmente, verificar a aderência da pasta de cimento e o agregado fresado e 
possíveis falhas na zona de transição. As amostras não precisaram de nenhum tratamento para a realização dos ensaios.

As imagens foram obtidas por meio de um microscópio óptico do tipo Olympus BX51M (Figura 58), disponibilizado pelo Laboratório de Cerâmica (LACER) da Universidade Federal do Rio Grande do Sul - UFRGS. A imagem obtida no microscópio óptico pode ser vista na Figura 59. A avaliação das imagens obtidas por microscópio óptico permite verificar a estrutura do concreto obtido de uma perspectiva geral. Assim, é possível identificar, de uma forma comparativa, a quantidade de poros presentes nos diferentes CCR analisados.
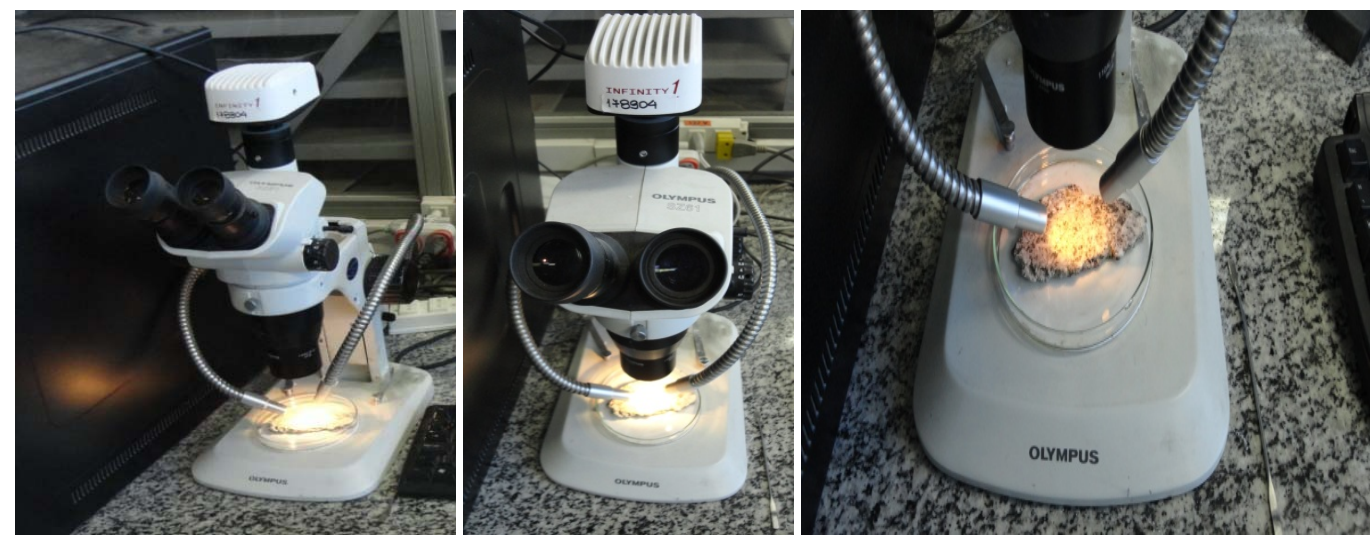

Figura 58 - Observações no microscópio óptico Olympus BX51M

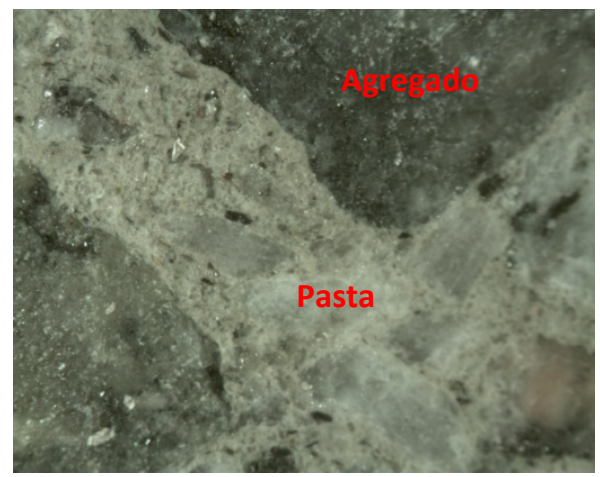

Figura 59 - Imagem obtida por meio microscópio óptico Olympus BX51M

\subsubsection{Observações Com Lupa Estereoscópica}

Complementarmente aos demais ensaios, foram realizadas observações com lupa estereoscópica, nas amostras de CCR, com o intuito de identificar a existência de 
grumos de RAP no CCR, comparar a interface agregado/pasta de cimento nos CCR com RAP e no CCR de referência, observar a porosidade de cada mistura e se a ruptura da corpo de prova se deu nos grãos do agregado fresado ou na pasta de cimento.

As observações foram feitas nas faces fraturadas, de corpos-de-prova cilíndricos ensaiados à compressão diametral.

As observações foram feitas na Universidade Estadual de São Paulo - Ilha Solteira, no laboratório do GDAM (Grupo de Desenvolvimento e Aplicação de Materiais) da Faculdade de Engenharia. A lupa utilizada no estudo é da marca Carl Zeiss Jena (Figura 60).

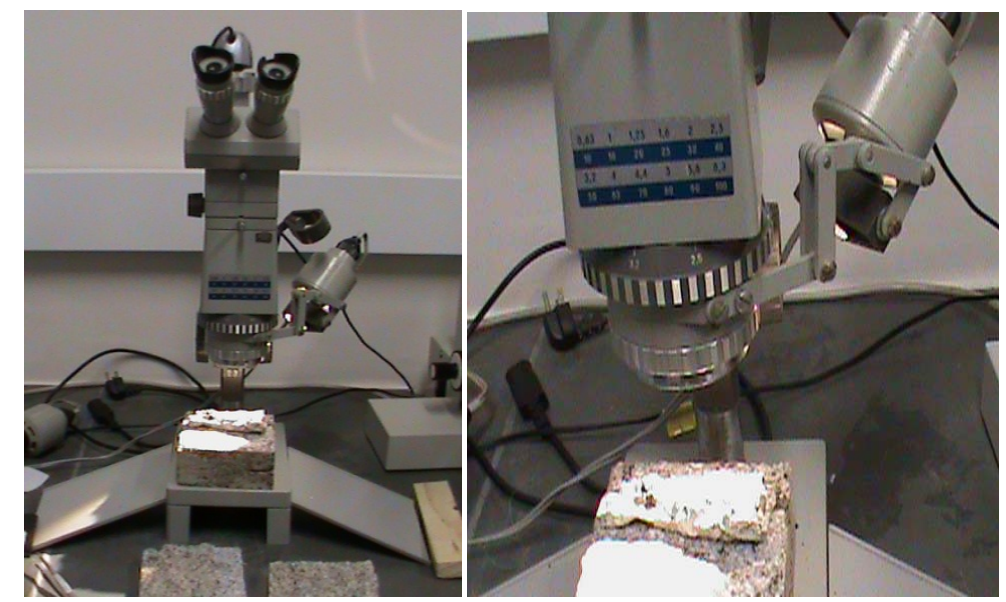

Figura 60 - Lupa estereoscópica do tipo Carl Zeiss Jena 


\section{APRESENTAÇÃO E ANÁLISE DOS RESULTADOS}

O presente capítulo tem como objetivo apresentar e analisar os resultados dos ensaios realizados durante a pesquisa e apresentados no capítulo 3 deste trabalho. Nos anexos A e B estão apresentadas as análises estatísticas dos resultados de tensão de ruptura e módulos de elasticidade.

\subsection{ENSAIOS DE COMPACTAÇÃO}

Os ensaios de compactação foram realizados para as amostras de CCR com areia industrial com consumos de cimento de 90,110 e $130 \mathrm{~kg} / \mathrm{m}^{3}$, assim como, para os CCR com areia natural e areia industrial com consumo de cimento de $100 \mathrm{~kg} / \mathrm{m}^{3}$, conforme pode ser visto na Figura 61.

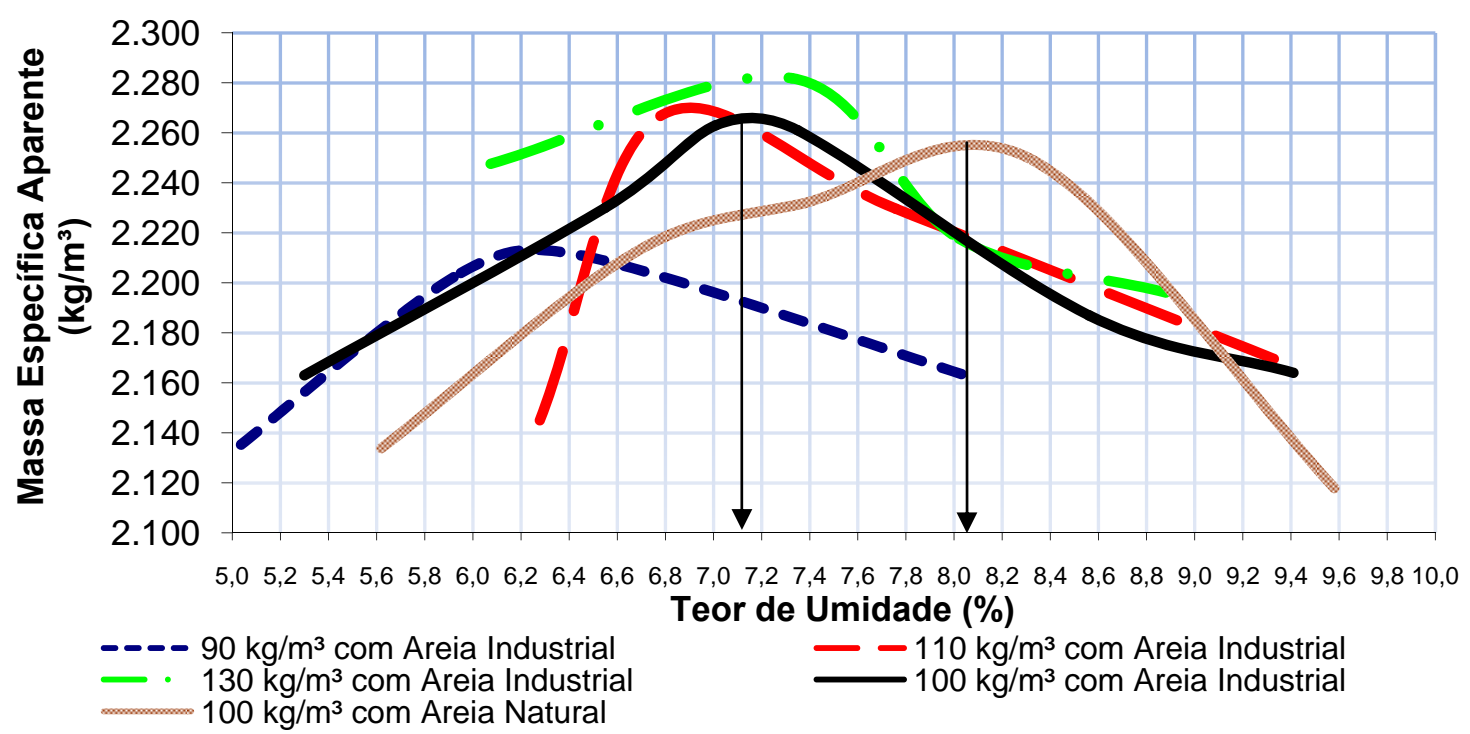

Figura 61 - Curvas de compactação do CCR padrão e do CCR com areia natural 
No CCR padrão observou-se que o aumento no consumo de cimento leva ao acréscimo da massa específica das amostras.

Para os concretos com fresados asfálticos (Figura 62), os comportamentos das curvas se mostraram mais anômalos. Esse comportamento pode ser regido pela presença do ligante asfáltico hidrófugo no agregado fresado. Verificaram-se quedas nos valores das massas específicas em comparação aos concretos com areia industrial e areia natural. Essa discrepância nas curvas é atribuída ao fato de que surgem irregularidades na distribuição dos agregados quando o RAP é inserido na mistura. Esse fato tem influência na tensão de ruptura e módulo de elasticidade das misturas, uma vez que interfere na compactação do material. A queda nos valores de massa específica aparente também pode estar relacionada ao aumento no número de vazios quando da incorporação do RAP na mistura.

As curvas de compactação, para o caso dos CCR com RAP, não apresentaram pico definido de umidade ótima. Portanto, adotou-se o pico em que se pudesse utilizar menor quantidade de água. O efeito do betume envolvendo agregados deixam claras as dificuldades do ensaio de compactação para a adoção da umidade ótima.

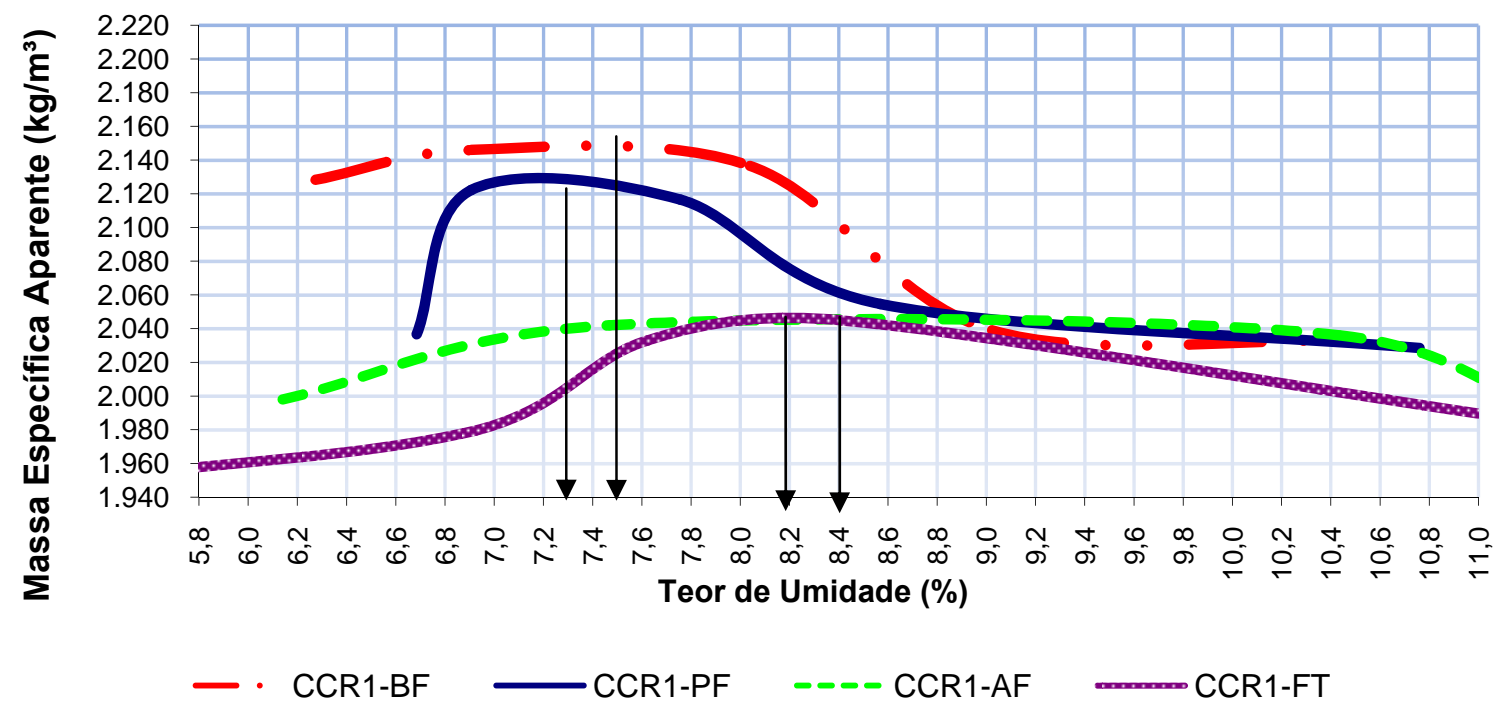

Figura 62 - Curvas de compactação do CCR com fresado

Comparando-se as umidades de todos os CCR produzidos, notou-se que o CCR contendo a fração areia com agregados de RAP (CCR1-AF) foi o que apresentou maior umidade e também maior exsudação durante a compactação. A exsudação da água 
das misturas com RAP é causada devido ao excesso de água nos poros, fato que gerou poro pressão, fazendo a água migrar para a superfície. Isso foi atribuído à baixa absorção de água dos agregados fresados (Figura 63). Na Tabela 15 estão apresentadas as umidades ótimas, relação a/c e as massas específicas aparentes secas obtidas para cada CCR confeccionado.

Tabela 15 - Umidade ótima para os CCR estudados

\begin{tabular}{|c|c|c|c|}
\hline Tipo de CCR & $\begin{array}{c}\text { Umidade ótima } \\
(\%)\end{array}$ & $\begin{array}{c}\text { Relação } \\
\text { a/c }\end{array}$ & $\begin{array}{c}\text { Massa Específica } \\
\text { Aparente Seca } \\
\left(\mathrm{kg} / \mathrm{m}^{3}\right)\end{array}$ \\
\hline CCR1 & 7,15 & 1,137 & 2.268 \\
\hline CCR2 & 8,05 & 1,196 & 2.258 \\
\hline CCR1-FT & 8,20 & 1,302 & 2.048 \\
\hline CCR1-AF & 8,40 & 1,334 & 2.046 \\
\hline CCR1-PF & 7,30 & 1,159 & 2.130 \\
\hline CCR1-BF & 7,50 & 1,175 & 2.148 \\
\hline
\end{tabular}
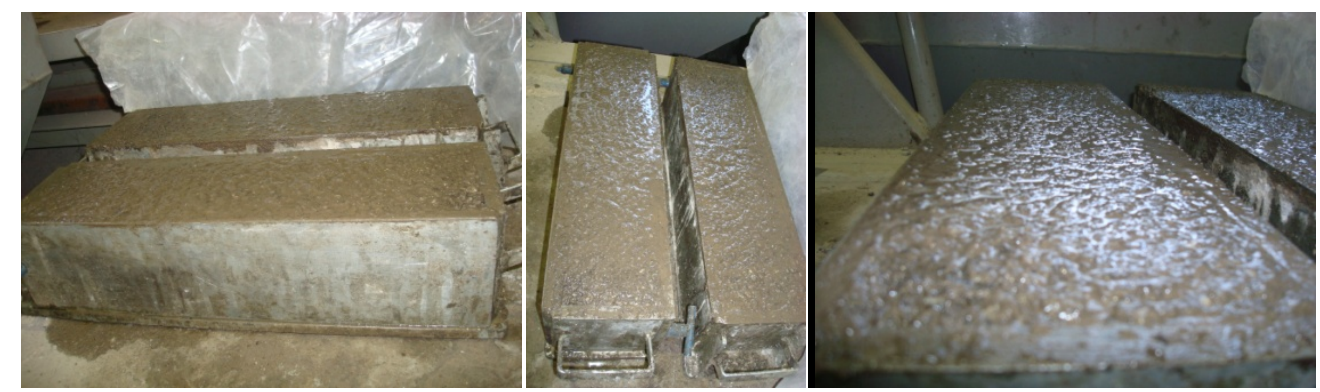

Figura 63 - Exsudação da água na superfície do CCR com RAP

Pinto et al. (2009) observaram, em seu trabalho com CCR, que a inserção da escória como fração areia no CCR, demandou maior umidade em relação ao CCR padrão confeccionado com areia industrial. Fato que também foi observado por Ricci (2007), que estudou a incorporação de agregado reciclado de construção e de demolição em misturas de CCR. As umidades aumentaram para os CCR com agregado reciclado, em relação ao CCR convencional. O autor também observou exsudação da água para a superfície destes corpos de prova, durante a compactação. 


\subsection{ENSAIO DE COMPRESSÃO DIAMETRAL}

Os ensaios de compressão diametral foram realizados em corpos de prova cilíndricos (100 mm x $200 \mathrm{~mm}$ ), sendo rompidas três amostras aos 7 dias de cura e 6 amostras aos 35 dias de cura para os consumos de cimento de 90, 110 e $130 \mathrm{~kg} / \mathrm{m}^{3}$ (Figuras 63 e 64). Os ensaios também foram realizados, com estes tempos de cura, para o CCR padrão (CCR1) e para o CCR com areia natural (CCR2). Para os CCR contendo RAP, os ensaios de compressão diametral foram realizados somente após 35 dias de cura. Nas Tabelas 16 e 17 estão apresentados os valores de resistência à tração dos CCR1 e CCR2. Nas Figuras 64 e 65 estão apresentados gráficos de ganho de resistência para os tempos de cura de 7 e 35 dias.

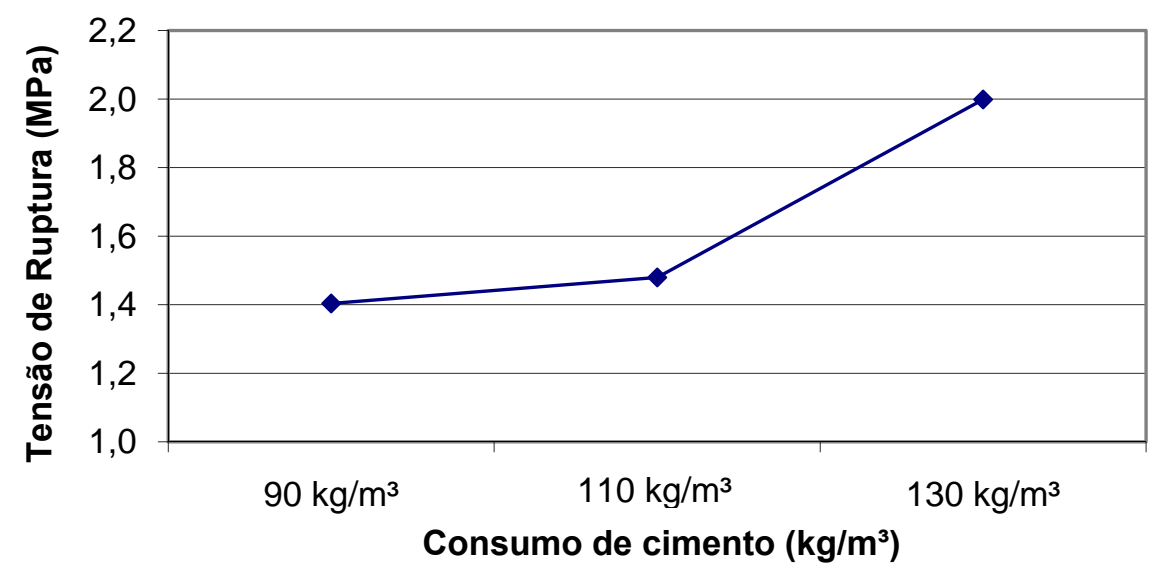

Figura 64 - Ganho de resistência para tempo de cura de 7 dias dos CCR de dosagem com areia industrial, com 90, 110 e $130 \mathrm{~kg} / \mathrm{m}^{3}$ de cimento (cilíndricos)

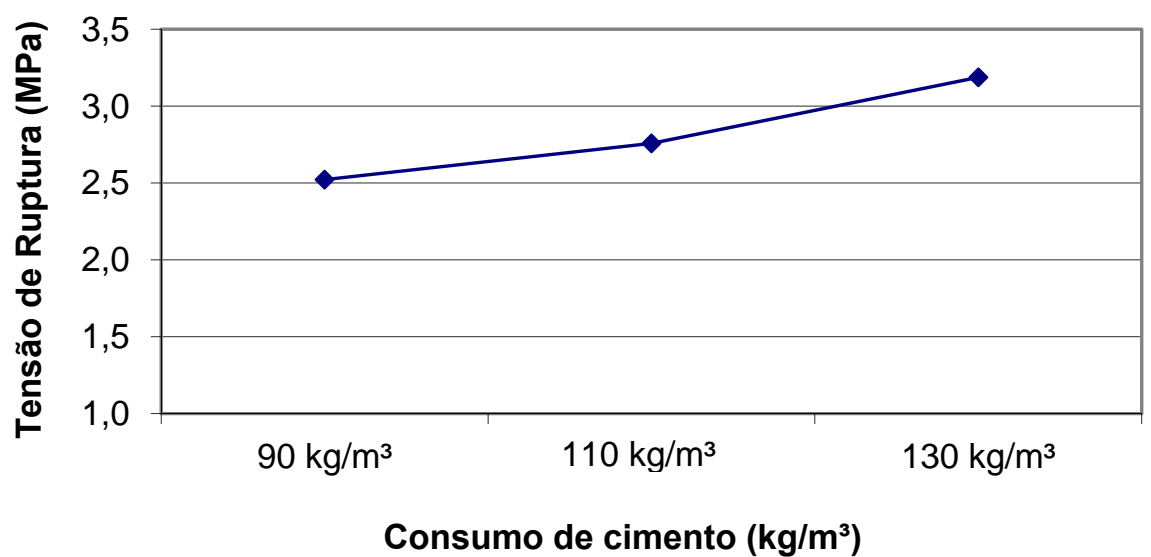

Figura 65 - Ganho de resistência com tempo de cura de 35 dias para os CCR de dosagem com areia industrial, com 90, 110 e $130 \mathrm{~kg} / \mathrm{m}^{3}$ de cimento (cilíndricos) 
Observou-se que o CCR com $90 \mathrm{~kg} / \mathrm{m}^{3}$ de cimento teve um acréscimo de $44 \%$ na tensão de ruptura, dos 7 para os 35 dias de cura; o CCR com $110 \mathrm{~kg} / \mathrm{m}^{3}$ teve um aumento de $46 \%$; e o CCR com $130 \mathrm{~kg} / \mathrm{m}^{3}$ teve aproximadamente $37,5 \%$ de acréscimo do menor para o maior tempo de cura.

Nas Tabelas 16 e 17 é possível observar a queda nos valores das massas específicas das misturas com RAP, em relação aos CCR sem RAP. As tensões de ruptura também são afetadas negativamente quando o RAP é inserido na mistura. A queda na tensão de ruptura foi de 60,8\% para o CCR1-AF e de 50,6\% para o CCR1-FT. Para o CCR1-PF a redução na resistência à compressão ficou em torno de 33,0\% e o CCR1-BF teve queda de $39,6 \%$, em relação ao CCR1 (referência). Portanto, a mistura que teve maior queda na tensão de ruptura foi a CCR1-AF, a qual pode ser atribuída à quantidade de pequenos grumos que são formados por material fino e ligante asfáltico, mascarando a real granulometria da areia de agregado fresado e causando um aumento da quantidade de poros nessa mistura. Na Figura 66 estão apresentados os valores de tensão de ruptura à compressão de todas as misturas.

Tabela 16 - Valores de resistência à tração indireta dos CCR com areia industrial (CCR1) e areia natural (CCR2)

\begin{tabular}{|c|c|c|c|c|c|c|}
\hline Mistura & $\begin{array}{c}\text { No de } \\
\text { Amostras }\end{array}$ & $\begin{array}{c}\text { Tempo } \\
\text { de Cura } \\
\text { (dias) }\end{array}$ & $\begin{array}{c}\text { Massa } \\
\text { Específica } \\
\left(\mathrm{kg} / \mathrm{m}^{3}\right)\end{array}$ & $\begin{array}{c}\text { Tensão de } \\
\text { Ruptura } \\
\text { Média } \\
(\mathrm{MPa})\end{array}$ & $\begin{array}{c}\text { Desvio } \\
\text { Padrão } \\
(\mathrm{MPa})\end{array}$ & $\begin{array}{c}\mathrm{CV} \\
(\%)\end{array}$ \\
\hline CCR1 & 3 & 7 & $2.425,29$ & 1,15 & 0,07 & 4,7 \\
\hline CCR1 & 6 & 35 & $2.416,60$ & 2,45 & 0,08 & 3,4 \\
\hline CCR2 & 3 & 7 & $2.400,74$ & 1,19 & 0,04 & 3,7 \\
\hline CCR2 & 6 & 35 & $2.347,39$ & 2,06 & 0,05 & 2,6 \\
\hline
\end{tabular}

Tabela 17 - Valores de resistência à tração indireta dos CCR com RAP

\begin{tabular}{|c|c|c|c|c|c|c|}
\hline Mistura & $\begin{array}{c}\text { No de } \\
\text { Amostras }\end{array}$ & $\begin{array}{c}\text { Tempo } \\
\text { de Cura } \\
\text { (dias) }\end{array}$ & $\begin{array}{c}\text { Massa } \\
\text { Específica } \\
\left(\mathrm{kg} / \mathrm{m}^{3}\right)\end{array}$ & $\begin{array}{c}\text { Tensão de } \\
\text { Ruptura } \\
\text { Média } \\
\text { (MPa) }\end{array}$ & $\begin{array}{c}\text { Desvio } \\
\text { Padrão } \\
\text { (MPa) }\end{array}$ & $\begin{array}{c}\mathrm{CV} \\
(\%)\end{array}$ \\
\hline CCR1-AF & 6 & 35 & $2.248,30$ & 0,96 & 0,04 & 4,1 \\
\hline CCR1-PF & 6 & 35 & $2.310,23$ & 1,64 & 0,10 & 6,1 \\
\hline CCR1-BF & 6 & 35 & $2.302,25$ & 1,48 & 0,09 & 6,6 \\
\hline CCR1-FT & 6 & 35 & $2.285,22$ & 1,21 & 0,07 & 6,3 \\
\hline
\end{tabular}




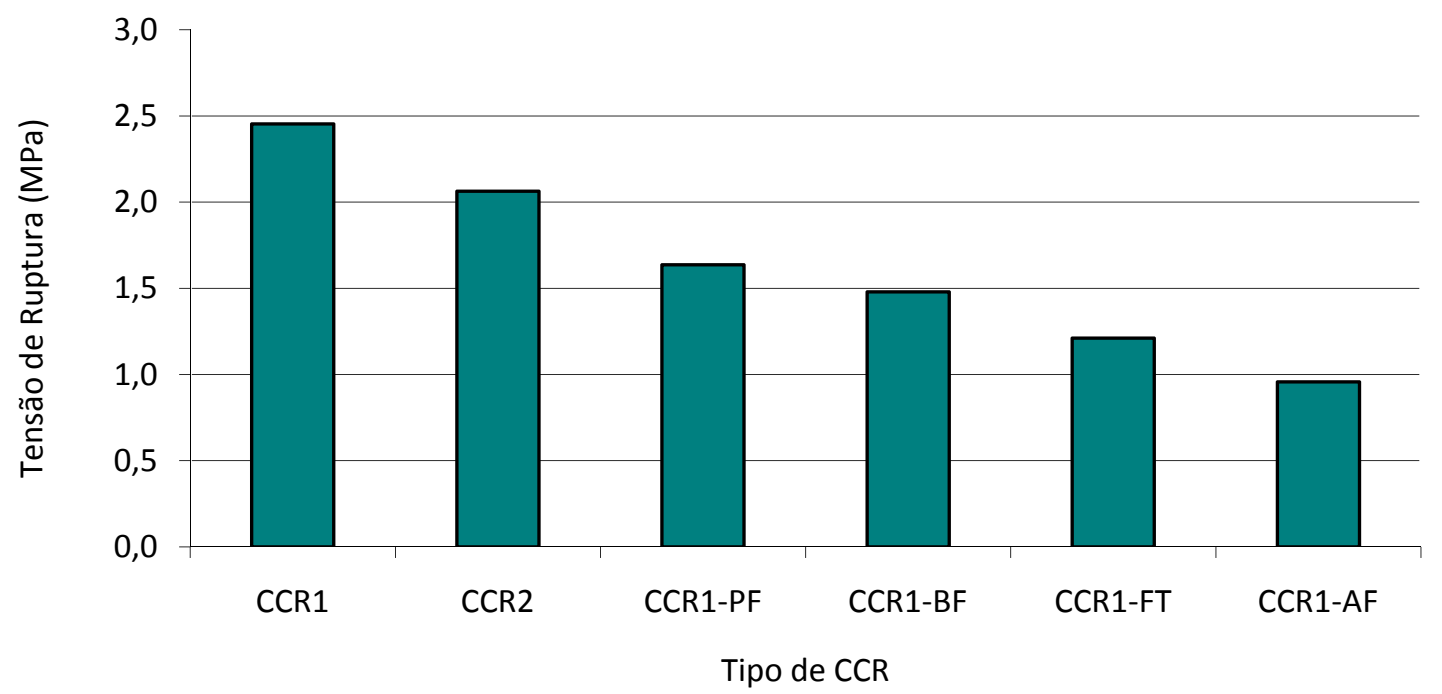

Figura 66 - Tensão de ruptura das misturas de CRR (cilíndricos)

Com base nos resultados apresentados nas Tabelas 16 e 17 e na Figura 65 pode-se afirmar que as misturas contendo RAP apresentaram redução nos valores de resistência à tração indireta em relação ao CCR1. Na Tabela 18 também fica clara a queda nos módulos de elasticidade.

Tabela 18 - Valores de Módulo de elasticidade dos CCR estudados

\begin{tabular}{|c|c|c|c|c|c|}
\hline Mistura & $\begin{array}{c}\text { No de } \\
\text { Amostras }\end{array}$ & $\begin{array}{c}\text { Tempo } \\
\text { de Cura } \\
\text { (dias) }\end{array}$ & $\begin{array}{c}\text { Módulo de } \\
\text { Elasticidade } \\
\text { (MPa) }\end{array}$ & $\begin{array}{c}\text { Desvio } \\
\text { Padrão } \\
\text { (MPa) }\end{array}$ & $\begin{array}{c}\text { CV } \\
\text { (\%) }\end{array}$ \\
\hline CCR1 & 6 & 35 & 30.403 & 6.176 & 20,3 \\
\hline CCR2 & 6 & 35 & 19.029 & 6.285 & 33,0 \\
\hline CCR1-AF & 3 & 35 & 15.037 & 2,743 & 26,0 \\
\hline CCR1-PF & 2 & 35 & 7.685 & 1.569 & 20,4 \\
\hline CCR1-BF & 3 & 35 & 18.920 & 2.351 & 12,4 \\
\hline CCR1-FT & 6 & 35 & 7.038 & 1.570 & 22,3 \\
\hline \multicolumn{7}{r}{${ }^{1}$ pela curva tensão-deformação } \\
\end{tabular}

Essa queda de resistência pode ser atribuída à presença do ligante asfáltico no RAP e pelo fato deste material possuir muitos grumos, que são formados pelo material asfáltico e a porção fina do RAP, o que gera certa heterogeneidade da mistura em consequência da granulometria do fresado. Além disso, o filme asfáltico presente nos grãos de RAP provavelmente desfavoreceu o estabelecimento de ligações de cristais 
de hidratação do cimento com os mesmos, causando redução na resistência à tração, já que é bastante dependente da zona de transição.

Paulon e Monteiro (1991) partem do princípio que "no concreto de cimento Portland, a pasta de cimento forma uma auréola em torno do agregado, onde a cristalização dos hidratados é diferente da existente na mesma pasta, fora dessa zona de transição. Essa auréola ou zona de transição é um local com características mais fracas do concreto". Segundo os autores, a zona de transição é uma zona com relação água/cimento mais elevada e de menos coesão, na qual as fissuras se propagam com maior facilidade. Nos concretos secos, em que a quantidade de pasta não é suficiente para cobrir todos os agregados de forma homogênea e completa, é dúbio o fato de que a auréola exista ou não, mas constata-se a fragilidade da zona de transição entre agregado e pasta de cimento, conforme pode ser obervado nas observações microscópicas.

Um dado interessante observado durante a realização dos ensaios de tração indireta foi o comportamento das amostras de CCR. Os CCR1 e CCR2 tiveram fraturas do tipo abruptas com separação do cilindro. As amostras com adição de RAP tiveram as fraturas mais sutis, ou seja, os cilindros não se separaram e continuaram sustentando alguma carga após a fratura inicial (Figura 67). Esse comportamento durante a ruptura pode ser atribuído ao fato de que o agregado fresado é um agregado fraturado, pela natureza da sua extração no campo. Portanto, a ruptura provavelmente se dá no agregado fraturado e não na argamassa.
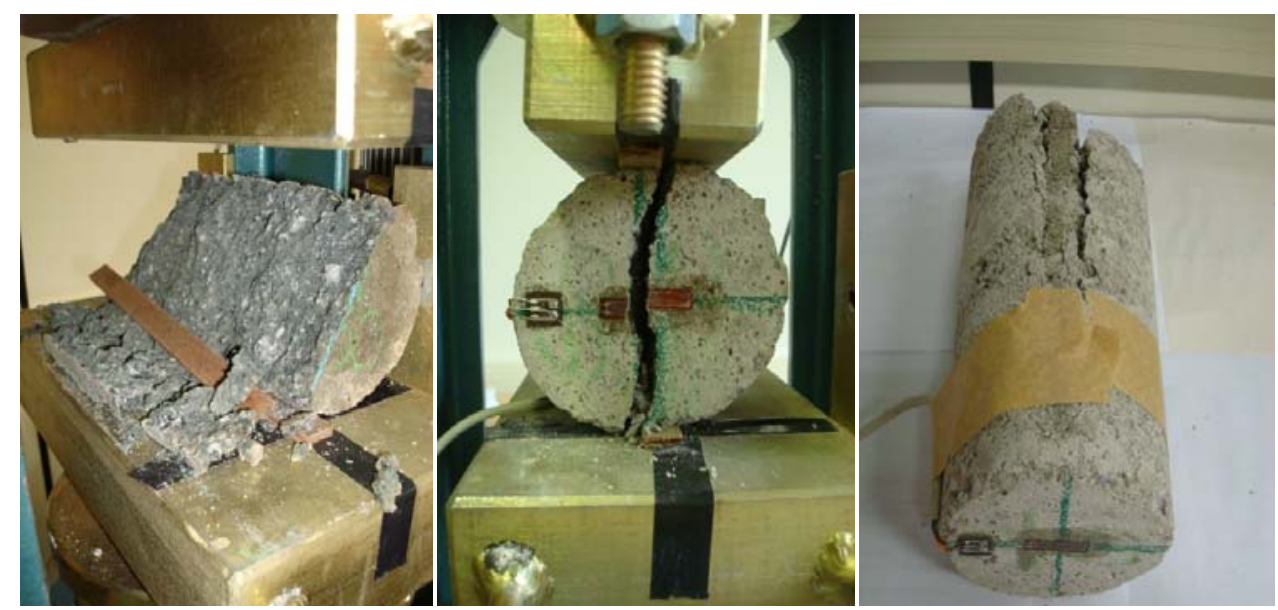

Figura 67 - Ensaio de compressão diametral do CCR1 (foto à esquerda - ruptura abrupta) e CCR com fresado (foto central e a direita - ruptura sem separação abrupta) 
Com base nas análises estatísticas realizadas (Anexo A) fica clara a diferença entre todas as misturas de CCR estudadas, ou seja, as amostras não pertencem ao mesmo universo, quando comparados seus valores de tensão de ruptura, a níveis de significância de $1 \%, 5 \%$ e $10 \%$. Considerando o pequeno número de amostras analisadas, esses valores podem incorrer em erros. De qualquer forma a análise estatística auxilia de forma que as comparações não sejam feitas apenas pelo desvio padrão e pelo coeficiente da variação das amostras.

Na Figura 68 estão apresentados graficamente os valores de módulo estimados por meio da curva tensão x deformação (strain gage).

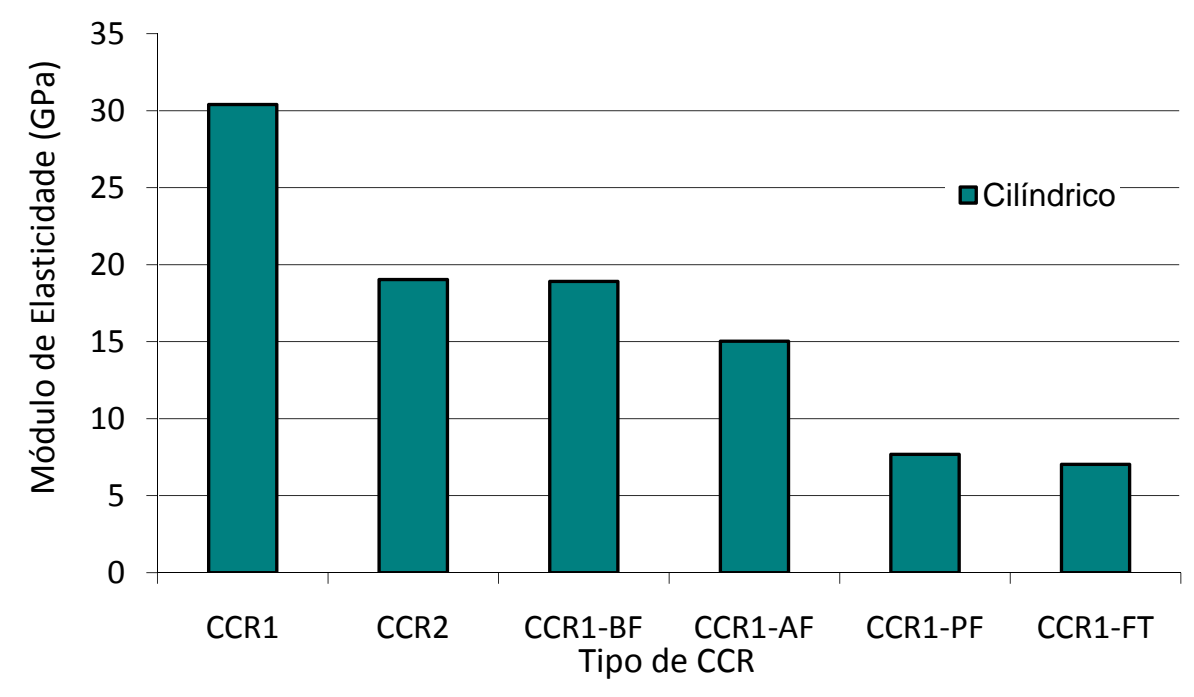

Figura 68 - Módulo de elasticidade para os diferentes tipos de CCR por meio da curva tensão x deformação (strain gage)

Para os valores de módulos de elasticidade estimados, as análises estatísticas não rejeitaram a hipótese de que o CRR1 é igual ao CCR2 e ao CCR1-AF a níveis de significância de 1\%, 5\% e 10\%. O CCR1-AF não foi rejeitado na análise quando comparado com o CCR1-BF e CCR1-PF. A níveis de significância de $1 \%$ e 5\%, as amostras CCR1-BF e CCR1-PF podem ser considerados estatisticamente equivalententes, assim como, CCR1-PF e CCR1-FT. Considerando os resultados pode-se dizer que a amostra que mais se dispersa do grupo é a CCR1-FT (ver Anexo A).

Na Figura 69, pode ser verificada a presença do RAP (agregados mais escuros), na superfície dos corpos de prova de cada mistura, em suas diferentes granulometrias. 
As imagens foram obtidas a partir das faces de fratura após os ensaios de compressão diametral.
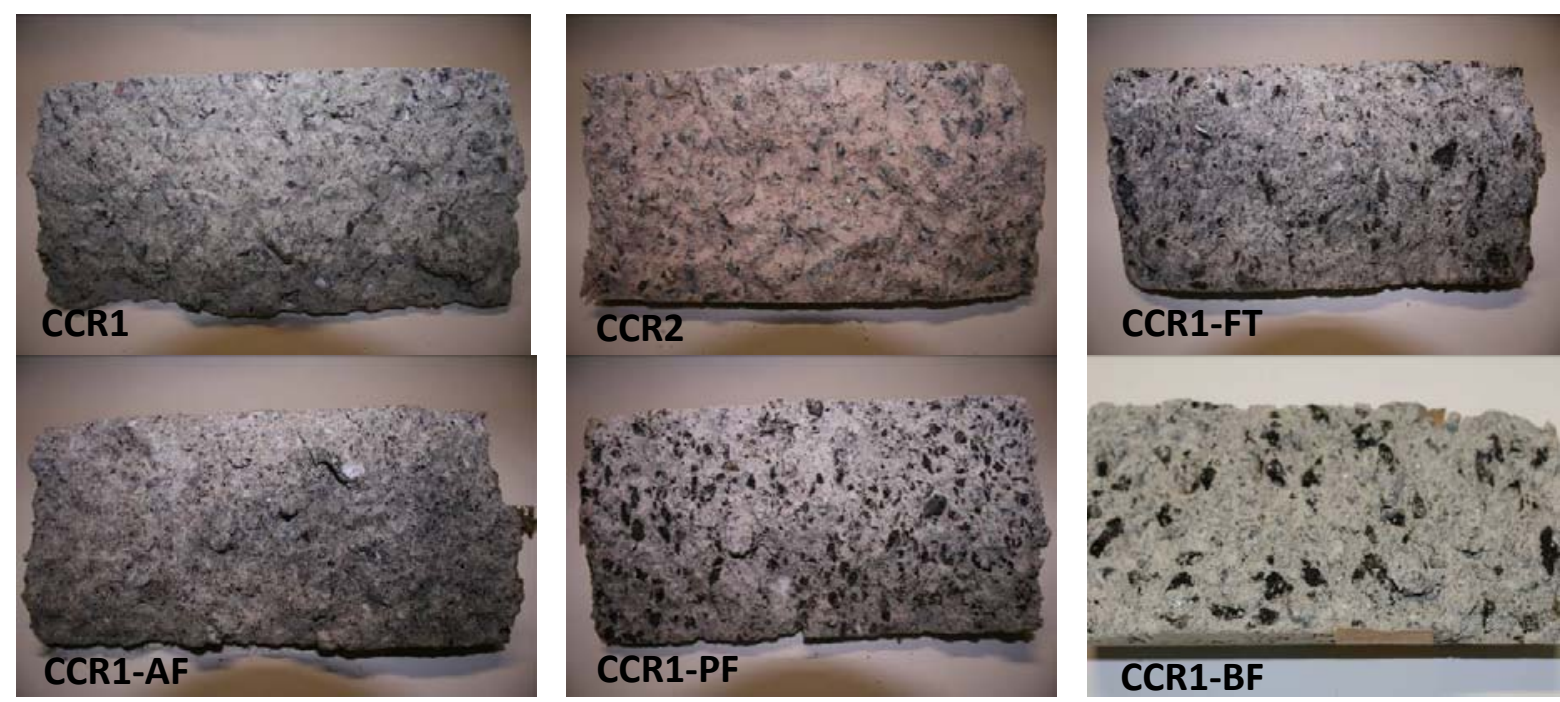

Figura 69 - Faces das misturas de CCR

\subsection{ENSAIO DE TRAÇÃO NA FLEXÃO}

Os ensaios de tração na flexão foram realizados em corpos de prova prismáticos, sendo em 3 amostras aos 7 dias e 6 amostras aos 35 dias de cura para as misturas com 90, 110 e $130 \mathrm{~kg} / \mathrm{m}^{3}$ (Figuras 70 e 71). O CCR1 e o CCR2 foram ensaiados também com estes dois períodos de cura ( 7 e 35 dias), já os CCR contendo fresado foram ensaiados aos 35 dias.

Pode-se observar nos gráficos abaixo que, conforme aumenta o consumo de cimento e o tempo de cura, também aumentam as tensões de ruptura para os ensaios de tração na flexão. O maior aumento foi observado na mistura com consumo de cimento $110 \mathrm{~kg} / \mathrm{m}^{3}$, que aumentou em torno de $46 \%$, quando comparado com o tempo de cura de 7 para 35 dias. 


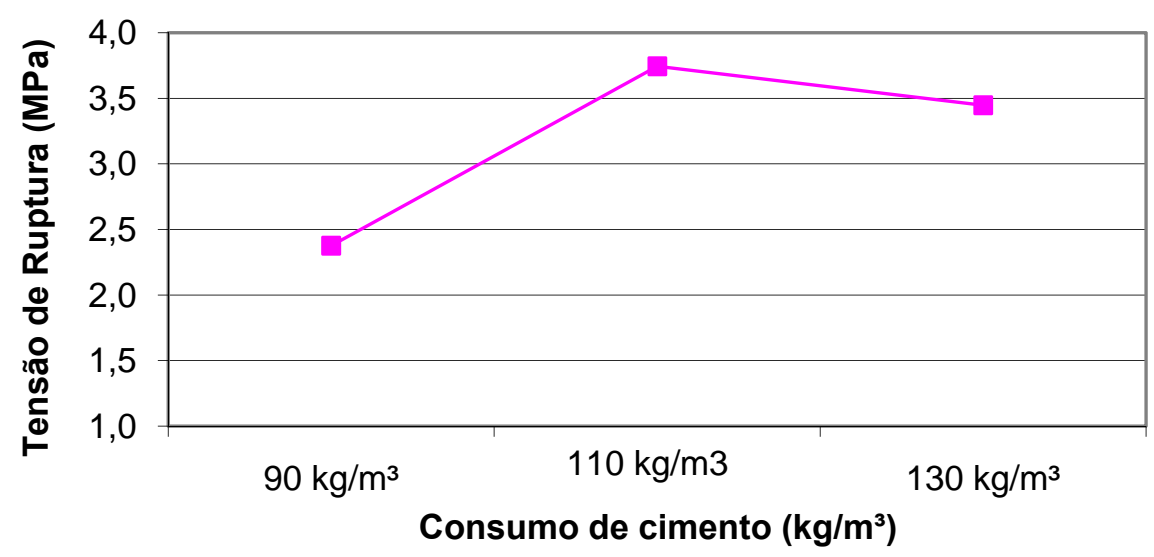

Figura 70 - Ganho de resistência para tempo de cura de 7 dias dos CCR com de dosagem com areia industrial, 90, 110 e $130 \mathrm{~kg} / \mathrm{m}^{3}$ de cimento (prismáticos)

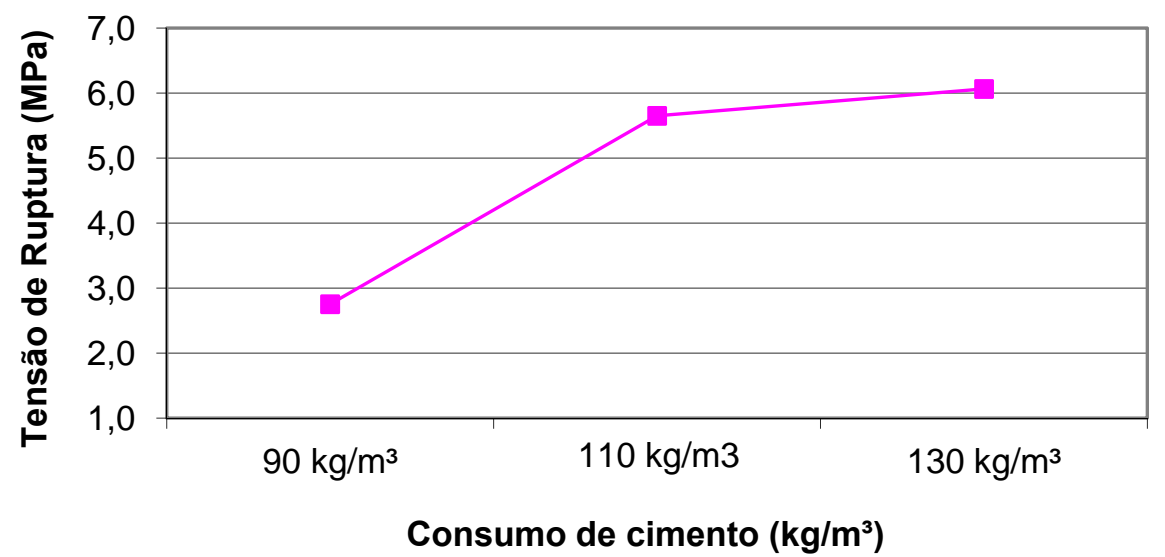

Figura 71 - Ganho de resistência para tempo de cura de 35 dias dos CCR com de dosagem com areia industrial, 90,110 e $130 \mathrm{~kg} / \mathrm{m}^{3}$ de cimento (prismáticos)

Nas Tabelas 19 e 20 estão apresentados os resultados dos ensaios para os CCR1, CCR2 e para os CCR com RAP com consumo de cimento de $100 \mathrm{~kg} / \mathrm{m}^{3}$.

Tabela 19 - Valores de resistência à tração na flexão dos CCR com areia industrial (CCR1) e areia natural (CCR2)

\begin{tabular}{|c|c|c|c|c|c|c|}
\hline Mistura & $\begin{array}{c}\text { No de } \\
\text { Amostras }\end{array}$ & $\begin{array}{c}\text { Tempo } \\
\text { de Cura } \\
\text { (dias) }\end{array}$ & $\begin{array}{c}\text { Massa } \\
\text { Específica } \\
\left(\mathrm{kg} / \mathrm{m}^{3} \text { ) }\right.\end{array}$ & $\begin{array}{c}\text { Tensão de } \\
\text { Ruptura } \\
\text { Média } \\
\text { (MPa) }\end{array}$ & $\begin{array}{c}\text { Desvio } \\
\text { Padrão } \\
\text { (MPa) }\end{array}$ & $\begin{array}{c}\text { CV } \\
\text { (\%) }\end{array}$ \\
\hline CCR1 & 3 & 7 & $2.446,05$ & 2,31 & 0,04 & 1,7 \\
\hline CCR1 & 6 & 35 & $2.320,56$ & 4,23 & 0,32 & 8,7 \\
\hline CCR2 & 3 & 7 & $2.347,17$ & 2,18 & 0,02 & 1,1 \\
\hline CCR2 & 6 & 35 & $2.291,80$ & 3,91 & 0,24 & 6,2 \\
\hline
\end{tabular}


Tabela 20 - Valores de resistência à tração na flexão dos CCR com RAP

\begin{tabular}{|c|c|c|c|c|c|c|}
\hline Mistura & $\begin{array}{c}\text { No de } \\
\text { Amostras }\end{array}$ & $\begin{array}{c}\text { Tempo } \\
\text { de Cura } \\
\text { (dias) }\end{array}$ & $\begin{array}{c}\text { Massa } \\
\text { Específica } \\
\left(\mathrm{kg} / \mathrm{m}^{3}\right)\end{array}$ & $\begin{array}{c}\text { Tensão de } \\
\text { Ruptura } \\
\text { Média } \\
\text { (MPa) }\end{array}$ & $\begin{array}{c}\text { Desvio } \\
\text { Padrão } \\
\text { (MPa) }\end{array}$ & $\begin{array}{c}\mathrm{CV} \\
(\%)\end{array}$ \\
\hline CCR1-AF & 6 & 35 & $2.269,48$ & 3,78 & 0,10 & 2,9 \\
\hline CCR1-PF & 6 & 35 & $2.296,45$ & 3,80 & 0,32 & 8,9 \\
\hline CCR1-BF & 6 & 35 & $2.299,62$ & 2,37 & 0,31 & 11,6 \\
\hline CCR1-FT & 6 & 35 & $2.164,40$ & 2,55 & 0,21 & 8,6 \\
\hline
\end{tabular}

Pelas análises estatísticas realizadas nas amostras, em relação à tensão de ruptura, o CCR1 e CCR1-PF são iguais, ou seja, pertencem ao mesmo universo, tendo valores próximos de tensão de ruptura. O CCR1-AF é igual ao CCR1-PF, para níveis de significância de 1\%, 5\% e 10\%. Os valores de tensão de ruptura das misturas CCR1-AF e CCR1-PF foram os que apresentaram menores quedas de resistência, de 10,6 e 10,2\%, respectivamente.

O CCR1-BF é igual ao CCR1-FT, para níveis de significância de 1\% e 5\%, sendo que o CCR1-BF foi a mistura que apresentou a maior diminuição na tensão de ruptura (44,0\%), seguido do CCR1-FT com $39,7 \%$ de queda. Fato que pode ser explicado pela quantidade de grumos presentes nas duas misturas, o que também resulta em misturas com módulos de elasticidade menores.

Os grumos representam boa parte dos agregados graúdos, a união de grãos grossos e finos com ligante asfáltico enfraquece o agregado que tem papel fundamental no suporte das cargas. Esta fração estando enfraquecida leva a quedas nas resistências e módulos de elasticidade. Esse fato se intensifica no CCR1-FT, no qual se utiliza a faixa total de agregados fresados, pois contempla os grumos tanto dos materiais finos como dos materiais grossos. O aumento na quantidade de agregados de baixo módulo na mistura é também um fator importante que interfere na resistência e módulos de elasticidade das misturas. Na Figura 72 estão apresentadas as tensões de ruptura de todas as misturas de CCR (prismáticos).

Observa-se através dos resultados obtidos que as misturas CCR1-PF e CCR1-AF, foram as que menos sofreram influência nos resultados de resistência devido à presença do ligante asfáltico, em relação à mistura de referência (CCR1). 


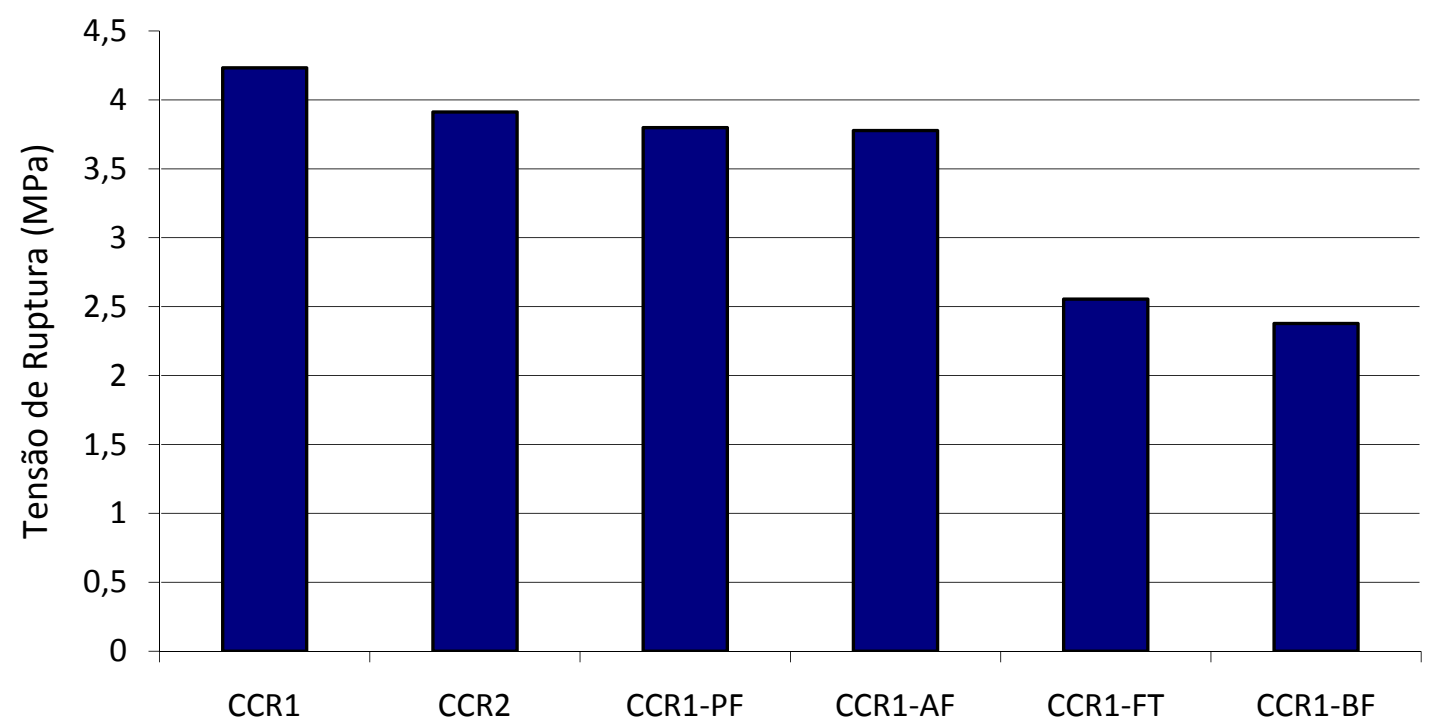

Tipo de CCR

Figura 72 - Tensão de ruptura das misturas de CRR (prismáticos)

Os resultados de módulo de elasticidade determinados nos CCR estudados estão apresentados na Tabela 21.

Tabela 21 - Valores de Módulo de elasticidade com medida da flecha e pela curva tensão-deformação dos CCR estudados

\begin{tabular}{|c|c|c|c|c|c|c|c|c|}
\hline Mistura & $\begin{array}{c}\text { № de } \\
\text { Amostras }\end{array}$ & $\begin{array}{l}\text { Tempo } \\
\text { de } \\
\text { Cura } \\
\text { (dias) }\end{array}$ & $\begin{array}{l}\text { Módulo de } \\
\text { Elasticidade } \\
\text { (MPa) }\end{array}$ & $\begin{array}{l}\text { Desvio } \\
\text { Padrão } \\
\text { (MPa) }\end{array}$ & $\begin{array}{l}C V \\
\text { (\%) }\end{array}$ & $\begin{array}{l}\text { Módulo de } \\
\text { Elasticidade } \\
\text { (MPa) }\end{array}$ & $\begin{array}{c}\text { Desvio } \\
\text { Padrão } \\
\text { (MPa) }\end{array}$ & $\begin{array}{l}\text { CV } \\
\text { (\%) }\end{array}$ \\
\hline CCR1 & 6 & 35 & 24.313 & 3.494 & 14,4 & 28.632 & 4.373 & 15,3 \\
\hline CCR2 & 6 & 35 & 27.540 & 6.126 & 22,2 & 31.357 & 5.779 & 18,4 \\
\hline CCR1-AF & 6 & 35 & 13.394 & 3.216 & 24,0 & 17.888 & 5.594 & 31,3 \\
\hline CCR1-PF & 5 & 35 & 12.132 & 1.186 & 17,1 & 18.725 & 1.630 & 12,4 \\
\hline CCR1-BF & 5 & 35 & 10.416 & 922 & 8,9 & 13.925 & 2.402 & 21,3 \\
\hline CCR1-FT & 6 & 35 & 7.972 & 1.453 & 18,2 & 13.017 & 3.426 & 26,3 \\
\hline
\end{tabular}

Em relação aos módulos de elasticidade, as análises estatísticas mostraram que tanto para aqueles obtidos pela curva tensão $x$ deformação como aqueles obtidos pela medida da flecha, o CCR1 pode ser considerado estatisticamente equivalente ao CCR2 considerando os níveis de significância de 1\%, $5 \%$ e 10\%, fato expresso pela proximidade dos valores obtidos. As misturas CCR1-AF e CCR1-PF não foram rejeitados 
pela análise, concluindo assim que pertencem ao mesmo universo. Isso igualmente ocorre para as misturas CCR1-FT e CCR1-BF quando o módulo de elasticidade em questão é aquele obtido pela curva tensão x deformação (ver Anexo B).

Os módulos de deformação nos corpos de prova prismáticos, determinados por meio da curva tensão $x$ deformação e pela Analogia de Möhr (medida de flecha) estão apresentados graficamente na Figura 73. Pode-se observar que os módulos obtidos a partir da flecha (LVDT) são menores que aqueles obtidos pela curva tensão $x$ deformação.

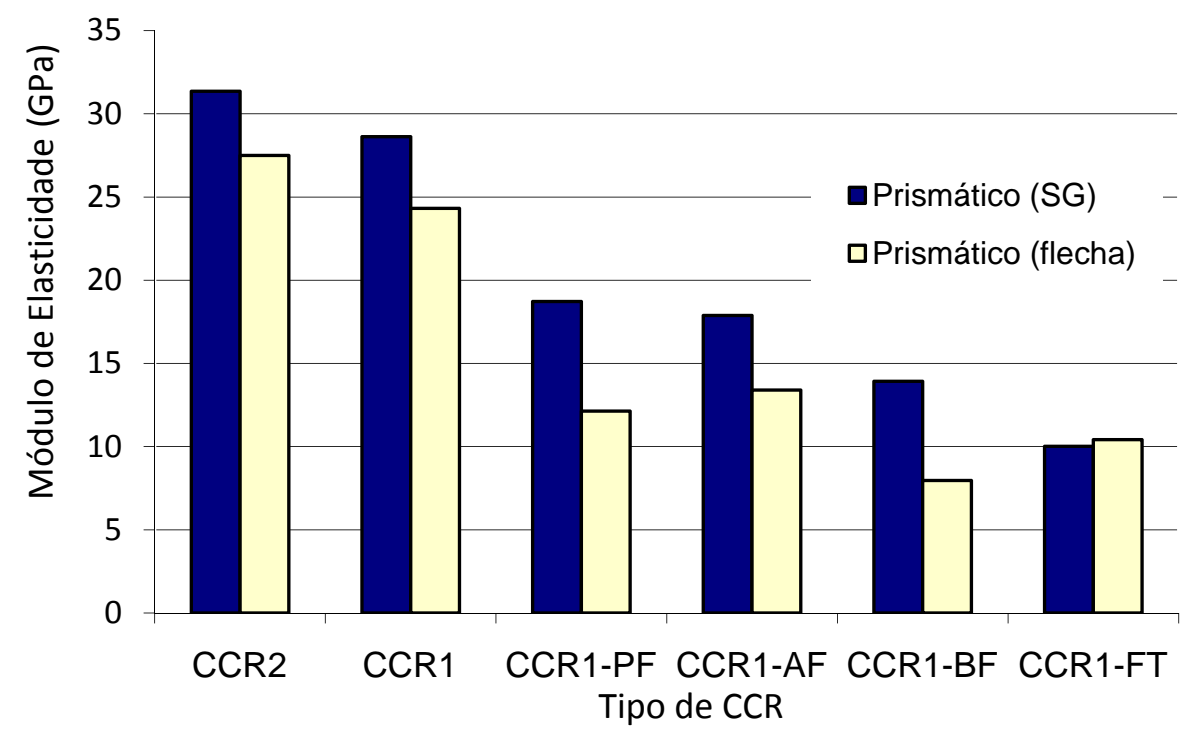

Figura 73 - Módulos de elasticidade dos corpos-de-prova prismáticos: (1) curva tensão x deformação (strain gage) e; (2) Por Analogia de Möhr (flecha)

Baseados nos resultados obtidos pode-se afirmar que, das misturas confeccionadas com RAP, o CCR1-PF foi o que apresentou as maiores resistências à tração indireta e à tração na flexão, ou seja, foi a mistura que teve as menores quedas nos valores de ruptura.

Os resultados do CCR1-FT foram os menos favoráveis, pois combinam baixos valores de módulo de elasticidade com baixa resistência à tração, tendo quedas de $50 \%$ para os corpos de prova cilíndricos. Nos corpos de prova prismáticos, a mistura 
que apresentou o pior desempenho nos valores de módulo de elasticidade, foi o CCR1BF, seguida pela mistura CCR1-FT com quedas de $44 \%$ e $39,7 \%$, respectivamente.

De forma geral, a queda nos valores de resistência à tração indireta e à tração na flexão para as amostras com RAP, segundo Huang et al. podem ser atribuídas à presença do ligante asfáltico que pode gerar uma concentração de tensões causando microfissura dentro da matriz do concreto. Conforme Al-qadi et al. (2007), a estrutura do ligante asfáltico começa a mudar suas cadeias e formar uma estrutura maior que é proporcionada também pelo aumento do peso molecular com a oxidação dos asfaltos.

\subsection{ENSAIO POR PULSO DE ONDA ULTRASSÔNICA}

Antes de serem ensaiados à compressão diametral e à tração na flexão, os corpos de prova de CCR eram submetidos ao ensaio de pulso ultrassônico. $O$ ensaio permitiu a determinação do módulo de elasticidade dinâmico de todas as misturas de CCR com 90, 110 e $130 \mathrm{~kg} / \mathrm{m}^{3}$, CCR1, CCR2 e dos CCR com RAP.

Todos os corpos de prova tinham suas dimensões confirmadas por meio de três medidas de suas dimensões e eram pesados logo que retirados da câmara úmida. Posteriormente, eram feitas as leituras, determinação dos pesos específicos de cada amostra e calculados os módulos dinâmicos. Na Figura 74 está apresentado um exemplo da tabela de controle dos corpos de prova antes e após os ensaios de ultrassom.

\begin{tabular}{|c|c|c|c|c|c|c|c|c|c|c|c|c|c|c|c|c|c|c|c|}
\hline \multicolumn{20}{|c|}{ Corpos de Prova de CCR com $50 \%$ de Fresado na Fração Total } \\
\hline \multirow{2}{*}{$\begin{array}{l}\mathrm{CP} \\
\left(\mathrm{n}^{\circ}\right) \\
\end{array}$} & \multirow{2}{*}{ Tipo } & \multirow{2}{*}{\begin{tabular}{|l|} 
Idade \\
(dias)
\end{tabular}} & \multicolumn{9}{|c|}{ Dimensões $(\mathrm{cm})$} & \multirow{2}{*}{\begin{tabular}{|c|}
$\begin{array}{c}\text { Peso } \\
(\mathrm{g})\end{array}$ \\
\end{tabular}} & \multirow{2}{*}{\begin{tabular}{|c|} 
Leitura \\
$(\mu \mathrm{s})$ \\
\end{tabular}} & \multirow{2}{*}{\begin{tabular}{|c|} 
Peso Esp. \\
$\left(\mathrm{kg} / \mathrm{m}^{3}\right)$
\end{tabular}} & \multirow{2}{*}{\begin{tabular}{|r|} 
Vel. Ondas \\
$(\mathrm{mm} / \mathrm{ms})$
\end{tabular}} & \multirow{2}{*}{\begin{tabular}{|l|}
$\mathrm{ME}$ din. \\
$\left(\mathrm{MN} / \mathrm{m}^{2}\right)$
\end{tabular}} & \multirow{2}{*}{$\begin{array}{l}\text { Carga } \\
\text { (t) }\end{array}$} & \multirow{2}{*}{$\begin{array}{c}\text { Tensão } \\
\text { (Mpa) }\end{array}$} & \multirow{2}{*}{$\begin{array}{l}\text { Vel. Rupt. } \\
\text { (Mpa/s) }\end{array}$} \\
\hline & & & H1 & $\mathrm{H} 2$ & $\mathrm{H} 3$ & $\varnothing 1$ & \begin{tabular}{|c|}
$\varnothing 2$ \\
\end{tabular} & \begin{tabular}{|c|}
03 \\
\end{tabular} & $\mathrm{~L} 1$ & $\mathrm{~L} 2$ & L3 & & & & & & & & \\
\hline 1 & $C$ & \begin{tabular}{|l|}
35 \\
\end{tabular} & 20,05 & 20,10 & 20,12 & 9,92 & 10,04 & 9,96 & & & & 3583,30 & 54,40 & 2278,96 & 3,69 & 28.001 & 3,32 & 1,055 & 0,20000 \\
\hline 2 & C & 35 & 20,12 & 20,03 & 20,00 & 9,96 & 10,03 & 10,03 & & & & 3614,30 & 55,40 & 2290,61 & 3,62 & 26.949 & 3,56 & 1,130 & 0,25000 \\
\hline 3 & $\mathrm{C}$ & 35 & 20,10 & 20,05 & 20,15 & 10,01 & 10,00 & 9,96 & & & & 3620,40 & 56,20 & 2293,35 & 3,58 & 26.402 & 3,50 & 1,110 & 0,25000 \\
\hline 4 & $\mathrm{C}$ & 35 & 19,98 & 20,10 & 20,05 & 10,02 & 10,00 & 9,99 & & & & 3596,10 & 55,70 & 2283,63 & 3,60 & 26.631 & 3,66 & 1,162 & 0,27000 \\
\hline 5 & C & 35 & 20,10 & 20,05 & 20,15 & 10,00 & \begin{tabular}{|l|}
9,93 \\
\end{tabular} & 9,99 & & & & 3580,00 & 54,30 & 2270,02 & 3,70 & 27.994 & 3,59 & 1,140 & 0,21000 \\
\hline 6 & $\mathrm{C}$ & 35 & 20,00 & 20,15 & 20,05 & 10,01 & \begin{tabular}{|l|}
9,98 \\
\end{tabular} & 10,00 & & & & 3613,60 & 55,50 & 2294,75 & 3,61 & 26.954 & 3,86 & 1,225 & 0,29000 \\
\hline 1 & $\bar{P}$ & 35 & 10,58 & 10,54 & 10,45 & & & & 40,25 & 40,12 & 40,26 & 9351,0 & 118,80 & 2091,27 & 3,39 & 21.605 & 0,76 & 4,104 & 0,06800 \\
\hline 2 & $P$ & 35 & 10,29 & 10,34 & 10,00 & & & & 40,05 & 40,10 & 39,75 & \begin{tabular}{|l|}
9379,0 \\
\end{tabular} & 114,60 & 2211,68 & 3,49 & 24.311 & 0,69 & 3,727 & 0,13000 \\
\hline 3 & $P$ & 35 & 10,42 & \begin{tabular}{|l|l|}
10,47 \\
\end{tabular} & 10,21 & & & & 40,20 & 39,95 & 40,25 & \begin{tabular}{|c|}
9255,0 \\
\end{tabular} & 114,40 & 2120,39 & 3,51 & 23.564 & 0,69 & 3,727 & 0,04000 \\
\hline 4 & $P$ & 35 & 10,20 & 10,41 & 10,28 & & & & 40,12 & 40,15 & 40,00 & 9333,0 & 111,40 & 2201,27 & 3,60 & 25.696 & 0,66 & 3,564 & 0,07000 \\
\hline 5 & $\mathrm{P}$ & 35 & 10,46 & 10,38 & 10,24 & & & & 40,15 & 40,10 & 40,20 & 9345,0 & 114,40 & 2160,23 & 3,51 & 23.948 & 0,72 & 3,888 & 0,09000 \\
\hline 6 & $P$ & 35 & 10,14 & 10,24 & $\begin{array}{ll}10,31 \\
\end{array}$ & & & & 39,95 & 40,00 & 40,05 & \begin{tabular}{|l|}
9234,0 \\
\end{tabular} & 112,20 & 2201,56 & 3,57 & 25.183 & 0,71 & 3,834 & 0,07000 \\
\hline
\end{tabular}

Figura 74 - Dados para obtenção dos módulos de elasticidade dinâmicos dos corpos de prova cilíndricos (C) e prismáticos (P) 
Na Tabela 22 estão apresentados os resultados de módulos de elasticidade dinâmicos para todas as amostras. Na Figura 75 estão mostrados graficamente os valores de módulos dinâmicos para os corpos de prova cilíndricos e prismáticos. Os resultados dos módulos dinâmicos diferem daqueles encontrados pelos outros dois métodos, já que apresenta valores mais altos e muito próximos para os dois de tipos de corpos de prova. A mistura que obteve menor queda nos módulos dinâmicos foi a CCR1-BF, com diminuição de 3,8\% para os prismas e $12,4 \%$ para os cilindros, em relação ao CCR1. Os prismas, de forma geral, são os que apresentam as menores reduções de módulo dinâmico, em relação ao CCR1, assim como nos valores de módulo estático. As duas misturas que apresentam maior redução nos módulos de elasticidade dinâmicos são a CCR1-FT e CCR1-AF, mesmo comportamento encontrado nos valores de módulos de elasticidade obtidos para os cilindros.

Pelos resultados obtidos pode-se concluir que a compactação dos corpos de prova se deu de forma muito eficiente, pois os valores de velocidades de onda e dos módulos de elasticidade foram muito parecidos para todos os corpos de prova, constatando o controle de qualidade mantido em laboratório. O ultrassom é largamente utilizado para detecção de descontinuidades internas em vários tipos de materiais.

Tabela 22 - Valores de Módulo de elasticidade por meio de pulso ultrassônico dos CCR estudados

\begin{tabular}{|c|c|c|c|c|c|c|}
\hline Mistura & $\begin{array}{c}\text { No de } \\
\text { Amostras }\end{array}$ & $\begin{array}{c}\text { Tempo de } \\
\text { Cura (dias) }\end{array}$ & Tipo & $\begin{array}{c}\mathrm{E}_{\text {dinâmico }} \\
\left(\mathrm{MN} / \mathrm{m}^{2}\right)\end{array}$ & $\begin{array}{c}\text { Desvio Padrão } \\
(\mathrm{MPa})\end{array}$ & $\begin{array}{c}\mathrm{CV} \\
(\%)\end{array}$ \\
\hline CCR1 & 6 & 35 & $\mathrm{C}$ & 37.607 & 1.260 & 3,0 \\
\hline CCR1 & 6 & 35 & $\mathrm{P}$ & 37.285 & 1.237 & 5,0 \\
\hline CCR2 & 6 & 35 & $\mathrm{C}$ & 40.588 & 534 & 6,5 \\
\hline CCR2 & 6 & 35 & $\mathrm{P}$ & 37.407 & 2.536 & 9,9 \\
\hline CCR1-AF & 6 & 35 & $\mathrm{C}$ & 24.511 & 1.434 & 5,2 \\
\hline CCR1-AF & 6 & 35 & $\mathrm{P}$ & 27.046 & 767 & 3,1 \\
\hline CCR1-PF & 6 & 35 & $\mathrm{C}$ & 29.862 & 1.265 & 3,3 \\
\hline CCR1-PF & 6 & 35 & $\mathrm{P}$ & 30.441 & 1.618 & 6,6 \\
\hline CCR1-BF & 6 & 35 & $\mathrm{C}$ & 32.944 & 2.782 & 6,7 \\
\hline CCR1-BF & 6 & 35 & $\mathrm{P}$ & 35.887 & 1.591 & 3,0 \\
\hline CCR1-FT & 6 & 35 & $\mathrm{C}$ & 27.155 & 684 & 4,9 \\
\hline CCR1-FT & 6 & 35 & $\mathrm{P}$ & 24.051 & 1.434 & 3,6 \\
\hline
\end{tabular}


Comparando os módulos de elasticidade obtidos pelos três diferentes métodos (curva tensão x deformação, analogia de Möhr e ultrassom) na Figura 76, observa-se que os menores valores foram àqueles obtidos por meio do LVDT. O módulo dinâmico foi o que apresentou maiores valores, fato que também foi confirmado por Kolias (1996), que encontrou módulos dinâmicos maiores que os módulos estáticos em estudos realizados em concretos.

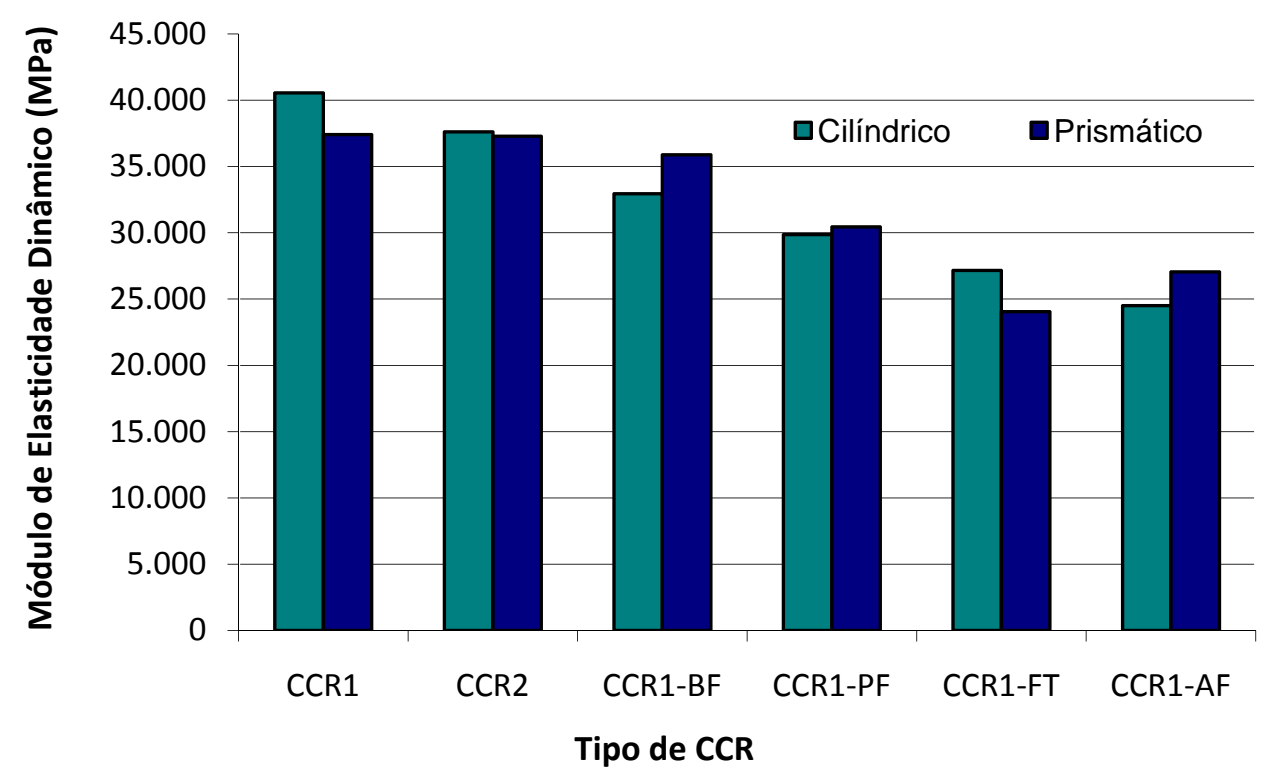

Figura 75 - Módulos de elasticidade dinâmicos dos corpos de prova cilíndricos e prismáticos

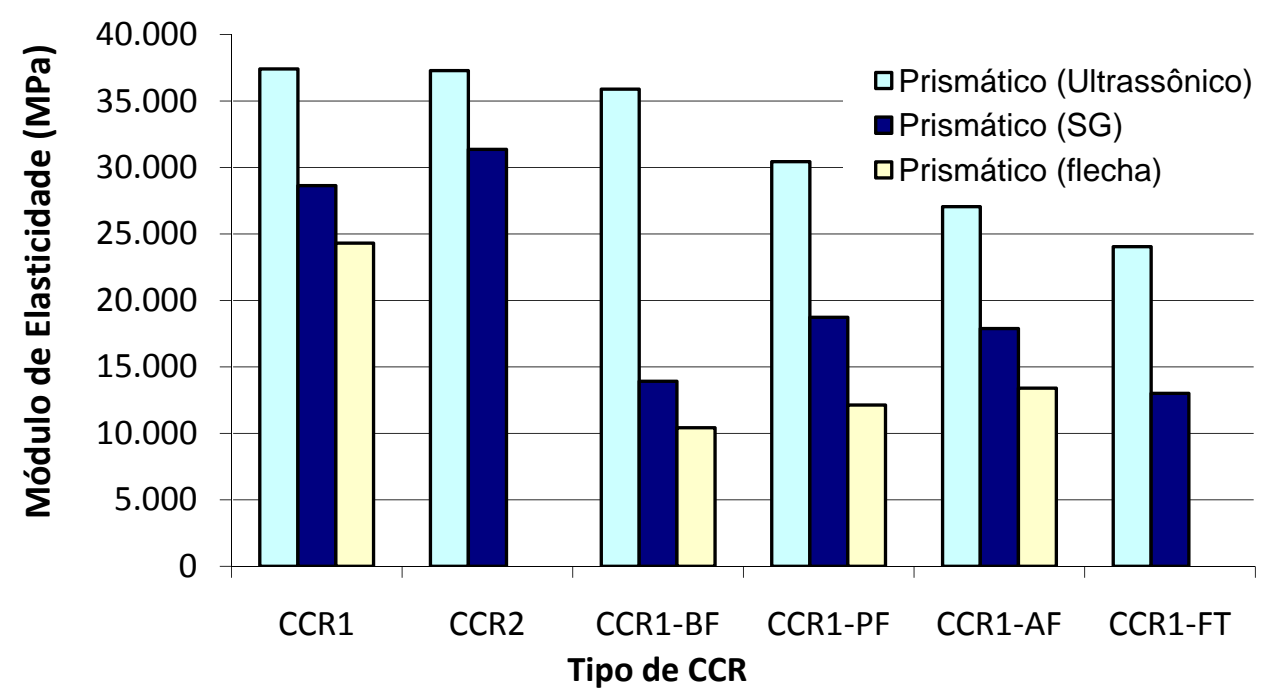

Figura 76 - Comparação dos módulos de elasticidade pela curva tensão x deformação (strain gage), pela analogia de Möhr (flecha) e por pulso ultrassônico, dos corpos-de-prova prismáticos 
Nos corpos de prova cilíndricos, a mistura que apresentou maior diferença de valores entre módulo dinâmico e estático foi a fração pedrisco (CCR1-PF), com uma queda em torno de quatro vezes para o modulo estático em relação ao dinâmico (Figura 77). Este comportamento pode ser justificado pela significativa incorporação de vazios nas misturas, aliada a exsudação ocorrida durante a sua compactação, principalmente nas misturas CCR1-AF e CCR1-PF.

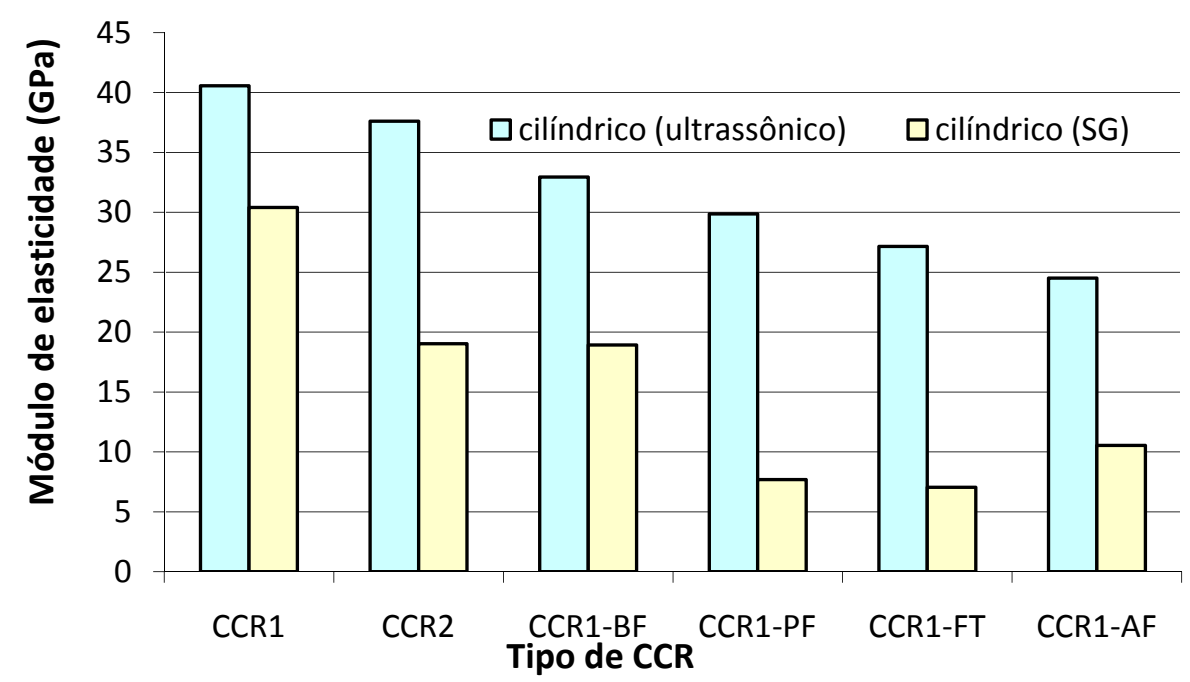

Figura 77 - Comparação dos módulos de elasticidade pela curva tensão x deformação (SG) e por pulso ultrassônico dos corpos-de-prova cilíndricos

Como o pulso ultrassônico detecta imperfeições na mistura, como trincas, vazios, entre outros, a determinação do módulo de elasticidade dinâmico se torna uma medida questionável e não confiável do ponto de vista da pavimentação. Os módulos de elasticidade desempenham papel muito importante para o dimensionamento de estruturas de pavimento.

Na Figura 78 fica claro que o aumento na tensão de ruptura tende a um acréscimo no valor do módulo de elasticidade. Na Figura 79 estão apresentados os módulos elásticos dinâmicos versus tensão de ruptura. Neste caso os cilíndricos apresentaram comportamento mais homogêneo em relação aos prismáticos, pois seguem uma tendência de aumento de módulo com aumento da tensão de ruptura. 


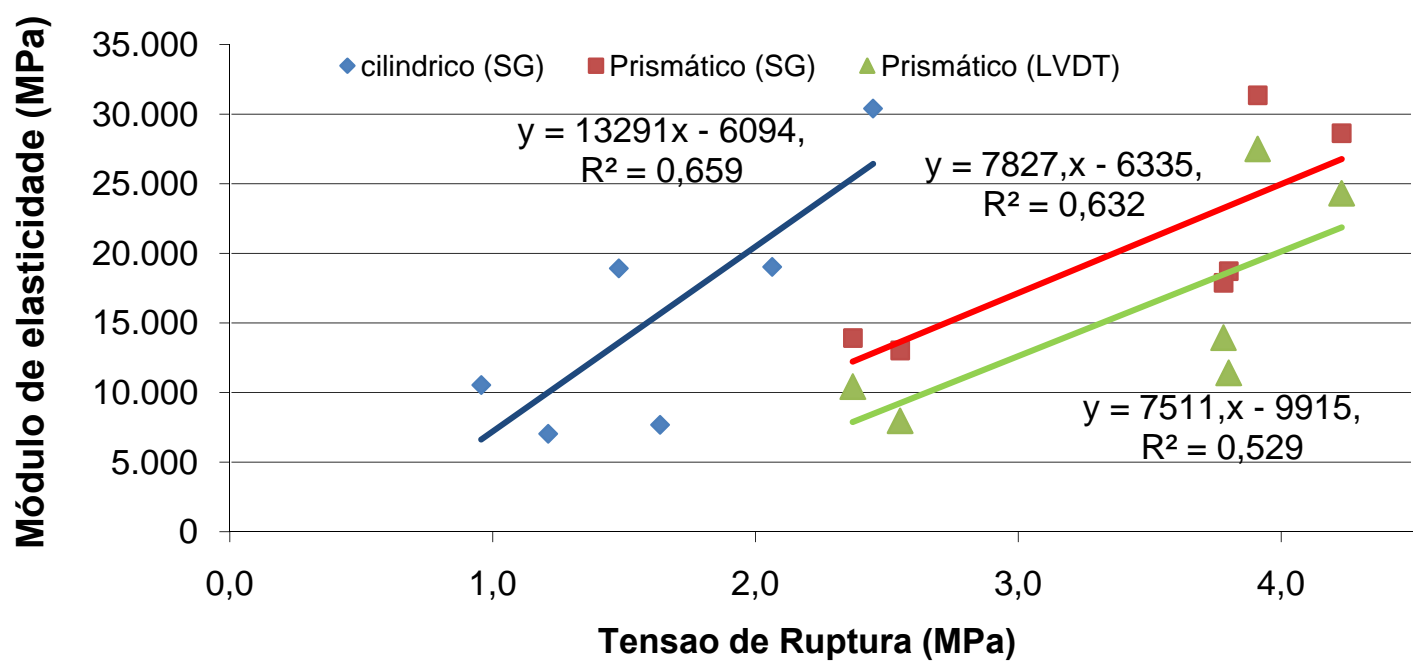

Figura 78 - Relação entre módulo de elasticidade e tensão de ruptura

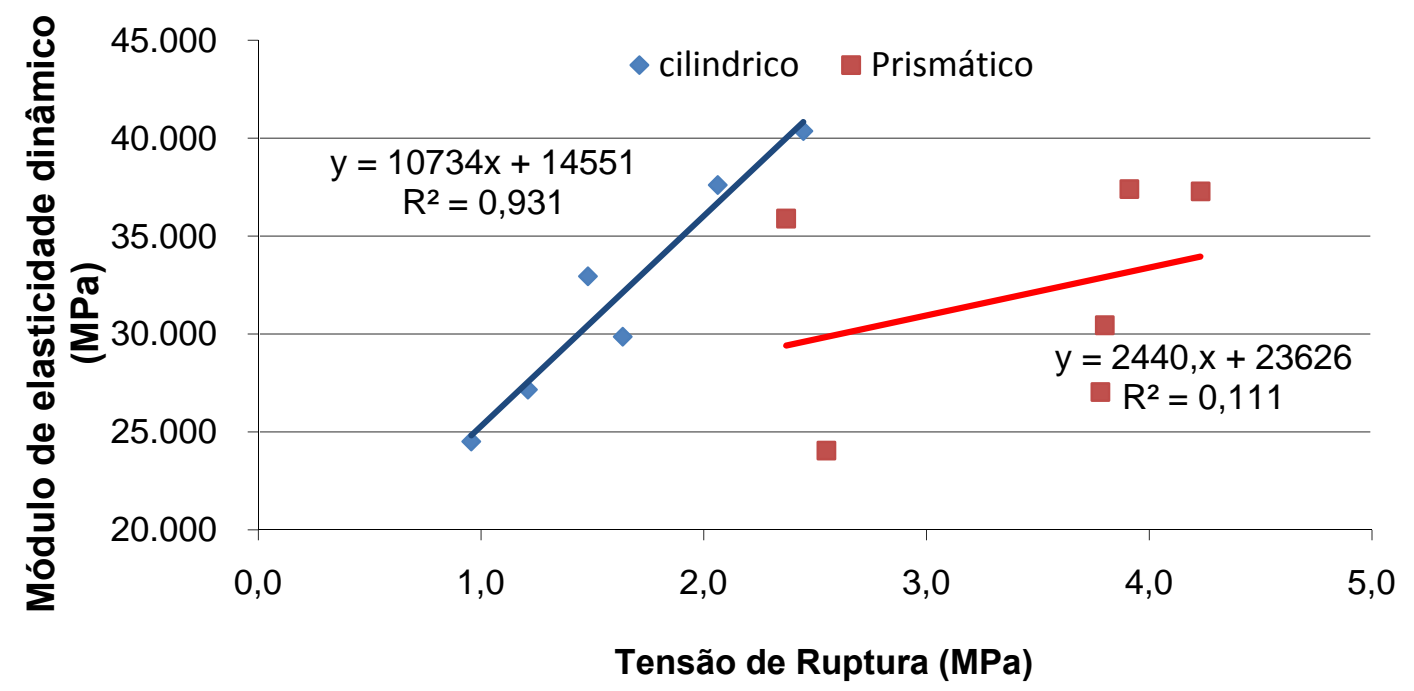

Figura 79 - Relação entre módulo de elasticidade dinâmico e tensão de ruptura

Na Figura 80 é visível a relação direta da velocidade de onda obtida em cada mistura com seu respectivo módulo de elasticidade dinâmico. Os módulos de elasticidade para os corpos de prova cilíndricos foram ligeiramente maiores que os módulos para os corpos de prova prismáticos. Portanto, isso leva a crer que a compacidade dos corpos de prova cilíndricos é maior devido à melhor distribuição dos 
golpes nesse tipo de molde. Pode-se também dizer que o número de defeitos, vazios e fissuras dentro do cilindro é menor que aqueles presentes no prisma.

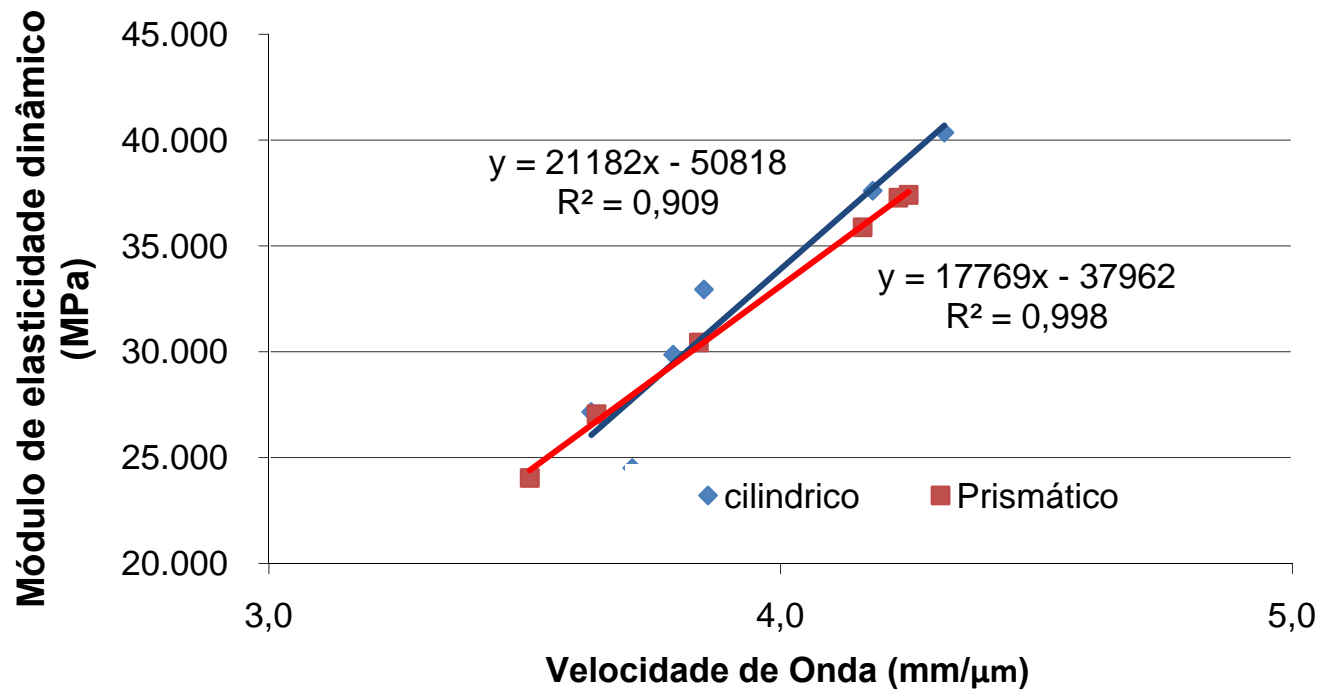

Figura 80 - Relação entre módulo de elasticidade dinâmico e velocidade de onda

De forma a elucidar os resultados de todos os ensaios mecânicos citados anteriormente, é apresentada, nas Figuras 81 a 84, uma compilação dos resultados obtidos. Como pode ser verificado na Figura 80, o comportamento da tensão de ruptura é semelhante para ambos os corpos de prova (cilíndricos e prismáticos). A diferença entre as tensões de ruptura dos corpos de prova cilíndricos atingem aproximadamente a metade das alcançadas nos prismas. As misturas CCR1-AF e CCR1FT apresentaram menores resistências nos cilindros e foram aquelas que obtiveram maiores umidades no ensaio de compactação. A mistura CCR1-AF revelou ser uma mistura muito porosa nos ensaios microscópicos. 


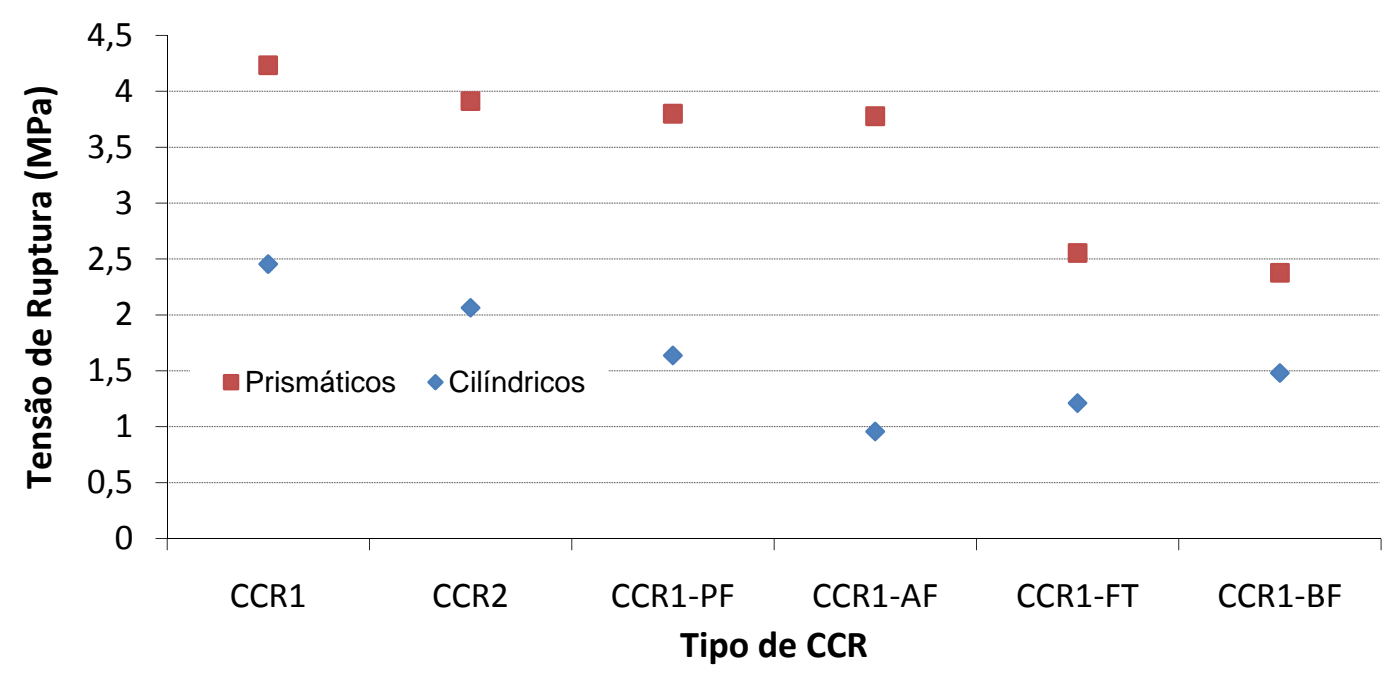

Figura 81 - Tensão de ruptura dos corpos de prova cilíndricos e prismáticos

Os resultados das massas específicas dos corpos de prova cilíndricos e prismáticos apresentaram valores muito próximos, confirmando a qualidade de compactação em ambos (Figura 82). Os valores de umidade ótima, como esperado, têm comportamento que acompanha os resultados das massas específicas, ou seja, maior umidade menor massa específica. As maiores massas específicas foram conferidas às misturas sem RAP, sendo que a mistura CCR1 foi a que apresentou o maior valor de massa especifica e menor valor de umidade. Os agregados fresados possuem menor massa específica, fato que reflete nas misturas com este material.

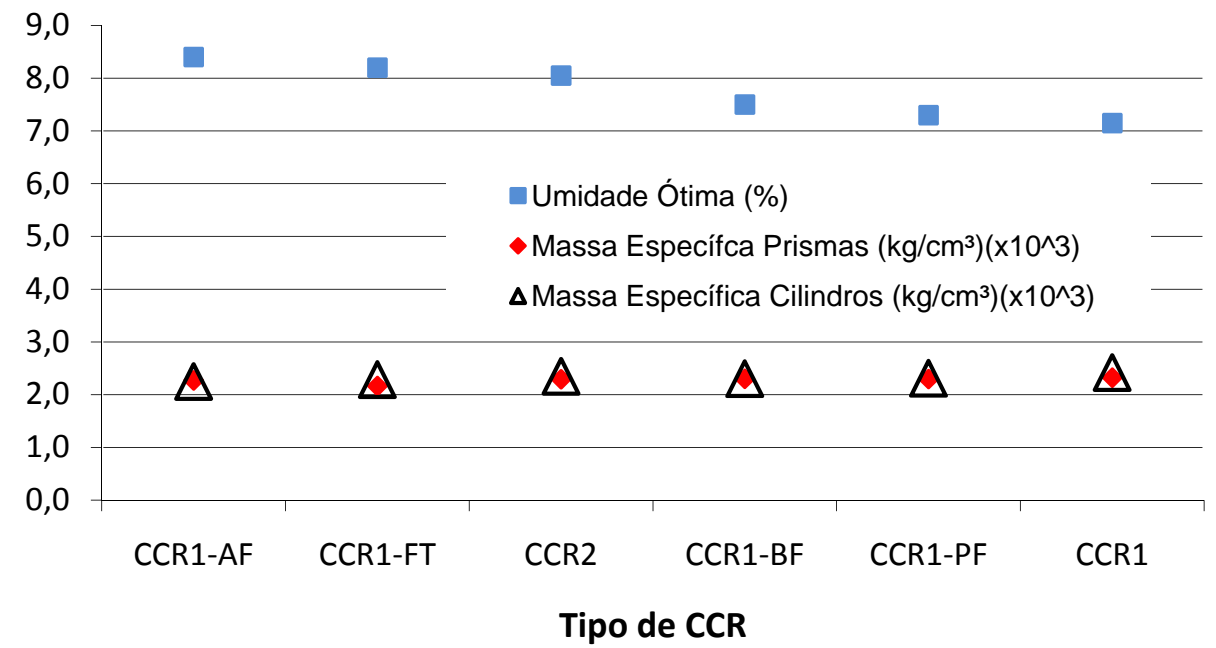

Figura 82 - Umidades ótimas e massas específicas dos prismas e cilindros 
Verificou-se que os valores de umidade, massa específica e tensão de ruptura tendem a um comportamento esperado, ou seja, maiores umidades resultam em menores tensões de ruptura e menores massas específicas, indicando aumento de porosidade.

Nos corpos de prova cilíndricos houve algumas diferenças quanto ao comportamento dos módulos elásticos em relação aos valores de umidade ótima, tensão de ruptura e massa específica, fato que pode estar relacionado ao pequeno número de amostras ensaiadas e também pelo modo de ruptura desse tipo de ensaio. (Figura 83).

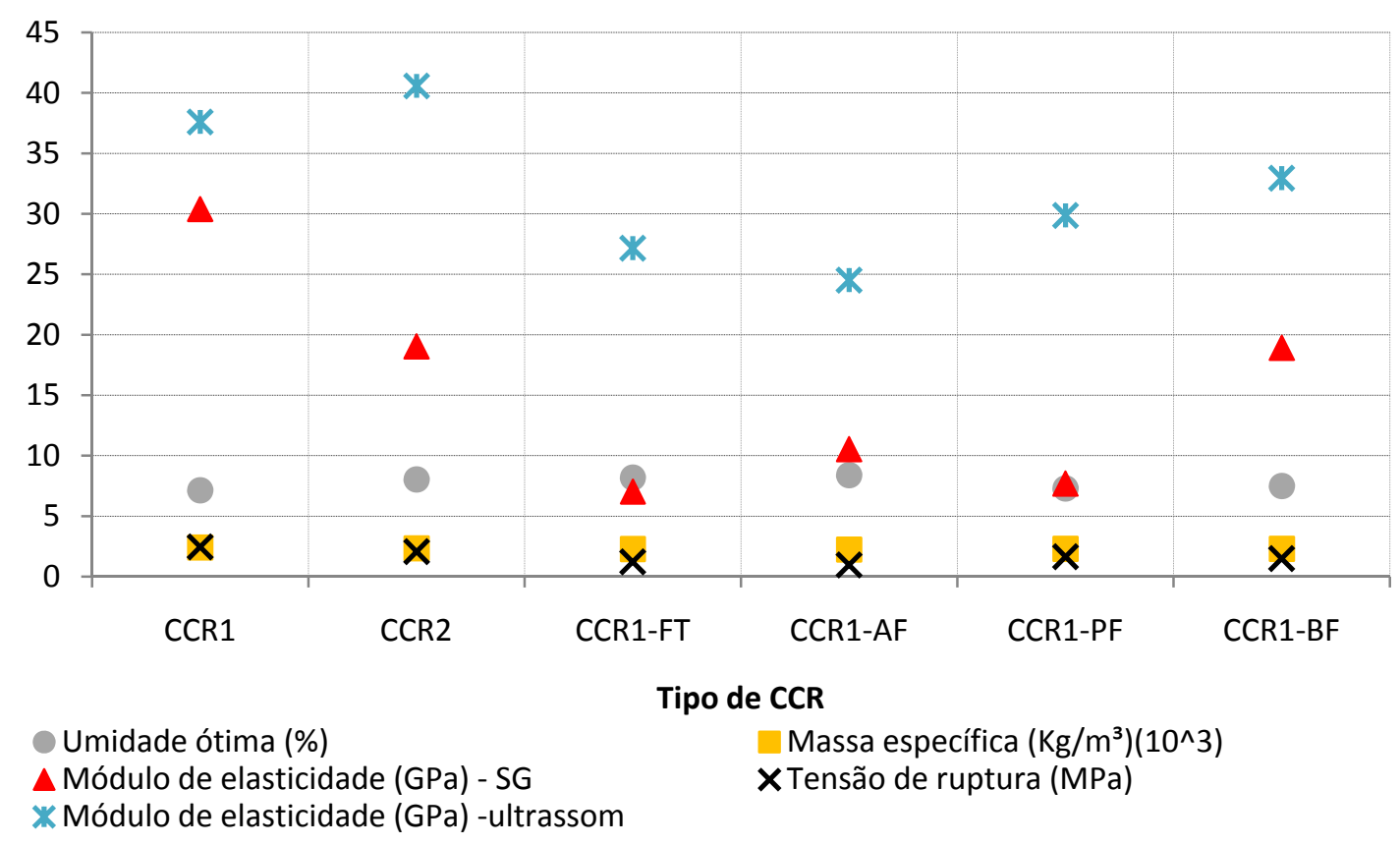

Figura 83 - Compilação dos resultados dos ensaios dinâmicos nos cilindros

Nos corpos de prova prismáticos houve um melhor comportamento em relação a todos os ensaios realizados (Figura 84). Os módulos de elasticidade obtidos pelos três métodos mantiveram um mesmo comportamento, com exceção de um ponto (CCR1BF) que não manteve a tendência no módulo dinâmico em relação aos outros dois métodos. A mistura CCR1-FT mostrou ter um comportamento esperado em relação a todos os resultados obtidos, ou seja, foi a mistura que obteve uma das maiores 
umidades, menor tensão de ruptura e apresentou os menores módulos elásticos, tanto nos prismas quanto nos cilindros.

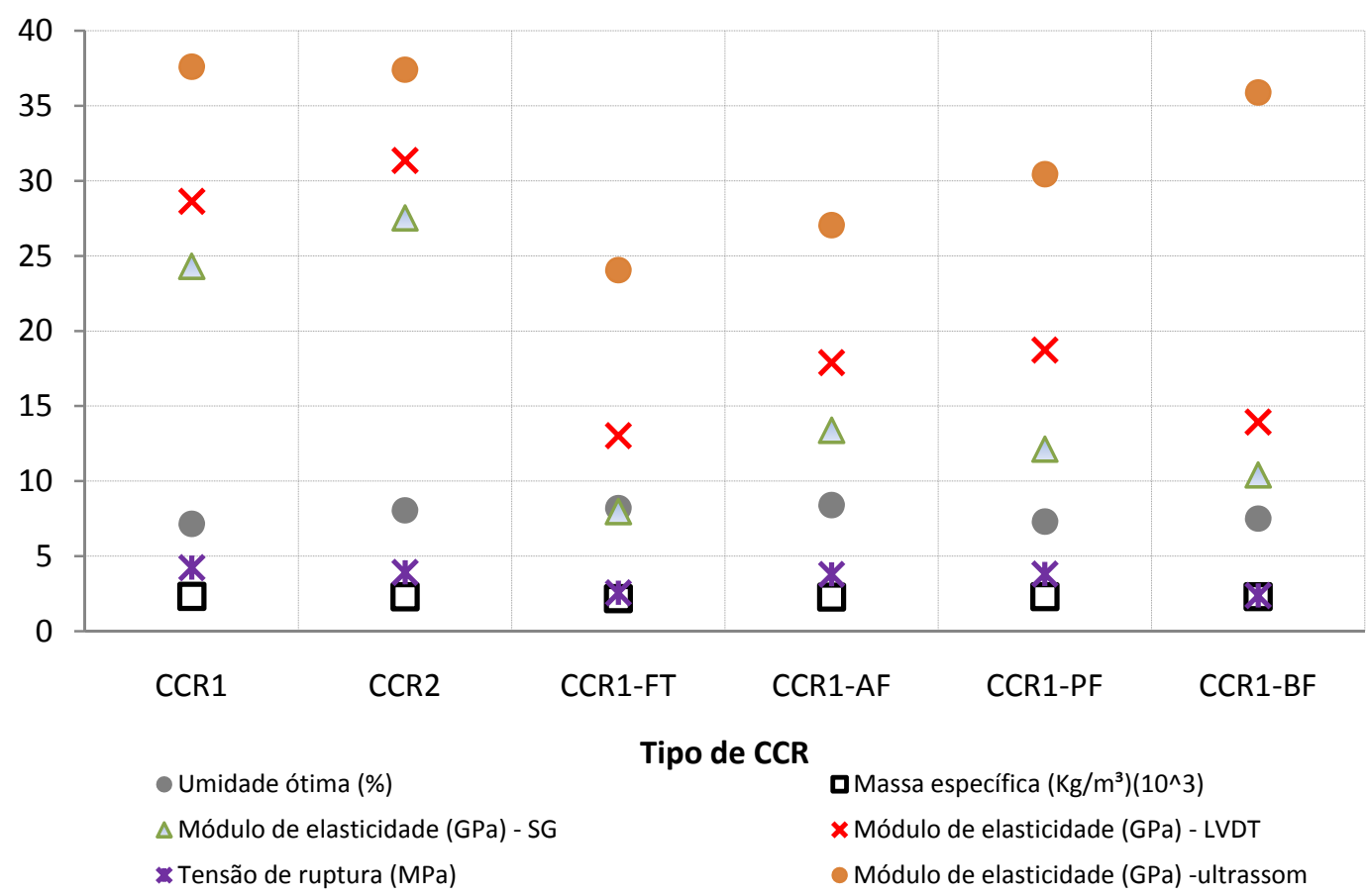

Figura 84 - Compilação dos resultados dos ensaios dinâmicos nos prismas

\subsection{ENSAIO DE TENACIDADE}

O ensaio de tenacidade foi realizado no CCR1 (referência) e no CCR1-FT (50\% da fração total de fresado). Quatro corpos de prova do CCR1 e quatro corpos de prova do CCR-FT foram preparados para o ensaio.

Na Figura 85 está apresentada a curva força versus deslocamento das amostras do CCR1 (referência) e do CCR1-FT obtidas por meio do ensaio de flexão a três pontos, conforme descrito no item 3.3.4. Devido ao tempo requerido para a execução de cada ensaio, apenas um corpo de prova foi ensaiado por dia, o que implicou em datas diferentes de execução de ensaio para cada um dos corpos de prova. 
O comportamento do CCR1-FT (com RAP) é muito parecido ao do CCR1 (referência), entretanto apresenta as curvas carga versus deslocamento um pouco abaixo.

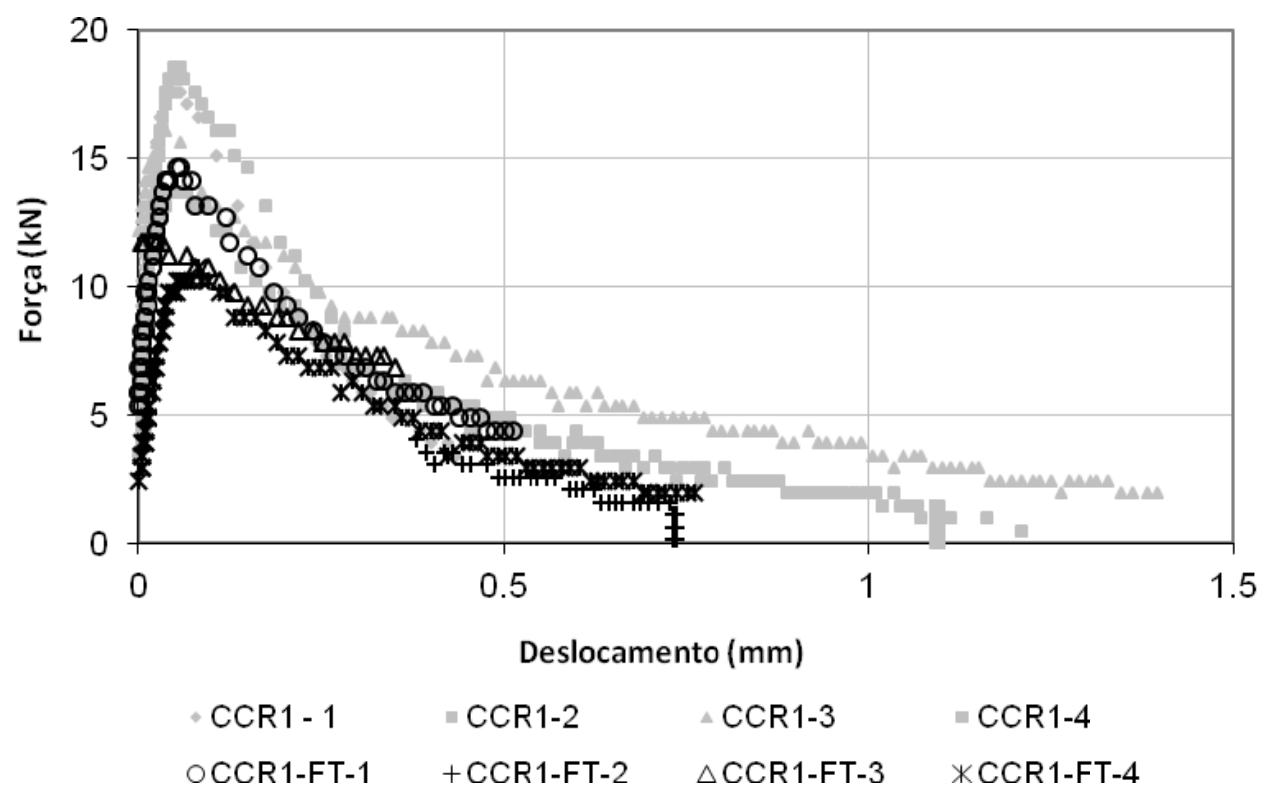

Figura 85 - Sobreposição da curva força x deslocamento do CCR1 com CCR-FT

Como pode ser visto na Figura 86, o comportamento do CCR1-FT é muito semelhante ao do CCR1, sendo que as duas misturas apresentaram curva-R e $K_{R}$ crescentes. As curvas-R são apresentadas de duas formas distintas: (a) a resistência à abertura da trinca (R) no material em função da trinca normalizada, (b) o fator de intensidade de tensão $\left(K_{l}\right)$ em função da abertura da trinca normalizada, curva $K_{R} . O$ comportamento dos CCR indica um aumento de resistência à propagação da trinca com o crescimento da mesma. Este fato pode ter ocorrido porque o concreto possui grãos graúdos e, portanto, a ligação entre os grãos nas duas superfícies de fratura que estão se formando resultará grande. Este processo acaba formando um mecanismo que dissipa a energia de propagação de trinca, por isso a curva-R é crescente. 

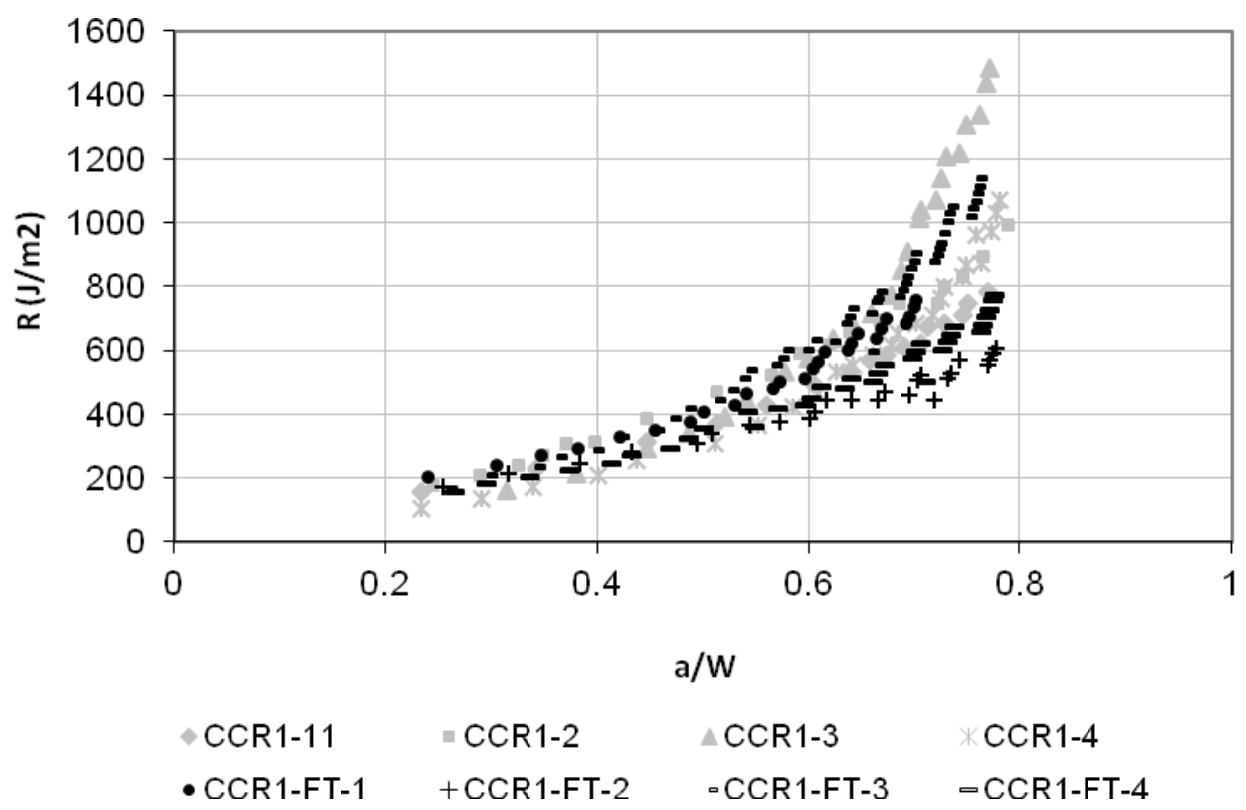

(a) Curva-R

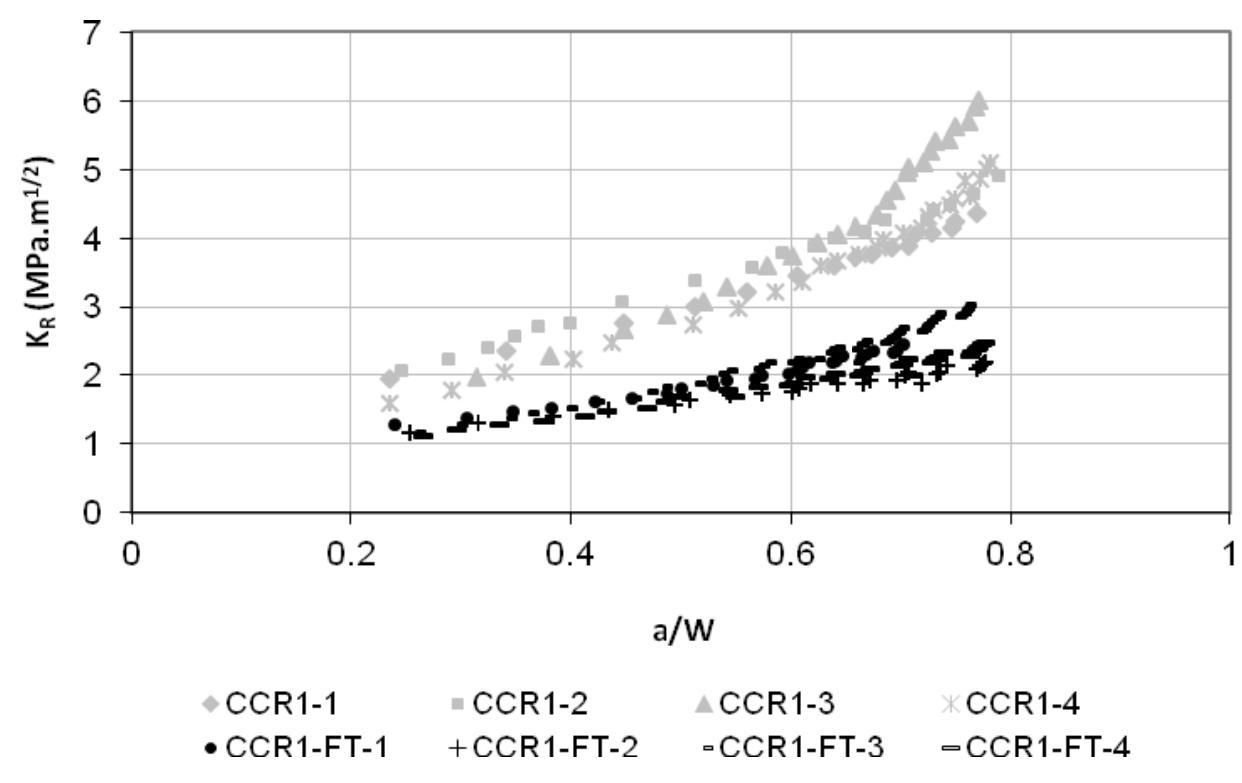

(b) $K_{R}$

Figura 86 - (a) Sobreposição das curvas-R e (b) sobreposição das curvas $K_{R}$ do CCR1 e do CCR-FT

Os valores de tenacidade à fratura para início de propagação da trinca $\left(\mathrm{K}_{\mathrm{ICIP}}\right)$, de energia de fratura por área de propagação de trinca $\left(2 \mathrm{Y}_{\text {wof }}\right)$ e os respectivos valores médios de $R(\bar{R})$ para as misturas estudadas estão apresentados na Tabela 23. Pelos valores apresentados observa-se que o valor de tenacidade ( $\left.\mathrm{K}_{\mathrm{ICIP}}\right)$ do CCR1 foi de $38 \%$ 
maior que do CCR1-FT e o valor de $\mathrm{R}_{\text {médio }}(\bar{R})$ resultou $21 \%$ maior. Conclui-se assim, que a presença de $50 \%$ da fração total dos fresados ocasiona expressiva redução na tenacidade à fratura para o início da propagação da fissura. Isso leva a inferir que a resistência à fadiga desses concretos seria menor. Em pavimentação esse fato exigirá bases mais espessas para os concretos secos com fresados.

O critério para avaliar a confiabilidade dos valores de $\mathrm{R}$ foi a comparação do valor médio de $R$ e da energia total de fratura $2 Y_{\text {wof }}$. Tanto o CCR com RAP como $p$ convencional apresentaram $\mathrm{R}$ médio maior que $2 \mathrm{Y}_{\text {wof }}$.

Tabela 23 - Valores de tenacidade para o início de propagação da trinca $\left(K_{I C I P}\right)$, de resistência média à abertura de trinca ( ${ }^{\mathbf{R}}$ ) e de energia de fratura por área de propagação (2Y wof $)$ para o CCR1 e CCR1-FT

\begin{tabular}{|c|c|c|c|c|}
\hline Mistura & Amostra & $\begin{array}{c}\mathrm{K}_{\text {ICIP }} \\
\left(\mathrm{MPa}, \mathrm{m}^{1 / 2}\right)\end{array}$ & $\begin{array}{c}\bar{F} \\
\left(\mathrm{~J} / \mathrm{m}^{2}\right)\end{array}$ & $\begin{array}{c}2 \mathrm{Y}_{\text {wof }} \\
\left(\mathrm{J} / \mathrm{m}^{2}\right)\end{array}$ \\
\cline { 2 - 5 } & 1 & 1,94 & 574 & 426 \\
\cline { 2 - 5 } & 2 & 2,06 & 589 & 524 \\
\cline { 2 - 5 } & 3 & 1,98 & 809 & 569 \\
\cline { 2 - 5 } & 4 & 1,60 & 616 & 404 \\
\cline { 2 - 5 } & Média & $\mathbf{1 , 8 9}$ & $\mathbf{6 4 7}$ & $\mathbf{4 7 5}$ \\
\hline \multirow{4}{*}{ CCR1-FT } & 1 & 1,28 & 526 & 446 \\
\cline { 2 - 5 } & 2 & 1,16 & 443 & 372 \\
\cline { 2 - 5 } & 3 & 1,16 & 739 & 558 \\
\cline { 2 - 5 } & 4 & 1,12 & 500 & 405 \\
\cline { 2 - 5 } & Média & $\mathbf{1 , 1 6}$ & $\mathbf{5 1 3}$ & $\mathbf{4 2 6}$ \\
\hline
\end{tabular}

Para comparar os resultados deste estudo com outras pesquisas em concreto, nas Figuras 87 a 90, estão apresentados resultados de algumas curvas-R, de concretos, obtidas por outros autores com a geometria do ensaio de flexão.

Lemaistre (1998) obteve curvas-R, no ensaio de flexão a quatro pontos, para diferentes concretos. As curvas- $R$ mostraram-se sempre crescentes como pode ser visto na Figura 87. 


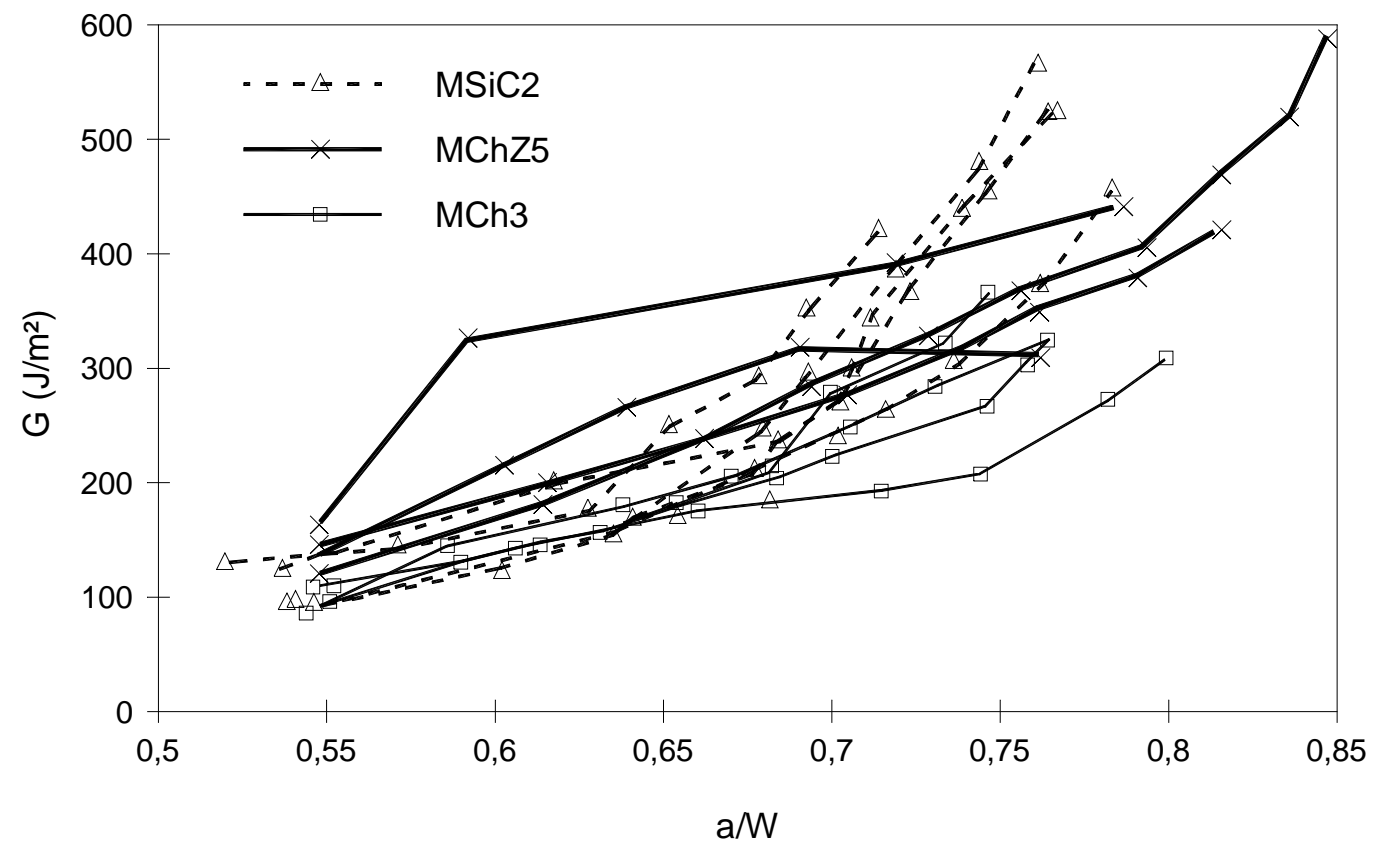

Figura 87 - Curvas-R obtidas com diferentes concretos (Lemaistre, 1988)

Reinhardt \& Xu (1999) obtiveram curvas-R obtidas para cinco diferentes concretos, os quais variam a resistência à compressão, a resistência à tração e o módulo de elasticidade do material. A simulação numérica foi realizada para a geometria do ensaio de flexão a três pontos (Figura 88).

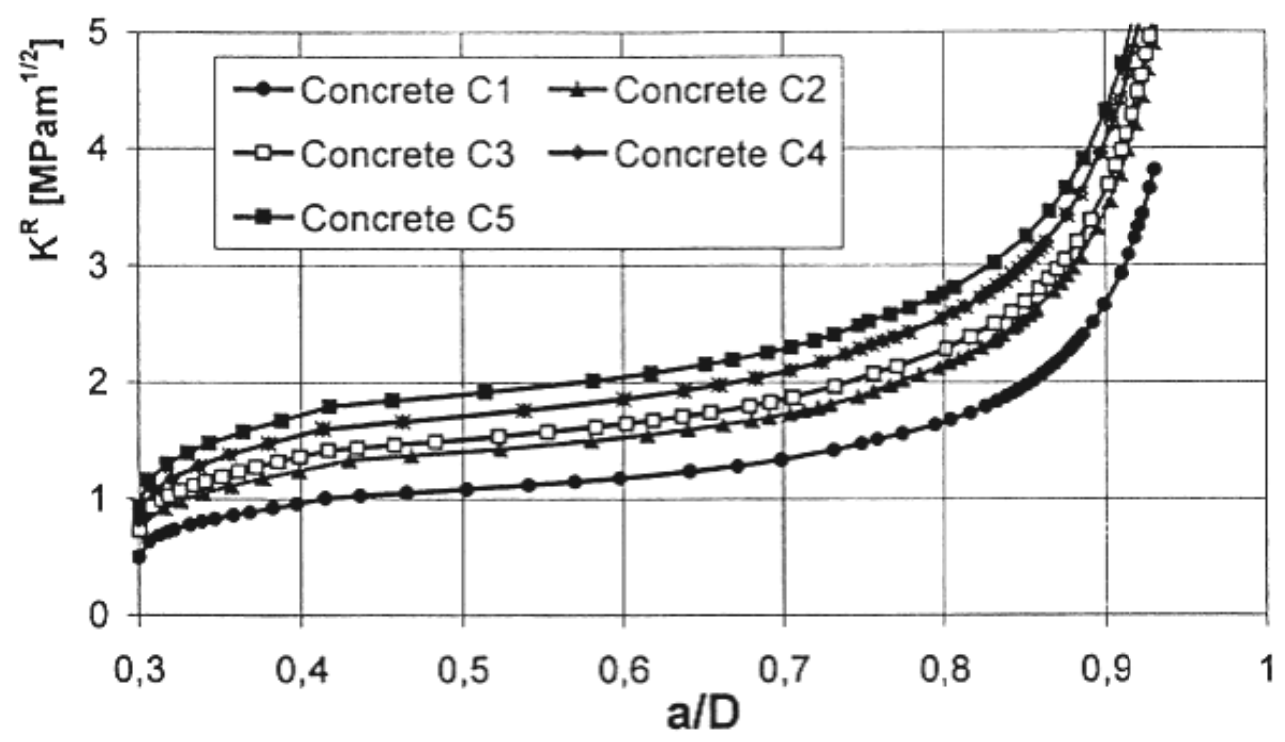

Figura 88 - Curvas- $K_{R}$, para cinco diferentes concretos (Reinhardt \& Xu, 1999) 
$\mathrm{Na}$ Figura 89 estão apresentadas curvas-R para um concreto de alto desempenho (HPC). Na Figura 90 é observada a mesma curva-R, porém sobrepostas do mesmo concreto com adição de diferentes teores de fibras de aço (Ferreira, 2007). 0 ensaio para obtenção destas curvas foi de flexão a três pontos. Os valores de $\alpha$ são validos até o limite 0,7 .

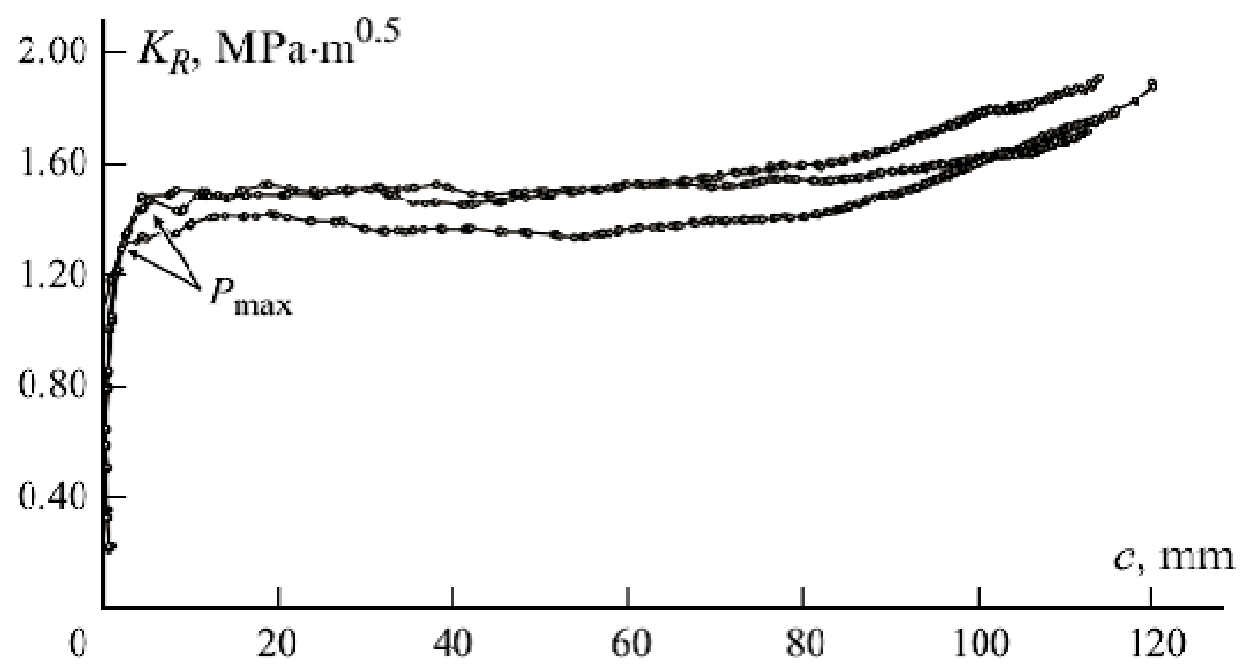

Figura 89 - Curvas- $K_{R}$ obtidas em concreto de alta resistência com ensaio de flexão a três pontos (Ferreira 2007)

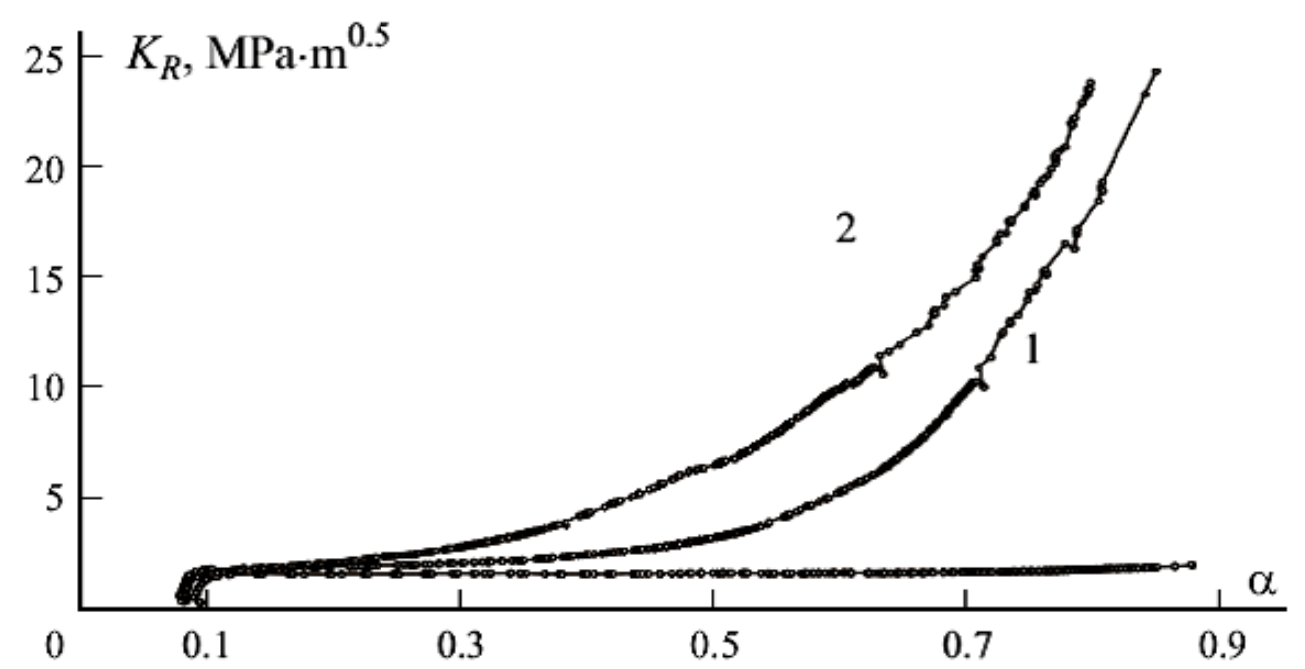

Figura - 90 Curvas- $K_{R}$ obtidas do concreto de alta resistência, Curva 1: concreto com adição de $40 \mathrm{~kg} / \mathrm{m} 3$ de fibras de aço e Curva-2: com adição de 80 kg/m3 de fibras de aço, curva 2 (Ferreira, 2007). 
O comportamento da curva-R do CCR estudado na presente pesquisa, curva- $R$ crescente, está de acordo com materiais com grãos grandes como é o caso de concreto estudado por Lemaistre (1998), Reinhart e Xu (1999) e Ferreira (2007). Esses autores também obtiveram curvas-R crescentes sem patamar, exceção feita ao HPC de Ferreira (2007), o qual é um material com uma resistência muito maior e muito mais frágil, sendo assim a zona de processo deve ser menor.

Comparando as curvas- $\mathrm{R}$ e $\mathrm{K}_{\mathrm{R}}$ apresentadas neste estudo, com as mostradas nas Figuras 87 a 90, em relação aos valores absolutos, se pode afirmar que o CCR de referência apresenta melhor desempenho de resistência à abertura da trinca, que os concretos convencionais e de alta resistência, com exceção ao de alta resistência com adição de fibra de aço de Ferreira (2007). A mesma observação é válida para o CCR com fresado. É importante lembrar que os valores devem ser analisados para $\alpha$ até 0,7 .

As curvas força $\mathrm{x}$ deslocamento conseguidas por Balbo (2006) para BGTC, em tração, mostram que as misturas com maior resistência são aquelas em que a compactação se deu na menor umidade. Estas apresentam tenacidade à tração inferior que aquelas compactadas na umidade ótima (5,5\%). Portanto, a fragilidade do material aumentaria quando compactado no ramo seco, em sentido contrário ao aumento de resistência esperado (Figura 16).

Os resultados obtidos para os CCR com RAP são melhores que os alcançados na BGTC estudada por Balbo (2006).

\subsection{MICROSCOPIA ELETRÔNICA DE VARREDURA}

A microscopia eletrônica de varredura foi realizada em todas as seis misturas estudadas. Como esperado, as análises com MEV permitiram a identificação da zona de transição entre pasta de cimento e agregados fresados e naturais, bem como as possíveis falhas na ligação entre ambos. 


\section{MEV SE (Elétrons Secundários)}

As imagens obtidas dos corpos de prova de CCR contendo fresado asfáltico e os corpos de prova de CCR1 e CCR2 (agregado convencional) apresentaram microestrutura característica de etringita e outros produtos de hidratação, evidenciando que as reações de hidratação efetivamente ocorreram mesmo nos concretos contendo agregados fresados. Contudo, não foi possível estimar se a quantidade de etringita formada foi equivalente nos CCR1 e CCR2 e nos CCR com fresado asfáltico.

Na Figura 91, é possível ver que na mistura CCR1 a pasta é compacta e não homogênea. Observou-se nesta mistura a formação dos produtos de hidratação como, por exemplo, o C-S-H e a etringita.
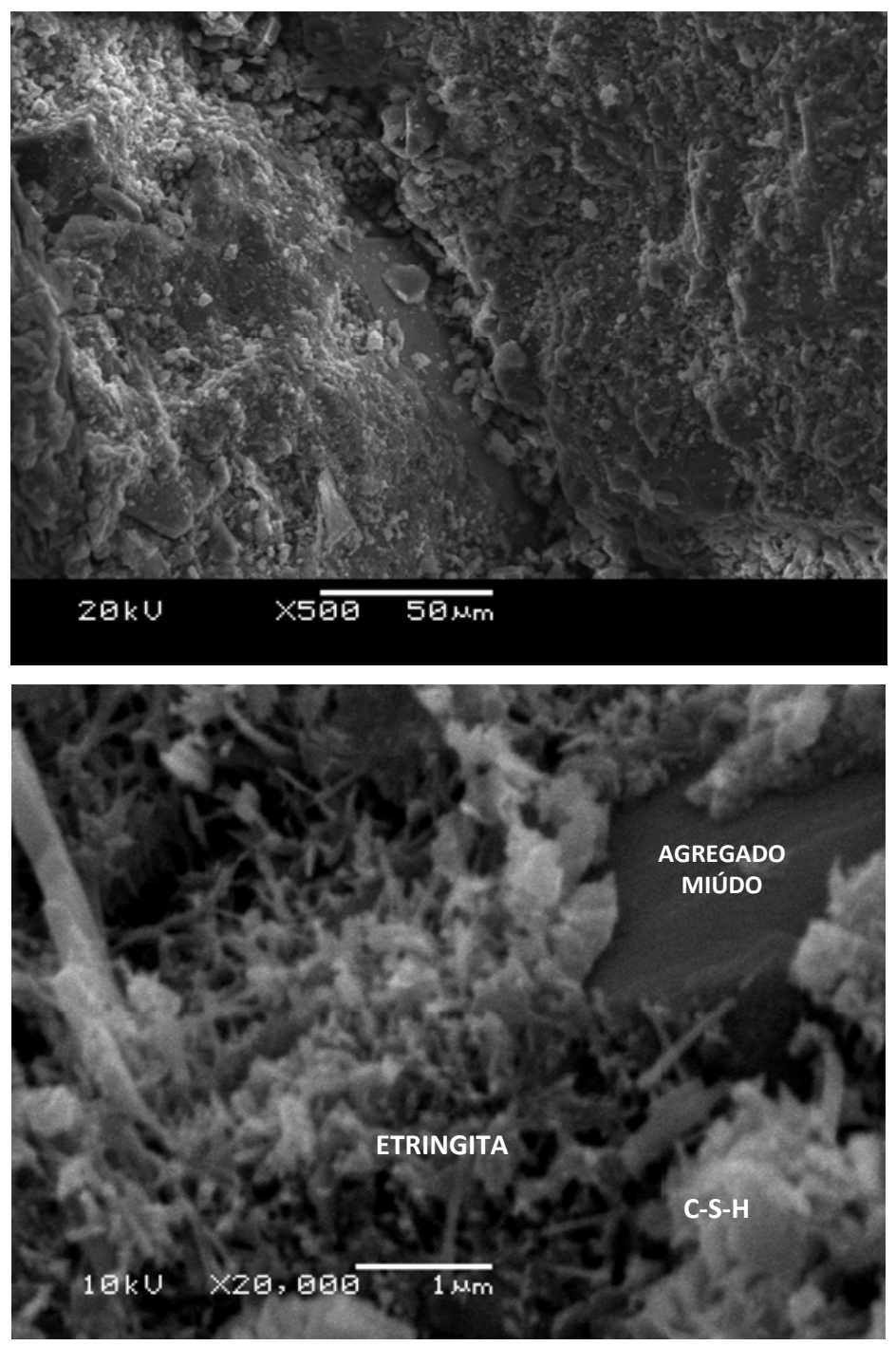

Figura 91 - Observações com MEV na mistura CCR1 
Como mostrado na Figura 92, para a mistura CCR2 a quantidade de pasta também é pouca em relação à quantidade de agregados, não sendo suficiente para envolvê-los. Existe uma grande quantidade de vazios característicos de ar incorporado.
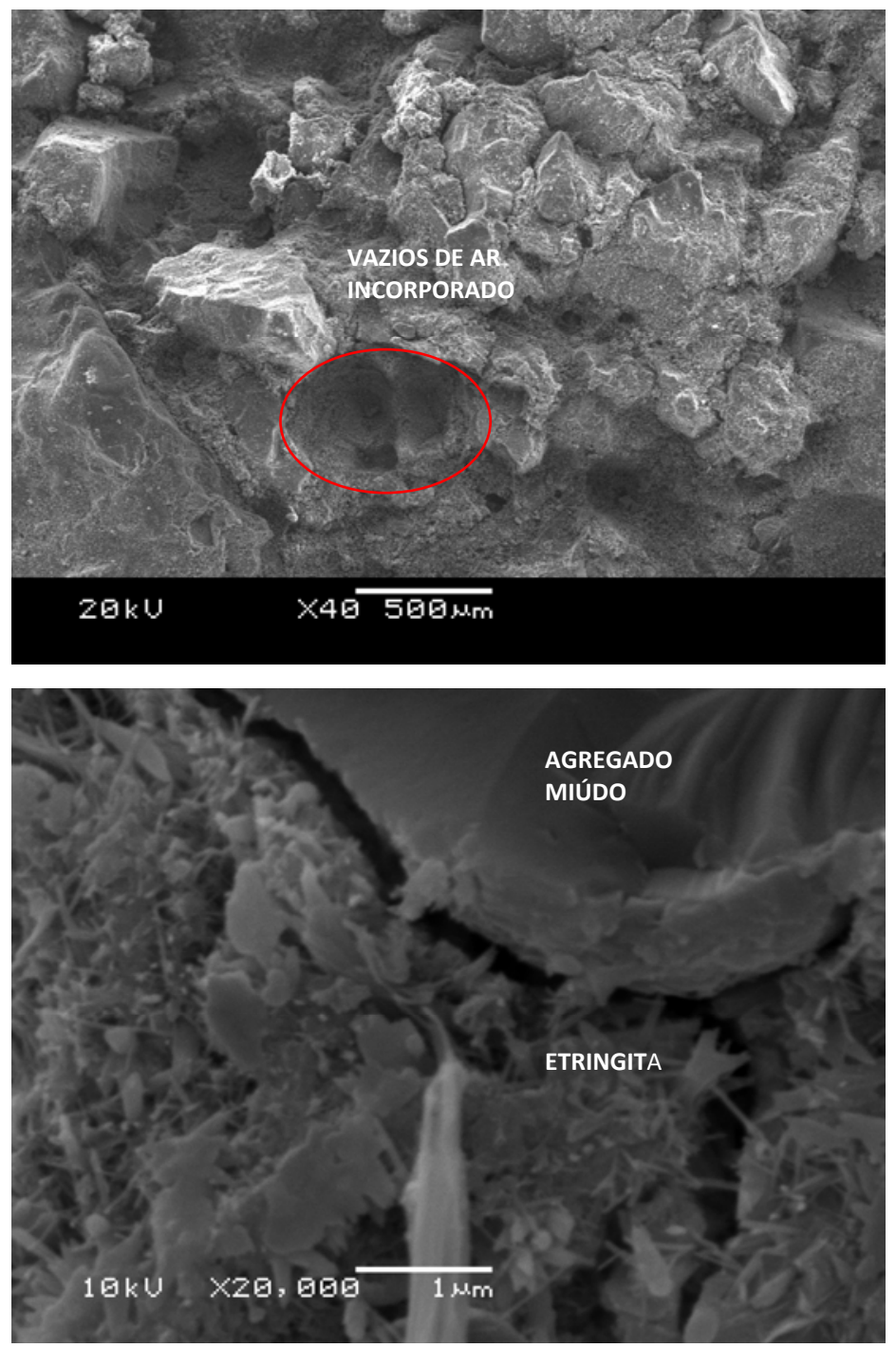

Figura 92 - Observações com MEV na mistura CCR2

Na mistura CCR1-FT, fica evidente a formação de produtos de hidratação como o CSH (silicato de cálcio hidratado) e que a mistura não é compacta nem homogênea (Figura 93). 


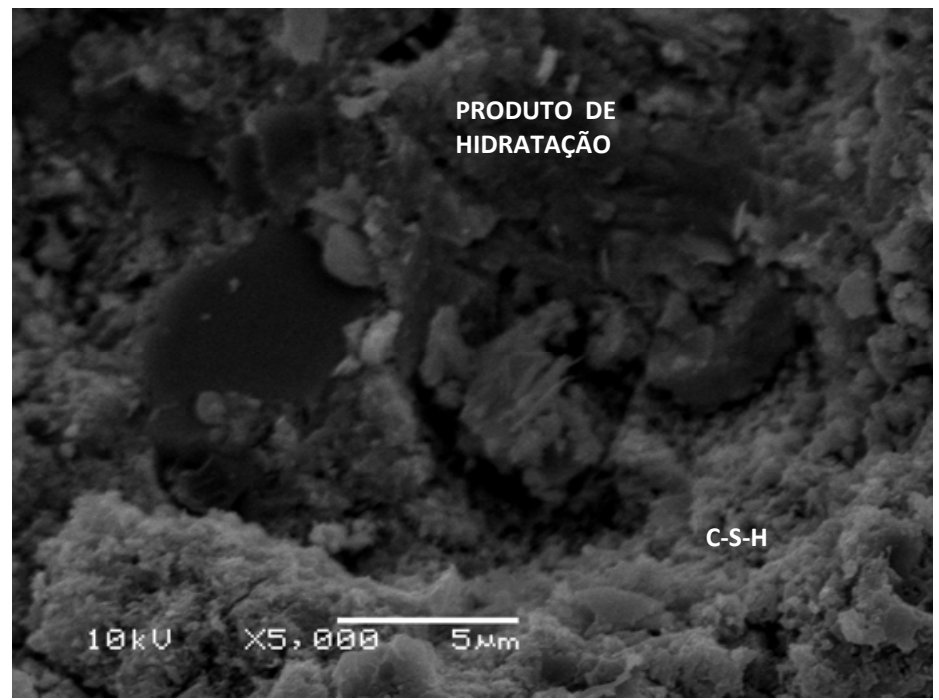

Figura 93 - Observações com MEV na mistura CCR1 - FT

$\mathrm{Na}$ Figura 94, mistura CCR1-AF, observou-se a presença de poro de ar incorporado com fissuras de retração por secagem e formação de C-S-H (silicato de cálcico), um dos responsáveis pela resistência da mistura.

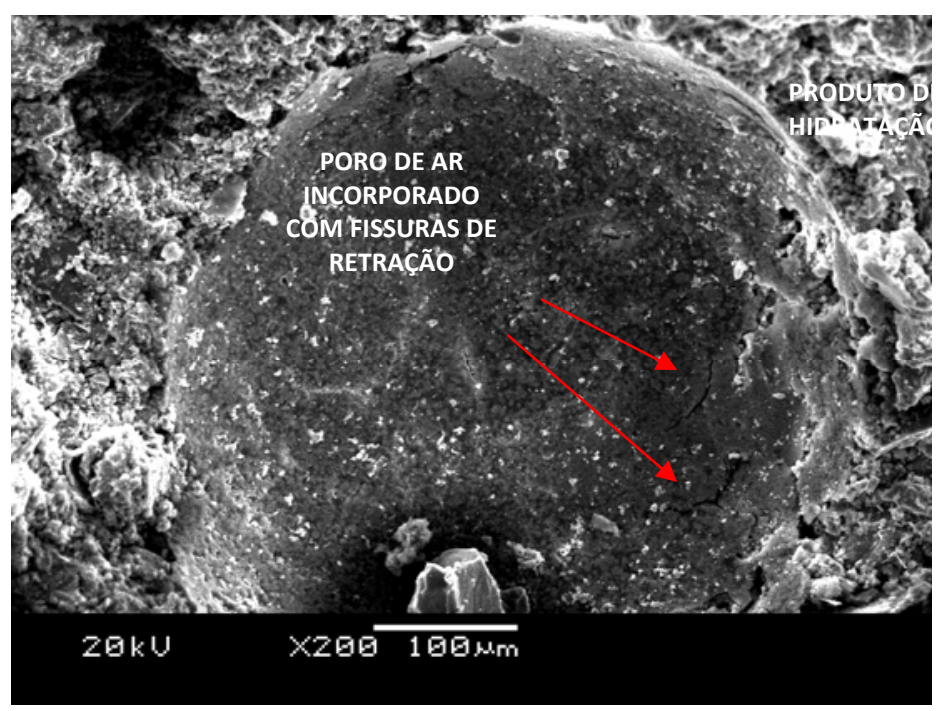

Figura 94 - Observações com MEV na mistura CCR1-AF

A presença de uma pasta heterogênea é evidente na mistura CCR1-PF, onde também se observou a presença da formação de trisulfoaluminato de cálcio e etringita 
(Figura 95). A porosidade é característica importante desta mistura que também possui baixa quantidade de pasta em relação à quantidade de fração fina do agregado.
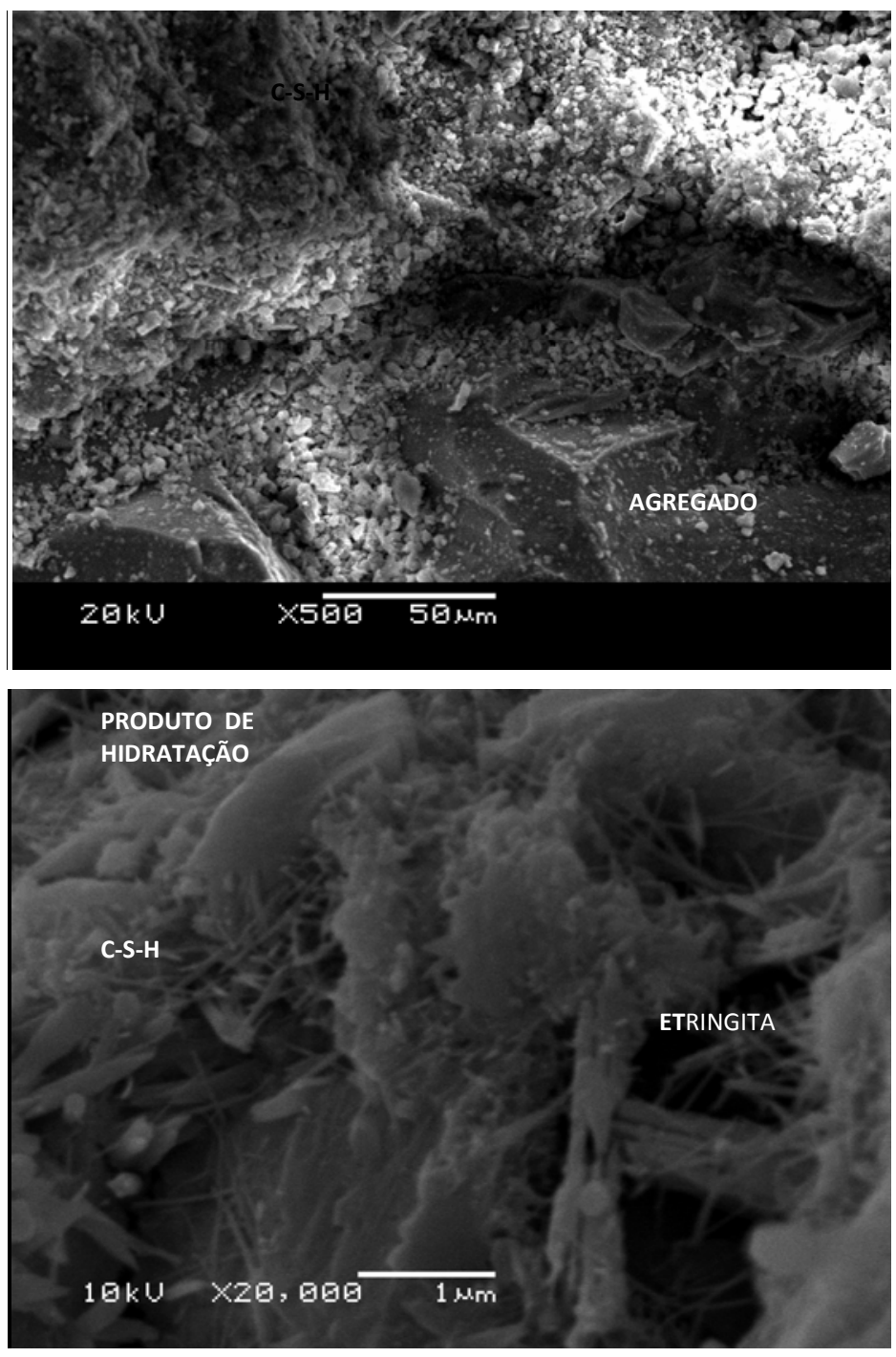

Figura 95 - Observações com MEV na mistura CCR1-PF

A falta de aderência é visível na mistura CCR1-BF (Figura 96). Observa-se a presença de água de amassamento envolvendo o agregado sem reagir com outros componentes. Sais de cálcio foram identificados nas imagens dessa mistura. 


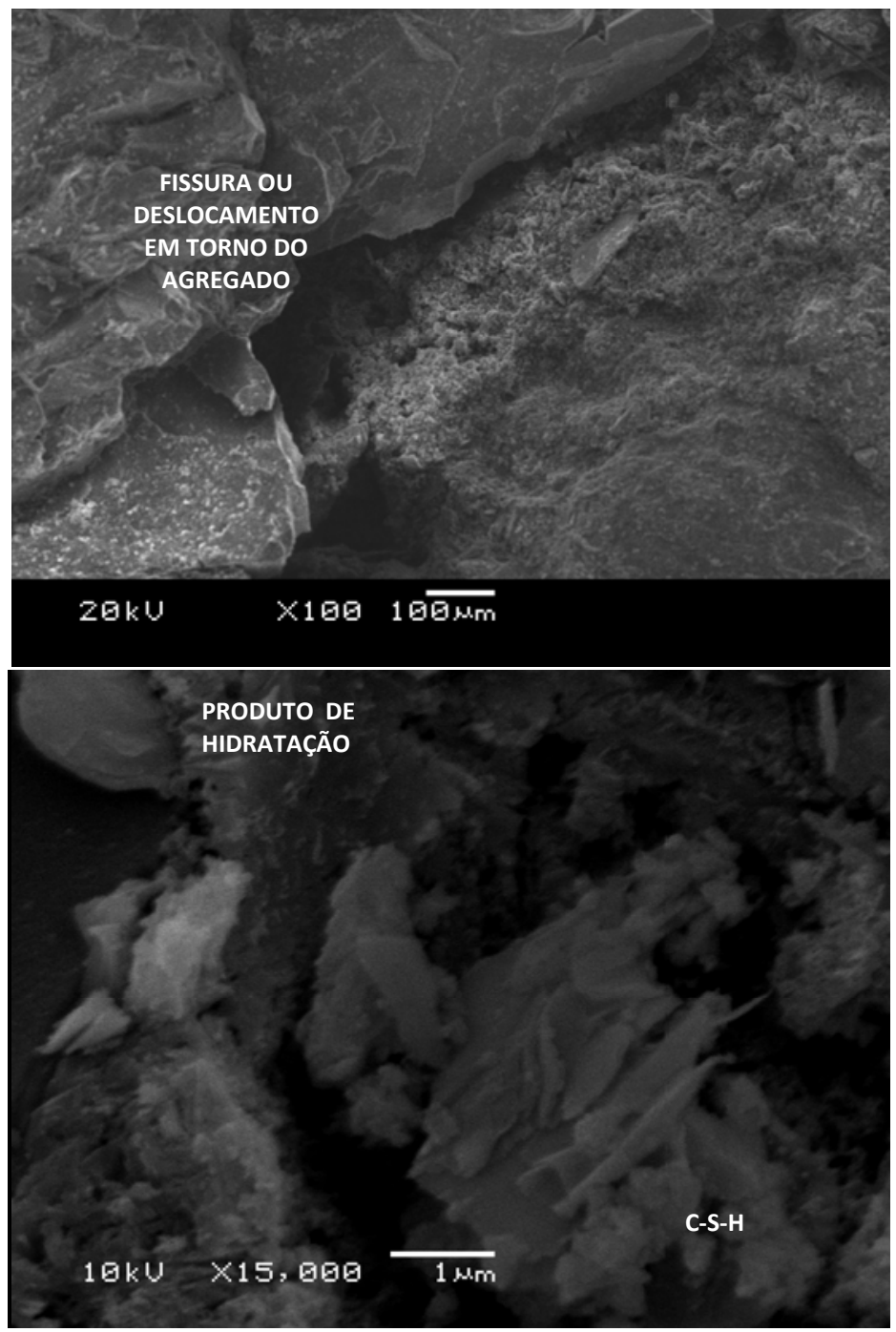

Figura 96 - Observações com MEV na mistura CCR1-BF

Depois de analisar todas as misturas é possível dizer que na mistura CCR1 a pasta é compacta e não homogênea, e assim como em todas as misturas, sua quantidade é reduzida em relação à de agregados, ou seja, o volume não foi suficiente para envolver os grãos. Isso é típico em concretos compactados com rolo empregados em pavimentação.

\section{MEV BSE (Elétrons Retroespalhados)}

Os resultados obtidos nas observações com MEV BSE possibilitaram observar alguns pontos importantes na zona de transição entre a pasta de cimento e os agregados. Notou-se que em todas as misturas existe uma tendência de falha na 
ligação entre pasta de cimento e agregados, isso se sobressai nas misturas de CCR com agregados fresados.

Pela forma de ruptura dos corpos de prova, onde a tendência da trinca é contornar os agregados fresados e não quebrá-los, percebe-se a fraca ligação entre pasta e agregados fresados, o que vai ao encontro às conclusões obtidas por Paulon e Monteiro (1991) em que enfatizam o fato de que a zona de transição é o ponto mais frágil da mistura.

Pelas imagens obtidas com MEV BSE fica evidente essa falha de ligação, bem como, a formação de poros característicos de ar incorporado, gerados durante a compactação dos corpos de prova. As misturas que aparentemente apresentaram maior quantidade de poros foram aquelas com incorporação de fresados, especialmente a mistura CCR1-AF em que há um aumento nítido de poros em relação à mistura padrão (CCR1).

Todos esses dados correlacionados acabam por justificar as quedas nas resistências e módulos de elasticidade das misturas com agregados fresados.

O CCR1 apresentou uma zona mais compacta no entorno do agregado, como pode ser observado na Figura 97.

A micrografia do CCR2 apresentou uma zona de transição compacta e uma pasta de cimento mais compacta e homogênea que aquela observada nas misturas com fresados asfálticos, como pode ser observado na Figura 98.

Por meio da micrografia do CCR1-AF constataram-se microfissuras na zona de transição entre agregados e pasta de cimento, conforme mostrado na Figura 99. Ainda que o agregado fresado esteja fraturado, ele não se torna indispensável ou não aproveitável em pavimentação.

Para o CCR1-FT as análises das imagens possibilitaram visualizar microfissuras na zona de transição entre o agregado fresado e a pasta de cimento, além de apresentar regiões bastante heterogêneas, como pode ser visto na Figura 100.

Pelas micrografias do CCR1-PF percebeu-se que o agregado de fresado asfáltico não está bem aderido à pasta de cimento (Figura 101), o que aparentemente resultou na diminuição de sua resistência mecânica. 
As imagens da micrografia do CCR1-BF demonstraram uma zona de transição não compacta, favorecendo a formação de uma ligação mais frágil, resultando em menor resistência (Figura 102).

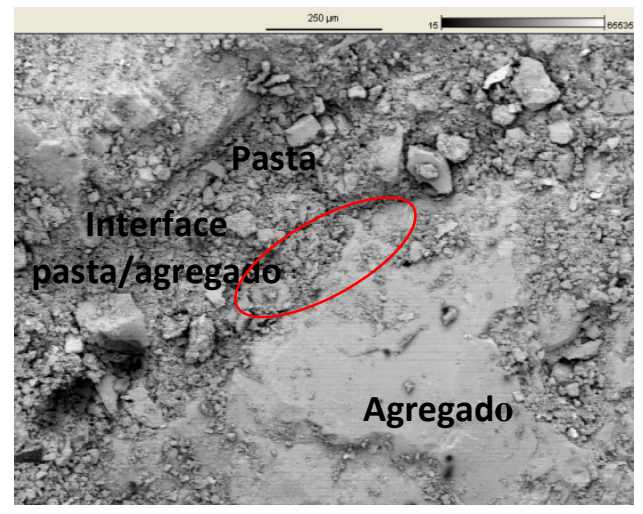

Aumento 100x
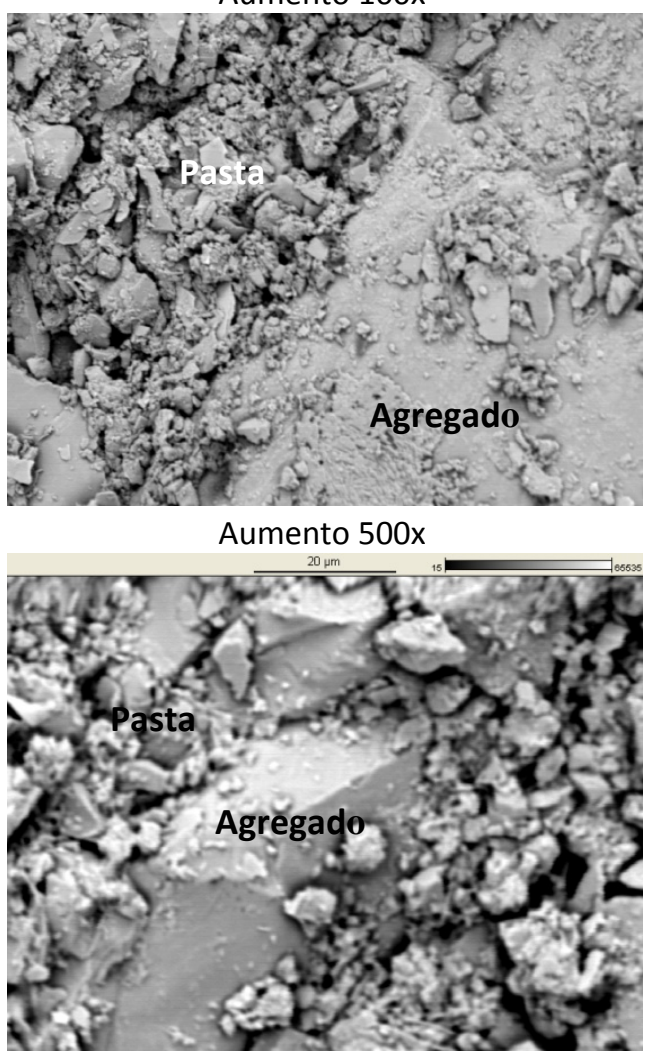

Aumento $1500 x$

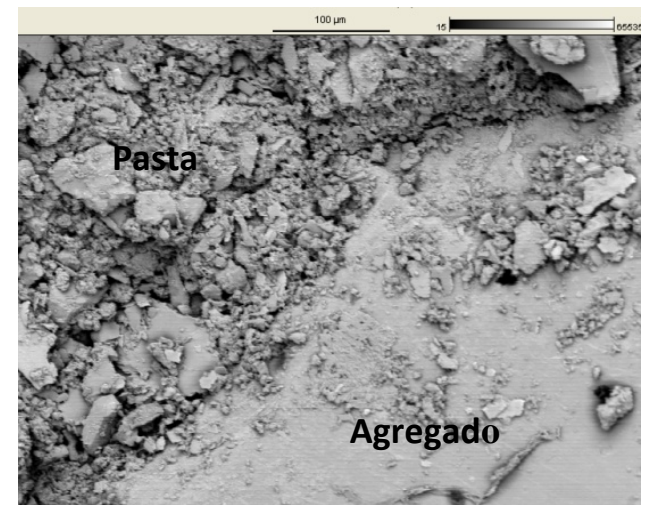

Aumento $250 x$

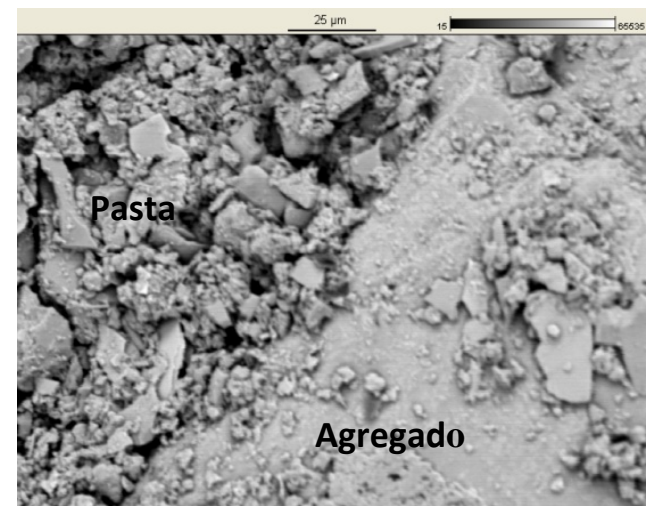

Aumento 750x

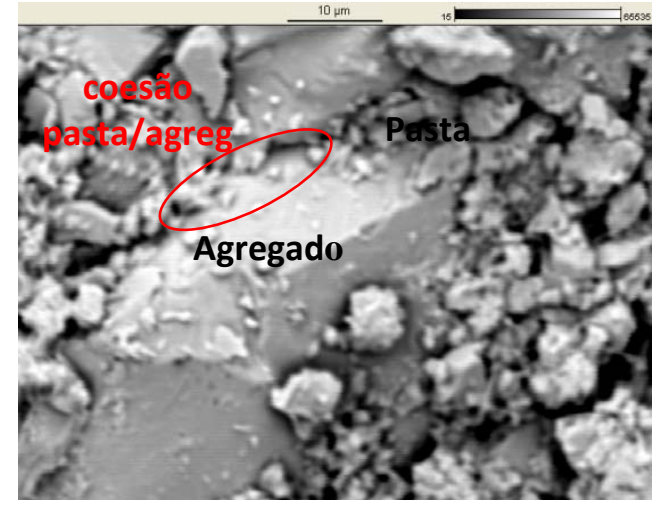

Aumento 2000x

Figura 97 - Observações com MEV BSE na mistura CCR1 


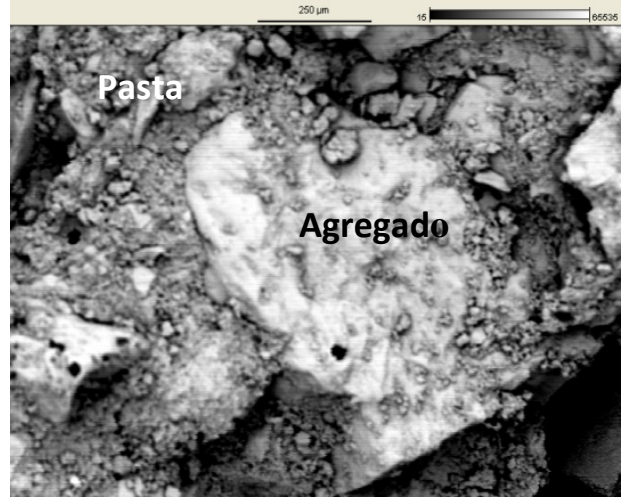

Aumento $100 x$

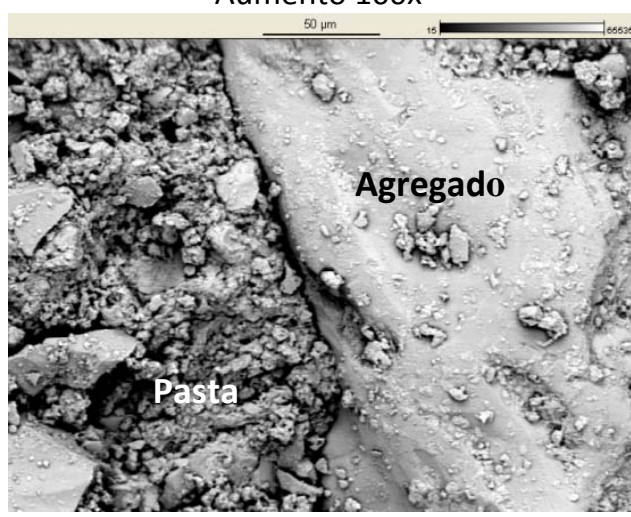

Aumento 500x

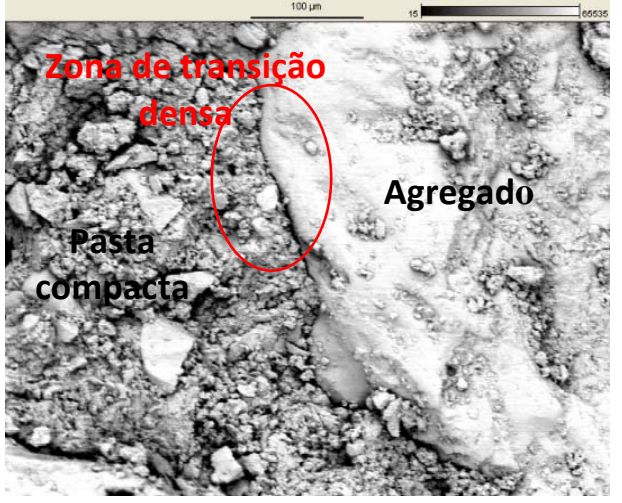

Aumento 250x

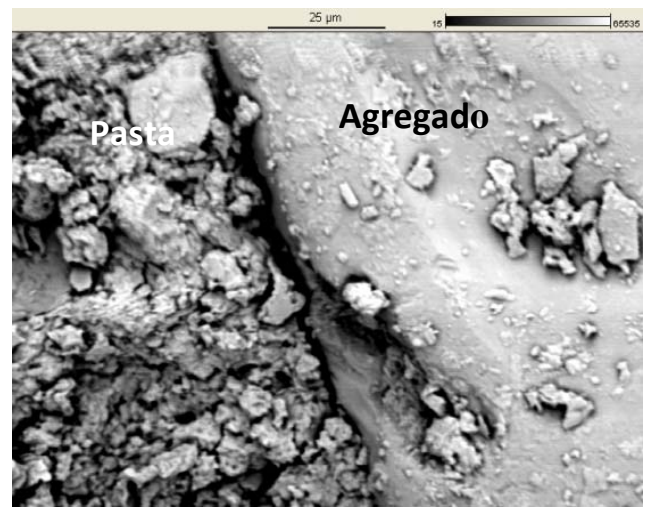

Aumento $1000 x$

Figura 98 - Observações com MEV BSE na mistura CCR2

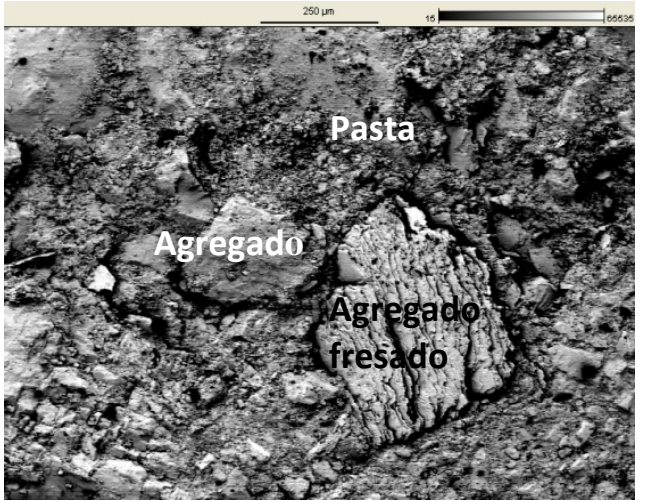

Aumento $100 x$

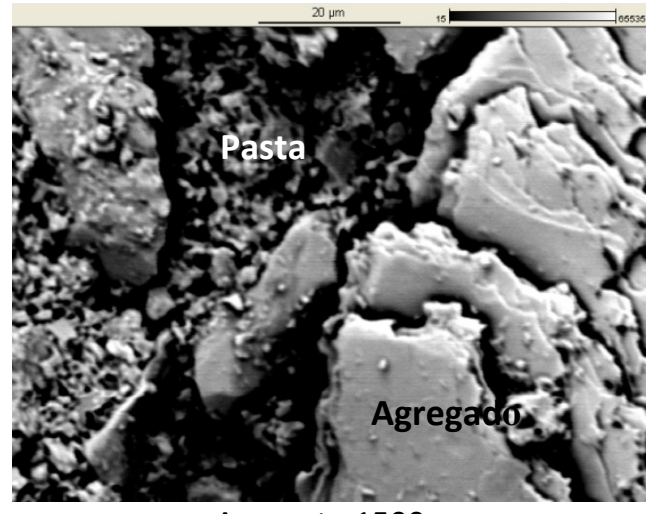

Aumento $1500 x$

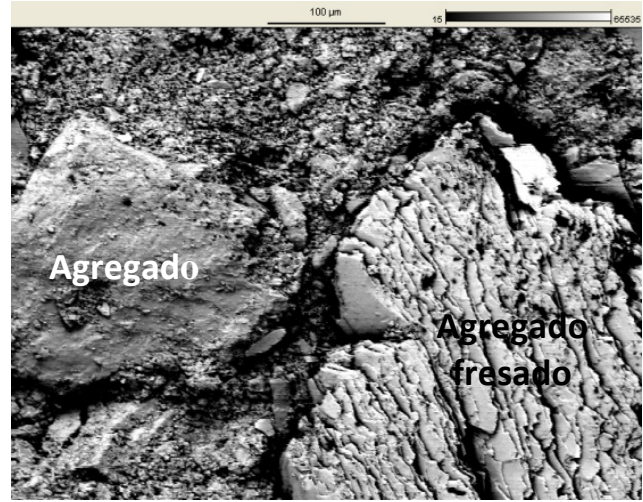

Aumento $250 x$

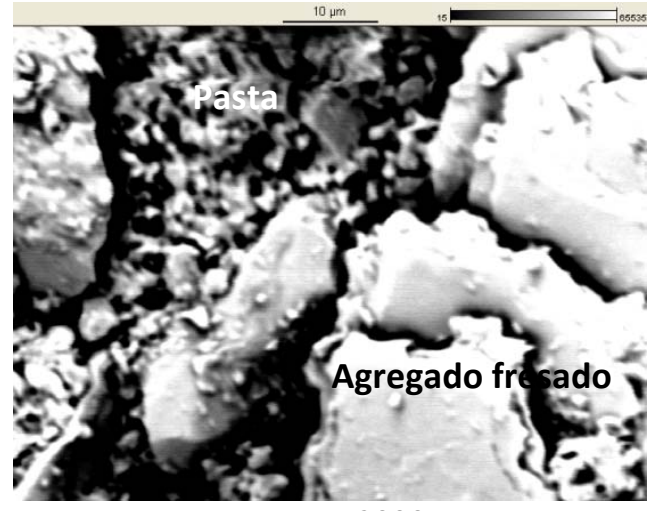

Aumento 2000x

Figura 99 - Observações com MEV BSE na mistura CCR1-AF 


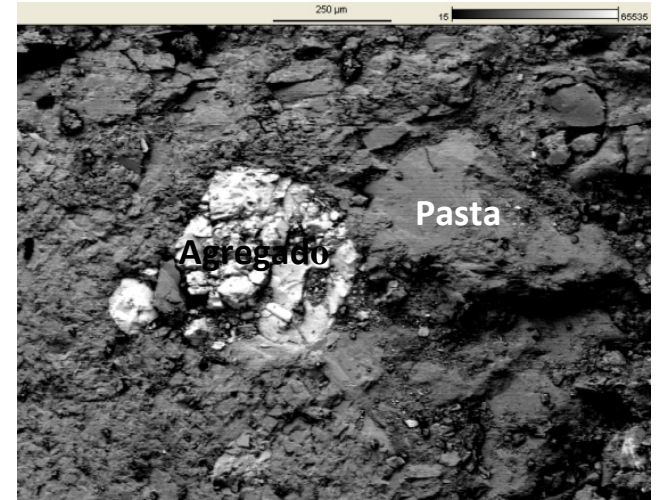

Aumento 100x

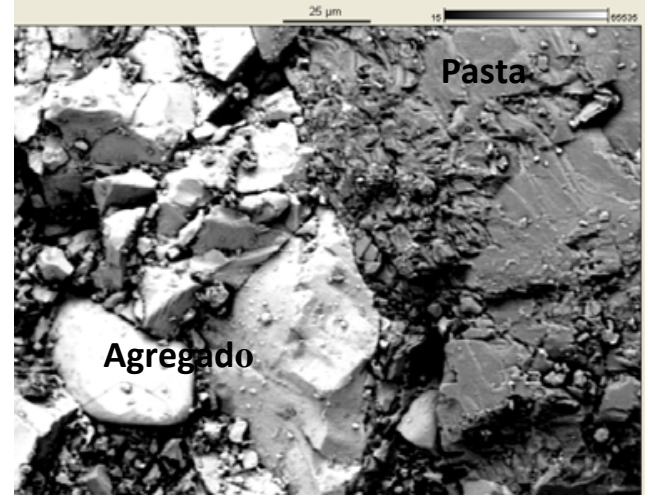

Aumento 750x

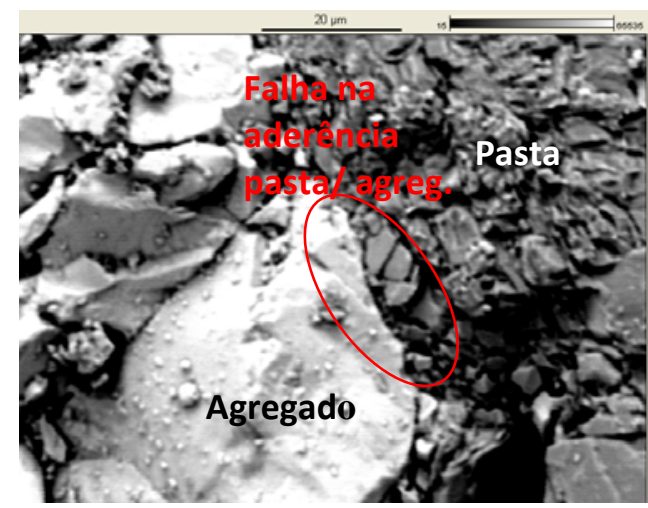

Aumento $1500 \mathrm{x}$

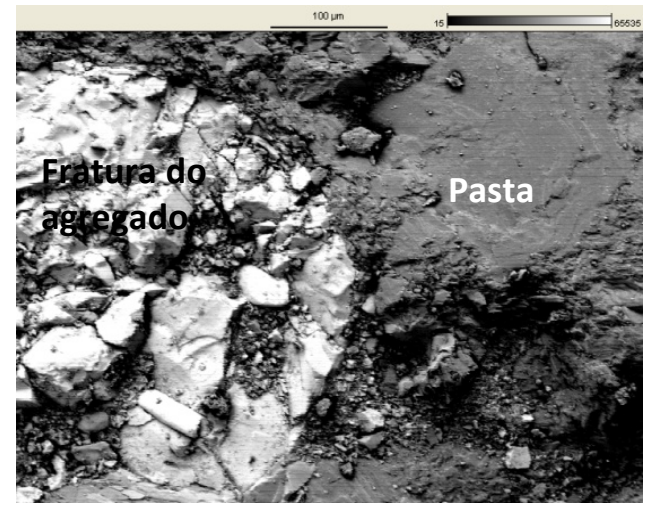

Aumento 250x

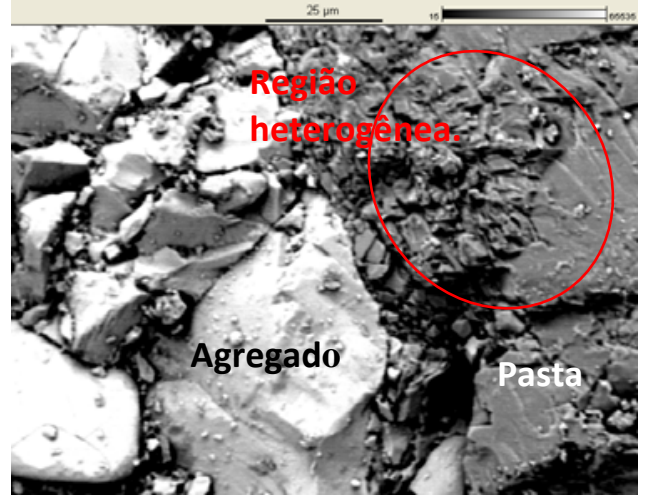

Aumento $1000 x$

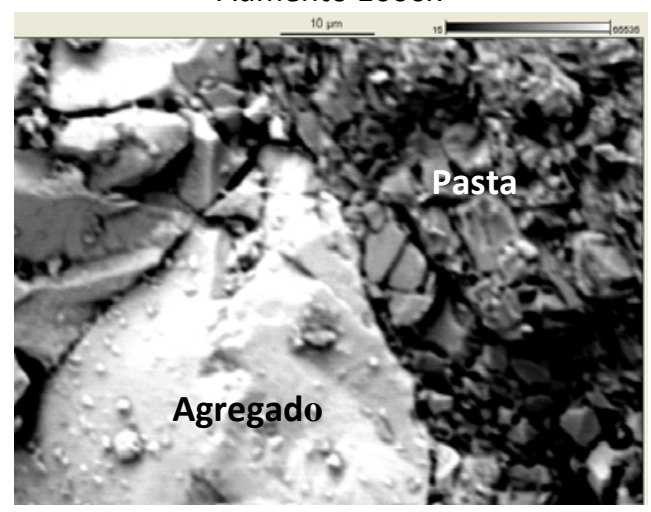

Aumento de 2000x

Figura 100 - Observações com MEV BSE na mistura CCR1 - FT 


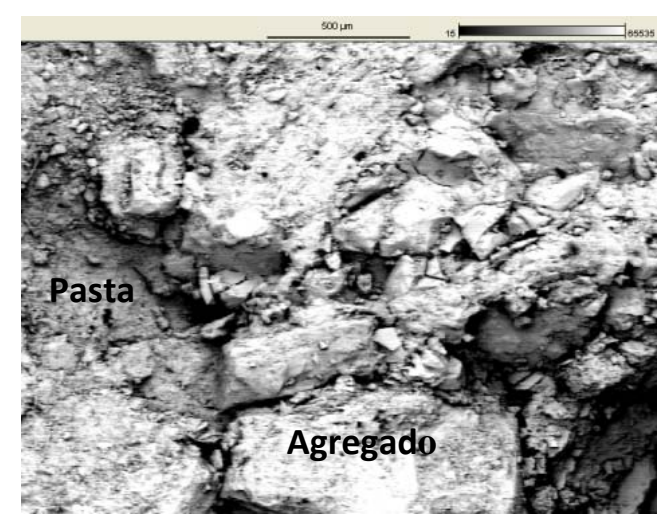

Aumento 60x

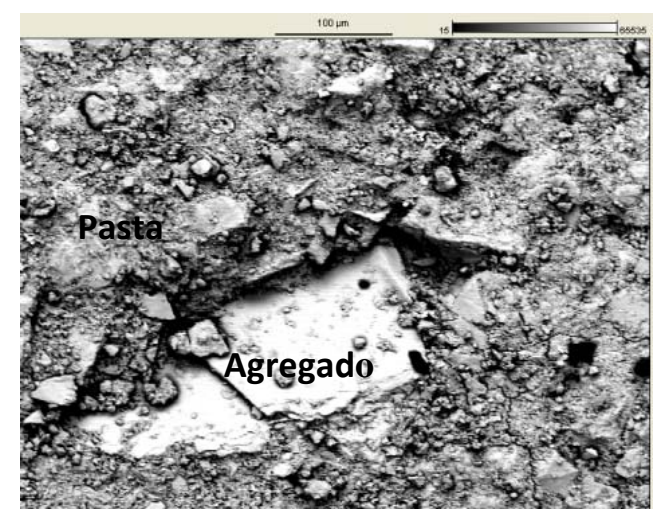

Aumento 250x

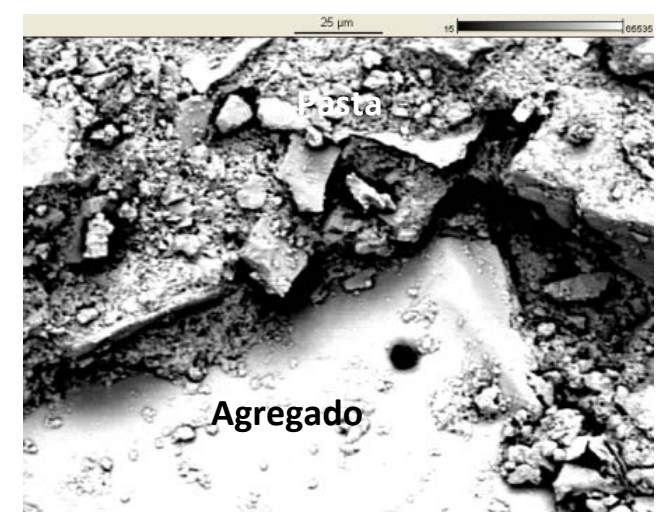

Aumento 750x

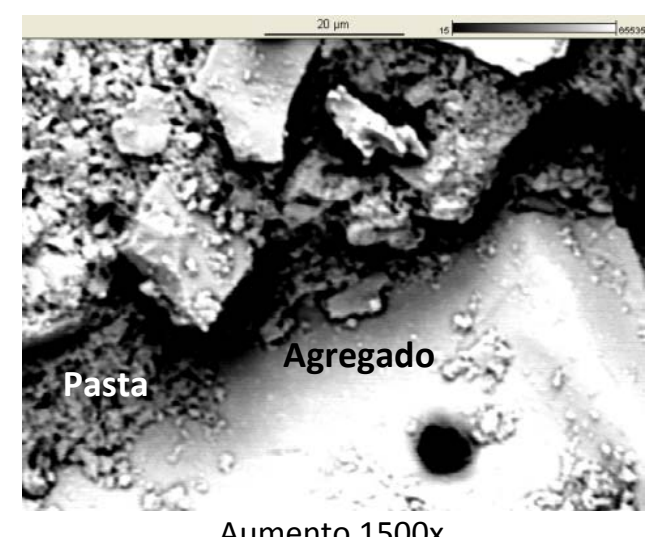

Aumento 1500x Aumento 2000x

Figura 101- Observações com MEV BSE na mistura CCR1-PF

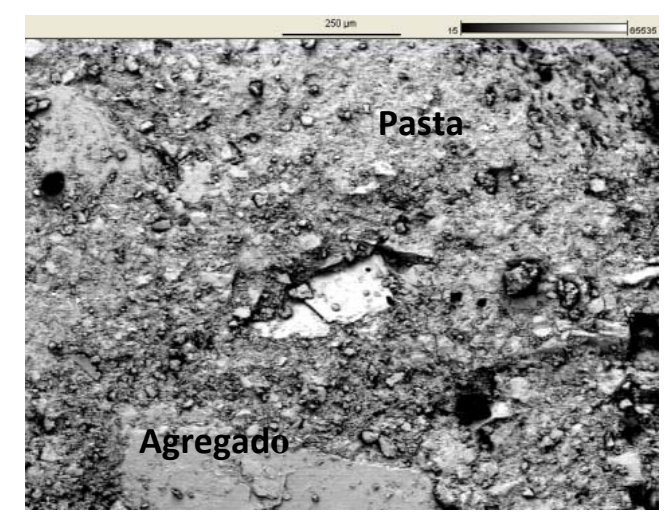

Aumento 100x

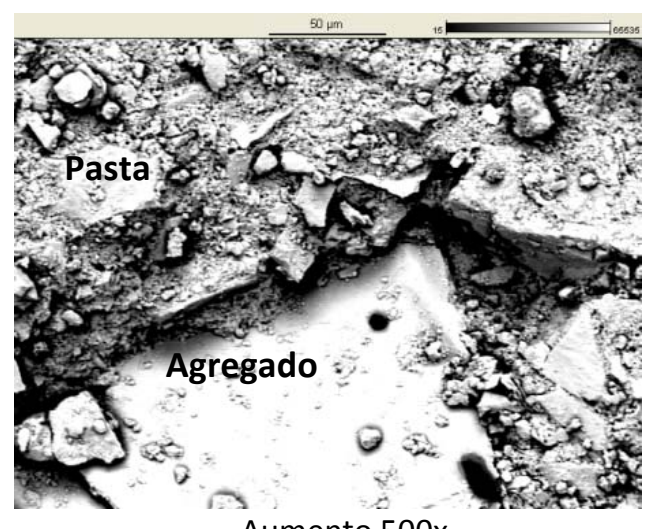

Aumento 500x

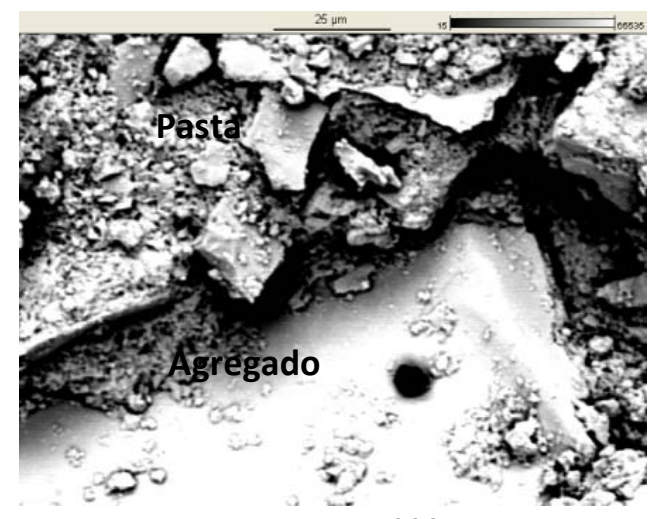

Aumento 1000x

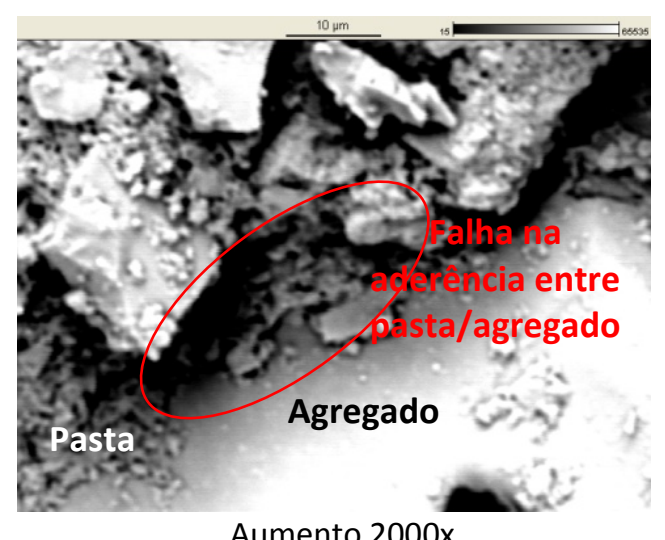

(u) 


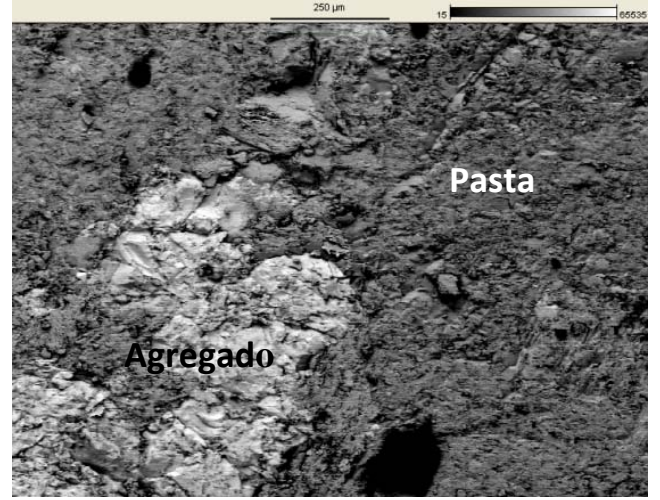

Aumento $100 x$

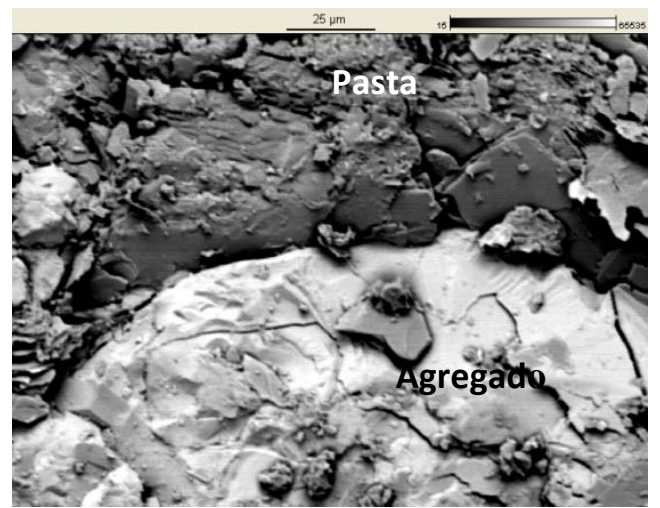

Aumento $750 x$

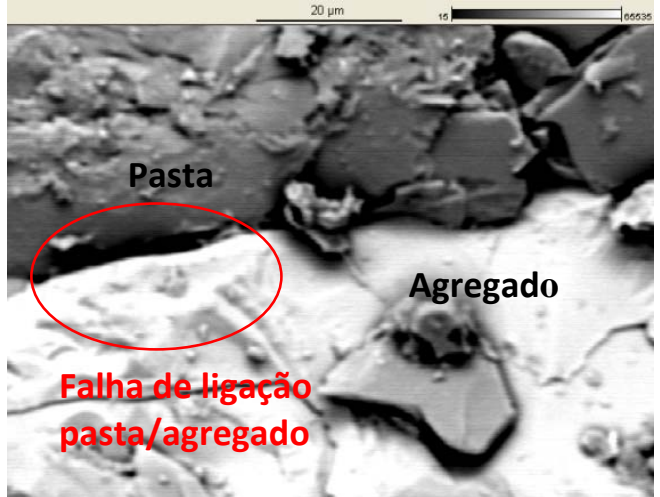

Aumento $1500 x$

Aumento 2000x

Figura 102 - Observações com MEV BSE na mistura CCR1-BF

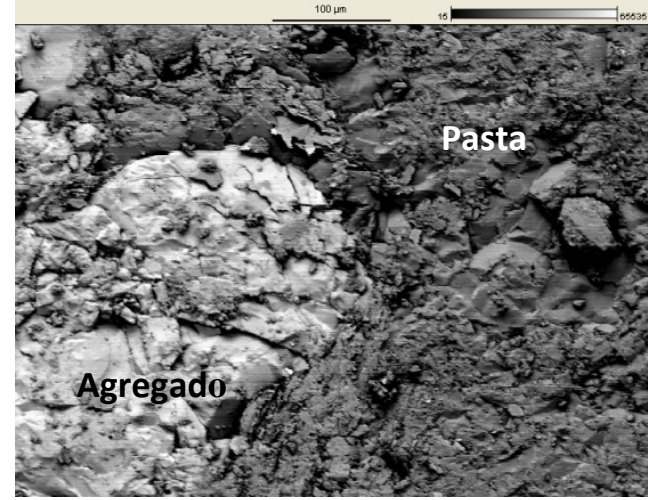

Aumento 250x

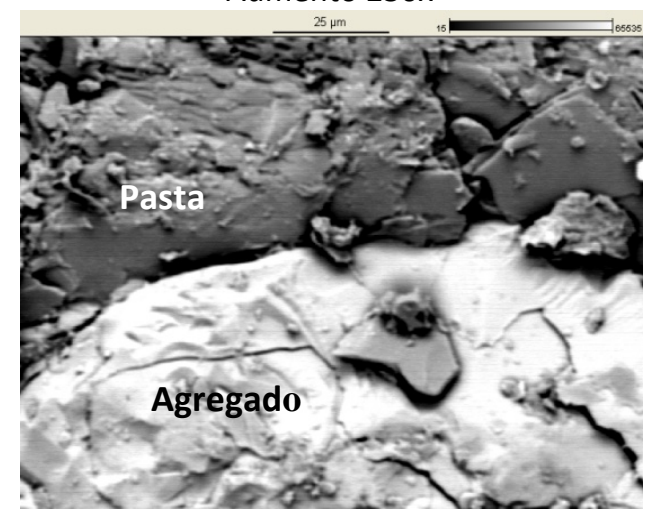

Aumento $1000 x$

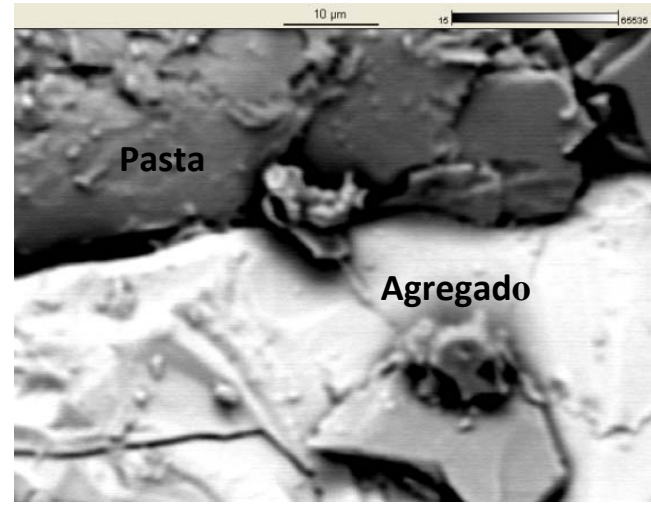

\subsection{MICROSCOPIA ÓPTICA}

Pelas imagens obtidas no microscópio óptico (Figuras 103 a 108), não se percebeu grandes diferenças entre as amostras de CCR produzidas com agregados naturais (CCR1 e CCR2) e aquelas produzidas com agregados de fresado asfáltico. Contudo, parece haver uma melhor ligação entre os agregados naturais e a pasta de cimento, ou 
seja, a menor resistência dos CCR feitos com agregados fresados pode estar relacionada com a baixa adesão mecânica das partículas do fresado asfáltico à matriz cimentícia. Desta forma, acredita-se ser esta uma das causas que contribuíram para que os CCR com agregados fresados tenham apresentado valores de resistência inferiores aos obtidos nos CCR1 e CCR2.
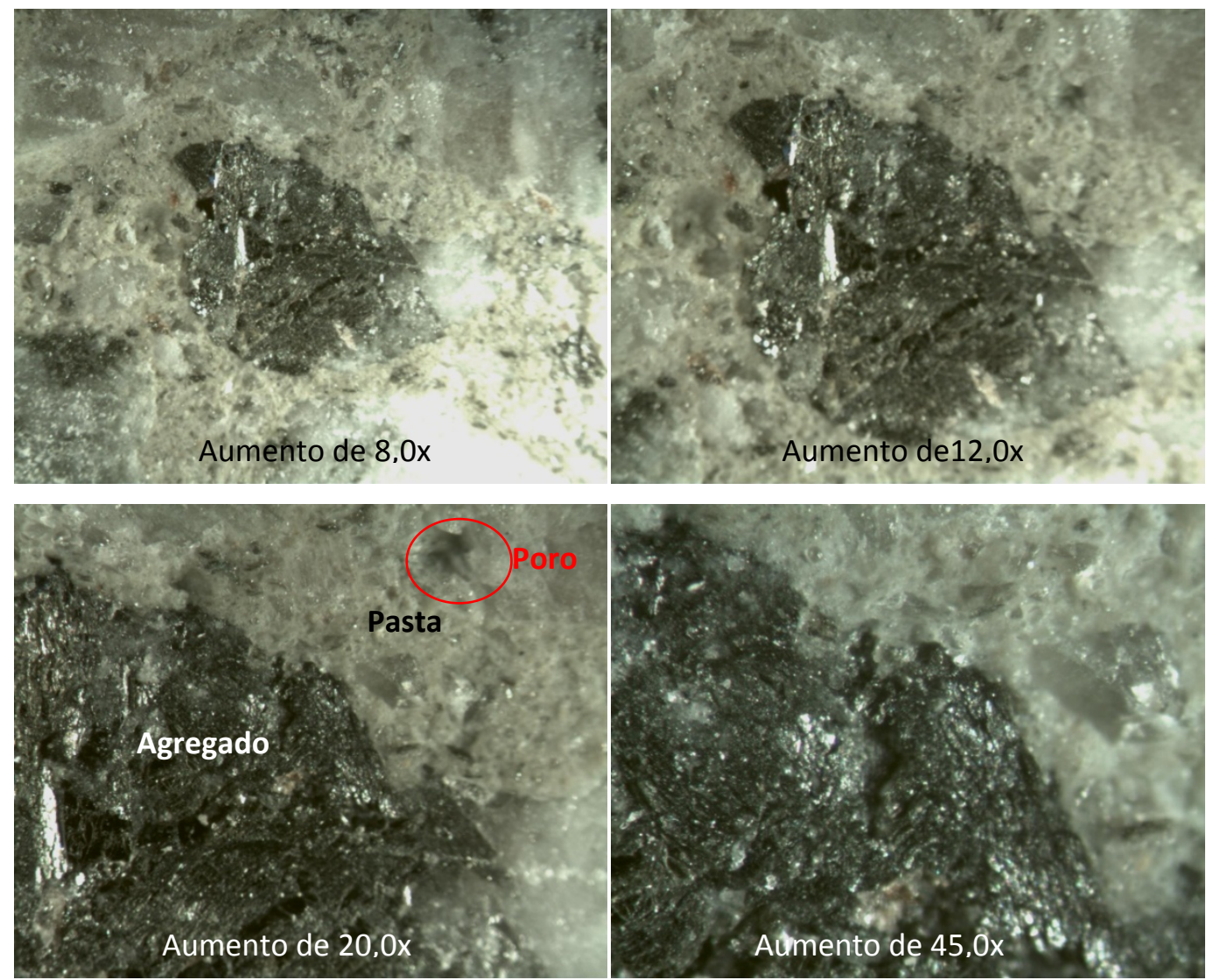

Figura 103 - Observações com microscópio óptico na mistura CCR1 


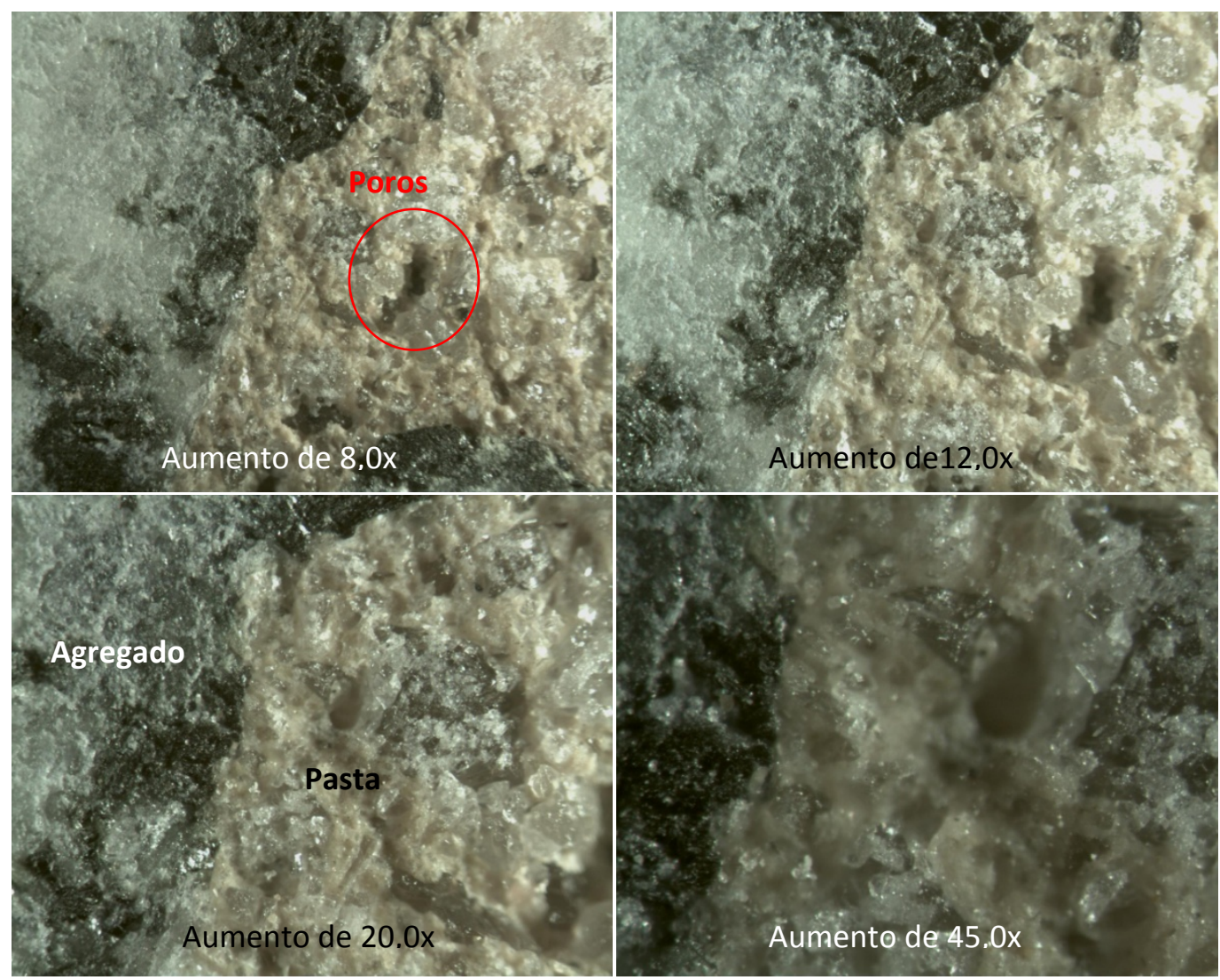

Figura 104 - Observações com microscópio óptico na mistura CCR2

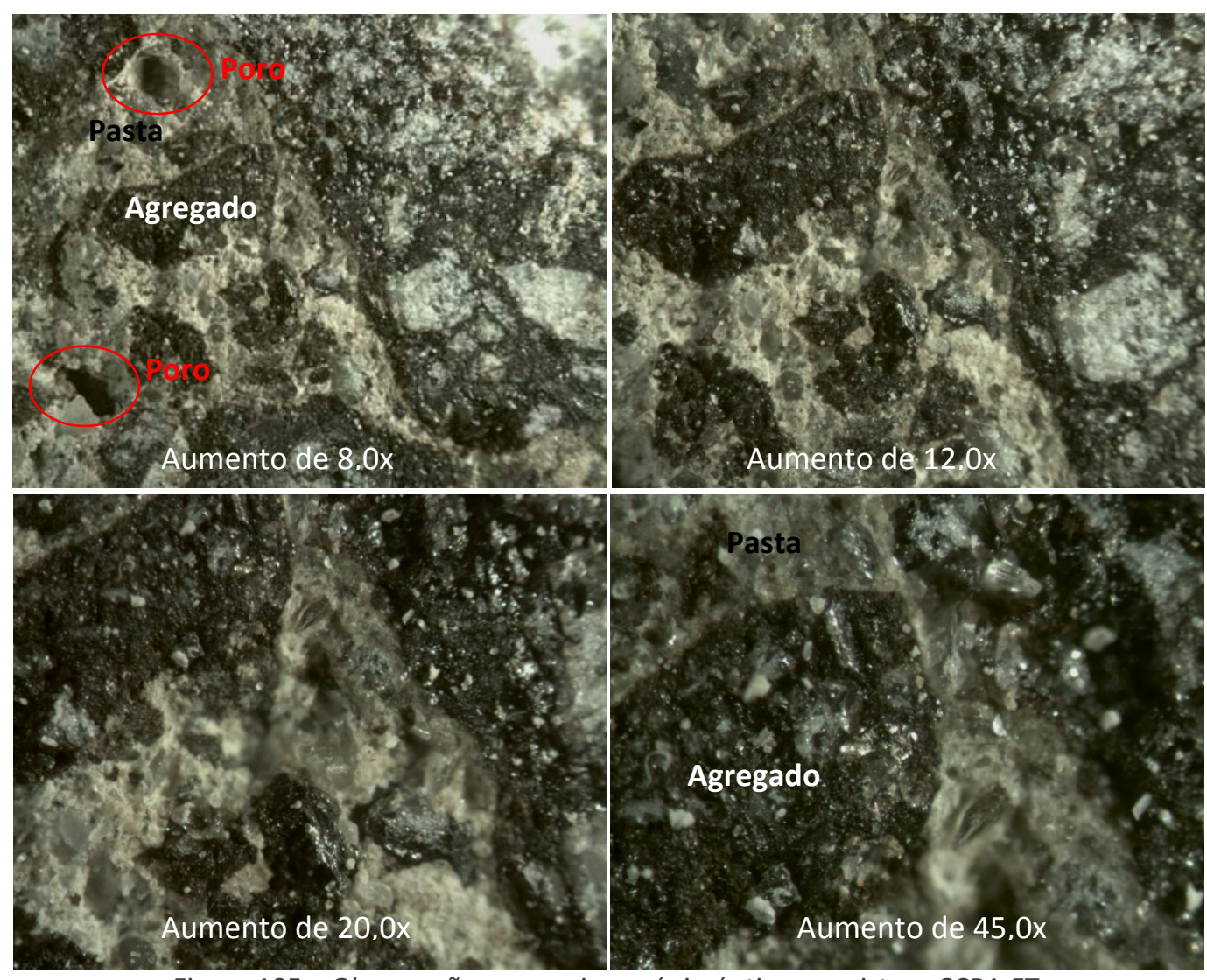

Figura 105 - Observações com microscópio óptico na mistura CCR1-FT 


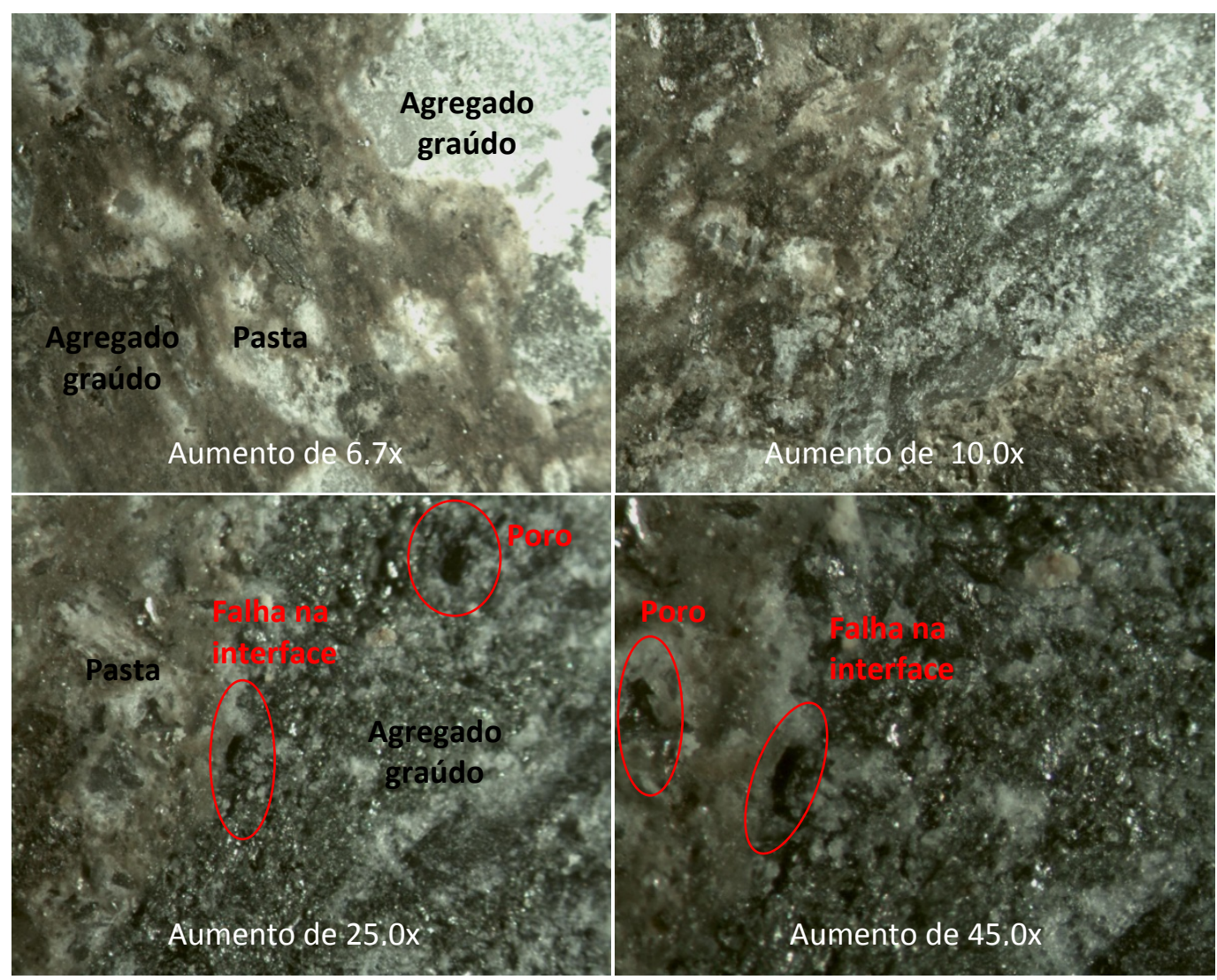

Figura 106 - Observações com microscópio óptico na mistura CCR1-AF

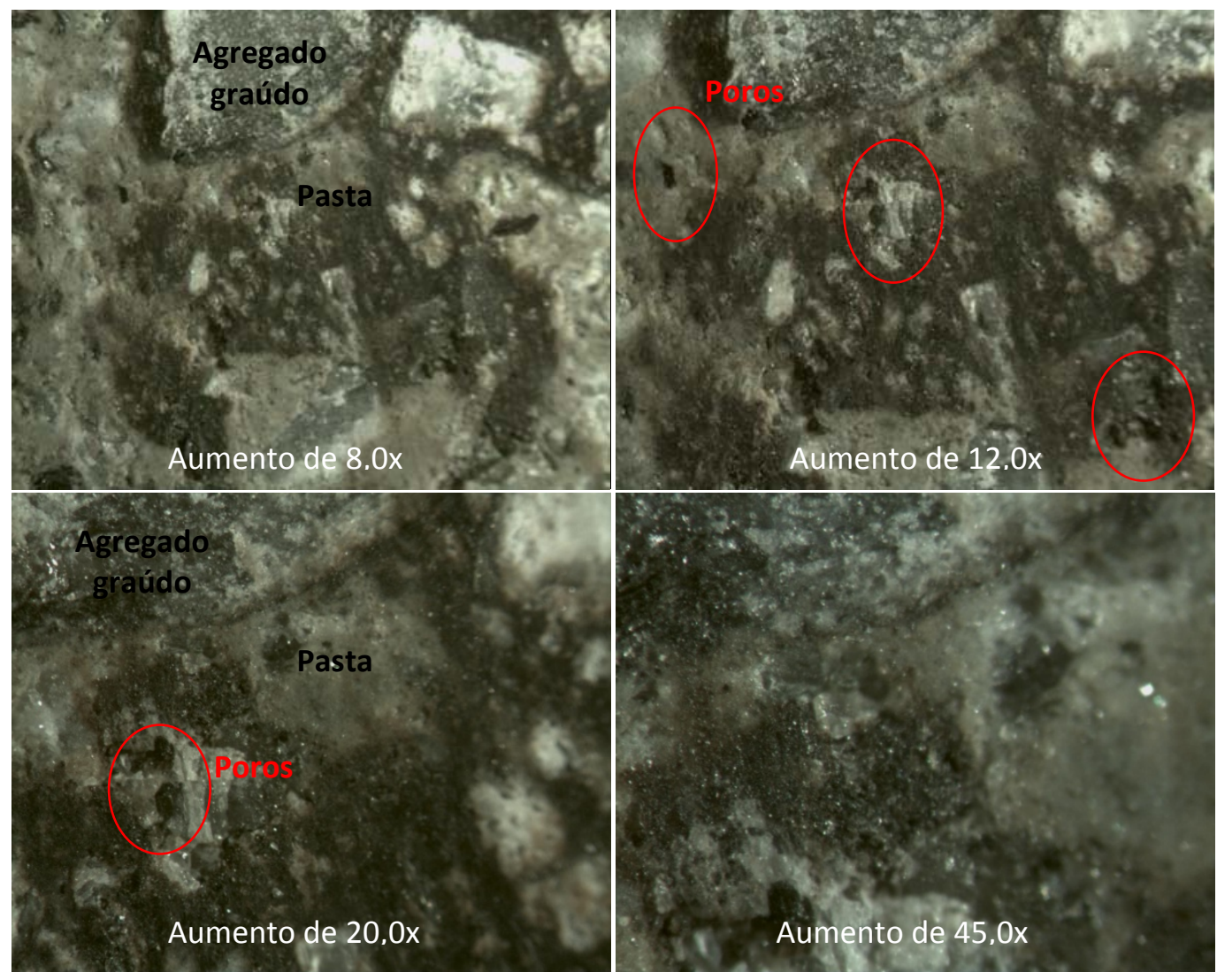

Figura 107 - Observações com microscópio óptico na mistura CCR1-PF 


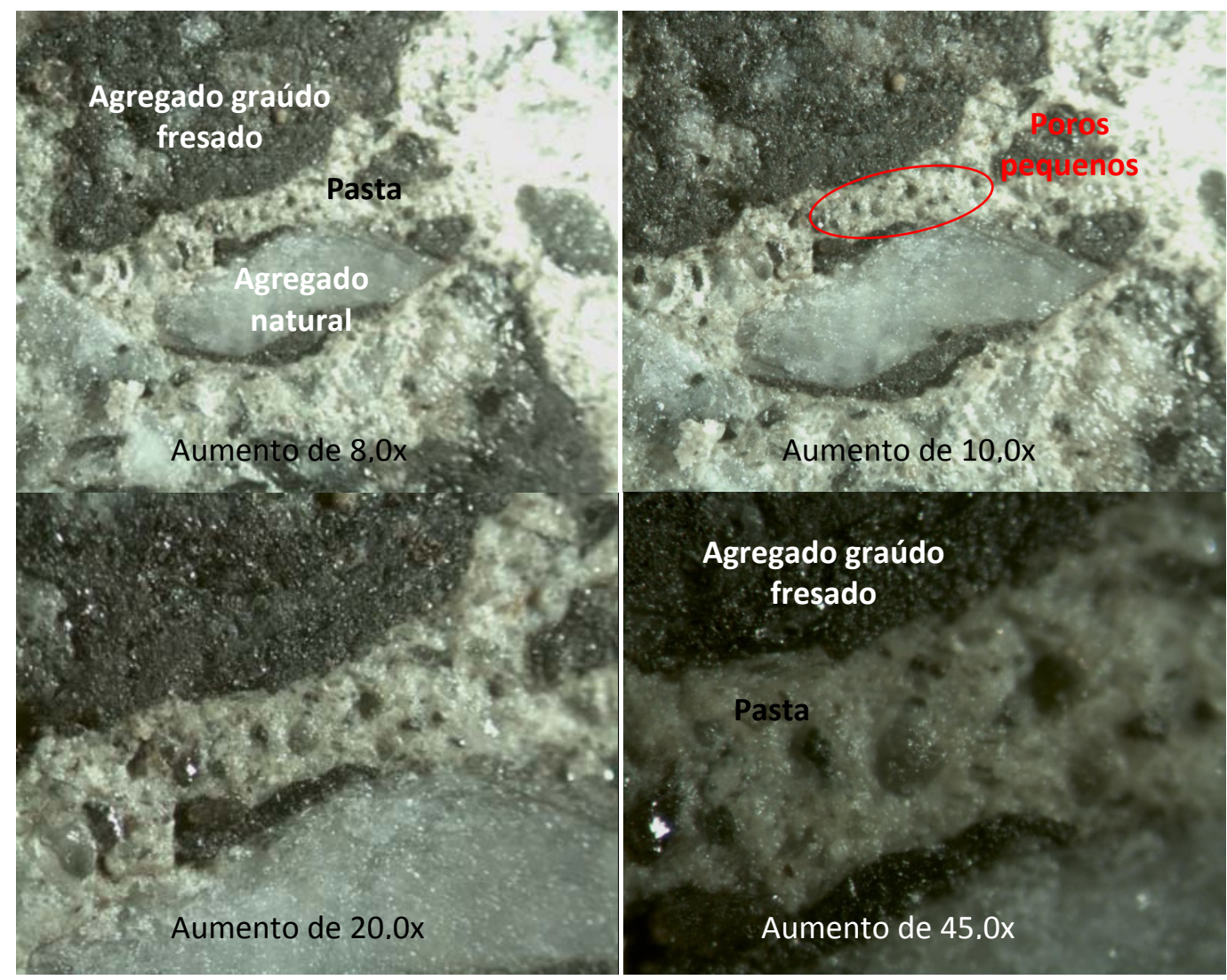

Figura 108 - Observações com microscópio óptico na mistura CCR1-BF

\subsection{OBSERVAÇÕES COM LUPA ESTEREOSCÓPICA}

De maneira semelhante às observações realizadas com microscópio óptico, as imagens obtidas com a lupa estereoscópica possibilitaram a verificação da existência de poros nas misturas, bem como o comportamento dos agregados na face rompida dos corpos de prova.

A mistura CCR1, aparentemente possui uma ligação mais forte entre pasta de cimento e agregados, observou-se uma baixa presença de poros e certa homogeneidade da mistura, como pode ser visto na Figura 109. 

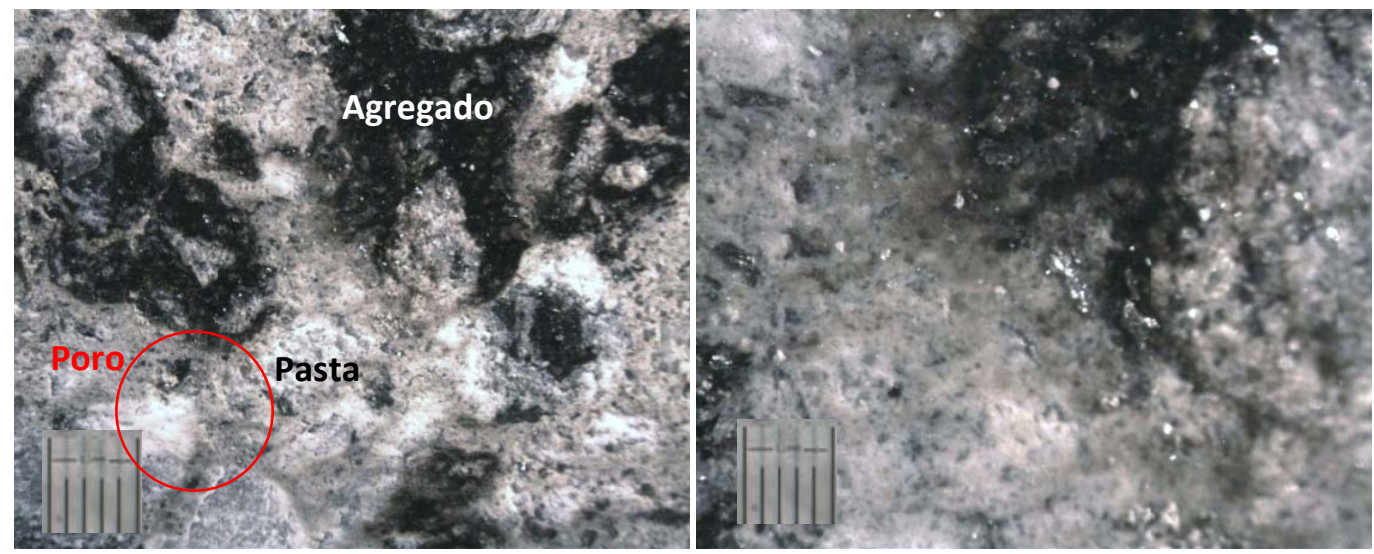

Figura 109 - Observações com lupa da mistura CCR1

A mistura CCR2 (Figura 110) apresentou maior quantidade de poros, em relação ao CCR1, boa ligação entre pasta de cimento e agregado. Os poros presentes nesta mistura são muito pequenos em relação aos observados na mistura CCR1.

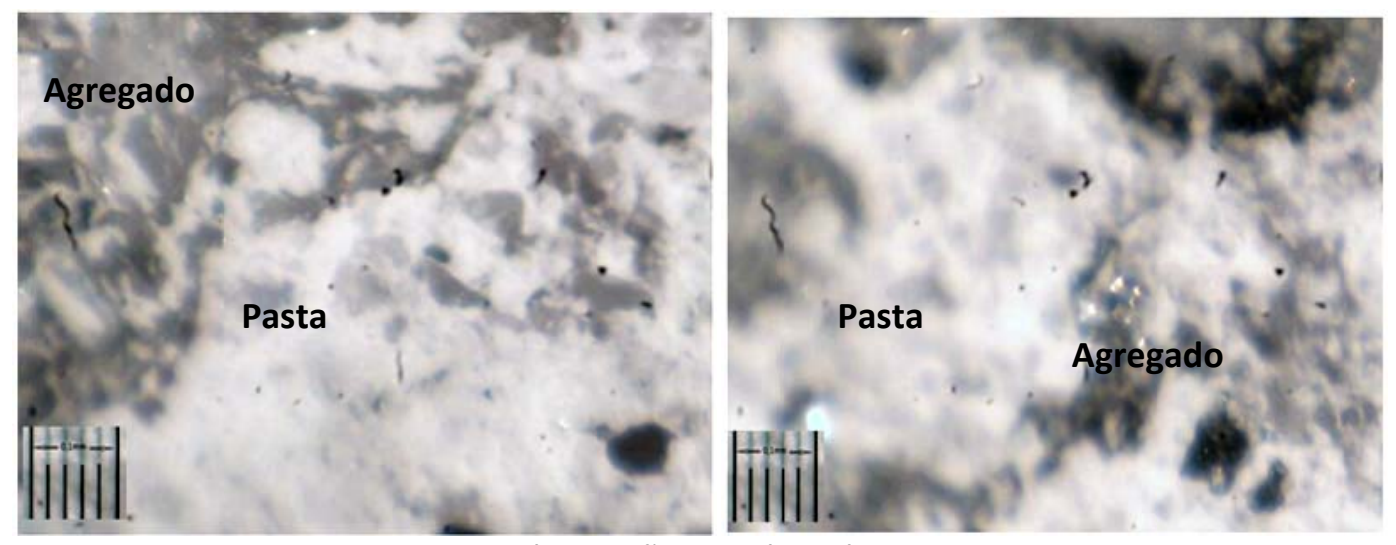

Figura 110 - Observações com lupa da mistura CCR2

Na mistura CCR-FT foi possível observar a presença de poros arredondados que são caracterizados pela presença de ar na mistura (Figura 111). As superfícies dos agregados fresados apresentaram relevo, significando que durante a ruptura não ocorreu quebra do agregado graúdo e sim que a ruptura se deu entre o agregado e a pasta de cimento, possivelmente ajudada pela presença do filme asfáltico. Também foi observado que a pasta de cimento, na maior parte da amostra, cobre os agregados graúdos, significando que a ruptura se deu na pasta de cimento. Entretanto, percebese a presença de agregados miúdos quebrados na face rompida. 


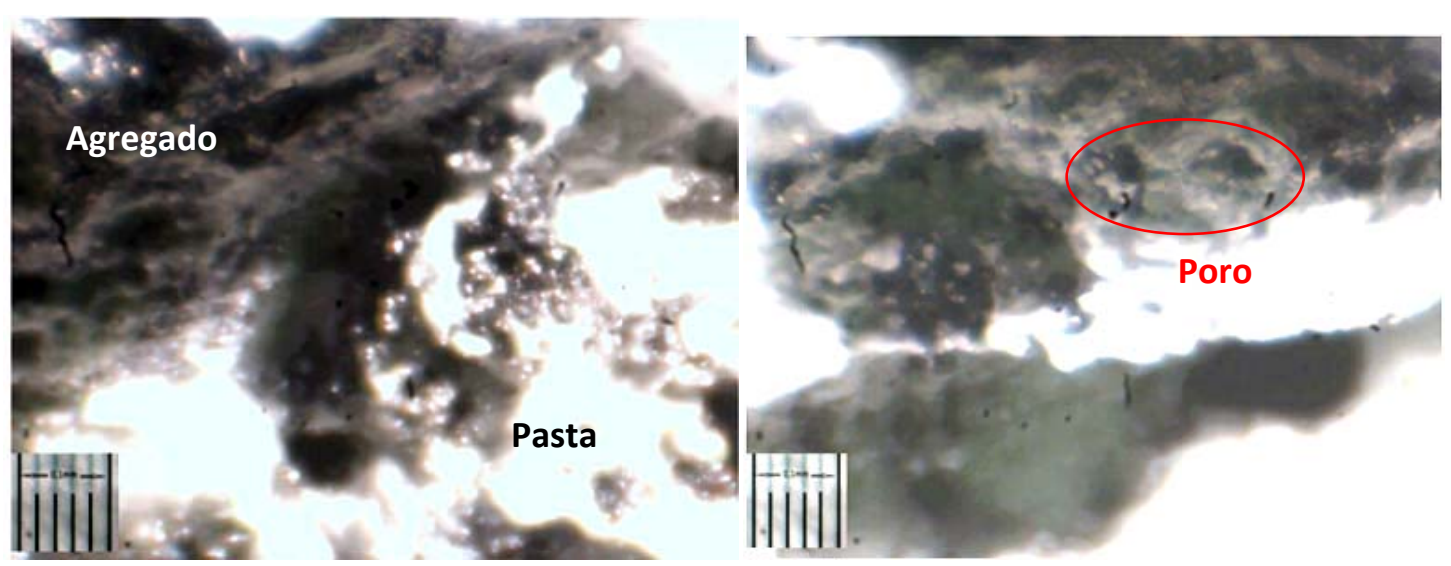

Figura 111 - Observações com lupa da mistura CCR1-FT

Na mistura CCR1-PF a presença de poros também é acentuada e tem formas arredondadas, ocasionado pela presença de ar na mistura. O agregado pedrisco fresado não quebrou na ruptura do corpo de prova (Figura 112).

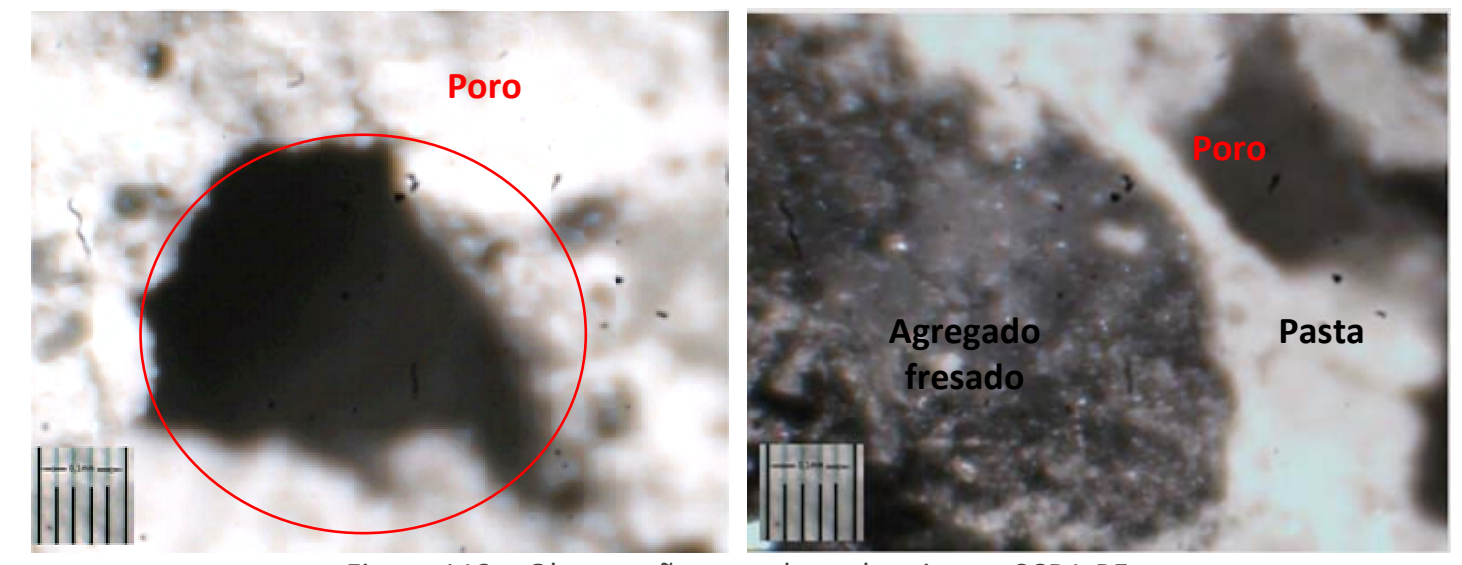

Figura 112 - Observações com lupa da mistura CCR1-PF

A mistura CCR1-AF apresentou uma quantidade elevada de poros muito pequenos, sendo esta, a mistura com maior porosidade entre todas as estudadas. Os grumos formados com grãos de areia fresados quebraram na ruptura do corpo de prova (Figura 113). 

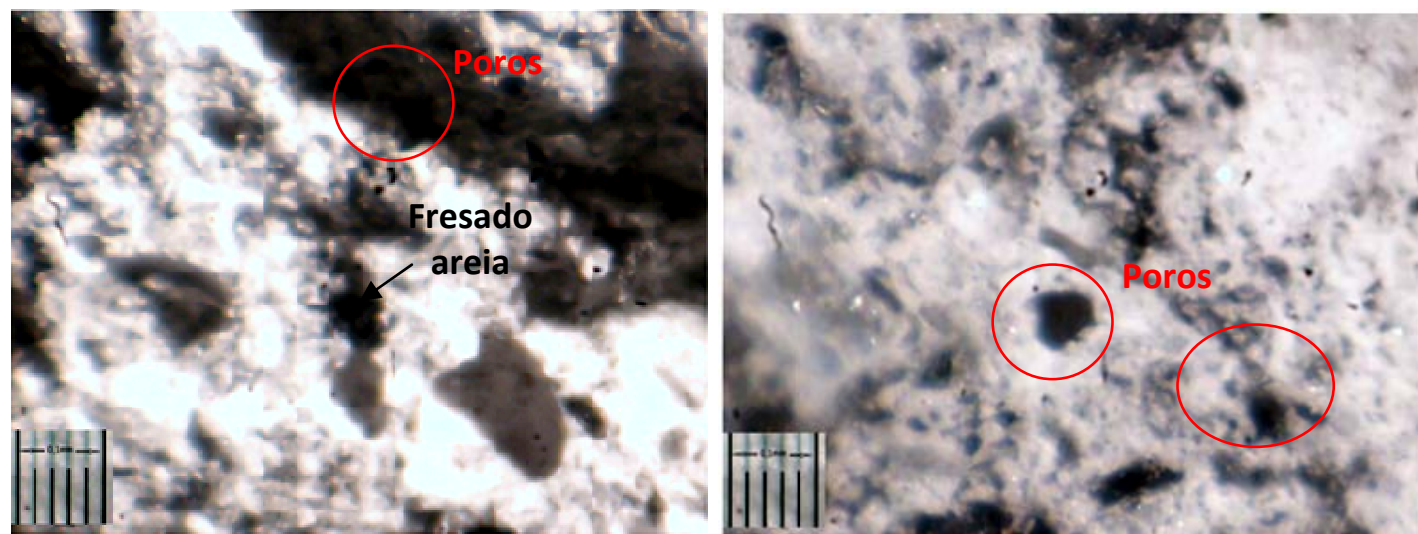

Figura 113 - Observações com lupa da mistura CCR1-AF

Na mistura CCR1-BF observou-se a presença de poros grandes e arredondados e agregados graúdos com relevo, significando que a ruptura se deu na pasta de cimento e não no agregado (Figura 114).
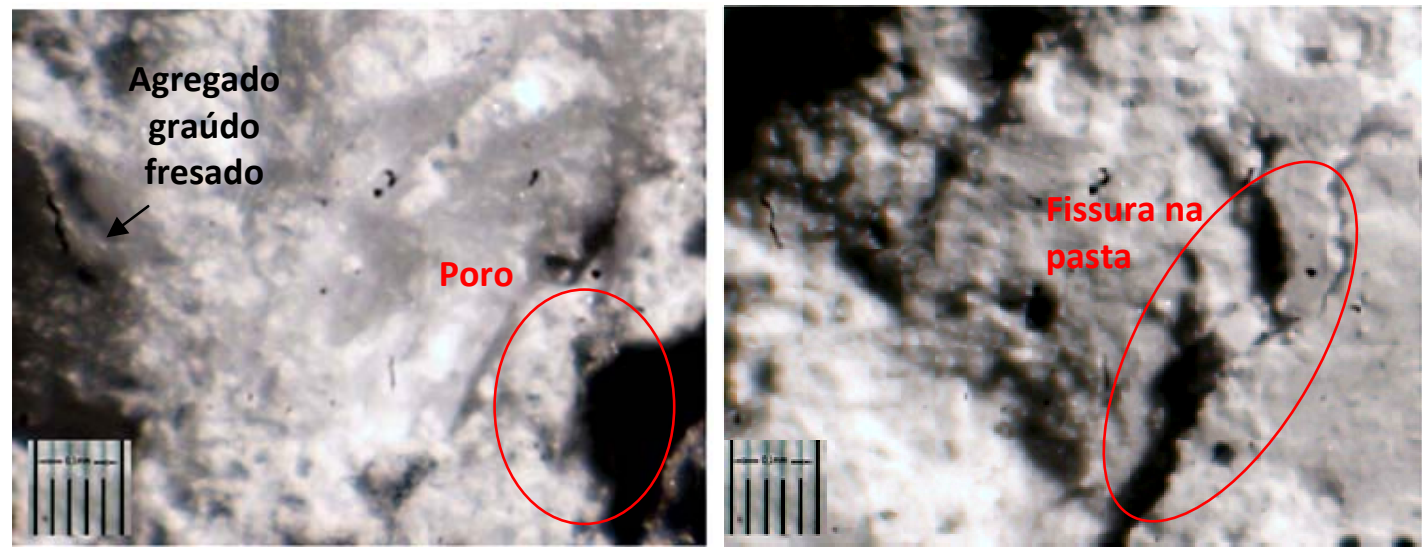

Figura 114- Observações com lupa da mistura CCR1-BF

Nas Figuras 115 a 120 estão apresentadas imagens das faces fraturadas dos CCR produzidos, as quais possibilitaram, a olho nu, observar a presença de porosidade, o comportamento dos agregados na face rompida, ou seja, se houve arrancamento ou quebra dos agregados. As figuras comprovam as conclusões já citadas acima. 


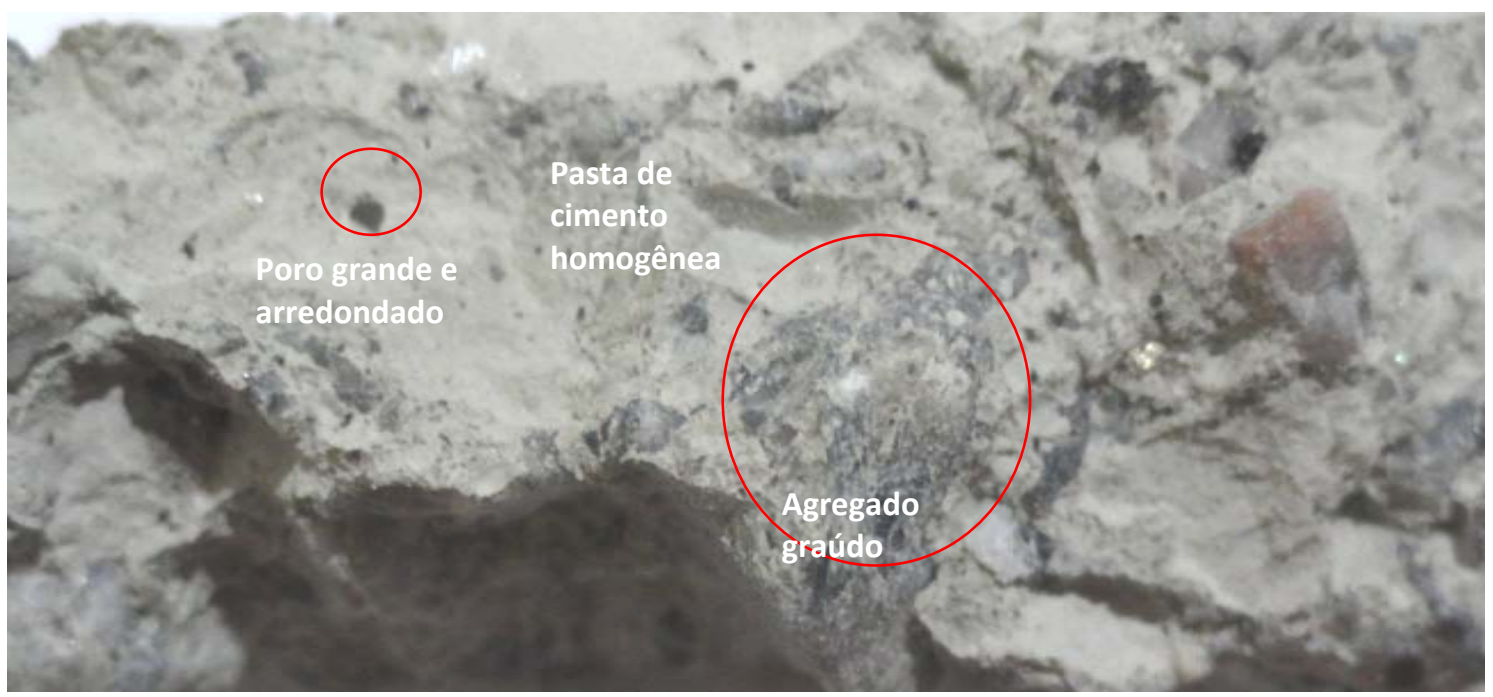

Figura 115 - Imagem da mistura CCR1

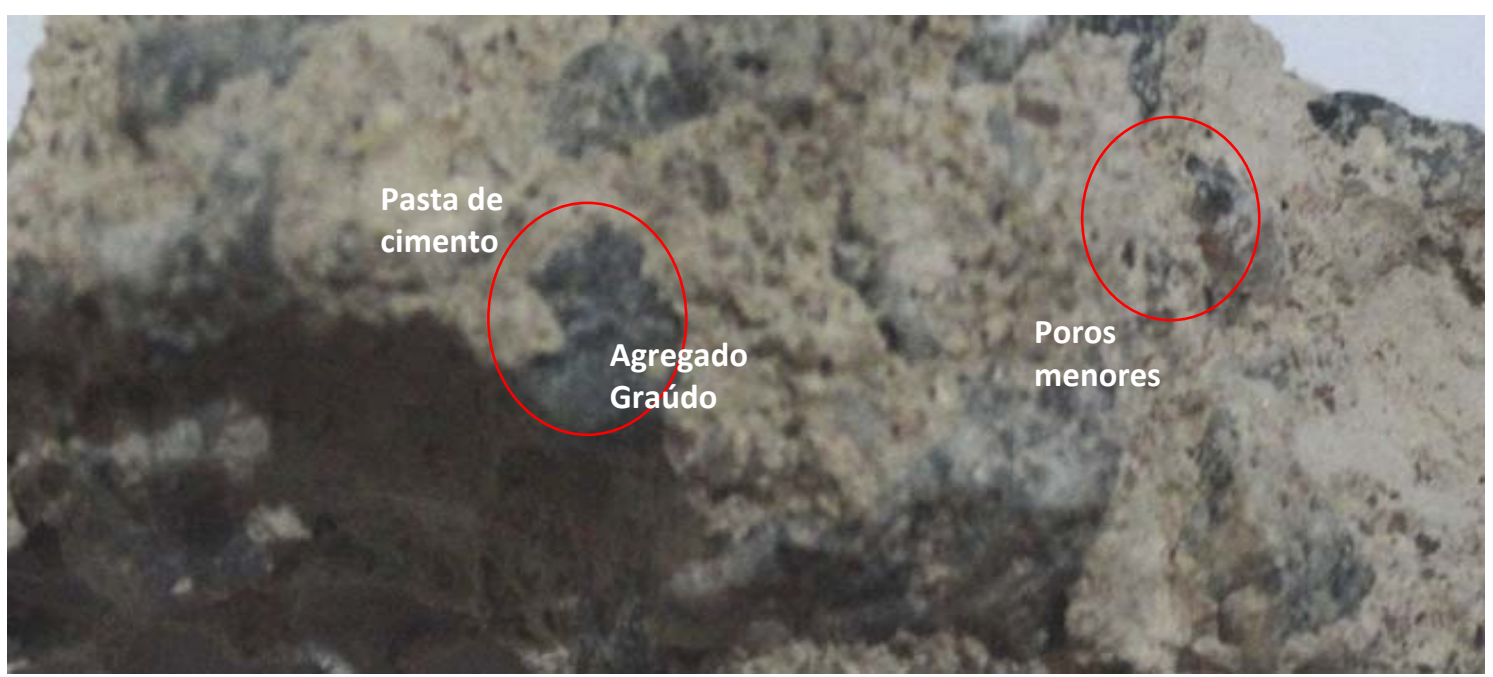

Figura 116 - Imagem da mistura CCR2

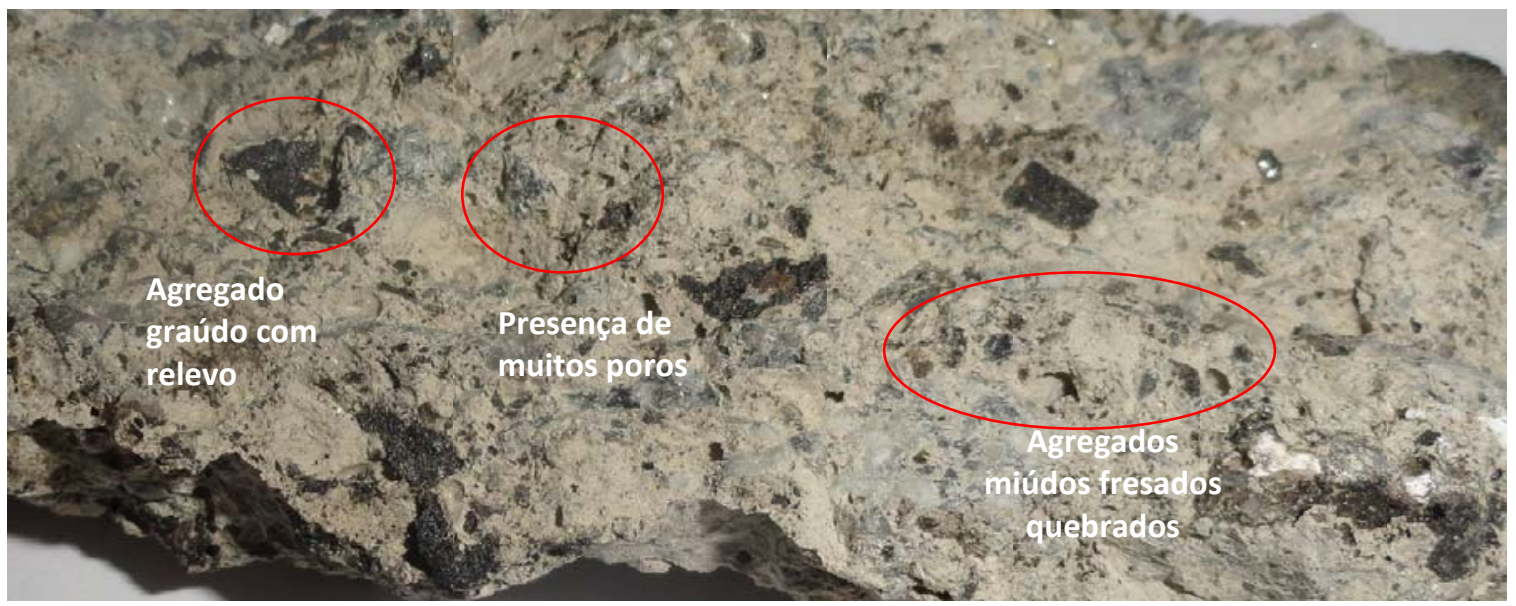

Figura 117 - Imagem da mistura CCR1-FT 


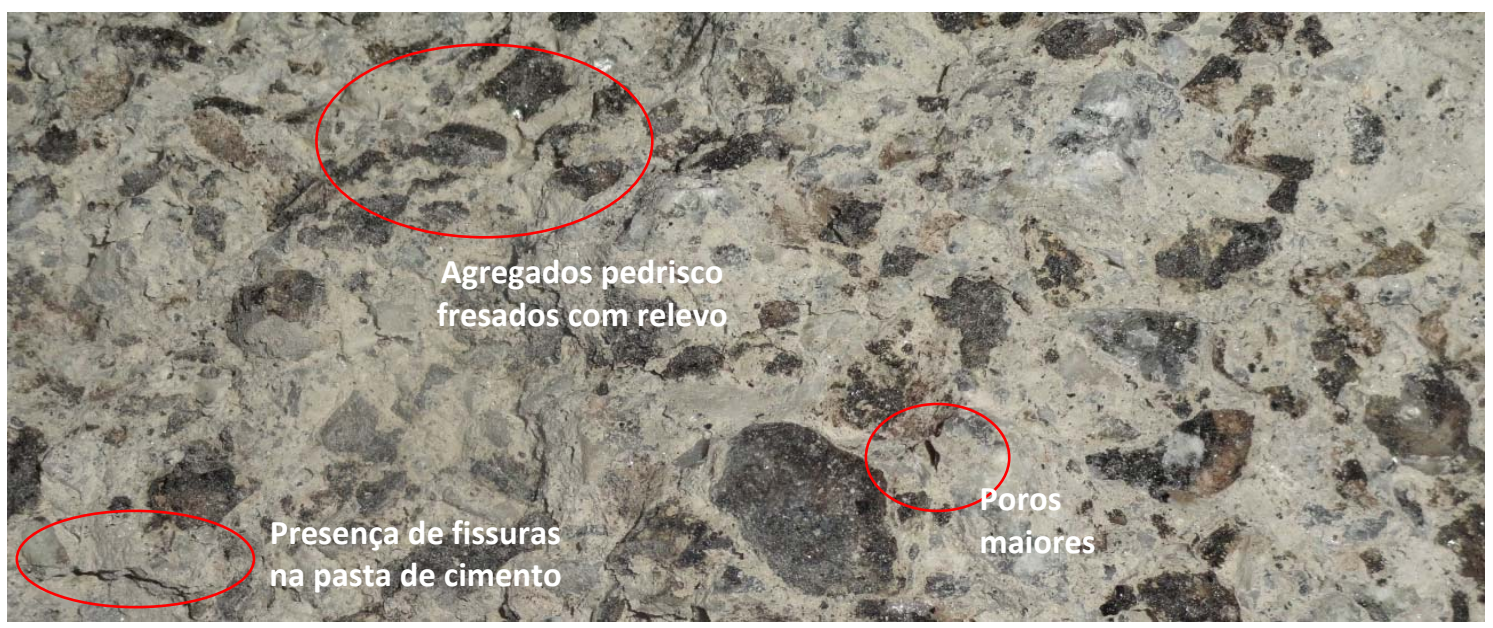

Figura 118 - Imagem da mistura CCR1-PF

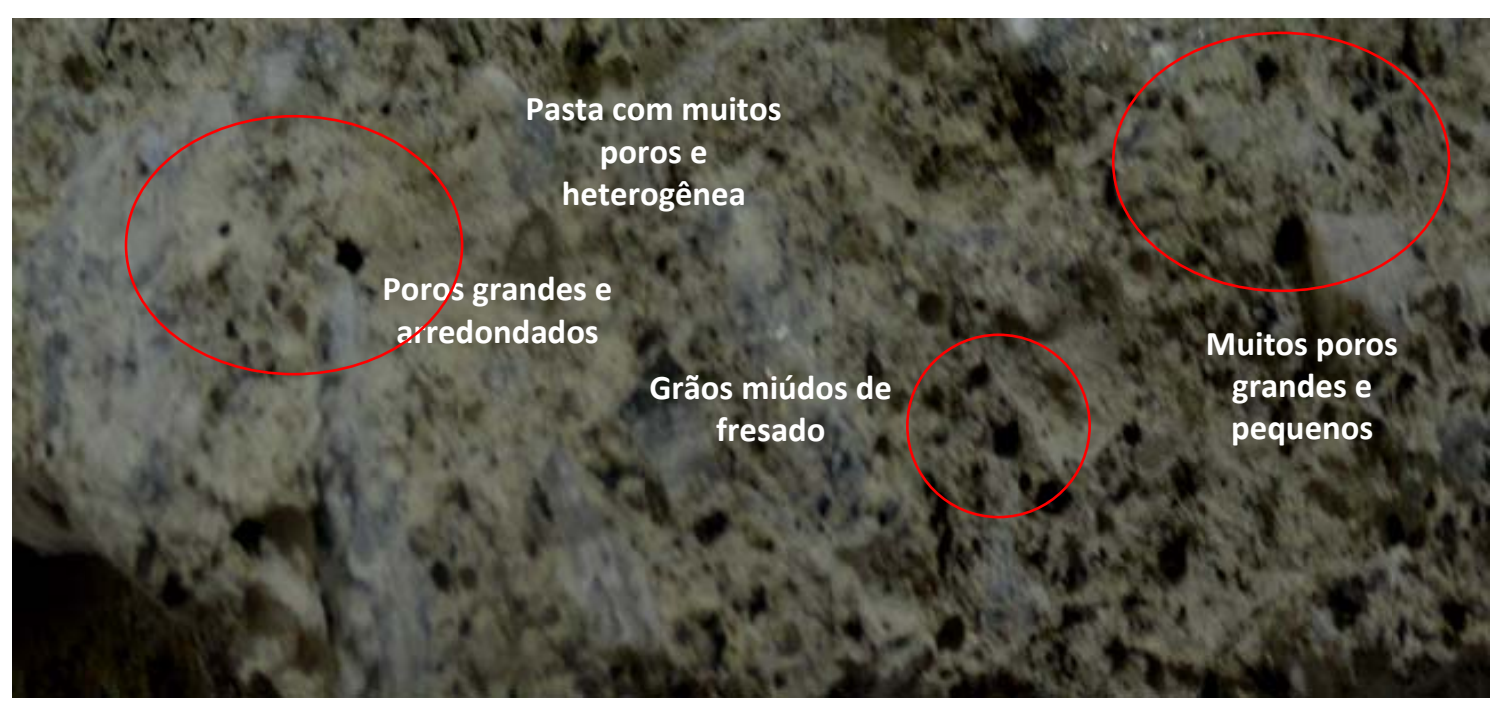

Figura 119 - Imagem da mistura CCR1-AF

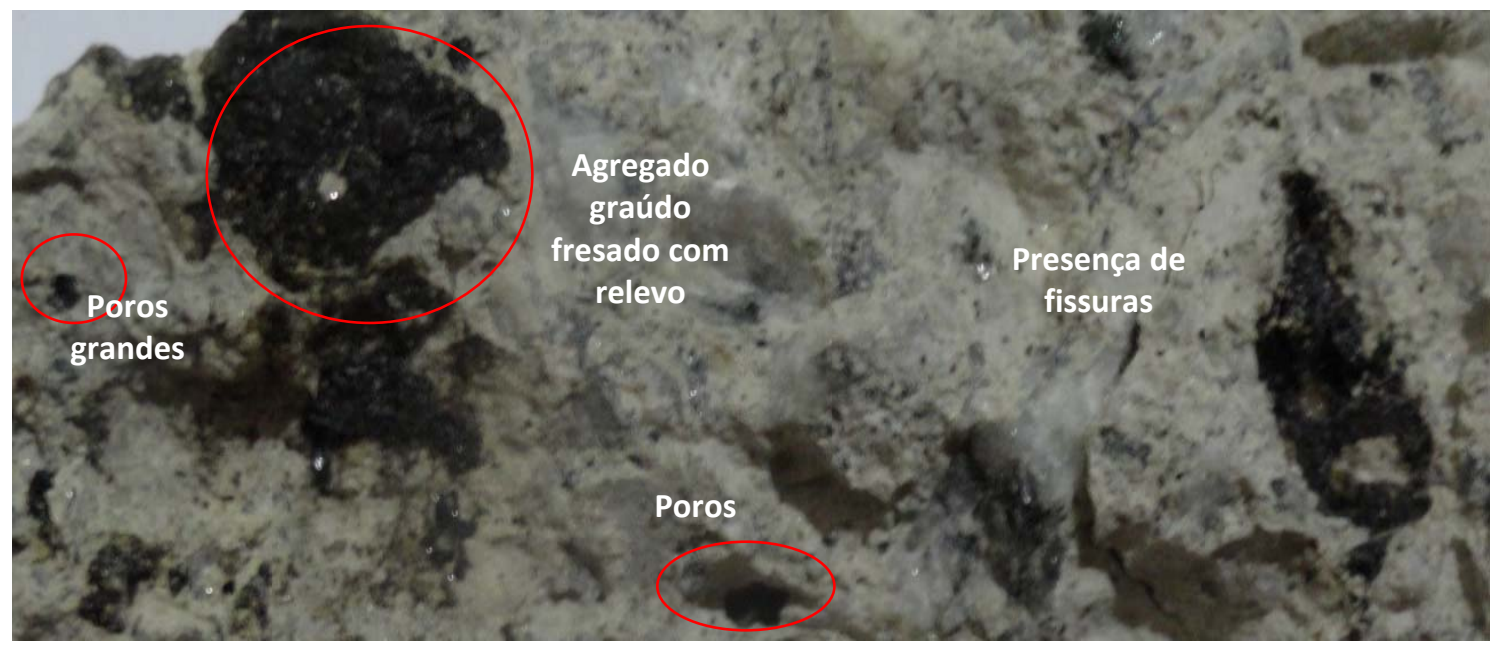

Figura 120 - Imagem da mistura CCR1-BF 


\subsection{COMPARAÇÃO DE ESTRUTURAS DE PAVIMENTOS COM BASES DE CCR CONVENCIONAL E CCR COM RAP}

Como forma de analisar e empregar os CCR confeccionados foram dimensionadas estruturas de pavimentos, para verificar a influência das diferentes misturas na composição das camadas do pavimento.

Para a verificação das tensões e deformações, atuante nas camadas de CCR, foi utilizado o Programa computacional ELSYM5. O Programa foi desenvolvido originariamente pela University of California at Berkeley.

O principal objetivo do programa é o cálculo das tensões e deformações atuantes em diversos pontos da estrutura de pavimentos, quando submetidos às cargas do tráfego.

Os parâmetros utilizados no dimensionamento das estruturas estão apresentados na Tabela 24. Além disso, considerou-se uma relação de tensões (RT = $\left.\sigma_{\text {aplicada }} / \sigma_{\text {ruptura }}\right)$ igual a 0,5 , como critério de fadiga.

Tabela 24 - Parâmetros utilizados no dimensionamento e espessuras obtidas para as estruturas de pavimentos

\begin{tabular}{|c|c|c|c|c|c|c|c|c|c|c|}
\hline Tipo CCR & \multicolumn{2}{|c|}{ CCR1 (Referência) } & \multicolumn{2}{|c|}{ CCR1-AF } & \multicolumn{2}{|c|}{ CCR1-PF } & \multicolumn{2}{|c|}{ CCR1-BF } & \multicolumn{2}{|c|}{ CCR1-FT } \\
\hline & $E(\mathrm{MPa})$ & $\begin{array}{l}\text { Esp. } \\
\text { (cm) }\end{array}$ & $\mathrm{E}(\mathrm{MPa})$ & $\begin{array}{l}\text { Esp. } \\
\text { (cm) }\end{array}$ & $\mathrm{E}(\mathrm{MPa})$ & $\begin{array}{l}\text { Esp. } \\
\text { (cm) }\end{array}$ & E (MPa) & $\begin{array}{l}\text { Esp. } \\
\text { (cm) }\end{array}$ & $\mathrm{E}(\mathrm{MPa})$ & $\begin{array}{l}\text { Esp. } \\
\text { (cm) }\end{array}$ \\
\hline CAUQ & 6.000 & 12,5 & 6.000 & 12,5 & 6.000 & 12,5 & 6.000 & 12,5 & 6.000 & 12,5 \\
\hline CCR & 24.000 & 10,0 & 13.400 & 22,0 & 12.100 & 10,0 & 10.500 & 12,0 & 8.000 & 14,0 \\
\hline BGS & 150 & 10,0 & 150 & 10,0 & 150 & 10,0 & 150 & 10,0 & 150 & 10,0 \\
\hline SUBLEITO & 120 & & 120 & & 120 & & 120 & & 120 & \\
\hline
\end{tabular}

Nas Figuras 121 a 125 estão apresentadas estruturas finais alcançadas para cada um dos CCR estudados na pesquisa. Observa-se que, em comparação ao CCR1, a estrutura que apresentou melhor resultado no dimensionamento foi aquela com base de CCR1-PF, obtendo a mesma estrutura do CCR1. O resultado é possível na medida 
em que se trabalha com $\mathrm{RT}=0,50$, já que se tem queda no módulo de elasticidade, bem como na tensão de ruptura.

A segunda estrutura com melhores resultados, em termos de espessuras, foi a CCR1-BF, seguida pela CCR1-FT. A estrutura que se mostrou menos viável para uso foi a dimensionada com CCR1-AF.

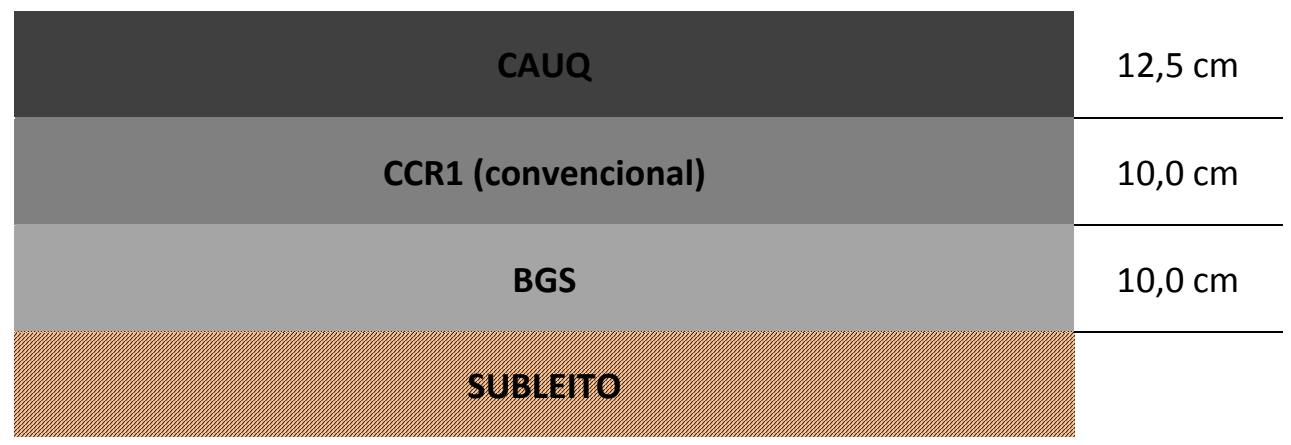

Figura 121 - Estrutura dimensionando com CCR1

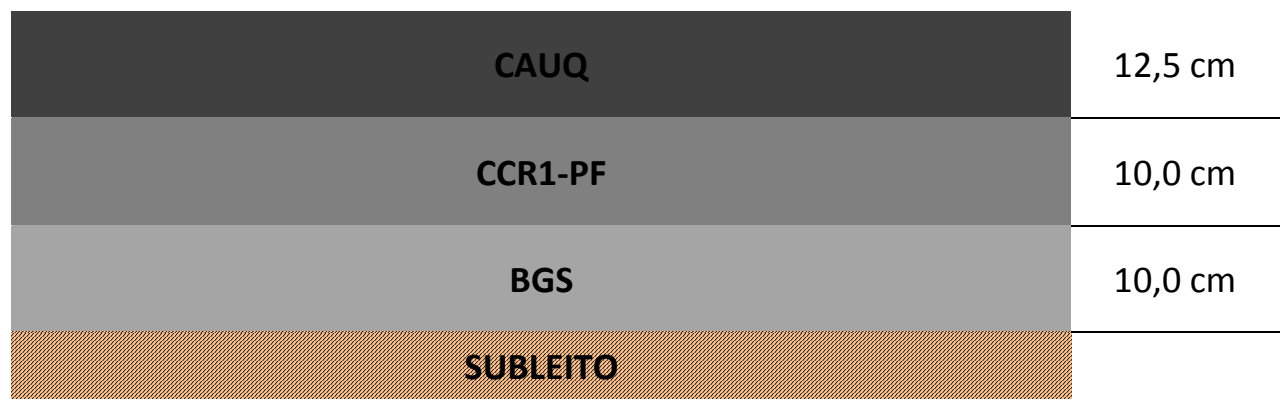

Figura 122 - Estrutura dimensionando com CCR1-PF

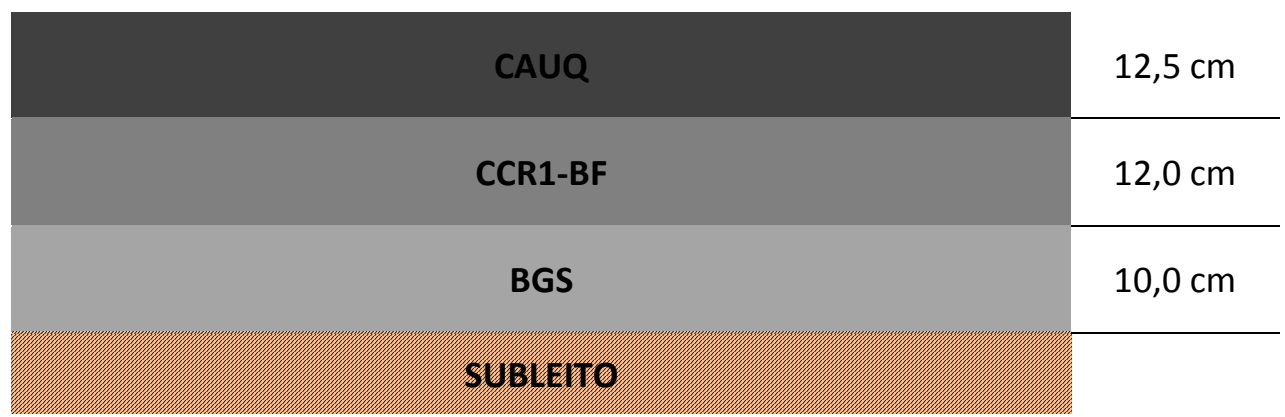

Figura 123 - Estrutura dimensionando com CCR1-BF 


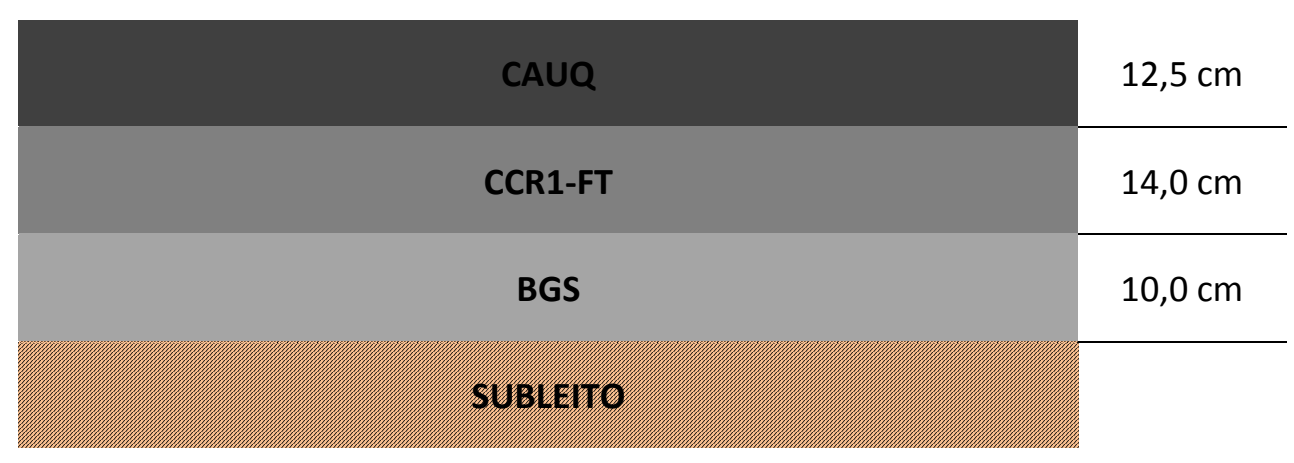

Figura 124 - Estrutura dimensionando com CCR1-FT

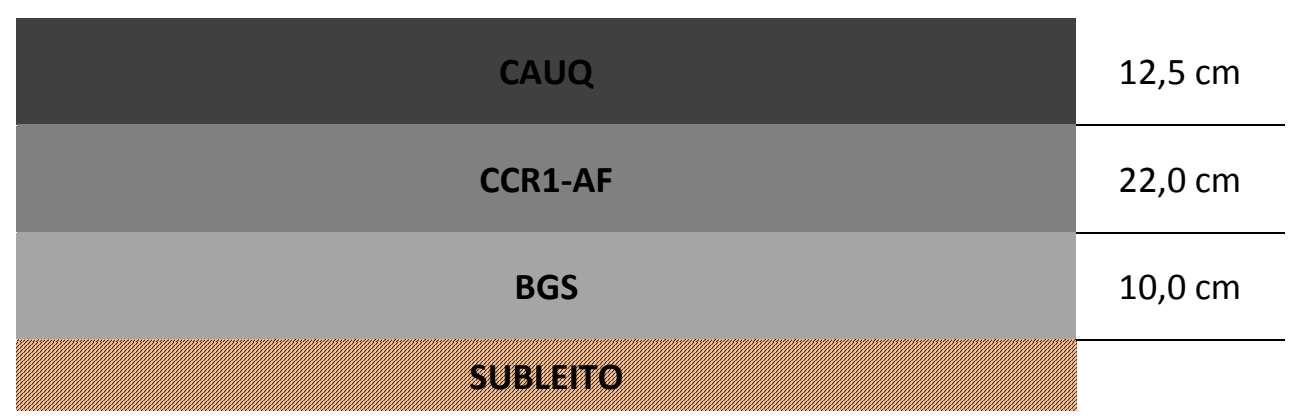

Figura 125 - Estrutura dimensionando com CCR1-AF

Embora a estrutura com CCR1-FT tenha apresentado maior espessura para a camada de CCR, ainda assim deve ser considerado seu uso como a opção mais viável do ponto de vista econômico e técnico. As vantagens desta fração estão na possibilidade do seu uso sem tratamentos prévios como, por exemplo, o peneiramento. Contudo, a fração pedrisco (CCR1-PF) não deve ser descartada já que apresentou os melhores resultados nos ensaios mecânicos e espessuras compatíveis com as utilizadas em estruturas com CCR convencional. 


\section{CONCLUSÕES E RECOMENDAÇÕES PARA NOVOS ESTUDOS}

O presente estudo pretendeu observar o comportamento de concretos compactados com rolo com a incorporação de fresados asfálticos (RAP) nas várias frações de agregado estudadas. Por meio de ensaios mecânicos e de observações microscópicas realizados em laboratório observou-se que:

- Os ensaios de compactação mostraram que a inserção de RAP nas misturas provocou quedas nos valores das massas específicas aparentes secas, quando comparadas com as misturas confeccionadas com areia natural e areia industrial (CCR1 - referência). Ainda constatou-se que o CCR produzido com areia natural apresentou menor massa específica aparente seca que aquele produzido com areia industrial;

- As curvas de compactação dos CCR confeccionados com RAP apresentaram comportamentos anômalos que podem ser justificados pela irregularidade na distribuição granulométrica dos agregados fresados, bem como por serem agregados fraturados devido às técnicas de remoção na pista;

- As misturas com RAP apresentaram maior número de vazios, fato que aparentemente interferiu na queda dos valores de massa específica dessas misturas;

- Nos ensaios de compactação foi possível perceber que o CCR1-AF apresentou maior umidade e maior exsudação durante o ensaio. A exsudação se manifestava com maior intensidade durante a compactação das últimas camadas. Esse fato ocorreu pelo excesso de água nos poros da misturas, gerando poro-pressão e fazendo com que a água migrasse para a superfície e ocasionando a formação de poros de ar incorporado; 
- A relação a/c dos CCR com RAP aumentaram em comparação ao CCR1 (referência). Este aumento pode ser justificado pela característica dos agregados fresados de serem fraturados e, pela presença do filme asfáltico em torno dos agregados. O CCR que apresentou maior relação a/c foi o CCR1-AF, seguido pelo CCR1-FT. Essas duas frações granulométricas, areia e faixa total, foram as que apresentaram maiores quedas de resistência nos ensaios de compressão diametral;

- A tensão de ruptura das misturas com RAP, nos ensaios de compressão diametral, apresentou quedas significativas quando comparados ao CCR1 (referência). O CCR1-AF teve a maior queda, ficando em torno de 60\%, o CCR1-PF teve queda de 33\%, o CCR1-BF apresentou queda de aproximadamente $40 \%$ e para o CCR1-FT a diminuição na resistência foi de cerca de 51\%. O CCR2 apresentou queda menos expressiva em relação ao CCR1, ficando em torno de $15 \%$;

- Os corpos de prova cilíndricos dos CCR1 e CCR2, ensaiados à tração indireta, apresentaram fraturas do tipo abruptas e cônicas com separação do cilindro, caracterizadas pelo rompimento da argamassa. Entretanto, os CCR com incorporação de RAP apresentaram fraturas sutis, ou seja, os cilindros, na sua maioria, não se separaram e continuaram sustentando alguma carga após a fratura inicial. Isto se caracteriza pelo fato de que a ruptura se dá no meio do agregado fresado que já está fraturado antes de ser incorporado à mistura;

- Os módulos de elasticidade dos CCR com RAP, nos cilindros, obtidos por meio da curva tensão $x$ deformação (strain gage), apresentaram diminuições bruscas nos seus valores. A maior foi observada no CCR1-FT;

- $\quad$ Os CCR com RAP apresentaram quedas significativas das tensões de ruptura nos ensaios de tração na flexão, mas menores que aquelas observadas nos ensaios de compressão diametral;

- Os módulos de deformação à tração obtidos por meio do ensaio de tração na flexão também apresentaram quedas para os CCR com RAP. As maiores quedas foram observadas no CCR1-BF e no CCR1-FT, como esperado, já que foram as duas misturas que apresentaram as menores resistências neste ensaio; 
- Os módulos de deformação à tração obtidos por meio da curva tensão $x$ deformação (strain gage) apresentaram valores menores que aqueles obtidos com medida de flecha (LVDT);

- No ensaio de determinação da velocidade por pulso de onda ultrassônica, constatou-se que a compactação dos corpos de prova durante a moldagem, se deu de forma homogênea, apresentando velocidades de onda muito parecidas em todos os corpos de prova (cilíndricos e prismáticos) ensaiados para cada mistura;

- Os módulos dinâmicos obtidos por meio do ensaio de ultrassom foram os que apresentaram maiores valores, sendo que o CCR1-BF foi o que manteve o valor mais próximo ao CCR1;

- Os ensaios de tenacidade mostraram que tanto o CCR1 quanto o CCR1-FT apresentaram curva-R crescente e sem patamar. Fato que pode ter ocorrido devido ao tamanho relativamente grande da zona de processo em relação ao do corpo de prova;

- Todos os CCR ensaiados apresentaram altos valores de resistência à propagação da trinca durante o processo de crescimento da mesma, ou seja, tiveram um bom desempenho de curva-R. Este comportamento é muito favorável para pavimentos, pois apresenta maior dificuldade à propagação catastrófica da trinca e consequentemente aumentam a vida útil do pavimento, permitindo manutenção antes de haver perda estrutural do mesmo;

- Embora o CCR1-FT tenha apresentado valores de resistência e tenacidade menores que aqueles alcançados pelo CCR1 (referência), ainda assim atingiu valores de resistência aceitáveis para base de pavimentos e bons resultados de curvas-R crescentes;

- As imagens de microscopia eletrônica de varredura foram importantes na medida em que possibilitaram a observação do aspecto da pasta no entorno do agregado fresado. Ficou evidente a falta de uma ligação mais forte entre pasta e agregado fresado;

- Pelas análises estatísticas pode-se dizer que para os corpos de prova cilíndricos, em relação à média das resistências obtidas nos ensaios de tração indireta, os 
CCR não pertencem a um mesmo universo, ou seja, não são semelhantes quando se compara o CCR1 com os demais CCR estudados. Da mesma forma, os CCR com fresados são diferentes entre si. Esses resultados podem ser influenciados pelo pequeno número de amostras ensaiadas;

- Quanto aos módulos de elasticidade das amostras cilíndricas, fica evidente que CCR1 em relação ao CCR2 e ao CCR1-AF pertencem ao mesmo universo de amostras, diferentemente das demais amostras. CCR1-AF é semelhante ao CCR1$\mathrm{BF}$, assim como o CCR1-PF que é semelhante ao CCR1-BF e ao CCR1-FT;

- No caso dos corpos de prova prismáticos a análise estatística apontou que o CCR1 é semelhante ao CCR1-PF, que o CCR1-AF é semelhante ao CCR1-PF e que CCR1-FT pertence ao mesmo universo do CCR1-BF;

- Os módulos de elasticidade analisados estatisticamente mostraram que na comparação de CCR1/CCR2, CCR1-AF/CCR1-PF e CCR1-FT/CCR1-BF as amostras pertencem ao mesmo universo, não sendo rejeitada a hipótese de igualdade das mesmas;

As seguintes conclusões são possíveis de serem estabelecidas neste trabalho:

- $\quad$ O agregado fraturado combinado com o filme asfáltico e com a maior relação a/c, trabalham em conjunto para a perda da capacidade de resistência e de deformação das misturas. Esse fato combinado com as diferentes quantidades de agregado de cada fração tende a prejudicar as propriedades mecânicas dos CCR produzidos com RAP;

- Em relação à umidade das misturas, poderia se ter reduzido o teor de umidade, pois houve exsudação da água. A redução da umidade poderia implicar em melhoria da resistência mecânica e do módulo de elasticidade;

- O módulo de elasticidade é reduzido pela presença dos agregados compostos (grumos) que contém fase asfáltica. Além disso, o agregado sofreu fratura mecânica pela fresagem que por consequência, reduziu seu módulo; 
- A fração que apresentou os melhores resultados mecânicos e em termos de espessuras de CCR foi a CCR1-PF, e seu uso não deve ser ignorado, mesmo que para isso seja necessário o seu peneiramento;

- A fração que se mostra mais viável técnica e economicamente, para uso em pavimentos, é a CCR1-FT. Esta fração tem a vantagem de poder ser utilizada sem tratamentos prévios ou peneiramento. Portanto, implica em menores custos com transportes, menor emissão de poluentes, diminuição na exploração de pedreiras entre outros benefícios ambientais;

- Embora a incorporação do RAP na mistura de CCR diminua a resistência das misturas e afete todos os parâmetros mecânicos, ainda assim é um material que pode ser utilizado como base e sub-base de pavimentos.

O estudo revelou o RAP como um material possível de ser utilizado em concretos compactados com rolo, para uso em bases e sub-bases de pavimentos, atingindo parâmetros exigidos e trazendo consigo a consciência de preservação do meio ambiente, já que reutiliza materiais oriundos de restaurações dos próprios pavimentos asfálticos. Está lançado um novo conceito de CCR que possibilitará a realizações de novos estudos.

\section{Recomendações para novos estudos}

Dentre tantas possibilidades citam-se algumas sugestões para continuação do trabalho:

- Recomenda-se a continuação da pesquisa por meio de ensaios de fadiga para identificar as diferenças de comportamento do CCR com RAP para o CCR convencional, como forma de ampliar os resultados já obtidos;

- Um estudo mais aprofundado da microestrutura dos concretos secos, pois são poucas as referências neste sentido que possibilite entender melhor como este material se comporta;

- Desenvolvimento de um estudo econômico e de comportamento do CCR com RAP comparado ao de um CCR convencional, obtidos por meio de pista experimental; 
- Desenvolvimento de parâmetros que possibilitem o uso de CCR com RAP em obras, com o intuito de se criar ou ampliar as especificações técnicas existentes;

- Aprofundar os estudos relacionados à compactação de CCR com incorporação de RAP, haja vista as dificuldades observadas em se estabelecer a umidade ótima por meio desse método de dosagem (de compactação). 
ALBUQUERQUE, M. C. F., BALBO, J. T., SANSONE, E. C., PINTO, P. C. Fracture characterization of roller compacted concrete mixtures with blast furnace slag and industrial sand. In: Internacional DUTWorkshop on Design and Performance of Sustainable and Durable Concrete Pavements, 7, 2010, Carmona, Espanha. Proceedings. Carmona, Espanha, 2010.

ALBUQUERQUE, M. C. F. Adaptação do ensaio de dupla-torção para determinação da curva-R de concretos refratários. 2003. Tese (Doutorado) - Universidade de São Carlos, São Carlos. 2003. 121p.

ALBUQUERQUE, M. C. F. Determinação da Tenacidade à fratura em rochas brasileiras. 1998. Dissertação (Mestrado) - Escola de Engenharia de São Carlos, Universidade de São Paulo. São Carlos. 1998. 110p.

ALVAREZ, H. I. P. Ensaios não convencionais para determinação da tenacidade à fratura em rochas: análise e comparação. Dissertação (Mestrado) - Escola de Engenharia de São Carlos, Universidade de São Paulo. São Carlos. 2004.

AI-QADI I. L., MOSTAFA E., CARPENTER S. H. Reclaimed asphalt pavement - a literature review. FHWAICT-07-001, Illinois Center for Transportation, Series no 07-001, Illinois, 2007.

AMERICAN CONCRETE INSTITUTE. Roller compacted mass concrete. v.85, n.5, 46p.; 1988.

AMERICAN CONCRETE INSTITUTE. Compilation N.8. Roller Compacted Concrete - Authorized Reprint form Concrete International: Design and Construction. V.9, n.2, 55p.; 1987.

AMERICAN CONCRETE PAVEMENT ASSOCIATION. Econocrete. Arlington Heights. 70 p. (Report n. 1). 1975.

ANDRIOLO, F. R. The use of roller compacted concrete. São Paulo: Oficina de Textos, 1998. 554p.

ARAÚJO, L. M. D., de FARIAS, M. M., de CRAVALHO, J. C. Análise comparativa de alternativas de restauração de bases com incorporação de asfalto fresado. In: Reunião Anual de Pavimentação, 35ạ, 2004, Rio de Janeiro, RJ. ANAIS. Rio de Janeiro. 2004.

ASPHALT RECYCLING \& RECLAIMED ASSOCIATION - ARRA. An overview of recycling and reclamation methods for asphalt pavements rehabilitation. Anapolis, MD, 1992.

ASSOCIAÇÃO BRASILEIRA DE NORMAS TÉCNICAS. Projeto CB 18:400.04-008. Argamassa para assentamento e revestimento de paredes e tetos: determinação do módulo de elasticidade dinâmico através da propagação de onda ultra-sônica. 6p. 2008.

NBR9778: Argamassa e concreto endurecidos - Determinação da absorção de água, índice de vazios e massa específica. 4p. Rio de Janeiro, 2005.

NBR7222: Argamassa e Concreto - Determinação da resistência à tração por compressão diametral de corpos-de-prova cilíndricos. 3p. Rio de Janeiro. 1994.

NBR8802: Concreto endurecido - Determinação da velocidade de propagação de onda ultrasônica. 8p. Rio de Janeiro. 1994.

1994.

NBR5738: Moldagem e curo de corpos-de-prova cilíndricos ou prismáticos. 9p. Rio de Janeiro, 
NBR5427/1985 - versão corrigida 1989: Planos de Amostragem e Procedimentos por Inspeção de Atributos. 26p. Rio de Janeiro, 1989.

NBR9776: Agregados - Determinação da massa específica de agregados miúdos por meio do frasco de areia. 3p. Rio de Janeiro, 1987.

NBR7217: Agregados - Determinação da composição granulométrica. 3p. Rio de Janeiro, 1987.

NBR7182: Solos - Ensaio de compactação. 10p. Rio de Janeiro, 1986.

NBR5427: Guia para utilização da norma NBR 5426 - Planos de amostragem e procediemntos na inspeção por atributos. 26p. Rio de Janeiro, 1985.

NBR7211: Agregado para concreto. 5p. Rio de Janeiro, 1983.

ASTM. C78-08: Standard test method for flexural strength of concrete (using simple beam with thirdpoint loading). 4p. 2008.

ES 399-90. Standard test method for linear-elastic plane-strain fracture toughness of metallic materials. 31p. 1997.

BALBO, J. T. Pavimentação asfáltica - materiais, projeto e restauração. São Paulo: Oficina de Textos, 2007. 560p.

BALBO, J. T. Britas graduadas tratadas com cimento: uma avaliação de sua durabilidade sob o enfoque de porosidade, tenacidade e fratura. Transportes, São Paulo, v. 14, n. 1, p. 45-53, jun. 2006.

BALBO, J. T., Bodi, J. Reciclagem quente de misturas asfálticas em usinas: alternativa para bases de elevado módulo de elasticidade. Panorama Nacional da Pesquisa em Transportes, 18a ANPET. Florianópolis, SC, v. 1, p. 174-185, Nov. 2004.

BARR, B., GETTU, R., AL-ORAIMI, S.K.A, BRYARS, L.S. Toughness measurement - the need to think again. Cement \& Concrete Composites, v. 18. p. 281-297. 1996.

BEJARANO, M. Evaluation of recycled asphalt concrete materials as aggregate base. University of California. Pavement Research Center, Berkeley, 2001. (Technical Memorandum TM-UCB-PRC-2001-4)

BONFIM. V. Fresagem de Pavimentos Asfálticos. 3ạ ed. revisada e atual. São Paulo: Ed Exceção, 2007. $127 \mathrm{p}$.

BORNHAUSER, A., KROMP, K. PABST, R. F. Crack extension resistance based on the cohesive force in concrete, Engineering Fracture Mechanics, v. 64(5), pp.563-587. 1999.

CANADIAN PORTLAND CEMENT ASSOCIATION. Roller compacted concrete (RCC) pavements - design and construction. Otawa. (CP018.01P.). (sem data).

CARVALHO, M. D. Estado da arte do dimensionamento de pavimentos com camadas de concreto rolado. In: Reunião Anual de Pavimentação, 25ạ , 1991, São Paulo, SP. ANAIS. São Paulo, 1991. v.3, p. 1435-1456.

CARVALHO, M. D., GODINHO, D. P., JÚNIOR, S. F. Características e aplicações do concreto rolado em pavimentação. In: Reunião de Anual de Pavimentação, 22ạ, Maceió, AL. ANAIS. Maceio, Alagoas: Ed. Grafitex, 1988. v. 1, p. 275-316.

CERVO, T. C. Estudo da resistência à fadiga de concreto de cimento Portland para pavimentação. Tese (doutorado) - Escola Politécnica, Universidade de São Paulo. 2004. 
CONSELHO NACIONAL DO MEIO AMBIENTE - CONAMA. Resolução CONAMA № 307 - Estabelece diretrizes, critérios e procedimentos para a gestão dos resíduos da construção civil. 3 p. 2002.

DEDAVID, A. B., GOMES, I. C., MACHADO, G. Microscopia eletrônica de varredura - aplicações e preparação de amostras. Centro de Microscopia Eletrônica e Microanálise (CEMM) do IDEIA-PUCRS. EDIPUCRS, 60 p. Porto Alegre. 2007.

DELWAR, M., FAHMY, M., TAHA, R. Use of reclaimed asphalt pavement as an aggregate in Portland cement concrete. ACI Materials Journal, Technical Paper, v. 94, n-3. p 251-256. 1997.

DEPARTAMENTO DE ESTRADAS DE RODAGEM DO ESTADO DE SÃO PAULO - DER/SP. Especificação Técnica: ET-DE-P00/038 - Fresagem de pavimento asfáltico. São Paulo, SP. 6p. 2006.

DEPARTAMENTO NACIONAL DE INFRA-ESTRUTURA E TRANSPORTE. DNIT: IPR/714 - Manual de pavimentos rígidos - Manuais. Rio de Janeiro. 2005.

DUARTE, L. C., JUCHEM, P. L., PUIZ, G. M., BRUM, T. M. M., CHODUR, N., LICCARDO, A., FISCHER, A. C., ACUAN, R. B. Aplicações de microscopia eletrônica de varredura (MEV) e sistema de energia dispersiva (EDS) no estudo de gemas: exemplos brasileiros. Pesquisas em Geociências, v.30(2), p.3-15, Porto Alegre. 2003.

EFFTING, C., BRESSAN, J.D. Enasios de fratura em concreto: Parte I. In: Jornadas Associação Argentina de Materiais (SAM) - CONAMET - Simposio Materia. Rio Negro, Argentina. 2003.

FEDERAL HIGHWAY ADMINISTRATION. Reclaimed Asphalt Pavement. Disponível em: <http://www.tfhrc.gov/hnr20/recycle/waste/rap131.htm>. Acesso em: 03/07/2009.

FEDERAL HIGHWAY ADMINISTRATION. Pavement recycling for state \& local governments. FHWA. (Publicação N.: FHWA-SA-98-054). 1997.

FERREIRA, L. E. T. Fracture analysis of a high strength concrete and a high-strength steel-fiber-reinforced concrete. Mechanics of Composite Materials, v. 43, no 5, p. 479-486. 2007.

FILHO, L. M. O uso do concreto compactado com rolo em barragens - tendências futuras. Dissertação (Mestrado) - Universidade Federal de Itajubá, Itajubá/MG. 2003.

FLORIDA DEPARTMENT OF TRANSPORTATION. Developing specifications for using recycled asphalt pavement as base, subbase or general fill materials. Flórida. 2001. (Sumary of Final Report, BB-892).

FORTES, C. Mecânica da Fratura. Assistência Técnica Consumíveis. 2003. (ESAB BR. 72 p.).

GARG, N., THOMPSON, R.M. Lincoln avenue reclaimed asphalt pavement base project. Transportation Research Record: Journal of the Transportation Research Board, no1547, p 89-95. 1996.

GODINHO, P.D., GROSSI, C.L. Construção de pavimentos de concreto rolado. In: Reunião Anual de Pavimentação, 25ạ , 1991, São Paulo. ANAIS. São Paulo, 1991.v. 3, p. 1561-1574.

GUTHRIE, S. W., BROWN, V. A., EGGETT, D. L. Cement stabilization of aggregate base material blended with reclaimed asphalt pavement. Transportation Research Record: Journal of the Transportation Research Board, no2026, p 47-53. 2007.

GUTHRIE, S. W., COOLEY D., EGGETT, D. L. Effects of reclaimed asphalt pavement on mechanical properties of base materials. Transportation Research Record: Journal of the Transportation Research Board, no2005, p 44-52. 2007.

HOSSINEY, N., WANG, G., TIA, M.,BERGIN, M. J. Evaluation of concrete containing RAP for use in concrete pavement. TRB Annual Meeting - Transportation Research Record. 13p. 2008. 
HUANG, B., SHU, X., BURDET, E., G. Mechanical properties of concrete containing recycled asphalt pavements. Magazine of Concrete Research. v.58. no5, p. 313-320. 2006.

HUANG, B., SHU, X., LI, G. Laboratory investigation of Portland cement concrete containing recycled asphalt pavements. Science Direct - Cement and Concrete Research. v. 35. p 2008-2013. 2005.

IRWIN, G. R. Analysis of stresses and strain near the end of a crack. Journal of Applied Mechanics. Trans. ASME. v 79, p. 361-374. 1957.

KEARNEY E. J. HUFFMAN J. E. Full-Depth Reclamation Process. Transportation Research Record: Journal of the Transportation Research Board, no1684, p. 203-2093. 1999.

KIM W., LABUZ J. F., DAI S. Resilient modulus of base course containing recycled asphalt pavement. Transportation Research Record: Journal of the Transportation Research Board, №2005, p.27-35. 2007.

KIM, Y. S. Roller-compacted concrete shoulder construction on interstate highway in Georgia. Transportation Research Record: Journal of the Transportation Research Board, no2040, p.71-79. 2007.

KLEINLEIN, F. W., HUBNER, R-Curve Evaluation with Ceramic Materials at Elevated Temperatures by an Energy Approach using Direct Observation and Compliance Calculation Of The Crack Length. Proceedings of ICF4:. Waterloo, Canadá, v. 3, p. 883. 1977.

KOLIAS, S. Mechanical properties of cement-treated mixtures of milled bituminous concrete and crushed aggregates. Materials and Structures/Matériaux et Constructions, v. 29, Aug./Sep., p. 411-417. 1996.

KUPERMAN, S., C. Concreto massa convencional e compactado com rolo para barragens. In: IBRACON. CONCRETO: Ensino, Pesquisas e Realizações. São Paulo: G.C. Isaia, p. 1259-1295. 2005.

LEMAISTRE H. Étude des propriétés thermomécaniques de divers réfractaires. [Unpublished D. Phill Thesis].Lyon: École Doctorale Matériaux - Institut National de Sciences Appliquées, 1998.

MARCHAND, J., HORNAIN, H., DIAMOND, S., PIGEON, M., GUIRAUD, H. The microstructure of dry concretes products. Cement and Concrete Research, v. 26. no3. p.427-438. 1996.

MATHIAS, V., SEDRAN, T., LARRAD, F. Recycling reclaimed asphalt pavement in concrete roads. In: Internacional RILEM Conference on the Use of Recycled Materials in Building and Structures. Proceedings. Ed. RILEM Publications SARL, 2004. p.66-75.

MEHTA, P. K., MONTEIRO, P. J. M. Concreto: estrutura, propriedades e materiais. São Paulo: PINI, 573p. 1994.

PATTERSON, W. A., CHAN, H. C. Fracture toughness of glass fibre-reinforced cement. Composites. 3 p. 1975.

PAULON, V. A.,DAL MOLIN, D. C. C., MARQUES FILHO, J., ANDRADE, W. P. Caracterização de concreto compactado com rolo em laboratório. E-Mat - Revista de Ciência Tecnológica de Materiais de Construção Civil, v. 1, n 1. p 66-78. 2004.

PAULON, V. A., MONTEIRO, P. J. M. Estudos da microestrutura da zona de transição entre a pasta de cimento e o agregado. São Paulo, EPUSP. 1991. (Boletim Técnico BT/PCC/43).

PEPLOE, R., J. Applications for asphalt millings on New Zealand roads. Land Transport New Zealand Research Report 298. Land Transport New Zealand, Wellington, New Zealand. 2006. 
PETERSSON, P. E. Fracture energy of concrete: method of determination. Cement and Concrete Research. v. 10, p. 78-89. 1980.

PINTO, P. C., BALBO, J. T., SACHET, T., MUgAYAR, A. N., ALBUQUERQUE, M. C. F. Análise Comparativa de Misturas de CCR com Areia Natural, Industrial e com Incorporação de Escória Granulada de Alto Forno. In: Congresso Brasileiro do Concreto - IBRACON, 53ำ, 2009, Curitiba, PR.

PITTMAN, D. W., RAGAN, S. A. Drying shrinkage of roller-compacted concrete for pavement applications. ACI Materials Journal, v. 95, no1, p.19-26. 1998.

PITTMAN, D. W. Load transfer characteristics of roller compacted concrete pavement joints and cracks. Transportation Research Record: Journal of the Transportation Research Board, n1525, p.01-09. 1996.

PORTLAND CEMENT ASSOCIATION. Structural design of roller compacted concrete for industrial pavements. Concrete Information, Portland Cement Association. 7 p. 1987.

REINHARDT, H. W., XU, S. Crack extension resistance base don the coesive force in concrete. Engineering Fracture Mechanics. 64(5), p. 563-587, 1999.

RICCI, G. Estudo de características mecânicas do concreto compactado com rolo com agregados reciclados de construção e de demolição para pavimentação. Dissertação (mestrado) - Escola Politécnica, Universidade de São Paulo. 2007. 203p.

RICE, J. R. A path independent integral and the approximate analysis of strain concentration by notches and cracks. Journal of Applied Mechanics. v. 35, p. 379-386. 1968.

SACHET, T. Controle tecnológico de obras rodoviárias envolvendo a reciclagem in situ de bases granulares de pavimentos asfálticos. Dissertação (Mestrado) - Universidade de Passo Fundo, Passo fundo-RS, 2007. 170p.

SADECKI, R., W., BUSACKER, G.P., MOXNESS, K. L., FARUQ, K. C., ALLEN, L. G. An investigation of water quality runoff from stockpiles of salvaged concrete and bituminous paving. Minnesota Dept. of Transportation. 1996. (Final Report MNR-96/31).

SANTOS, A.C., SOUSA, J. L. A. O., BITTENCOURT, T. N. Determinação experimental da tenacidade ao fraturamento do concreto com corpos de prova do tipo "short-rod". São Paulo, EPUSP. 2003. (Boletim Técnico).

SAYED, S. M. PULSIFER, J., SCHMITT, R. Construction and performance of shoulders using UNRAP base. Geotechnical Consultant. Florida. 1993.

SIMPÓSIO INTERNACIONAL DE CONCRETO COMPACTADO COM ROLO. Instituto Brasileiro de Concreto IBRACON, 2008. Disponível em: < http://www.ibracon.org.br/eventos/50cbc/cobertura.asp>. Acesso em: 5 nov. 2010.

SOUZA, R. A. Análise de fraturamento em estruturas de concreto utilizando programas de análise estrutural. Dissertação (Mestrado) - Universidade Estadual de Campinas. Campinas, São Paulo. 2001.

SULIVAN, J. Pavement recycling executive summary and report. FWHA-SA-95-060. Federal highway Administration, Washington, D.C. 1996.

TAHA, R. Evaluation of cement klin dust-stabilized reclaimed asphalt pavement aggregate systems in road bases. Transportation Research Record: Journal of the Transportation Research Board, no1819, p.11-179. 2003. 
TAHA, R., AL-HARTHY, A., AL-SHAMSI, K., AL-ZUBEIDI, M. Cement stabilization of reclaimed asphalt pavement aggregate for road bases and subbases. Journal of Materials in Civil Engineering. v.14, no 3, Jun.1, 2002.

TAHA, R., ALI G., BASMA A., AL-TURK O. Evaluation of reclaimed asphalt pavement aggregate in road bases and subbases. Transportation Research Record: Journal of the Transportation Research Board, no1652, p.264-269. 1999.

TAYABJI, S. D., HALPENNY, D. J. Thickness design of roller compacted concrete pavements. Transportation Research Record: Journal of the Transportation Research Board, nำ1136, p.23-31. 1987.

TRICHÊS, G. Concreto compactado com rolo para aplicação em pavimentação: estudo do comportamento na fadiga e proposição de metodologia de dimensionamento. Tese (Doutorado) Instituto Tecnológico de Aeronáutica (ITA). São José dos Campos, SP. 1993.

TUCHUMANTEL, O. JR. Reciclagem de pavimentos - conceitos, interpretações e controle. In: Reunião Anual de Pavimentação, 23ạ, 1998, Florianópolis, SC. ANAIS. Florianóplis, SC, p.1303-1330, 1998. 
Foram realizadas análises estatísticas para todos os resultados de tensão de ruptura e módulos de elasticidades (obtidos pela curva tensão $x$ deformação e pela flecha) para os corpos de prova cilíndricos e prismáticos.

Inicialmente foram comparadas as médias e os desvios-padrão, das resistências e dos módulos de elasticidade, das amostras de CCR1 com todas as demais, com o intuito de observar se as amostras pertenciam ou não a um mesmo universo. Em seguida, foram comparadas, entre si, as amostras com incorporação de fresados. Da mesma forma foram realizadas análises para os valores dos módulos de elasticidade.

O programa computacional utilizado para verificação das hipóteses foi o StatTools versão 5.7 que é um suplemento de estatística para Excel.

A hipótese gerada leva em conta a média de uma amostra tida como referência, ou seja, trabalha-se com a hipótese nula e com a hipótese alternativa de que não é igual ao valor nulo. O programa rejeita ou não rejeita a hipótese de que as amostras confrontadas pertencem ao mesmo universo.

A amostra tida como padrão em cada tabela apresentada abaixo, significa que todas as amostras foram verificadas em função dos seus parâmetros. 
O primeiro teste baseou-se em correlacionar os dados de tensão de ruptura (tração indireta) do CCR1 (amostra de referência) com as demais amostras estudadas, como mostrado na Tabela abaixo.

\begin{tabular}{|l|c|c|c|c|c|c|}
\hline \multicolumn{7}{|c|}{ TEST-1 } \\
\hline \multirow{5}{*}{} & Padrão & Análise 1 & Análise 2 & Análise 3 & Análise 4 & Análise 5 \\
\cline { 2 - 7 } & CCR1 & CCR2 & CCR1-AF & CCR1-BF & CCR1-PF & CCR1-FT \\
\cline { 2 - 7 } & 2,37 & 2,04 & 0,99 & 1,62 & 1,75 & 1,13 \\
\cline { 2 - 7 } & 2,37 & 2,06 & 0,88 & 1,41 & 1,58 & 1,18 \\
\cline { 2 - 7 } & 2,49 & 2,09 & 0,96 & 1,54 & 1,58 & 1,18 \\
\cline { 2 - 7 } & 2,41 & 2,09 & 0,96 & 1,35 & 1,75 & 1,21 \\
\cline { 2 - 7 } & 2,53 & 2,06 & 0,98 & 1,52 & 1,58 & 1,22 \\
\cline { 2 - 7 } & 2,57 & 1,94 & 0,96 & 1,44 & 1,58 & 1,35 \\
\hline MÉDIA & 2,45 & 2,05 & 0,96 & 1,48 & 1,64 & 1,21 \\
\hline DESVIO P. & 0,08 & 0,05 & 0,04 & 0,10 & 0,09 & 0,08 \\
\hline No AMOSTRAS & 6 & 6 & 6 & 6 & 6 & 6 \\
\hline
\end{tabular}

\begin{tabular}{|c|c|c|c|c|c|}
\hline TESTE DE HIPÓTESES (UMA AMOSTRA) & $\begin{array}{c}\text { CCR2 } \\
\text { TESTE-1_CCR-1 } \\
\end{array}$ & $\begin{array}{c}\text { CCR1-AF } \\
\text { TESTE-1_CCR-1 } \\
\end{array}$ & $\begin{array}{c}\text { CCR1-BF } \\
\text { TESTE-1_CCR-1 } \\
\end{array}$ & $\begin{array}{c}\text { CCR1-PF } \\
\text { TESTE-1_CCR-1 } \\
\end{array}$ & $\begin{array}{c}\text { CCR1-FT } \\
\text { TESTE-1_CCR-1 } \\
\end{array}$ \\
\hline Tamanho da amostra & 6 & 6 & 6 & 6 & 6 \\
\hline Média da amostra & 2,04688 & 0,95656 & 1,47994 & 1,63668 & 1,21106 \\
\hline Desv. Padrão da amostra & 0,05414 & 0,03995 & 0,09701 & 0,08701 & 0,07602 \\
\hline Hipótese de média & 2,45 & 2,45 & 2,45 & 2,45 & 2,45 \\
\hline Hipótese alternativa & $<>2.45$ & $<>2.45$ & $<>2.45$ & $<>2.45$ & $<>2.45$ \\
\hline Erro padrão da média & 0,02210 & 0,01631 & 0,03960 & 0,03552 & 0,03104 \\
\hline Graus de liberdade & 5 & 5 & 5 & 5 & 5 \\
\hline t-Teste Estatístico & $-18,2371$ & $-91,5698$ & $-24,4934$ & $-22,8976$ & $-39,9187$ \\
\hline p-Valor & $<0.0001$ & $<0.0001$ & $<0.0001$ & $<0.0001$ & $<0.0001$ \\
\hline Hipótese nula em $10 \%$ de significância & Rejeitar & Rejeitar & Rejeitar & Rejeitar & Rejeitar \\
\hline Hipótese nula em $\mathbf{5} \%$ de significância & Rejeitar & Rejeitar & Rejeitar & Rejeitar & Rejeitar \\
\hline Hipótese nula em $1 \%$ de significância & Rejeitar & Rejeitar & Rejeitar & Rejeitar & Rejeitar \\
\hline
\end{tabular}


O segundo, o terceiro e o quarto testes basearam-se em correlacionar os dados de tensão de ruptura (tração indireta) dos CCR com incorporação de fresados, como mostrado na Tabela abaixo. Neste caso, a amostra padrão utilizada foi a CCR1-AF, para ser correlacionada com as demais misturas. A escolha da amostra foi aleatória.

\begin{tabular}{|l|c|c|c|c|}
\hline \multicolumn{5}{|c|}{ TEST-2 } \\
\hline \multirow{4}{*}{} & Padrão & Análise 1 & Análise 2 & Análise 3 \\
\cline { 2 - 5 } & CCR1-AF & CCR1-BF & CCR1-PF & CCR1-FT \\
\cline { 2 - 5 } & 0,99 & 1,62 & 1,75 & 1,13 \\
\cline { 2 - 5 } & 0,88 & 1,41 & 1,58 & 1,18 \\
\cline { 2 - 5 } & 0,96 & 1,54 & 1,58 & 1,18 \\
\cline { 2 - 5 } & 0,96 & 1,35 & 1,75 & 1,21 \\
\cline { 2 - 5 } & 0,98 & 1,52 & 1,58 & 1,22 \\
\cline { 2 - 5 } & 0,96 & 1,44 & 1,58 & 1,35 \\
\hline MÉDIA & 0,96 & 1,48 & 1,64 & 1,21 \\
\hline DESVIO P. & 0,04 & 0,10 & 0,09 & 0,08 \\
\hline No AMOSTRAS & 6 & 6 & 6 & 6 \\
\hline
\end{tabular}

CCR1-BF CCR1-PF CCR1-FT

\begin{tabular}{lccc} 
TESTE DE HIPÓTESES (UMA AMOSTRA) & TESTE-2_CCR1-AF & TESTE-2_CCR1-AF & TESTE-2_CCR1-AF \\
\hline \hline Tamanho da amostra & 6 & 6 & 6 \\
Média da amostra & 1,47994 & 1,63668 & 1,21106 \\
Desv. Padrão da amostra & 0,09701 & 0,08701 & 0,07602 \\
\hline Hipótese de média & 0,096 & 0,096 & 0,096 \\
Hipótese alternativa & $<>0.096$ & $<>0.096$ & $<>0.096$ \\
Erro padrão da média & 0,03960 & 0,03552 & 0,03104 \\
Graus de liberdade & 5 & 5 & 5 \\
t-Teste Estatístico & 34,9437 & 43,3754 & 35,9275 \\
p-Valor & $<0.0001$ & $<0.0001$ & $<0.0001$ \\
Hipótese nula em 10\% de significância & Rejeitar & Rejeitar & Rejeitar \\
Hipótese nula em 5\% de significância & Rejeitar & Rejeitar & Rejeitar \\
Hipótese nula em 1\% de significância & Rejeitar & Rejeitar & Rejeitar
\end{tabular}




\begin{tabular}{|l|c|c|c|}
\hline \multicolumn{4}{|c|}{ TEST-3 } \\
\hline \multirow{5}{*}{} & Padrão & Análise 1 & Análise 2 \\
\cline { 2 - 4 } & CCR1-BF & CCR1-PF & CCR1-FT \\
\cline { 2 - 4 } & 1,62 & 1,75 & 1,13 \\
\cline { 2 - 4 } & 1,41 & 1,58 & 1,18 \\
\cline { 2 - 4 } & 1,54 & 1,58 & 1,18 \\
\cline { 2 - 4 } & 1,35 & 1,75 & 1,21 \\
\cline { 2 - 4 } & 1,52 & 1,58 & 1,22 \\
\cline { 2 - 4 } & 1,44 & 1,58 & 1,35 \\
\hline MÉDIA & 1,48 & 1,64 & 1,21 \\
\hline DESVIO P. & 0,10 & 0,09 & 0,08 \\
\hline No AMOSTRAS & 6 & 6 & 6 \\
\hline
\end{tabular}

CCR1-PF

CCR1-FT

TESTE DE HIPÓTESES (UMA AMOSTRA)

TESTE-3 CCR1-BF

TESTE-3_CCR1-BF

Tamanho da amostra

Média da amostra

1,63668

6

Desv. Padrão da amostra

1,21106

Hipótese de média

0,08701

0,07602

Hipótese alternativa

1,48

1,48

$<>1.48$

$<>1.48$

Erro padrão da média

0,03552

5

0,03104

Graus de liberdade

4,4111

5

t-Teste Estatístico

0,0069

$-8,6652$

p-Valor

Rejeitar

Hipótese nula em $10 \%$ de significância

Rejeitar

Rejeitar

0,0003

Rejeitar

Hipótese nula em $\mathbf{5 \%}$ de significância

Hipótese nula em $1 \%$ de significância

Rejeitar

Rejeitar 


\begin{tabular}{|l|c|c|}
\hline \multicolumn{3}{|c|}{ TEST-4 } \\
\hline \multirow{5}{*}{} & Padrão & Análise 1 \\
\cline { 2 - 3 } & CCR1-PF & CCR1-FT \\
\cline { 2 - 3 } & 1,75 & 1,13 \\
\cline { 2 - 3 } & 1,58 & 1,18 \\
\cline { 2 - 3 } & 1,58 & 1,18 \\
\cline { 2 - 3 } & 1,75 & 1,21 \\
\cline { 2 - 3 } & 1,58 & 1,22 \\
\cline { 2 - 3 } MÉDIA & 1,58 & 1,35 \\
\hline DESVIO P. & 1,64 & 1,21 \\
\hline No AMOSTRAS & 0,09 & 0,08 \\
\hline
\end{tabular}

CCR1-FT

TESTE DE HIPÓTESES (UMA AMOSTRA) TESTE-4_CCR1-PF

\begin{tabular}{lc}
\hline \hline Tamanho da amostra & 6 \\
Média da amostra & 1,21106 \\
Desv. Padrão da amostra & 0,07602 \\
\hline Hipótese de média & 1,64 \\
Hipótese alternativa & $<>1.64$ \\
Erro padrão da média & 0,03104 \\
Graus de liberdade & 5 \\
t-Teste Estatístico & $-13,8204$ \\
p-Valor & $<0.0001$ \\
Hipótese nula em 10\% de significância & Rejeitar \\
Hipótese nula em 5\% de significância & Rejeitar \\
Hipótese nula em 1\% de significância & Rejeitar
\end{tabular}


Nos testes abaixo são mostradas as análises feitas com os resultados de módulo de elasticidade obtidos com a curva tensão $x$ deformação para os corpos de prova cilíndricos.

\begin{tabular}{|l|c|c|c|c|c|c|}
\hline \multicolumn{7}{|c|}{ TEST-5 } \\
\hline \multirow{4}{*}{} & Padrão & Análise 1 & Análise 2 & Análise 3 & Análise 4 & Análise 5 \\
\cline { 2 - 7 } & CCR1 & CCR2 & CCR1-AF & CCR1-BF & CCR1-PF & CCR1-FT \\
\cline { 2 - 7 } & 35500,00 & 15367,00 & 8594,00 & 17034,00 & 6575,00 & 6350,00 \\
\cline { 2 - 8 } & 23534,00 & 15433,00 & 24044,00 & 21554,00 & 8795,00 & 7390,00 \\
\cline { 2 - 8 } & 32176,00 & 26286,00 & 12474,00 & 18172,00 & & 5096,00 \\
\cline { 2 - 8 } & & & & & & 9763,00 \\
\cline { 2 - 8 } & & & & & & 7281,00 \\
\hline & & & & & & 6350,00 \\
\hline MÉDIA & 30403,33 & 19028,67 & 15037,33 & 18920,00 & 7685,00 & 7038,33 \\
\hline DESVIO P. & 6176,82 & 6285,12 & 8037,64 & 2351,01 & 1569,78 & 1570,14 \\
\hline No AMOSTRAS & 3 & 3 & 3 & 3 & 2 & 6 \\
\hline
\end{tabular}

\begin{tabular}{|c|c|c|c|c|c|}
\hline TESTE DE HIPÓTESES (UMA & CCR2 & CCR1-AF & CCR1-BF & CCR1-PF & CCR1-FT \\
\hline AMOSTRA) & TEST-5_CCR1 & TEST-5_CCR1 & TEST-5_CCR1 & TEST-5_CCR1 & TEST-5_CCR1 \\
\hline Tamanho da amostra & 3 & 3 & 3 & 2 & 6 \\
\hline Média da amostra & 19028,67 & 15037,33 & 18920,00 & 7685,00 & 7038,33 \\
\hline Desv. Padrão da amostra & 6285,12 & 8037,64 & 2351,01 & 1569,78 & 1570,14 \\
\hline Hipótese de média & 30403,33 & 30403,33 & 30403,33 & 30403,33 & $\begin{array}{c}30403,33 \\
<>\end{array}$ \\
\hline Hipótese alternativa & <> 30403.33 & <> 30403.33 & $<>30403.33$ & <> 30403.33 & 30403.33 \\
\hline Erro padrão da média & 3628,72 & 4640,53 & 1357,35 & 1110,00 & 641,01 \\
\hline Graus de liberdade & 2 & 2 & 2 & 1 & 5 \\
\hline t-Teste Estatístico & $-3,1346$ & $-3,3113$ & $-8,4601$ & $-20,4670$ & $-36,4506$ \\
\hline p-Valor & 0,0885 & 0,0804 & 0,0137 & 0,0311 & $<0.0001$ \\
\hline $\begin{array}{l}\text { Hipótese nula em } 10 \% \text { de } \\
\text { significância }\end{array}$ & Rejeitar & Rejeitar & Rejeitar & Rejeitar & Rejeitar \\
\hline $\begin{array}{l}\text { Hipótese nula em } 5 \% \text { de } \\
\text { significância }\end{array}$ & Não Rejeitar & Não Rejeitar & Rejeitar & Rejeitar & Rejeitar \\
\hline $\begin{array}{l}\text { Hipótese nula em 1\% de } \\
\text { significância }\end{array}$ & Não Rejeitar & Não Rejeitar & Não Rejeitar & Não Rejeitar & Rejeitar \\
\hline
\end{tabular}




\begin{tabular}{|l|c|c|c|c|}
\hline \multicolumn{5}{|c|}{ TEST-6 } \\
\hline \multirow{4}{*}{} & Padrão & Análise 1 & Análise 2 & Análise 3 \\
\cline { 2 - 5 } & CCR1-AF & CCR1-BF & CCR1-PF & CCR1-FT \\
\cline { 2 - 5 } & 8594,00 & 17034,00 & 6575,00 & 6350,00 \\
\cline { 2 - 5 } & 24044,00 & 21554,00 & 8795,00 & 7390,00 \\
\cline { 2 - 5 } & 12474,00 & 18172,00 & & 5096,00 \\
\cline { 2 - 5 } & & & & 9763,00 \\
\cline { 2 - 5 } & & & & 7281,00 \\
\cline { 2 - 5 } & & & & 6350,00 \\
\hline MÉDIA & 15037,33 & 18920,00 & 7685,00 & 7038,33 \\
\hline DESVIO P. & 8037,64 & 2351,01 & 1569,78 & 1570,14 \\
\hline No AMOSTRAS & 3 & 3 & 2 & 6 \\
\hline
\end{tabular}

\begin{tabular}{|c|c|c|c|}
\hline TESTE DE HIPÓTESES (UMA AMOSTRA) & $\begin{array}{c}\text { CCR1-BF } \\
\text { TEST-6_CCR1-AF }\end{array}$ & $\begin{array}{c}\text { CCR1-PF } \\
\text { TEST-6_CCR1-AF }\end{array}$ & $\begin{array}{c}\text { CCR1-FT } \\
\text { TEST-6_CCR1-AF }\end{array}$ \\
\hline Tamanho da amostra & 3 & 2 & 6 \\
\hline Média da amostra & 18920,00 & 7685,00 & 7038,33 \\
\hline Desv. Padrão da amostra & 2351,01 & 1569,78 & 1570,14 \\
\hline Hipótese de média & 15037,33 & 15037,33 & 15037,33 \\
\hline Hipótese alternativa & <> 15037.33 & $<>15037.33$ & $<>15037.33$ \\
\hline Erro padrão da média & 1357,35 & 1110,00 & 641,01 \\
\hline Graus de liberdade & 2 & 1 & 5 \\
\hline t-Teste Estatístico & 2,8605 & $-6,6237$ & $-12,4788$ \\
\hline p-Valor & 0,1036 & 0,0954 & $<0.0001$ \\
\hline Hipótese nula em 10\% de significância & Não rejeitar & Rejeitar & Rejeitar \\
\hline Hipótese nula em $5 \%$ de significância & Não rejeitar & Não rejeitar & Rejeitar \\
\hline Hipótese nula em $1 \%$ de significância & Não rejeitar & Não rejeitar & Rejeitar \\
\hline
\end{tabular}




\begin{tabular}{|l|c|c|c|}
\hline \multicolumn{4}{|c|}{ TEST-7 } \\
\hline \multirow{4}{*}{} & Padrão & Análise 1 & Análise 2 \\
\cline { 2 - 4 } & CCR1-BF & CCR1-PF & CCR1-FT \\
\cline { 2 - 4 } & 17034,00 & 6575,00 & 6350,00 \\
\cline { 2 - 4 } & 21554,00 & 8795,00 & 7390,00 \\
\cline { 2 - 4 } & 18172,00 & & 5096,00 \\
\cline { 2 - 4 } & & & 9763,00 \\
\cline { 2 - 4 } & & & 7281,00 \\
\cline { 2 - 4 } & & & 6350,00 \\
\hline MÉDIA & 18920,00 & 7685,00 & 7038,33 \\
\hline DESVIO P. & 2351,01 & 1569,78 & 1570,14 \\
\hline No AMOSTRAS & 3 & 3 & 6 \\
\hline
\end{tabular}

\begin{tabular}{lcc} 
& CCR1-PF & CCR1-FT \\
TESTE DE HIPÓTESES (UMA AMOSTRA) & TEST-7_CCR1-BF & TEST-7_CCR1-BF \\
\hline \hline Tamanho da amostra & 2 & 6 \\
Média da amostra & 7685,00 & 7038,33 \\
Desv. Padrão da amostra & 1569,78 & 1570,14 \\
\hline Hipótese de média & 18920 & 18920 \\
Hipótese alternativa & $<>18920$ & $<>18920$ \\
Erro padrão da média & 1110,00 & 641,01 \\
Graus de liberdade & 1 & 5 \\
t-Teste Estatístico & $-10,1216$ & $-18,5360$ \\
p-Valor & 0,0627 & $<0.0001$ \\
Hipótese nula em 10\% de significância & Rejeitar & Rejeitar \\
Hipótese nula em 5\% de significância & Não Rejeitar & Rejeitar \\
Hipótese nula em 1\% de significância & Não Rejeitar & Rejeitar
\end{tabular}




\begin{tabular}{|l|c|c|}
\hline \multicolumn{3}{|c|}{ TEST-8 } \\
\hline \multirow{4}{*}{} & Padrão & Análise 1 \\
\cline { 2 - 3 } & CCR1-PF & CCR1-FT \\
\cline { 2 - 3 } & 6575,00 & 6350,00 \\
\cline { 2 - 3 } & 8795,00 & 7390,00 \\
\cline { 2 - 3 } & - & 5096,00 \\
\cline { 2 - 3 } & & 9763,00 \\
\cline { 2 - 3 } & & 7281,00 \\
\cline { 2 - 3 } MÉDIA & & 6350,00 \\
\hline DESVIO P. & 15685,00 & 7038,33 \\
\hline No AMOSTRAS & 2 & 1570,14 \\
\hline
\end{tabular}

CCR1-FT

\begin{tabular}{lc} 
TESTE DE HIPÓTESES (UMA AMOSTRA) & TEST-8_CCR1-PF \\
\hline \hline Tamanho da amostra & 6 \\
Média da amostra & 7038,33 \\
Desv. Padrão da amostra & 1570,14 \\
\hline Hipótese de média & 7685 \\
Hipótese alternativa & $<>7685$ \\
Erro padrão da média & 641,01 \\
Graus de liberdade & 5 \\
t-Teste Estatístico & $-1,0088$ \\
p-Valor & 0,3594 \\
Hipótese nula em 10\% de significância & Não Rejeitar \\
Hipótese nula em 5\% de significância & Não Rejeitar \\
Hipótese nula em 1\% de significância & Não Rejeitar
\end{tabular}


Foram realizadas análises estatísticas para todos os resultados de tensão de ruptura e módulos de elasticidades (obtidos pela curva tensão $x$ deformação e pela flecha) para os corpos de prova prismáticos.

Primeiramente são apresentadas as análises dos valores de tensão de ruptura obtidos no ensaio de tração na flexão.

\begin{tabular}{|l|c|c|c|c|c|c|}
\hline \multirow{5}{*}{} & Padrão & Análise 1 & Análise 2 & Análise 3 & Análise 4 & Análise 5 \\
\cline { 2 - 7 } & CCR1 & CCR2 & CCR1-AF & CCR1-BF & CCR1-PF & CCR1-FT \\
\cline { 2 - 7 } & 4,29 & 4,00 & 3,76 & 2,93 & 3,81 & 2,69 \\
\cline { 2 - 7 } & 3,95 & 4,33 & 3,71 & 1,16 & 4,54 & 2,68 \\
\cline { 2 - 7 } & 3,68 & 3,83 & 3,91 & 2,48 & 3,66 & 2,36 \\
\cline { 2 - 7 } & 4,32 & 3,67 & 3,82 & 2,42 & 3,75 & 2,37 \\
\cline { 2 - 7 } & 4,45 & 3,78 & 3,80 & 2,89 & 3,47 & 2,77 \\
\cline { 2 - 7 } & 4,72 & 4,08 & 3,69 & 2,39 & & 2,47 \\
\hline MÉDIA & 4,23 & 3,95 & 3,78 & 2,38 & 3,85 & 2,55 \\
\hline DESVIO P. & 0,37 & 0,24 & 0,08 & 0,64 & 0,41 & 0,18 \\
\hline No AMOSTRAS & 6 & 6 & 6 & 6 & 5 & 6 \\
\hline
\end{tabular}

\begin{tabular}{lccccc} 
TESTE DE HIPÓTESES (UMA AMOSTRA) & $\begin{array}{c}\text { CCR2 } \\
\text { TEST-1_CCR1 }\end{array}$ & $\begin{array}{c}\text { CCR1-AF } \\
\text { TEST-1_CCR1 }\end{array}$ & $\begin{array}{c}\text { CCR1-BF } \\
\text { TEST-1_CCR1 }\end{array}$ & $\begin{array}{c}\text { CCR1-PF } \\
\text { TEST-1_CCR1 }\end{array}$ & $\begin{array}{c}\text { CCR1-FT } \\
\text { TEST-1_CCR1 }\end{array}$ \\
\hline \hline Tamanho da amostra & 6 & 6 & 6 & 5 & 6 \\
Média da amostra & 3,9483 & 3,78179 & 2,3773 & 3,8458 & 2,5542 \\
Desv. Padrão da amostra & 0,2373 & 0,07951 & 0,6433 & 0,4096 & 0,1773 \\
\hline Hipótese de média & 4,23 & 4,23 & 4,23 & 4,23 & 4,23 \\
Hipótese alternativa & $<>.23$ & $<>4.23$ & $<>4.23$ & $<>4.23$ & $<>4.23$ \\
Erro padrão da média & 0,0969 & 0,03246 & 0,2626 & 0,1832 & 0,0724 \\
Graus de liberdade & 5 & 5 & 5 & 4 & 5 \\
t-Teste Estatístico & $-2,9079$ & $-13,8085$ & $-7,0548$ & $-2,0973$ & $-23,1563$ \\
p-Valor & 0,0335 & $<0.0001$ & 0,0009 & 0,1040 & $<0.0001$ \\
Hipótese nula em 10\% de significância & Rejeitar & Rejeitar & Rejeitar & Não Rejeitar & Rejeitar \\
Hipótese nula em 5\% de significância & Rejeitar & Rejeitar & Rejeitar & Não Rejeitar & Rejeitar \\
Hipótese nula em 1\% de significância & Não Rejeitar & Rejeitar & Rejeitar & Não Rejeitar & Rejeitar
\end{tabular}




\begin{tabular}{|l|c|c|c|c|}
\hline \multirow{5}{*}{} & Padrão & Análise 1 & Análise 2 & Análise 3 \\
\cline { 2 - 5 } & CCR1-AF & CCR1-BF & CCR1-PF & CCR1-FT \\
\cline { 2 - 5 } & 3,76 & 2,93 & 3,81 & 2,69 \\
\cline { 2 - 5 } & 3,71 & 1,16 & 4,54 & 2,68 \\
\cline { 2 - 5 } & 3,91 & 2,48 & 3,66 & 2,36 \\
\cline { 2 - 5 } & 3,82 & 2,42 & 3,75 & 2,37 \\
\cline { 2 - 5 } & 3,80 & 2,89 & 3,47 & 2,77 \\
\cline { 2 - 5 } & 3,69 & 2,39 & & 2,47 \\
\hline MÉDIA & 3,78 & 2,38 & 3,85 & 2,55 \\
\hline DESVIO P. & 0,08 & 0,64 & 0,41 & 0,18 \\
\hline No AMOSTRAS & 6 & 6 & 5 & 6 \\
\hline
\end{tabular}

CCR1-BF CCR1-PF CCR1-FT

TESTE DE HIPÓTESES (UMA AMOSTRA) TEST-2_CCR1-AF TEST-2_CCR1-AF TEST-2_CCR1-AF

\begin{tabular}{lccc}
\hline \hline Tamanho da amostra & 6 & 5 & 6 \\
Média da amostra & 2,3773 & 3,8458 & 2,5542 \\
Desv. Padrão da amostra & 0,6433 & 0,4096 & 0,1773 \\
\hline Hipótese de média & 3,78 & 3,78 & 3,78 \\
Hipótese alternativa & $<>3.78$ & $<>3.78$ & $<>3.78$ \\
Erro padrão da média & 0,2626 & 0,1832 & 0,0724 \\
Graus de liberdade & 5 & 4 & 5 \\
t-Teste Estatístico & $-5,3413$ & 0,3593 & $-16,9381$ \\
p-Valor & 0,0031 & 0,7375 & $<0.0001$ \\
Hipótese nula em 10\% de significância & Rejeitar & Não Rejeitar & Rejeitar \\
Hipótese nula em 5\% de significância & Rejeitar & Não Rejeitar & Rejeitar \\
Hipótese nula em 1\% de significância & Rejeitar & Não Rejeitar & Rejeitar
\end{tabular}




\begin{tabular}{|l|c|c|c|}
\hline \multirow{5}{*}{} & Padrão & Análise 1 & Análise 2 \\
\cline { 2 - 4 } & CCR1-BF & CCR1-PF & CCR1-FT \\
\cline { 2 - 4 } & 2,93 & 3,81 & 2,69 \\
\cline { 2 - 4 } & 1,16 & 4,54 & 2,68 \\
\cline { 2 - 4 } & 2,48 & 3,66 & 2,36 \\
\cline { 2 - 4 } & 2,42 & 3,75 & 2,37 \\
\cline { 2 - 4 } & 2,89 & 3,47 & 2,77 \\
\cline { 2 - 4 } & 2,39 & & 2,47 \\
\hline MÉDIA & 2,38 & 3,85 & 2,55 \\
\hline DESVIO P. & 0,64 & 0,41 & 0,18 \\
\hline No AMOSTRAS & 6 & 5 & 6 \\
\hline
\end{tabular}

CCR1-PF CCR1-FT TEST-3_CCR1-BF TEST-3_CCR1-BF

TESTE DE HIPÓTESES (UMA AMOSTRA)

56

Tamanho da amostra

3,8458

2,5542

Média da amostra

0,4096

0,1773

Hipótese de média

2,38

2,38

Hipótese alternativa

$<>2.38$

$<>2.38$

Erro padrão da média

0,1832

4

0,0724

Graus de liberdade

8,0021

5

t-Teste Estatístico

0,0013

2,4074

p-Valor

Rejeitar

0,0611

Hipótese nula em $10 \%$ de significância

Rejeitar

Rejeitar

Hipótese nula em $\mathbf{5 \%}$ de significância

Rejeitar

Não Rejeitar

Hipótese nula em 1\% de significância

Não Rejeitar 


\begin{tabular}{|l|c|c|}
\hline \multirow{5}{*}{} & Padrão & Análise 1 \\
\cline { 2 - 3 } & CCR1-PF & CCR1-FT \\
\cline { 2 - 3 } & 3,81 & 2,69 \\
\cline { 2 - 3 } & 4,54 & 2,68 \\
\cline { 2 - 3 } & 3,66 & 2,36 \\
\cline { 2 - 3 } & 3,75 & 2,37 \\
\cline { 2 - 3 } & 3,47 & 2,77 \\
\cline { 2 - 3 } & & 2,47 \\
\hline MÉDIA & 3,85 & 2,55 \\
\hline DESVIO P. & 0,41 & 0,18 \\
\hline No AMOSTRAS & 5 & 6 \\
\hline
\end{tabular}

CCR1-FT

TESTE DE HIPÓTESES (UMA AMOSTRA) TEST-4_CCR1-PF

\begin{tabular}{lc}
\hline \hline Tamanho da amostra & 6 \\
Média da amostra & 2,5542 \\
Desv. Padrão da amostra & 0,1773 \\
\hline Hipótese de média & 3,85 \\
Hipótese alternativa & $<>3.85$ \\
Erro padrão da média & 0,0724 \\
Graus de liberdade & 5 \\
t-Teste Estatístico & $-17,9054$ \\
p-Valor & $<0.0001$ \\
Hipótese nula em 10\% de significância & Rejeitar \\
Hipótese nula em 5\% de significância & Rejeitar \\
Hipótese nula em 1\% de significância & Rejeitar
\end{tabular}


Nos testes abaixo são mostradas as análises feitas com os resultados de módulo de elasticidade obtidos com a curva tensão $\mathrm{x}$ deformação dos corpos de prova prismáticos.

\begin{tabular}{|l|c|c|c|c|c|c|}
\hline \multirow{5}{*}{} & Padrão & Análise 1 & Análise 2 & Análise 3 & Análise 4 & Análise 5 \\
\cline { 2 - 7 } & CCR1 & CCR2 & CCR1-AF & CCR1-BF & CCR1-PF & CCR1-FT \\
\cline { 2 - 7 } & 27340 & 32808 & 14964 & 13450 & 19900 & 13400 \\
\cline { 2 - 7 } & 33506 & 24990 & 10984 & 14222 & 18300 & 14200 \\
\cline { 2 - 7 } & 25051 & 36272 & 18167 & 13380 & 20100 & 13400 \\
\cline { 2 - 7 } & & & 26076 & 18435 & 16600 & 18400 \\
\cline { 2 - 7 } & & & 19248 & 10137 & & 10100 \\
\cline { 2 - 7 } & & & & & & 8600 \\
\hline MÉDIA & 28632 & 31357 & 17888 & 13925 & 18725 & 13017 \\
\hline DESVIO P. & 4373 & 5779 & 5594 & 2971 & 1630 & 3426 \\
\hline No AMOSTRAS & 3 & 3 & 5 & 5 & 4 & 6 \\
\hline
\end{tabular}

\begin{tabular}{lccccc} 
TESTE DE HIPÓTESES (UMA AMOSTRA) & $\begin{array}{c}\text { CCR2 } \\
\text { TEST-5_CCR1 }\end{array}$ & $\begin{array}{c}\text { CCR1-AF } \\
\text { TEST-5_CCR1 }\end{array}$ & $\begin{array}{c}\text { CCR1-BF } \\
\text { TEST-5_CCR1 }\end{array}$ & $\begin{array}{c}\text { CCR1-PF } \\
\text { TEST-5_CCR1 }\end{array}$ & $\begin{array}{c}\text { CCR1-FT } \\
\text { TEST-5_CCR1 }\end{array}$ \\
\hline \hline Tamanho da amostra & 3 & 5 & 5 & 4 & 6 \\
Média da amostra & 31356,67 & 17887,80 & 13924,80 & 18725,00 & 13016,67 \\
Desv. Padrão da amostra & 5779,33 & 5594,32 & 2970,69 & 1629,67 & 3426,03 \\
\hline Hipótese de média & 28632 & 28632 & 28632 & 28632 & 28632 \\
Hipótese alternativa & $<>28632$ & $<>28632$ & $<>28632$ & $<>28632$ & $<>28632$ \\
Erro padrão da média & 3336,70 & 2501,86 & 1328,53 & 814,84 & 1398,67 \\
Graus de liberdade & 2 & 4 & 4 & 3 & 5 \\
t-Teste Estatístico & 0,8166 & $-4,2945$ & $-11,0703$ & $-12,1583$ & $-11,1644$ \\
p-Valor & 0,5000 & 0,0127 & 0,0004 & 0,0012 & 0,0001 \\
Hipótese nula em 10\% de significância & Não Rejeitar & Rejeitar & Rejeitar & Rejeitar & Rejeitar \\
Hipótese nula em 5\% de significância & Não Rejeitar & Rejeitar & Rejeitar & Rejeitar & Rejeitar \\
Hipótese nula em 1\% de significância & Não Rejeitar & Não Rejeitar & Rejeitar & Rejeitar & Rejeitar
\end{tabular}




\begin{tabular}{|l|c|c|c|c|}
\hline \multirow{4}{*}{} & Padrão & Análise 1 & Análise 2 & Análise 3 \\
\cline { 2 - 5 } & CCR1-AF & CCR1-BF & CCR1-PF & CCR1-FT \\
\cline { 2 - 5 } & 14964 & 13450 & 19900 & 13400 \\
\cline { 2 - 5 } & 10984 & 14222 & 18300 & 14200 \\
\cline { 2 - 5 } & 18167 & 13380 & 20100 & 13400 \\
\cline { 2 - 5 } & 26076 & 18435 & 16600 & 18400 \\
\cline { 2 - 5 } & 19248 & 10137 & & 10100 \\
\cline { 2 - 5 } & & & & 8600 \\
\hline MÉDIA & 17888 & 13925 & 18725 & 13017 \\
\hline DESVIO P. & 5594 & 2971 & 1630 & 3426 \\
\hline No AMOSTRAS & 5 & 5 & 4 & 6 \\
\hline
\end{tabular}

CCR1-BF CCR1-PF CCR1-FT

\begin{tabular}{lccc} 
TESTE DE HIPÓTESES (UMA AMOSTRA) & TEST-6_CCR1-AF & TEST-6_CCR1-AF & TEST-6_CCR1-AF \\
\hline \hline Tamanho da amostra & 5 & 4 & 6 \\
Média da amostra & 13924,80 & 18725,00 & 13016,67 \\
Desv. Padrão da amostra & 2970,69 & 1629,67 & 3426,03 \\
\hline Hipótese de média & 17888 & 17888 & 17888 \\
Hipótese alternativa & $<>17888$ & $<>17888$ & $<>17888$ \\
Erro padrão da média & 1328,53 & 814,84 & 1398,67 \\
Graus de liberdade & 4 & 3 & 5 \\
t-Teste Estatístico & $-2,9831$ & 1,0272 & $-3,4828$ \\
p-Valor & 0,0406 & 0,3799 & 0,0176 \\
Hipótese nula em 10\% de significância & Rejeitar & Não Rejeitar & Rejeitar \\
Hipótese nula em 5\% de significância & Rejeitar & Não Rejeitar & Rejeitar \\
Hipótese nula em 1\% de significância & Não Rejeitar & Não Rejeitar & Não Rejeitar
\end{tabular}




\begin{tabular}{|l|c|c|c|}
\hline \multirow{5}{*}{} & Padrão & Análise 1 & Análise 2 \\
\cline { 2 - 4 } & CCR1-BF & CCR1-PF & CCR1-FT \\
\cline { 2 - 4 } & 13450 & 19900 & 13400 \\
\cline { 2 - 4 } & 14222 & 18300 & 14200 \\
\cline { 2 - 4 } & 13380 & 20100 & 13400 \\
\cline { 2 - 4 } & 18435 & 16600 & 18400 \\
\cline { 2 - 4 } & 10137 & & 10100 \\
\cline { 2 - 4 } MÉDIA & 13925 & 18725 & 13017 \\
\hline DESVIO P. & 2971 & 1630 & 3426 \\
\hline No AMOSTRAS & 5 & 4 & 6 \\
\hline
\end{tabular}

CCR1-PF CCR1-FT

\begin{tabular}{lcc} 
TESTE DE HIPÓTESES (UMA AMOSTRA) & TEST-7_CCR1-BF & TEST-7_CCR1-BF \\
\hline \hline Tamanho da amostra & 4 & 6 \\
Média da amostra & 18725,00 & 13016,67 \\
Desv. Padrão da amostra & 1629,67 & 3426,03 \\
\hline Hipótese de média & 13925 & 13925 \\
Hipótese alternativa & $<>13925$ & $<>13925$ \\
Erro padrão da média & 814,84 & 1398,67 \\
Graus de liberdade & 3 & 5 \\
t-Teste Estatístico & 5,8908 & $-0,6494$ \\
p-Valor & 0,0098 & 0,5447 \\
Hipótese nula em 10\% de significância & Rejeitar & Não Rejeitar \\
Hipótese nula em 5\% de significância & Rejeitar & Não Rejeitar \\
Hipótese nula em 1\% de significância & Rejeitar & Não Rejeitar
\end{tabular}




\begin{tabular}{|l|c|c|}
\hline \multirow{4}{*}{} & Padrão & Análise 1 \\
\cline { 2 - 3 } & CCR1-PF & CCR1-FT \\
\cline { 2 - 3 } & 19900 & 13400 \\
\cline { 2 - 3 } & 18300 & 14200 \\
\cline { 2 - 3 } & 20100 & 13400 \\
\cline { 2 - 3 } & 16600 & 18400 \\
\cline { 2 - 3 } & & 10100 \\
\cline { 2 - 3 } & & 8600 \\
\hline MÉDIA & 18725 & 13017 \\
\hline DESVIO P. & 1630 & 3426 \\
\hline No AMOSTRAS & 4 & 6 \\
\hline
\end{tabular}

CCR1-FT

TEST-8_CCR1-PF

\begin{tabular}{lc} 
TESTE DE HIPÓTESES (UMA AMOSTRA) & TEST-8_CCR1-PF \\
\hline \hline Tamanho da amostra & 6 \\
Média da amostra & 13016,67 \\
Desv. Padrão da amostra & 3426,03 \\
\hline Hipótese de média & 18725 \\
Hipótese alternativa & $<>18725$ \\
Erro padrão da média & 1398,67 \\
Graus de liberdade & 5 \\
t-Teste Estatístico & $-4,0813$ \\
p-Valor & 0,0095 \\
Hipótese nula em 10\% de significância & Rejeitar \\
Hipótese nula em 5\% de significância & Rejeitar \\
Hipótese nula em 1\% de significância & Rejeitar
\end{tabular}


Os últimos testes foram realizados com os resultados de módulo de elasticidade obtidos com a medida da flecha dos corpos de prova prismáticos.

\begin{tabular}{|l|c|c|c|c|c|c|}
\hline \multirow{5}{*}{} & Padrão & Análise 1 & Análise 2 & Análise 3 & Análise 4 & Análise 5 \\
\cline { 2 - 7 } & CCR1 & CCR2 & CCR1-AF & CCR1-BF & CCR1-PF & CCR1-FT \\
\cline { 2 - 7 } & 20822 & 27123 & 15947 & 10479 & 11102 & 10100 \\
\cline { 2 - 7 } & 24305 & 33864 & 14015 & 11217 & 11748 & 8269 \\
\cline { 2 - 7 } & 27811 & 21631 & 13939 & 9109 & 14044 & 7275 \\
\cline { 2 - 7 } & & & 17255 & 10860 & 12446 & 7977 \\
\cline { 2 - 7 } & & & 10271 & & 11318 & 8515 \\
\cline { 2 - 7 } & & & 8938 & & & 5698 \\
\hline MÉDIA & 24313 & 27540 & 13394 & 10416 & 12132 & 7972 \\
\hline DESVIO P. & 3494 & 6127 & 3216 & 922 & 1186 & 1454 \\
\hline No AMOSTRAS & 3 & 3 & 6 & 4 & 5 & 6 \\
\hline
\end{tabular}

\begin{tabular}{lccccc} 
& CCR2 & CCR1-AF & CCR1-BF & CCR1-PF & CCR1-FT \\
TESTE DE HIPÓTESES (UMA AMOSTRA) & TEST-9_CCR1 & TEST-9_CCR1 & TEST-9_CCR1 & $\begin{array}{c}\text { TEST-9_CCR1 } \\
\text { TEST-9_CCR1 }\end{array}$ \\
\hline \hline Tamanho da amostra & 3 & 6 & 4 & 5 & 6 \\
Média da amostra & 27539,56 & 13394,10 & 10416,14 & 12131,67 & 7972,36 \\
Desv. Padrão da amostra & 6126,87 & 3216,28 & 921,95 & 1186,00 & 1453,93 \\
\hline Hipótese de média & 24313 & 24313 & 24313 & 24313 & 24313 \\
Hipótese alternativa & $<>24313$ & $<>24313$ & $<>24313$ & $<>24313$ & $<>24313$ \\
Erro padrão da média & 3537,35 & 1313,04 & 460,97 & 530,40 & 593,56 \\
Graus de liberdade & 2 & 5 & 3 & 4 & 5 \\
t-Teste Estatístico & 0,9121 & $-8,3157$ & $-30,1468$ & $-22,9664$ & $-27,5298$ \\
p-Valor & 0,4580 & 0,0004 & $<0.0001$ & $<0.0001$ & $<0.0001$ \\
Hipótese nula em 10\% de significância & Não Rejeitar & Rejeitar & Rejeitar & Rejeitar & Rejeitar \\
Hipótese nula em 5\% de significância & Não Rejeitar & Rejeitar & Rejeitar & Rejeitar & Rejeitar \\
Hipótese nula em 1\% de significância & Não Rejeitar & Rejeitar & Rejeitar & Rejeitar & Rejeitar
\end{tabular}




\begin{tabular}{|l|c|c|c|c|}
\hline \multirow{7}{*}{} & Padrão & Análise 1 & Análise 2 & Análise 3 \\
\cline { 2 - 5 } & CCR1-AF & CCR1-BF & CCR1-PF & CCR1-FT \\
\cline { 2 - 5 } & 15947 & 10479 & 11102 & 10100 \\
\cline { 2 - 5 } & 14015 & 11217 & 11748 & 8269 \\
\cline { 2 - 5 } & 13939 & 9109 & 14044 & 7275 \\
\cline { 2 - 5 } & 17255 & 10860 & 12446 & 7977 \\
\cline { 2 - 5 } & 10271 & & 11318 & 8515 \\
\cline { 2 - 5 } & 8938 & & & 5698 \\
\hline MÉDIA & 13394 & 10416 & 12132 & 7972 \\
\hline DESVIO P. & 3216 & 922 & 1186 & 1454 \\
\hline No AMOSTRAS & 6 & 4 & 5 & 6 \\
\hline
\end{tabular}

CCR1-BF CCR1-PF CCR1-FT

TESTE DE HIPÓTESES (UMA AMOSTRA) TEST-10_CCR1-AF $\quad$ TEST-10_CCR1-AF TEST-10_CCR1-AF

\begin{tabular}{lccc}
\hline \hline Tamanho da amostra & 4 & 5 & 6 \\
Média da amostra & 10416,14 & 12131,67 & 7972,36 \\
Desv. Padrão da amostra & 921,95 & 1186,00 & 1453,93 \\
\hline Hipótese de média & 13394 & 13394 & 13394 \\
Hipótese alternativa & $<>13394$ & $<>13394$ & $<>13394$ \\
Erro padrão da média & 460,97 & 530,40 & 593,56 \\
Graus de liberdade & 3 & 4 & 5 \\
t-Teste Estatístico & $-6,4600$ & $-2,3800$ & $-9,1341$ \\
p-Valor & 0,0075 & 0,0760 & 0,0003 \\
Hipótese nula em 10\% de significância & Rejeitar & Rejeitar & Rejeitar \\
Hipótese nula em 5\% de significância & Rejeitar & Não Rejeitar & Rejeitar \\
Hipótese nula em 1\% de significância & Rejeitar & Não Rejeitar & Rejeitar
\end{tabular}




\begin{tabular}{|l|c|c|c|}
\hline \multirow{4}{*}{} & Padrão & Análise 1 & Análise 2 \\
\cline { 2 - 4 } & CCR1-BF & CCR1-PF & CCR1-FT \\
\cline { 2 - 4 } & 10479 & 11102 & 6350,00 \\
\cline { 2 - 4 } & 11217 & 11748 & 7390,00 \\
\cline { 2 - 4 } & 9109 & 14044 & 5096,00 \\
\cline { 2 - 4 } & 10860 & 12446 & 9763,00 \\
\cline { 2 - 4 } & & 11318 & 7281,00 \\
\cline { 2 - 4 } & & & 6350,00 \\
\hline MÉDIA & 10416 & 12132 & 7038 \\
\hline DESVIO P. & 922 & 1186 & 1570 \\
\hline No AMOSTRAS & 4 & 5 & 6 \\
\hline
\end{tabular}

\begin{tabular}{lcc} 
& CCR1-PF & CCR1-FT \\
TESTE DE HIPÓTESES (UMA AMOSTRA) & TEST-11_CCR1-BF & TEST-11_CCR1-BF \\
\hline \hline Tamanho da amostra & 5 & 6 \\
Média da amostra & 12131,67 & 7038,33 \\
Desv. Padrão da amostra & 1186,00 & 1570,14 \\
\hline Hipótese de média & 10416 & 10416 \\
Hipótese alternativa & $<>10416$ & $<>10416$ \\
Erro padrão da média & 530,40 & 641,01 \\
Graus de liberdade & 4 & 5 \\
t-Teste Estatístico & 3,2347 & $-5,2693$ \\
p-Valor & 0,0318 & 0,0033 \\
Hipótese nula em 10\% de significância & Rejeitar & Rejeitar \\
Hipótese nula em 5\% de significância & Rejeitar & Rejeitar \\
Hipótese nula em 1\% de significância & Não Rejeitar & Rejeitar
\end{tabular}




\begin{tabular}{|l|c|c|}
\hline \multirow{5}{*}{} & Padrão & Análise 1 \\
\cline { 2 - 3 } & CCR1-PF & CCR1-FT \\
\cline { 2 - 3 } & 11102 & 10100 \\
\cline { 2 - 3 } & 11748 & 8269 \\
\cline { 2 - 3 } & 14044 & 7275 \\
\cline { 2 - 3 } & 12446 & 7977 \\
\cline { 2 - 3 } & 11318 & 8515 \\
\cline { 2 - 3 } & & 5698 \\
\hline MÉDIA & 12132 & 7972 \\
\hline DESVIO P. & 1186 & 1454 \\
\hline No AMOSTRAS & 5 & 6 \\
\hline
\end{tabular}

CCR1-FT

TESTE DE HIPÓTESES (UMA AMOSTRA) TEST-12 CCR1-PF

\begin{tabular}{lc}
\hline \hline Tamanho da amostra & 6 \\
Média da amostra & 7972,36 \\
Desv. Padrão da amostra & 1453,93 \\
\hline Hipótese de média & 12132 \\
Hipótese alternativa & $<>12132$ \\
Erro padrão da média & 593,56 \\
Graus de liberdade & 5 \\
t-Teste Estatístico & $-7,0079$ \\
p-Valor & 0,0009 \\
Hipótese nula em 10\% de significância & Rejeitar \\
Hipótese nula em $\mathbf{5 \%}$ de significância & Rejeitar \\
Hipótese nula em 1\% de significância & Rejeitar
\end{tabular}




\section{VITA}

Taís Sachet, natural de Sertão - Rio Grande do Sul, é engenheira civil graduada em 2005 pela Universidade de Passo Fundo (UPF).

Em 2002 realizou estágio na Empresa Ivaí Engenharia, atuando nos setores de projetos e de laboratório.

Foi pesquisadora no Laboratório de Geotecnia e Pavimentação, com bolsa de iniciação científica, na Faculdade de Engenharia e Arquitetura da Universidade de Passo Fundo, com duração de seis meses no ano de 2003.

Em 2005 ingressou no programa de Pós-Graduação em Engenheira na Universidade de Passo Fundo, onde obteve em 2007, o título de Mestre em Engenharia - Área de Infraestrutura e Meio Ambiente.

Em 2007 ingressou no Programa de Pós-Graduação em Engenharia de Transportes da Escola Politécnica da USP, desenvolvendo pesquisas voltadas ao estudo de concretos compactados com rolo com emprego de agregados alternativos.

Atualmente trabalha como coordenadora e projetista da área de pavimentação na empresa LENC - Consultoria e Engenharia, em São Paulo. 